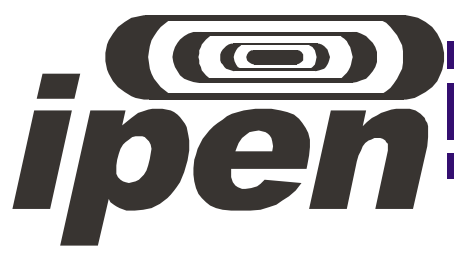

AUTARQUIA ASSOCIADA À UNIVERSIDADE DE SÃO PAULO

\title{
MICROUSINAGEM DE DIELÉTRICOS COM PULSOS LASER DE FEMTOSSEGUNDOS
}

Leandro Matiolli Machado

Tese apresentada como parte dos requisitos para obtenção do Grau de Doutor em Ciências na Área de Tecnologia Nuclear - Materiais

Orientador:

Prof. Dr. Wagner de Rossi 
Dedico esse trabalho aos meus pais Edison e Márcia, ao meu irmão Thomas, aos meus avós Armando e Tina, Edison e Tereza, e a minha namorada Letícia. 


\section{AGRADECIMENTOS}

Agradeço primeiramente a Deus e a minha família, meus pais Edison Furno Machado e Márcia Matiolli Machado por toda ajuda, paciência e força, e ao meu irmão Thomas Matiolli Machado pelo apoio, os momentos de filosofia e pela inspiração.

À minha namorada Letícia Bonfante Sicchieri pelo companheirismo, carinho, paciência e momentos de muita felicidade.

Agradeço ao meu orientador Dr. Wagner de Rossi pela atenção, longas conversas, orientação e pela grande amizade.

À Fundação de Amparo à Pesquisa do Estado de São Paulo (FAPESP) pelo apoio financeiro e institucional, que foi essencial à realização desse trabalho.

Ao Ipen pela infraestrutura e por possibilitar o desenvolvimento deste projeto.

Ao Dr. Ricardo Elgul Samad e ao Dr. Laércio Gomes pelas preciosas discussões a respeito do trabalho. Ao Dr. Nilson Vieira pela utilização da infraestrutura do laboratório.

Ao Dr. Anderson Zanardi de Freitas pela utilização do equipamento de OCT.

Ao José Tort Vidal pelos ensinamentos de eletrônica e programação.

Ao pessoal do CLA Thiago Cordeiro, Thiago Pereira, Ivanildo, Ana Cláudia, Débora, Jonas, Horácio, Fernando, Carolina Benetti, Moisés Santos, Viviane Goulart, Marcelo Noronha Veloso, Paulo Correa e Luiz pelas conversas na copa e momentos de descontração. 


\section{SUMÁRIO}

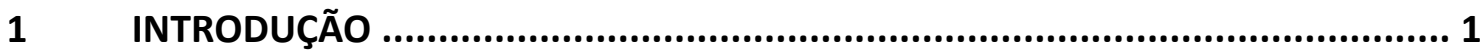

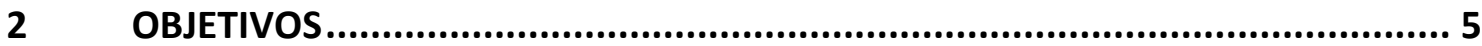

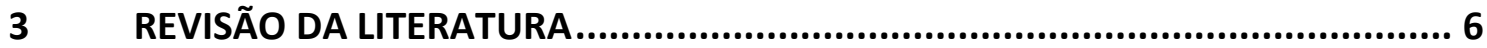

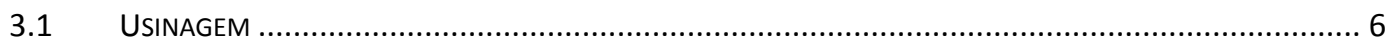

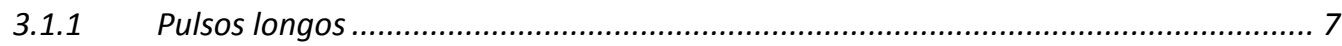

3.1.2 Pulsos ultracurtos - Modelo de Duas temperaturas ............................................. 8

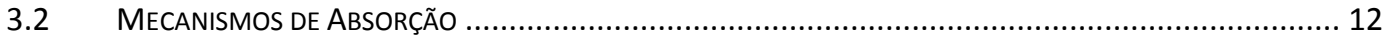

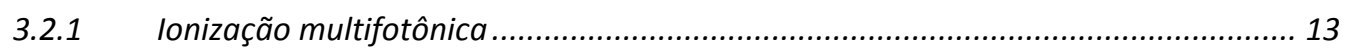

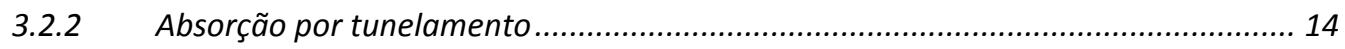

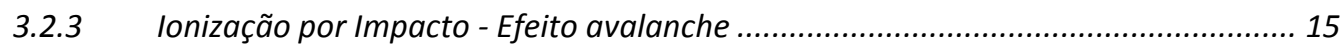

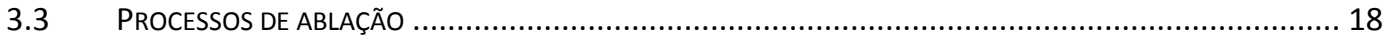

3.3.1 Efeito Coulomb - Ablação não térmica ................................................................. 18

3.3.2 Explosão de Fase - Ablação Térmica....................................................................... 21

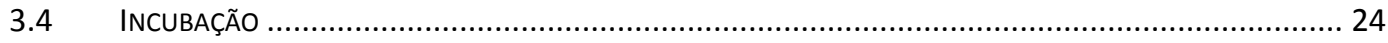

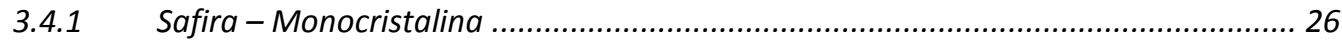

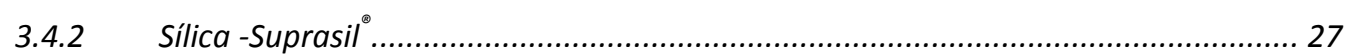

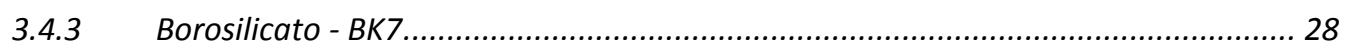

4 SIMULAÇÃO DA EXCITAÇÃO ELETRÔNICA POR PULSOS ULTRACURTOS ..........31

$5 \quad$ TÉCNICAS PARA A MEDIDA DO LIMIAR DE ABLAÇÃO ..................................42

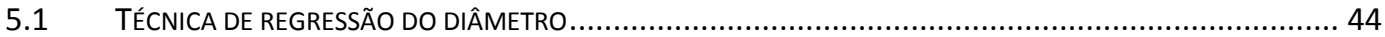

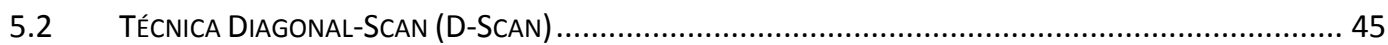

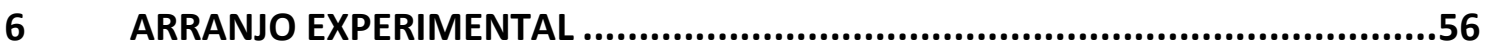

7 TÉCNICA DA REGRESSÃO DO DIÂMETRO COM PULSOS ÚNICOS .....................64

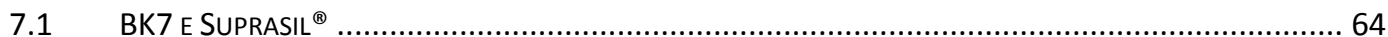

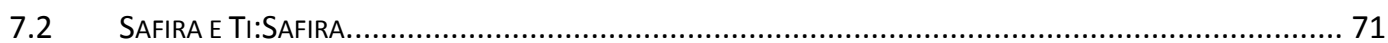

8 MEDIDA DO LIMIAR DE DANO PARA PULSOS SOBREPOSTOS. ........................80

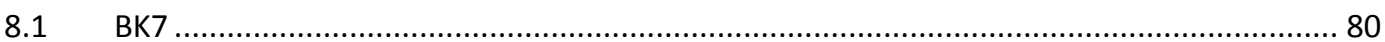

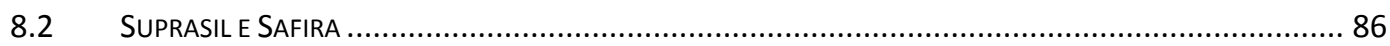


9 MICROCANAIS

9.1 ESTRATÉGIAS DE USINAGEM - CONTROLE DA FORMA ...................................................... 102

9.1.1 Primeira estratégia: Usinagem Direta .......................................................... 103

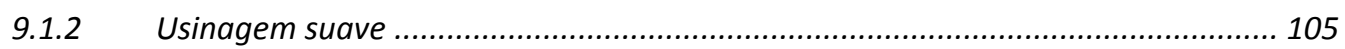

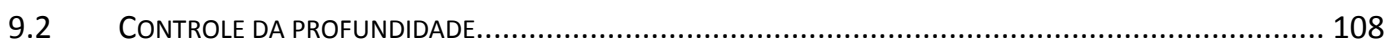

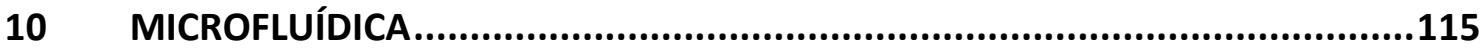

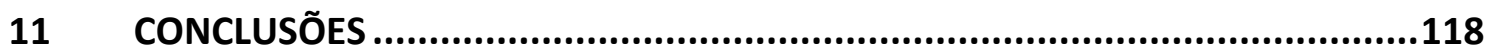

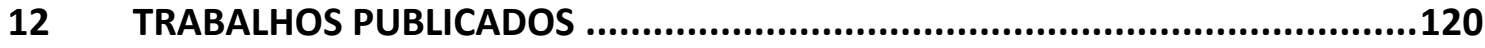

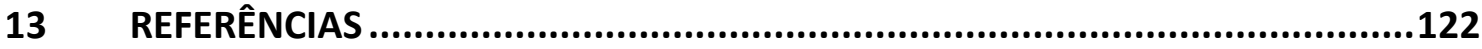




\section{Lista de Figuras}

Figura 3.1- Valores observados do limiar de dano em função da largura temporal ( $\lambda=1053 \mathrm{~nm})$ para sílica fundida e $\mathrm{CaF}_{2}$. Pode-se observar o desvio da relação com o efeito térmico para pulsos abaixo de 20ps [42].

Figura 3.2 - Curva universal do livre caminho médio do elétron para choques inelásticos na banda de condução. A região mais escura mostra o intervalo de energia dos elétrons que escapam da amostra. Adaptado de [47].

Figura 3.3 - Trajetórias termodinâmicas de um material hipotético sob irradiação de pulsos de fs (linha ponto-traço), ps (linha pontilhada), e ns (linha sólida). Linha sólida fina (binodal); linha tracejada: espinodal; cruz: ponto crítico. L: líquido; G: gás. As outras letras representam caminhos no diagrama de fase (veja texto), adaptado de [67].

Figura 3.4 - esquema da trajetória aproximada do material entrando na zona de instabilidade perto do ponto crítico

Figura 3.5 - níveis de energia de defeitos em safira (adaptado de [77; 79]).

Figura 3.6 - Diagrama de energia mostrando as principais frequências de absorção do $\mathrm{SiO}_{2}$ pelos centros de cor.......

Figura 3.7 -Imagem de uma janela de BK7 de $8 \mathrm{~mm}$ de espessura e $50 \mathrm{~mm}$ de diâmetro exposta à raios- $\mathrm{x}$ em diferentes energias 150, 300 e $450 \mathrm{KeV}$ (esquerda). Espectro de transmitância das regiões irradiadas [87] (direita).

Figura 4.1 - Simulação da intensidade do laser (linha vermelha) e intensidade do laser no centro do feixe menos a intensidade refletida (linha verde) pelo plasma eletrônico do material no Suprasil irradiado com um pulso de $100 \mathrm{fs}$ e $6 \mathrm{~J} / \mathrm{cm}^{2}$ de fluência. A linha azul representa a densidade eletrônica na banda de condução em função do tempo.

Figura 4.2 - densidade eletrônica máxima na banda de condução do Suprasil gerados pela irradiação de um pulso com diferentes fluências e 100 fs de largura temporal.

Figura 4.3- a) Simulação do Limiar de ablação em função da largura temporal. 40

Figura 5.1 - perfil gaussiano com raio definido a $1 / \mathrm{e}^{2}$ da fluência máxima 44

Figura 5.2- Irradiação da amostra com o laser de femtossegundos deslocando a amostra nos eixos $z$ e $y$ simultaneamente (Adaptado de [27]).

Figura 5.3- Gráfico para $P 0=3 e \pi w 02 I$ th $=6$ Pcrit . O plano representa a superfície da amostra irradiada. As linhas $+w(z)$ e $-w(z)$ representam o raio do feixe onde a intensidade tem $1 / e^{2}$ do pico; as linhas $+\rho(z) e-\rho(z)$, representam o raio de zona de interação com o feixe. Adaptado de [27]... 48

Figura 5.4 - Coordenadas para derivação da sobreposição. 50

Figura 5.5 - a linha vermelha é o cálculo usando a função theta de Jacobi, Eq. 55. A linha tracejada apresenta os resultados para Eq. 57. As linhas azuis mostram o calculo de $N$ usando a Eq. 54 no intervalo de $-m$ a $m$. Onde $m=1,10,100$ e 1000.

Figura 6.1 - Arranjo ótico do sistema de entrega do feixe e visualização. 
Figura 6.2 - Perfil espacial do foco do feixe laser focalizado por uma lente de $f=500 \mathrm{~mm}$. O perfil se aproxima muito de um perfil Gaussiano.

Figura 6.3 - Exemplo do procedimento usado para posicionar o foco na superfície da amostra (para uma melhor visualização, é mostrado uma amostra de aço). As posições focal e lateral são deslocadas, então a posição focal de menor marcação é usada para realização dos experimentos. 59

Figura 7.1 Fluência média $\times D^{2}$ com a lente de 10 e $38 \mathrm{~mm}$, primeiros testes na amostra $A 3$..... 65

Figura 7.2 - Gráfico do $D^{2}$ X Fluência média - usando mais pontos experimentais com intervalos menores de energias. Limiar de ablação: $4,43 \mathrm{~J} / \mathrm{cm}^{2}$.

Figura 7.3 - Limiar de dano calculado para o Suprasil com o laser1 apresentando instabilidades na energia. É possível observar um maior desvio dos dados devido à flutuação na energia dos pulsos.

Figura 7.4 - Irradiações com pulsos únicos. Cada linha representa energias médias diferentes, mas cada irradiação foi medida individualmente.

Figura 7.5 - Fluência em função do diâmetro ao quadrado de pulsos únicos irradiados no BK7. Medidas individuais da energia de cada irradiação foram feitas.

Figura 7.6 - Ajuste para o cálculo do limiar de ablação da amostra BK7 - A6.

Figura 7.7 - Gráfico da fluência x diâmetro ao quadrado - limiar de dano do Suprasil para pulsos únicos (regime de baixa e alta fluência).

Figura 7.8-a) Diâmetro ao quadrado x Fluência para pulsos únicos em safira, mostrando os regimes de baixa e de alta fluência, bem como o limiar de ablação. b) Ti: Safira.

Figura 7.9 - Efeito da baixa e alta fluência na safira.

Figura 7.10 - diagrama das bandas vibrônicas geradas no Ti:safira pelos íons $\mathrm{Ti}^{3+}$. O Ti:safira absorve linearmente fótons aproximadamente entre 400 e $600 \mathrm{~nm}$, e irradia numa banda larga que vai de 650 a $1050 \mathrm{~nm}$

Figura 8.1 - Imagem de regiões ablacionadas com pulsos de mesma energia em safira. Sobreposição de 1, 4 e 16 pulsos, da esquerda para a direita. É possível observar a transição da ablação não térmica para uma ablação térmica.

Figura 8.2 - Matriz de pontos com mesma energia variando a sobreposição (linhas) cada linha contem 6 elementos repedidos com mesma sobreposição.

Figura 8.3 - Imagem de microscopia óptica da zona afetada no BK7 com sobreposição de 510 pulsos (linha 1) e 1020 pulsos (linha 2).

Figura 8.4 - Limiar de ablação para sobreposição de 520 pulsos em BK7.

Figura 8.5 - Micrografias de amostras ablacionadas pelo método D-scan. a) 1267.3 pulsos sobrepostos para $E_{0}=71 \mu \mathrm{J}$ b) para $E_{0}=31 \mu \mathrm{J}$, os perfis superiores representam a sobreposição de 1.12 pulsos, e o perfil mais baixo é um perfil para pulsos únicos.

Figura 8.6 - Medidas do limiar da ablação do BK7 em função da sobreposição de pulsos usando a TRD e o $D$-scan com diferentes energias de pulso. 
Figura 8.7 - Micrografia dos traços irradiados com o método D-scan. Vista da superfície (figuras de cima) e visão lateral (figuras de baixo).

Figura 8.8 - Limiar de ablação do Suprasil em função da sobreposição para Suprasil - comparação entre os dois métodos.

Figura 8.9-Limiar de ablação da Safira em função da sobreposição - comparação entre os dois métodos.

Figura 8.10 - Comparação entre o $D$-scan e o TRD da distribuição de fluências típicas para a medida do limiar de ablação. Cada traço no eixo y equivale a $F_{t h}$.

Figura 8.11 - Cálculo da fluência pico e do gradiente de fluência utilizada pelos métodos TRD e $D$-scan. Devido à característica intrínseca de cada método, o gradiente de fluência e a fluência pico são distintos em comportamento e valores em função do tamanho da distância $\rho$ entre a borda do dano e o centro do feixe.

Figura 8.12 - Evidência de zona colateral afetada devido ao alto gradiente de fluências durante a irradiação para a TRD no Suprasil. Na safira não foi possível observar efeito colateral.

Figura 8.13 - Imagem de microscopia eletrônica de varredura da região onde é feita a medida de $\rho_{\max } \cdot 94$

Figura 8.14 - Imagem de MEV mostrando o detalhe da borda de um traço de $D$-scan. É possível observar a presença de "ripples" na borda do traço sem trincas. Ou seja, explosão Coulombiana.

Figura 8.15 - Microscopia óptica dos traços de D-scan realizados com pulsos de 152 fs e energia de 207 $\mu \mathrm{J}$. É possível observar as diferentes posições das medições de $\rho_{\max }$ para diferentes sobreposições.

Figura 8.16 - Limiares de ablação em função da sobreposição obtida pelo método $D$-scan. BK7 - 22,8 fs.

Figura 8.17 - Limiar de ablação em função da sobreposição obtida pelo método D-scan. BK7 - 144 fs.. 97

Figura 8.18 - Limiar de ablação para pulsos únicos obtidos através do ajuste da EEq. 19 dos valores de limiar de diversas medidas de D-scan e simulação do limiar de ablação no BK7.

Figura 8.19 - Limiar de ablação de saturação obtidos através do ajuste da EEq. 19 dos valores de limiar de diversas medidas de $\mathrm{D}$-scan.

Figura 8.20 -Parâmetros de incubação obtidos através do ajuste da EEq. 19 dos valores de limiar de diversas medidas de D-scan.

Figura 9.1 - Esquema do trajeto feito pelo laser para formar uma "camada" de usinagem. A polarização possui a mesma direção da varredura do laser. As varreduras foram feitas longitudinalmente aos canais com velocidade $v$.

Figura 9.2 - a) Esquema de usinagem resultante da aplicação da usinagem direta. Apenas uma camada é usada e a sobreposição longitudinal é suficientemente alta para alcançar a profundidade desejada. b)Imagens de OCT.

Figura 9.3 - a) método da ablação suave - O canal usinado é formado por várias camadas onde a sobreposição lateral e longitudinal são variadas em cada camada para levar em consideração o diâmetro de cada traço. b) Imagem de OCT dos canais usinados. Cada canal tem uma sobreposição total de $N$ pulsos (soma das camadas igual a N). Duas energias são mostradas 33 e $10 \mu \mathrm{J}$.......... 106 
Figura 9.4 - Microscopia eletrônica de varredura dos canais usinados com o método "Smooth ablation". Cada figura (a,b,c,d) mostram um mesmo canal de $\mathrm{N}=128$ e $200 \mu \mathrm{m}$ de largura com diferentes ampliações.

Figura 9.5 - Profundidade em função da sobreposição longitudinal de canais de $100 \mu \mathrm{m}$ usinados em BK7 usando o método suave para diferentes energias.

Figura 9.6 - Profundidade em função da sobreposição longitudinal N com pulsos de $30 \mu \mathrm{J}$. Pontos vermelhos: ajustou-se a posição focal para ficar na superfície da região usinada. Pontos verdes: a posição focal permaneceu na superfície da amostra durante a usinagem.

Figura 9.7 - Imagem de OCT de microcanais de $100 \mu \mathrm{m}$ de largura usinados com o método suave e $30 \mu \mathrm{J}$ por pulso. O conjunto de canais de cima corresponde à irradiação sem variar o foco, abaixo os canais foram usinados com o foco ajustado para ficar na superfície em cada camada. 109

Figura 9.8 - Imagem de MEV do canal com variação do foco e sobreposição total de 104 pulsos.

Figura 9.9 - Profundidade em função da sobreposição. Pontos verdes: Microcanais de $100 \mu \mathrm{m}$ usinados com o método suave com pulsos de $30 \mu \mathrm{J}$. Pontos pretos: traços únicos sobrepostos com mesma velocidade de varredura. Pontos vermelhos: traços únicos sobrepostos com apenas uma varredura, as diferentes sobreposições são alcançadas com diferentes velocidades de varredura.

Figura 9.10 - Exemplo de alta e baixa sobreposição em traços usinados no BK7 fora do foco (diâmetro do feixe 100 $\mu$ J). a) Alta sobreposição forma em "V" reflexões laterais. b) Baixa sobreposição forma mais arredondada.

Figura 9.11 - b) eficiência de incubação na usinagem com o método suave. 113

Figura 10.1 - Esquema do sistema de acoplamento das mangueiras fluídicas com o circuito microfluídico.

Figura 10.2 - Imagem da conexão feita usando a técnica desenvolvida nesse trabalho. 116

Figura 10.3 - Sistema de acoplamento microfluídico com sistema de visualização e controle de fluxo. 116

Figura 10.4 - Fluxo laminar de água colorida injetada nos microcanais usinados por laser. 117

Figura 10.5 - Microusinagem de canais de $100 \mu \mathrm{m}$ em BK7 em forma de cruz. 117

\section{Lista de Tabelas}

Tabela 1 - Valores das constantes encontradas na literatura para a simulação do modelo

Tabela 2 - Difusividade e ponto de vaporização dos dielétricos.

Tabela 3- Limiares de dano (pico) encontrado para BK7 e Suprasil com diferentes lasers e sistema de aquisição de medidas.

Tabela 4 - Limiar de ablação para um pulso único, parâmetro de incubação e limiar de saturação calculado pelo modelo de incubação exponencial (100 fs). 


\section{MICROUSINAGEM DE DIELÉTRICOS COM PULSOS LASER DE FEMTOSSEGUNDOS}

\section{Leandro Matiolli Machado}

\section{RESUMO}

Neste trabalho foi utilizado o método de regressão do diâmetro para a medida do limiar de ablação nos materiais Suprasil, BK7, Safira e Ti:Safira por pulsos de femtossegundos. Através de medidas dos limiares de ablação para pulsos únicos e pulsos sobrepostos, quantificou-se o parâmetro de incubação para cada dielétrico. Essas medidas preliminares serviram para validação do método denominado Diagonal Scan ou $D$-scan. Para tanto, o método $D$-scan teve seu formalismo expandido o que possibilitou a quantificação da sobreposição de pulsos durante o seu uso. A simplicidade e rapidez do método D-scan permitiram que o limiar de ablação no BK7 fosse medido para diferentes larguras temporais e sobreposições. O limiar de ablação para pulsos únicos em função da largura temporal dos pulsos foi comparado com uma simulação teórica. A partir do conhecimento do parâmetro de incubação desenvolveu-se uma metodologia de usinagem em dielétricos que considera a sobreposição de pulsos durante a ablação. Isso permitiu a fabricação de microcanais para uso em microfluídica em BK7. 


\title{
MICROMACHINING OF DIELETRICS WITH FEMTOSECOND LASER PULSES
}

\author{
Leandro Matiolli Machado
}

\begin{abstract}
In this study, the diameter regression method was used to measure the ablation threshold of Suprasil, BK7, Sapphire and Ti: Sapphire by femtosecond pulses. Through measurements of the ablation thresholds for single and overlapping pulses, the incubation parameter for each dielectric was quantified. These preliminary steps were used to validate the method called Diagonal Scan or D-scan. This was made possible by expanding the D-scan formalism, which allowed the quantification of overlapping pulses during its use. The simplicity of the D-scan method allowed the ablation threshold measurement in BK7 for different temporal widths and overlaps. The ablation threshold for single pulse for different temporal width was compared with a theoretical simulation. From the knowledge of the parameter of incubation, a methodology that considers dielectric machining overlapping pulses during ablation was developed. This allowed the manufacture of microchannels on BK7 for microfluidics.
\end{abstract}




\section{Introdução}

$\mathrm{O}$ interesse no processo de ablação de materiais a laser teve inicio junto à sua descoberta em 1960 [1]. Em 1962, pesquisadores na Ford Motors Company descobriram que a luz de um laser Q-switched de rubi podia ionizar o ar criando "faíscas" [2]; anos mais tarde foi reportado dano em vidro [3]. Essas descobertas levaram a investigações de como a luz interage com gases e sólidos e esse trabalho dura até os dias de hoje.

A indústria se beneficiou de aplicações de alta precisão na área de usinagem como corte, soldagem, oxidação induzida e outros tipos de tratamentos térmicos em metais. O advento de lasers pulsados com larguras temporais da ordem de nanossegundos e picossegundos através de técnicas de Q-switching e modelocking, trouxe a possibilidade de obtenção de intensidades da ordem de gigawatts por centímetro quadrado. Isto permitiu estender a interação de feixes laser a materiais semicondutores e dielétricos de uma maneira eficiente. Lasers de nanossegundos com comprimento de onda de 532 nm são capazes de ablacionar sílica fundida[4; 5], safira, plásticos e outros materiais transparentes.

A dinâmica de interação de pulsos laser de ns em alguns materiais que são transparentes à esta radiação, contudo, muitas vezes, não permite estabelecer um limiar de fluência de ablação bem definido, pois envolve processos estocásticos na absorção da radiação o que torna a zona ablacionada imprevisível e disforme, diminuindo a precisão na usinagem [6]. Em alguns dielétricos, como a sílica e a safira, os valores para limiar de fluência ou intensidade especifica para cada material não podem ser encontrados com precisão, porque estes valores podem variar em mais de uma ordem de grandeza[6].

Outro grande fator que influencia a precisão na usinagem a laser é a zona termicamente afetada, que se estende além da região de interação do pulso laser e é responsável por uma transformação de fase alterando as propriedades do material colateralmente. $\mathrm{O}$ efeito colateral termodinâmico é intrínseco ao processo de ablação, mas pode ser minimizado depositando-se a energia de forma rápida, através de pulsos curtos, e ablacionar o material antes que o calor se espalhe por difusão e afete a vizinhança da região de interação [5;7]. Lasers de nano ou picossegundos, com 
comprimento de onda na faixa do UV, são utilizados para aumentar a absorção e a eficiência de ablação em materiais dielétricos possibilitando maior precisão na escala micrométrica, entretanto, podem ocorrer nessa escala temporal de interação, efeitos térmicos $[5,8,9]$.

Na segunda metade da década de 80 a invenção da técnica de amplificação de pulsos com varredura de freqüência, ou "Chirped Pulse Amplification" [10; 11], e lasers de estado sólido bombeados por diodo [12] permitiram o uso de pulsos ultracurtos com energias da ordem de micro e milijoules $(\mu \mathrm{J}-\mathrm{mJ})$. Esses lasers são capazes de produzir pulsos com alguns femtossegundos de largura temporal e intensidades da ordem de $10^{13}$ a $10^{14} \mathrm{~W} / \mathrm{cm}^{2}$. Atualmente os principais tipos de laser ultracurtos utilizados para usinagem são o Ti:Safira e o Yb:fibra. Os sistemas de Ti:Safira são capazes de produzir pulsos com poucas dezenas de femtossegundos, centrados em 800 $\mathrm{nm}$, com energias da ordem de $\mathrm{mJ}$, e taxas de repetição acima de poucos $\mathrm{kHz}$; Os lasers baseados em Itérbio geram pulsos centrados em $1030 \mathrm{~nm}$ com duração de centenas de femtossegundos e energia limitada no intervalo de poucos $\mu \mathrm{J}$, operando com taxas de repetição no intervalo de $\mathrm{MHz}$, e permitem maiores velocidades de usinagem. Algumas das principais características destes pulsos, quando são usados para a usinagem, é a alta absorção em materiais dielétricos e a pequena zona afetada pelo calor. Estas características se devem a dinâmica particular de absorção e ablação gerada por esses pulsos ultracurtos e ultra intensos.

O processo de interação da radiação com a matéria envolve muitos fenômenos que ocorrem em diferentes escalas de tempo, desde femtossegundos até nanossegundos [13-19]. Diferentemente da interação em metais, em dielétricos, a banda de condução está inicialmente vazia e a matéria é transparente à radiação laser [20]. Elétrons da banda de valência devem ser transferidos para a banda de condução por processos de ionização não lineares para começar o aquecimento eletrônico pelo laser. A geração inicial de elétrons ocorre por fotoionização. Quando o processo de fotoionização é iniciado e elétrons "semente" são excitados para a banda de condução, esses então absorvem a energia do laser. Se a energia desses elétrons exceder um valor crítico, esses colidem com outros elétrons excitando mais elétrons para a banda de condução induzindo o processo de ionização por avalanche [21]. O meio dielétrico ionizado começa a se comportar como um metal, então, a densidade eletrônica na 
superfície atinge um valor crítico, a refletividade na superfície aumenta e íons são ejetados da superfície. Se o pulso for suficientemente curto, o pulso termina, a energia é transferida para a rede do material, a relaxação termodinâmica ocorre, e só então o material é ejetado da superfície por transformação de fase [21]. A absorção multifotônica eficiente só é permitida pelas altas intensidades geradas por pulsos ultracurtos (fs), e garante que diferentes materiais transparentes possam absorver energia do laser num mesmo comprimento de onda. Além disso, a curta duração dos pulsos permite que a transferência da energia ocorra de uma maneira rápida, minimizando a zona afetada pelo calor. Assim, os processos de fotoionização nessas intensidades são mais eficientes e possibilitam a absorção da radiação de uma maneira mais controlada resultando em limiares de dano bem definidos [22], o que trouxe a possibilidade de um melhor controle da região afetada em função da energia do pulso.

Os pulsos ultracurtos permitiram uma interação determinística com um limiar de ablação bem definido, porém, o limiar de ablação não depende apenas das características do pulso laser e do tipo de material ablacionado. A absorção do pulso também depende da presença de defeitos na estrutura cristalina desses materiais. A préirradiação por um pulso laser num material dielétrico, mesmo que abaixo do limiar de dano, pode criar defeitos na rede cristalina. Esse processo é chamado de "efeito de incubação" e é responsável pela diminuição do limiar de dano em materiais préirradiados [23]. O processo de relaxação dos elétrons da banda de condução cria defeitos, os quais criam níveis eletrônicos interbanda, que funcionam como canais de absorção [24]. Pulsos laser que atingirem o material pré-irradiado criam elétrons sementes com maior facilidade, multiplicando-os na banda de condução e facilitando a ablação do material.

O processo de usinagem superficial de materiais dielétricos exige a sobreposição de pulsos para que a quantidade de material necessária seja arrancada [25; 26]. Assim o limiar de ablação e o parâmetro de incubação são parâmetros importantes para a usinagem e devem ser previamente conhecidos.

Nesse contexto, este trabalho se focou no estudo dos principais fenômenos físicos envolvidos no processo de absorção de pulsos ultracurtos em safira monocristalina, Ti:safira e os vidros ópticos BK7 e Suprasil, e o processo de incubação de pulsos sobrepostos. 
Para a medida do limiar de ablação e o parâmetro de incubação, duas técnicas experimentais foram utilizadas. Primeiramente, um método bem conhecido para medir o limiar de ablação, de pulsos únicos e sobrepostos, chamado Técnica de Regressão do Diâmetro (TRD) introduzida por Liu [20]. A segunda Técnica foi o $D$ scan introduzido por Samad e colaboradores [27]. Essa última técnica caracteriza-se pela simplicidade prática e analítica. Porém, a sobreposição de pulsos que é intrínseca à técnica de $D$-scan, não considerava a quantificação dessa sobreposição. Contudo, quando utilizada em materiais sensíveis a irradiações precedentes, a sobreposição deve ser quantificada a fim de se obter o limiar de ablação para diferentes sobreposições. Portanto esse trabalho acrescentou à técnica de $D$-scan a possibilidade de quantificação da sobreposição e sua validação usando o método tradicional. Esse estudo permitiu que os resultados experimentais fossem comparados com uma simulação numérica do limiar de ablação em função da largura temporal dos pulsos.

Os parâmetros de incubação dos diferentes materiais foram medidos e utilizados para testar um método que leva em conta a sobreposição de pulsos para usinagem de microcanais microfluídicos em BK7. 


\section{Objetivos}

Os objetivos desse trabalho foram:

1. Estudo teórico e experimental dos principais processos físicos envolvidos na absorção de pulsos ultracurtos por materiais dielétricos com grande gap de banda e a simulação de um modelo que descreva o limiar de ablação em função das características do pulso e do dielétrico.

2. Calibrar o método tradicional com a técnica de regressão do diâmetro (TRD) para pulsos únicos e pulsos sobrepostos na safira, Suprasil, BK7 e Ti:safira e calcular o parâmetro de incubação.

3. Estender a técnica de $D$-scan para a quantificação da sobreposição de pulsos. Realizar as medidas de limiar de ablação para diferentes sobreposições e validar a extensão da técnica com a comparação com o método tradicional.

4. Utilizar a técnica $D$-scan para a medida do limiar de ablação em função da sobreposição e da largura temporal dos pulsos e comparar com a simulação numérica.

5. Desenvolver um protocolo de usinagem em BK7 que permita a utilização do limiar de ablação de pulsos sobrepostos e o parâmetro de incubação para a fabricação de microcanais para uso em microfluídica. 


\section{Revisão da Literatura}

\subsection{Usinagem}

A usinagem a laser é caracterizada pela remoção controlada de uma fração de material de um substrato através da absorção da energia laser. Neste processo, espera-se que a ejeção ou ablação do material da superfície ocorra via uma transformação de fase termodinâmica sólido-líquido-gás, sólido-gás ou mesmo sem aquecimento do material. Nesse último, o processo deve ocorrer por repulsão eletrostática de íons induzida pelo laser.

A maneira como a energia é depositada pelo laser e absorvida pelo material é de fundamental importância no processo de ablação e no controle dos diferentes regimes de usinagem. Os diferentes regimes de interação podem caracterizar o acabamento final da usinagem. $\mathrm{O}$ excesso de energia depositada no material e o plasma formado na superfície do material podem afetar colateralmente o substrato usinado gerando uma zona afetada pelo calor. A ejeção do material fundido durante a usinagem cria rebarbas e regiões disformes, o que prejudica um bom acabamento.

Alguns parâmetros do laser influenciam no processo de ablação, tais como: comprimento de onda, densidade espacial de potência (intensidade), distribuição temporal de potência do laser (largura temporal do pulso), o "caminho da ferramenta" ou estratégia de deposição da energia laser, e a atmosfera na região de interação.

O uso de lasers pulsados no processo de usinagem de materiais dielétricos é justificado, principalmente, pela alta potência pico alcançada, já que a energia do feixe laser é concentrada num período curto no tempo (ns, por exemplo) e permite maiiores intensidades. Através desses, maiores intensidades proporcionam maior absorção pelo material. Além disso, as altas intensidades alcançadas por esses lasers permitem que o material seja ablacionado mais rapidamente durante a interação, diminuindo o tempo de difusão térmica, já que parte do calor é levado junto com o material ablacionado.

No caso dos lasers pulsados, diferentes larguras temporais podem ser utilizadas, e como consequência, diferentes dinâmicas de ablação são possíveis. Pode-se 
separar o processo de absorção em duas dinâmicas de ablação distintas, a feita por pulsos longos, e a feita por pulsos ultracurtos.

\subsubsection{Pulsos longos}

$\mathrm{Na}$ interação de pulsos longos (maior que algumas dezenas de picossegundos), é considerado que o processo de dano ou ablação envolve o aquecimento dos elétrons na banda de condução pela radiação incidente e a transferência dessa energia para a rede. Essa transferência se dá num processo de quase equilíbrio entre a temperatura dos elétrons e da rede, ocorrendo durante todo o tempo de interação do pulso laser com o material. Se a difusão do calor via corrente eletrônica ou fônons na rede cristalina, não for suficiente para dissipar o calor absorvido, a ablação ocorre devido à transformação de fase do material dielétrico e simples evaporação[28; 29]. Se houver energia suficiente, o material é sublimado.

Considerando a conservação da energia do sistema, qualquer variação na energia interna $U$ de um volume $V$, deve ocorrer devido à absorção da luz do laser ou pela difusão da energia para fora desse volume ( $\boldsymbol{j}$ sendo o fluxo de energia); neste caso a variação pode ser descrita por:

$$
\frac{\partial U}{\partial t}=-\nabla(\mathbf{j} \cdot V)+S \cdot V
$$

Esta variação na energia interna pode ser relacionada à mudança de temperatura $T$ usando o capacidade térmica $C_{i}$ do material por unidade de volume $\left(\partial U / \partial t=C_{i} . V . \partial T / \partial t\right)$. A fonte de calor $S$ pode ser calculada com:

Eq. 2

$$
S=I(z, t) \cdot(1-R(t)) \cdot A(z, t)
$$

onde $R$ é a refletividade da superfície, $A$ é a absorção pelo material e $I$ é a intensidade do laser em função da posição no eixo $z$ na direção do eixo de propagação, e do tempo $t$.

Na maioria dos casos, a perda de energia será por difusão térmica, que pode ser descrita por: 


$$
\boldsymbol{j}=-k \cdot \nabla T
$$

aqui $k$ denota a condutividade térmica. Reescrevendo a Eq. 1:

$$
C_{i} \frac{\partial T}{\partial t}=\nabla(k . \nabla T)+S
$$

Esta é a conhecida equação do calor parabólica [30]. A dependência da temperatura com os parâmetros físicos $\left(C_{i}, k\right)$ e os parâmetros ópticos $(R, A)$ tornam a equação anterior não linear, e a solução analítica só pode ser obtida em alguns casos [30].

Aqui vamos resumir a discussão sobre o transporte do calor para mostrar, de uma forma apenas qualitativa, as escalas de tempo e espaço envolvidos neste processo com pulsos longos.

Supondo constante os valores $C_{i}$ e de $k$, pode-se derivar da Eq. 4 que a onda de calor após a absorção do laser se propagará por [30]

$$
l_{D} \approx \sqrt{2 D \cdot t}
$$

onde $l_{D}$ é o comprimento de difusão, e $D=k / C_{i}$ é a difusividade térmica do material irradiado. No caso da safira, a difusividade é de aproximadamente $14 \mathrm{~mm}^{2} / \mathrm{s}$, o que significa que para um pulso de 10 ns o comprimento de difusão é 0,5 mícrons. Em metais, como a difusividade é maior, $165 \mathrm{~mm}^{2} / \mathrm{s}$ no caso da prata, o comprimento de difusão é de 1,3 mícrons sendo maior que a penetração óptica. Isso implica que mesmo que esses pulsos sejam focalizados em um mícron, a zona afetada pelo calor será maior e prejudicará um controle preciso da zona usinada.

\subsubsection{Pulsos ultracurtos - Modelo de Duas temperaturas}

Ao contrário do que ocorre para pulsos longos, para caso de pulsos com largura temporal menor ou igual ao tempo de relaxação elétron-fônon (poucas centenas de femtossegundos: pulsos ultracurtos), os processos de absorção eletrônica e aquecimento da rede podem ser tratados separadamente. Neste caso, o pulso laser transfere parte da sua energia para os elétrons, e somente após o término da relaxação elétron-fônon leva a efeitos termodinâmicos que promovem a ejeção de grande 
quantidade de material. A taxa de relaxação elétron-fônon é tão alta (depende do dielétrico) que ocorre um aquecimento abrupto do material. Antes que este passe do estado sólido para o estado líquido, o material ultrapassa em milhares de graus Kelvin a temperatura de ebulição. Como consequência, ocorre uma explosão de fase e a consequente ablação térmica do material ou ionização do dielétrico [31].

A consequência deste processo é que o aquecimento ocorre em condições de não-equilíbrio extremo. Assim, a dinâmica dos estados dos elétrons e da rede devem ser descritas separadamente. Um modelo que descreve essa dinâmica é o modelo de duas temperaturas (MDT), proposto por Anisimov e colaboradores para metais[32], conforme descrito pelas seguintes equações:

$$
\begin{gathered}
C_{e} \frac{\partial T_{e}}{\partial t}=-\frac{\partial Q(z)}{\partial z}-\gamma\left(T_{e}-T_{i}\right)+S \\
C_{i} \frac{\partial T_{i}}{\partial t}=\nabla(k . \nabla T)+\gamma\left(T_{e}-T_{i}\right) .
\end{gathered}
$$

Aqui, $T_{e}$ e $T_{i}$ são as temperatura dos elétrons e da rede, respectivamente, $z$ é a direção perpendicular à superfície, $C_{e}$ e $C_{i}$ são as capacidades térmicas por unidade de volume dos elétrons e da rede, $Q(z)=-k_{e}\left(T_{e}\right) \partial T_{e} / \partial z$ é o fluxo de calor eletrônico e $S=I(t) A \alpha \exp (-\alpha z)$ é o termo de fonte de calor. $A$ e $\alpha$ são a absorção da superfície e o coeficiente de absorção do material, respectivamente, $I(t)$ é a intensidade do laser, e $k_{e}$ $e ́$ a condutividade térmica eletrônica. O parâmetro $\gamma$ caracteriza o acoplamento elétronfônon, isto é, a troca de energia entre os dois subsistemas, e expressões para ele podem ser encontrados em [33-35]. Esse modelo é muito usado para descrever a termodinâmica em metais [36], e visto que esse conjunto de equações leva em consideração a difusão térmica do calor pela rede e pelos elétrons livres. Além disso, uma descrição quantitativa em dielétricos não seria adequada, visto que o aprisionamento eletrônico na rede e sua recombinação constituem canais de deposição adicionais além do acoplamento elétron-fônon.

Os tempos característicos envolvidos na dinâmica do sistema acima podem ser escritos através de $\tau_{e}=C_{e} / \gamma$ e $\tau_{i}=C_{i} / \gamma$, onde $\tau_{e}$ é o tempo de resfriamento dos elétrons e $\tau_{\mathrm{i}}$ é o tempo de aquecimento da rede. 
Aqui deve ser enfatizado que, em dielétricos, o comportamento metálico do dielétrico atribuído à excitação de elétrons para a banda de condução é restrita a uma estreita camada abaixo da superfície. Isso resulta num acoplamento bem localizado, portanto a condutividade térmica eletrônica é restrita às regiões de alta densidade eletrônica [37]. Baseado nesta consideração, uma simplificação da dinâmica acima para uma descrição qualitativa no caso de dielétricos seria considerar que a duração do pulso é muito menor que o tempo de resfriamento eletrônico característico, e que a difusão eletrônica é baixa durante o resfriamento dos elétrons. Nesse caso o sistema se reduz ao caso da equação do calor parabólica. A fonte de calor da rede tem um tempo de interação igual ao tempo de resfriamento dos elétrons, ou seja, simplesmente $\tau_{\mathrm{e}} \mathrm{O}$ comprimento de difusão é $l_{t h} \approx\left(D \tau_{e}\right)^{1 / 2}$ e depende apenas do tempo de relaxação elétronfônon.

O tempo de relaxação elétron fônon no caso da safira é da ordem de 1 ps, implicando que para um pulso de 100 fs o comprimento de difusão é no mínimo igual a uma interação com um pulso de 1 ps. No caso da safira, este comprimento é de aproximadamente 0,005 mícrons. Isso mostra a influência do tempo de relaxação eletrônico na dinâmica de ablação.

Quanto mais curto o pulso, menor é o fluxo de calor para fora da região da interação do pulso, diminuindo a difusão térmica na rede cristalina (haja vista que a difusão eletrônica sempre ocorre durante todo o processo na banda de condução). Além disso, menor também é a energia necessária para que a mesma porção de material atinja temperaturas maiores, o que diminui o limiar de ablação. Portanto, após a ablação, grande parte do calor é retirado junto com o material ablacionado.

Neste sentido, um método usual para o estudo da dinâmica de ablação de materiais transparentes por pulsos laser é a medida da fluência de limiar para o dano óptico causado em diferentes durações temporais [38-41]. Assinaturas de efeitos térmicos têm sido observadas para pulsos acima de 20 ps de largura temporal (Figura 3.1), abaixo desse valor existe um desvio da relação entre a fluência de limiar $F_{t h}$ e a largura temporal do pulso $\tau_{\mathrm{L}}$ dada por:

$$
F_{t h} \propto \tau_{L}^{1 / 2}
$$


Para pulsos longos, esta dependência está diretamente relacionada ao tempo de difusão limitado pela largura temporal do pulso. Quando se tem o regime de quase equilíbrio (pulso longo) o aquecimento da rede se dá pelo acúmulo de calor até que a temperatura de fusão seja atingida (limiar de dano). Quanto mais curto o pulso menos o calor se difunde e menor é o limiar de dano. Abaixo de 20 picossegundos (nos materiais desse exemplo) a taxa de deposição de calor da rede não segue mais a duração do pulso, mas sim a dinâmica que envolve o tempo de relaxação elétron-fônon que é dado em função do tempo de relaxação do elétron na banda de condução [42].

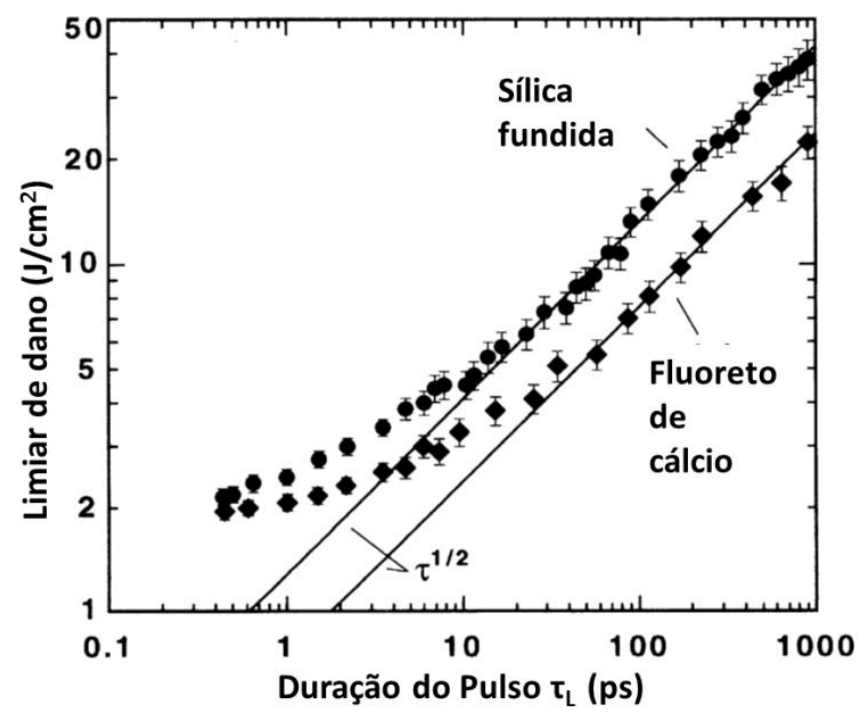

Figura 3.1- Valores observados do limiar de dano em função da largura temporal $(\lambda=1053 \mathrm{~nm})$ para sílica fundida e $\mathrm{CaF}_{2}$. Pode-se observar o desvio da relação com o efeito térmico para pulsos abaixo de 20ps [42].

O gráfico da Figura 3.1 mostra uma tendência à estabilização do limiar de dano para pulsos mais curtos, entretanto o valor não fica constante, haja vista que a interação com pulsos mais curtos tem dinâmicas de aquecimento dos elétrons diferente e devem levar em conta outros processos relacionados à dinâmica de absorção.

Para pulsos ultracurtos, a densidade eletrônica na banda de condução também está diretamente relacionada ao aumento da absorbância do material. Quanto mais elétrons livres, mais energia é absorvida pelo material. Então, para se alcançar o "rompimento do dielétrico" (Dielectric Breakdown) ou ablação do material dielétrico, esse deve produzir uma grande densidade de elétrons livres perto da densidade crítica, para que assim, haja energia suficiente para uma transformação de fase. A dinâmica de 
geração eletrônica e a metalização do dielétrico estão relacionadas aos mecanismos de absorção da radiação pela matéria, e devem ser explicada para a descrição adequada do processo de ablação com pulsos ultracurtos.

\subsection{Mecanismos de Absorção}

Uma teoria que pretende explicar a geração de dano ou o processo de ablação em materiais dielétricos, que são transparentes à radiação laser, deve explicar o processo de absorção dessa radiação e o consequente processo de geração dos elétrons livres no material transparente.

Os mecanismos de absorção nos sólidos são os seguintes [15]:

1. absorção interbanda, e contribuições dos elétrons livres em metais e semicondutores;

2. transição interbanda e excitações moleculares;

3. absorção por excitação coletiva (éxcitons, fônons);

4. absorção devido às impurezas e defeitos.

Os elétrons livres têm um papel dominante no processo de absorção em metais. Já em materiais dielétricos, o principal mecanismo de absorção em baixa intensidade na interação laser-sólido é a transição eletrônica interbanda.

No caso em que a energia do fóton é menor que intervalo interbanda do material, transições eletrônicas são proibidas em primeira aproximação, o que corresponde a um índice de refração com parte real bem maior que a parte imaginária. A absorção da radiação pode ser aumentada com comprimentos de onda menores, os quais possuem energia maior que o gap do material, ou se a intensidade da radiação incidente é grande o suficiente para que efeitos não lineares ocorram com maior probabilidade como a ionização multifotônica e ionização por tunelamento.

Atualmente, os sistemas lasers de pulsos ultracurtos de bancada são capazes de gerar facilmente intensidades da ordem de $10^{12}$ a $10^{18} \mathrm{~W} / \mathrm{cm}^{2}$, e o campo elétrico associado à onda eletromagnética $\left(10^{9}\right.$ a $\left.10^{12} \mathrm{~V} / \mathrm{m}\right)$ é comparável ao campo elétrico Coulombiano $\left(\sim 10^{11} \mathrm{~V} / \mathrm{m}\right.$ para o elétron-1s do hidrogênio) que prende o elétron ao núcleo. Consequentemente, a interação não pode ser mais tratada como uma 
perturbação fraca da matéria irradiada com uma resposta linear. Ao invés disso, o elétron "sente" o campo elétrico do laser que se sobrepõe ao campo Coulombiano do átomo [43]. Esse tipo de interação ultra intensa permite que esses processos de fotoionização não linear ocorram.

\subsubsection{Ionização multifotônica}

A interação multifotônica torna-se possível quando a densidade de fótons é alta o suficiente para que vários fótons estejam no mesmo sítio de interação espacial e temporal simultaneamente.

Numa descrição semiclássica a situação é equivalente a um campo elétrico muito intenso da onda eletromagnética, que pode ser introduzida na Hamiltoniana do sólido em uma abordagem perturbacional. O campo Coulombiano gerado pelo átomo que confina os elétrons é perturbado e sofre uma deformação periódica [43].

Isso pode ser considerado como a geração de um dipolo oscilante. $\mathrm{Na}$ Hamiltoniana, a anarmonicidade aumentada leva ao acoplamento de dois autoestados da Hamiltoniana não perturbada [43]. Os dipolos induzidos são equivalentes a uma polarização do meio, $\mathbf{P}$, que é proporcional apenas ao campo elétrico da luz, $\mathbf{E}$, onde $\alpha$ é a polarizabilidade do meio [43]:

$$
\boldsymbol{P}=\alpha \boldsymbol{E}
$$

Para intensidades maiores, a anarmorcidade torna-se maior. Na teoria de perturbação, isso é representado pelo desenvolvimento em séries de potências do campo elétrico:

$$
P=\left(\alpha+\alpha^{(2)} E+\alpha^{(3)} E E+\alpha^{(4)} E E E+\cdots\right) E
$$

as quais envolvem contribuições de maiores anarmonicidades do campo incidente, como pode ser visto quando se usa o campo elétrico como: $\boldsymbol{E}=\boldsymbol{E}_{\boldsymbol{0}} \exp [i(\omega t-\boldsymbol{k} \boldsymbol{r})]$. Na Hamiltoniana, isto é equivalente ao acoplamento de mais autoestados na função resultante. Para o caso da absorção, deve ser considerado que a energia do campo eletromagnético é dada pelo quadrado do campo, isto é, a contribuição não linear é proporcional ao quadrado do respectivo termo na polarização, pelo acoplamento da 
parte imaginária da polarização. Assim, a probabilidade para uma transição de n-fóton é proporcional a n-ésima potência da intensidade incidente:

$$
P_{(n)} \propto\left(\boldsymbol{P}^{(n)} \boldsymbol{E}\right)^{2} \propto\left(\operatorname{Im}\left(\alpha^{(n)}\right) \boldsymbol{E}^{n-1} \boldsymbol{E}\right)^{2}=\left(\operatorname{Im}\left(\alpha^{(n)}\right)\right)^{2} \boldsymbol{E}^{2 n} \propto I^{n} . \quad \text { Eq. } 11
$$

Em experimentos de absorção, transições multifotônicas podem ser identificadas em um gráfico log-log da energia absorvida (taxa de ionização) em função da intensidade. Linhas retas são ajustadas e o coeficiente angular indica a ordem do processo, ou seja, o número de fótons absorvidos.

Num sistema real, a situação é mais complexa devido às estruturas de energia do material que contém a estrutura explicita de $\alpha$. Ou seja, ressonâncias podem aumentar a polarizabilidade diminuindo a não linearidade. Um exemplo importante no caso desse trabalho é o acumulo de defeitos por irradiações precedentes que geram canais de absorção de menor ordem e consequentemente diminuem o limiar de dano.

\subsubsection{Absorção por tunelamento}

No processo de ionização por tunelamento o campo elétrico do laser perturba a barreira Coulombiana que blinda o elétron na banda de valência. Se este campo elétrico for suficientemente intenso, a barreira Coulombiana $\left(10^{11} \mathrm{~V} / \mathrm{m}\right.$ para o átomo de hidrogênio, correspondente a uma intensidade de $10^{16} \mathrm{~W} / \mathrm{cm}^{2}$ ) pode ser suprimida suficientemente para que o elétron ligado tunele através da pequena barreira e se torne livre [43]. Com 10\% dessa intensidade, o tratamento perturbativo já não é mais justificável [43] e a ionização por tunelamento se torna dominante no processo. A transição da ocorrência entre os processos foi expressa por Keldysh em termos do parâmetro adiabático $\gamma$, também conhecido como parâmetro de Keldysh [44], conforme a relação abaixo:

$$
\gamma=\frac{\omega}{e}\left[\frac{m c n \varepsilon_{0} E_{g}}{I}\right]^{1 / 2}
$$

onde $\omega$ é a frequência, $I$ é a intensidade no foco, $m$ e $e$ são a massa reduzida e a carga do elétron, $n$ é o índice de refração do material, $E_{g}$ é o gap da banda do material e $\varepsilon_{0}$ é a permissividade no vácuo. Quando o parâmetro de Keldysh é maior que 1,5, a 
fotoionização é um processo multifotônico e quando inferior a este valor, o processo se dá por tunelamento. Um valor intermediário de $\gamma$ corresponde a uma mistura dos dois processos.

A taxa de fotoionização depende fortemente da intensidade do laser. No regime de ionização multifotônica essa taxa é:

$$
P(I)_{A M F}=\sigma_{n} I^{n}
$$

onde $\sigma_{n}$ é o coeficiente de absorção multifotônica para $n$ fótons. O número de fótons necessário é o menor número $n$ que satisfaz a relação $n \hbar \omega \geq E_{g}$. A taxa de tunelamento, entretanto, cresce mais fracamente com o aumento da intensidade [45].

\subsubsection{Ionização por Impacto - Efeito avalanche}

No processo de absorção por efeito avalanche, os elétrons livres na banda de condução podem absorver fótons únicos. Depois de uma absorção sequencial de $n$ fótons, onde $n$ é o menor número inteiro no qual satisfaz a relação $n \hbar \omega \geq E_{g}$, esses elétrons são levados a níveis mais altos de energia na banda de condução. A energia excedente em relação ao nível mais baixo na banda de condução é transferida por colisão para um elétron na banda de valência criando outro elétron livre [46]; este processo é chamado de ionização por impacto e continua a ocorrer durante a interação com o pulso. A densidade de elétrons, $n_{e}$, na banda de condução cresce de acordo com

$$
\frac{d n_{e}}{d t}=\beta n_{e}
$$

onde $\beta$ é taxa de ionização por avalanche de cada elétron.

Os elétrons excitados para a banda de condução têm um livre caminho médio dado pela "curva universal" do livre caminho médio inelástico em função da energia do elétron [47]. Apenas os elétrons que estão perto da superfície da amostra têm maiores chances de sair e escapar da superfície por efeito fotoelétrico (Figura 3.2) e não contribuem para o processo de avalanche. Esses elétrons que escapam da amostra contribuem para um acúmulo de cargas positivas na superfície do dielétrico e são 
responsáveis pela ablação Coulombiana não térmica ocorrendo devido à presença de cargas na superfície do material.

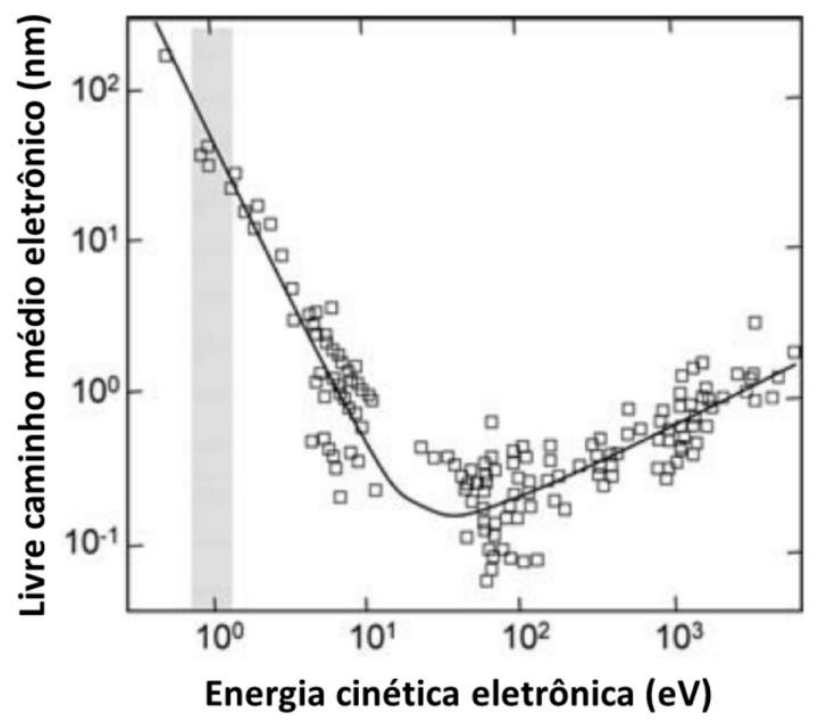

Figura 3.2 - Curva universal do livre caminho médio do elétron para choques inelásticos na banda de condução. A região mais escura mostra o intervalo de energia dos elétrons que escapam da amostra. Adaptado de [47].

Ainda que seja um processo de absorção eficiente, o processo de ionização por avalanche necessita de alguns elétrons "sementes" na banda de condução do material para ser iniciado. Esses podem ser gerados por excitação térmica, por impurezas iônicas ou defeitos, ou podem ser gerados por absorção multifotônica ou ionização por tunelamento [44].

Bloembergen e colaboradores já usavam o modelo de efeito avalanche para explicar a ionização em dielétricos [48] por lasers de nano e picossegundos. Stuart e colaboradores [42] mostraram que o modelo do efeito avalanche pode ser deduzido de modelos mais complexos como a equação de Fokker-Planck [42]. Essa simplificação define o efeito de ionização por avalanche no qual a taxa de avalanche depende linearmente da intensidade do laser (isto é, $\beta=\eta I$, onde $\eta$ é o coeficiente de ionização por avalanche). O aquecimento dos elétrons na banda de condução é levado em conta usando basicamente o modelo de Drude, levando também em consideração o modelo de condutividade dependente da energia do elétron [42].

Historicamente, antes de experimentos com pulsos ultracurtos, no caso dos dielétricos, era enfatizado que o principal processo de dano em materiais transparentes 
devia-se ao efeito avalanche [28; 48], especialmente em comprimentos de onda no infravermelho e infravermelho próximo. Esses argumentos se baseavam no caráter estatístico do limiar de dano induzido por laser, além de similaridades com o limiar de ionização de dielétricos em campos de potenciais constantes DC [28] e a baixa sensibilidade do limiar de ablação com o comprimento de onda na região do visível.

Mesmo num material dielétrico à temperatura ambiente, estatisticamente, existem elétrons excitados termicamente na banda de condução. Estes elétrons servem como "sementes" para o início do processo de avalanche ou geração de elétrons livres no material. Como essa concentração inicial de elétrons livres no material é relativamente pequena, ou pode variar aleatoriamente na região de interação do laser com o material, a iniciação do processo de dano tem um caráter estocástico [48]. Assim, o estudo experimental do limiar de ablação ou dano óptico para pulsos longos (maior que algumas dezenas de ps) sempre foi complicado pela dificuldade de se encontrar um limiar de ablação intrínseco do material livre de causas externas (calor, defeitos, qualidade da superfície) [15; 38]. Para pulsos de nanossegundos no infravermelho próximo, o limiar de dano não tem um caráter bem definido, pois o único processo de geração de mais elétrons livres no material é via processo avalanche, devido à menor intensidade produzida por esses pulsos.

A simples abordagem do modelo de ionização por avalanche como principal processo de absorção já foi muito criticada. Novos efeitos foram discutidos como o aquecimento dos elétrons livres (absorção de fóton pelos elétrons livres com criação de fônons para a conservação de momento e subsequente aquecimento da rede) ou aquecimento de pólarons [28; 29].

No regime de pulsos ultracurtos, a ideia de um modelo estatístico de dano baseado na probabilidade de um ou mais elétrons livres começarem o processo de avalanche não é mais usado, e se concluiu que mesmo absorções multifotônica de altas ordens podem prover uma grande quantidade de elétrons "sementes" para o processo de avalanche [28].

No processamento de materiais, a absorção multifotônica funciona como um gerador de dano determinístico, pois depende apenas da intensidade e da secção de 
choque multifotônica. Isso permite um melhor controle de processamento e a diminuição das flutuações associadas às variações do limiar de dano [42; 49].

\subsection{Processos de ablação}

A estrutura cristalina de materiais dielétricos e semicondutores permite que a rede tenha elétrons quase-localizados como consequência da condição de equilíbrio das ligações interatômicas. Sendo assim, qualquer mudança na configuração eletrônica influenciará fortemente a estabilidade cristalina do material [50]. Mesmo uma interação mais rápida que o período de relaxação elétron-fônon pode gerar um desequilíbrio da rede. Antes que o material possa ser alterado termodinamicamente via um equilíbrio entre elétron e rede [51], é possível observar a ejeção de elétrons e íons da superfície $[52 ; 53]$. A ejeção de elétrons e o acúmulo de íons perto da superfície são responsáveis por um desequilíbrio na estrutura cristalina e a consequente ejeção de íons do material. Esse é o chamado efeito Coulomb e é responsável pelo processo de ablação não térmico.

Após a relaxação eletrônica e transferência da energia para rede, processos termodinâmicos são responsáveis pela transformação de fase do material e caracterizam a ablação térmica. Definem-se, então, dois regimes de ablação: o de baixa e o de alta fluências. Em baixa fluência ocorre somente o efeito Coulomb, enquanto que em alta fluência existe energia suficiente para mudança de fase e ablação térmica.

\subsubsection{Efeito Coulomb - Ablação não térmica}

A explosão Coulombiana é guiada por mecanismos eletrônicos, normalmente em rápidas transições estruturais (transformações de fase não térmicas [54]) e emissão [37] não térmica de cargas e partículas neutras. Muitas vezes, as partículas emitidas têm uma grande energia cinética e distribuições angulares estreitas na direção normal à superfície.

A remoção de material ocorre normalmente em algumas camadas atômicas (poucos nanômetros). Os principais mecanismos da explosão Coulombiana são os seguintes. Os íons ejetados da superfície (por exemplo, alumínio e oxigênio provenientes da irradiação de safira por pulsos de fs [55]) observados em espectrômetro 
de massa por tempo de voo mostram que os íons são ejetados com mesma energia cinética e diferentes velocidades. Além disso, íons com o dobro de carga têm velocidades duas vezes maiores. Isso indica que esses íons foram arrancados e acelerados pelo campo elétrico da superfície. Portanto, o conceito de explosão Coulombiana é baseado no fato de que, devido à emissão fotoelétrica, a superfície irradiada acumula uma grande carga positiva, e a força de repulsão excede a força de ligação da rede, resultando na desintegração de uma camada da superfície.

Numa consideração macroscópica da explosão Coulombiana é suposto que, sob certas circunstâncias, a quebra das ligações interatômicas e a desintegração ocorrem após atingir um valor de limiar.

Para uma estimativa qualitativa do efeito fotoelétrico durante a irradiação serão feitas as seguintes considerações [19]: Supõe-se uma distribuição estatística dos elétrons livres num dielétrico com um grande gap, no qual a energia de nível de vácuo (energia do elétron fora da amostra) é bem próxima ao nível mínimo de energia na banda de condução e apenas elétrons com momento na componente normal à amostra e perto da superfície podem escapar para o vácuo. Para essa última consideração supõe-se que, em média, apenas metade dos elétrons que são excitados por absorção multifotônica ou efeito avalanche podem escapar da amostra. Os elétrons que escapam da amostra dependem do livre caminho médio eletrônico na rede cristalina. Para as energias envolvidas nesse caso, de poucos eV $(5 \mathrm{eV})$, de acordo com a "curva universal" da Figura 3.1 o livre caminho médio é da ordem de $\sim 50 \mathrm{~nm}$ e $l_{f e}$ corresponde ao comprimento de escape de elétrons.

Assim sendo, uma estimativa da densidade do número de elétrons que escapam da $\operatorname{amostra} n_{f e}$ pode ser expressa por [19]:

$$
\frac{\partial n_{f e}(r, z, t)}{\partial t}=\frac{1}{2}\left[\sigma_{n} I^{n}(r, z, t)+\eta I(r, z, t)\right] \frac{n_{a}}{n_{a}+n_{i}} \exp \left(-z / l_{f e}\right)
$$

onde $\sigma$ é coeficiente de absorção multifotônica, $n$ é número de fótons para absorção não linear, $I$ é a intensidade, $\eta$ é o coeficiente do efeito avalanche, $n_{a}$ e $n_{i}$ são a densidade de elétrons neutros e ionizados, respectivamente, e $z$ é a distância à superfície. 
A equação de Poisson pode ser usada para calcular o campo elétrico acumulado na camada de material que perdeu elétrons [37]:

$$
\frac{\partial E}{\partial z}=\frac{e}{\varepsilon \varepsilon_{0}}\left(n_{f e}\right)
$$

A estimativa para o limiar de ablação Coulombiana pode ser dada pelas seguintes considerações [56]: a densidade de energia volumétrica do campo elétrico é expressa como $w=\varepsilon \varepsilon_{0} E^{2} / 2$. O valor $W_{a t}=\varepsilon \varepsilon_{0} E^{2} V_{a t} / 2$ é a energia do campo elétrico correspondendo ao volume $V_{a t}=n_{0}^{-1}$ ocupado por um único elétron de um átomo no cristal, onde, $n_{0}$ é a densidade de elétrons na banda de valência por átomo. A energia necessária para remover um átomo do alvo pode ser estimada do calor latente de sublimação calculado para um átomo. Para a safira, por exemplo, essa energia é $L_{a t}=485,7 \mathrm{~kJ} / \mathrm{mol}$ [56], que corresponde a aproximadamente $5 \mathrm{eV}$ por átomo. Assim o limiar aproximado de campo elétrico na superfície é:

$$
E_{t h}=\sqrt{\frac{2 L_{a t}}{\varepsilon \varepsilon_{0} V_{a t}}}=\sqrt{\frac{2 L_{a t} n_{0}}{\varepsilon \varepsilon_{0}}}
$$

Para a safira $E_{t h} \sim 5 \times 10^{10} \mathrm{~V} / \mathrm{m}$, no caso do ouro e silício o campo é menor, sendo $2,76 \times 10^{10}$ e $2,65 \times 10^{10} \mathrm{~V} / \mathrm{m}$, respectivamente.

Essa consideração é válida para pulsos laser de femtossegundos onde a rede permanece fria durante a ejeção de elétrons. Para pulsos mais longos, a rede é aquecida durante o pulso e deve-se levar em conta o aquecimento dos átomos da superfície que tem maior probabilidade de escapar do que os átomos frios, fato que pode diminuir o limiar de ejeção de elétrons [37]. Assim pode-se escrever:

$$
\frac{\varepsilon \varepsilon_{0} E_{t h}^{2}}{2 n_{0}}+3 k T_{i}=L_{a t} \quad \text { ou } \quad E_{t h}=\sqrt{\frac{2\left(L_{a t}-3 k T_{i}\right) n_{0}}{\varepsilon \varepsilon_{0}}}
$$

Estudos sobre a explosão Coulombiana (EC) foram demonstrados experimentalmente $[23 ; 55 ; 57 ; 58]$ e teoricamente $[37 ; 58]$ em metais, semicondutores e dielétricos irradiados com pulsos de femtossegundos. Nas referências [19; 59], modelos foram aplicados considerando pulsos com $800 \mathrm{~nm}$ de comprimento de onda e 100 fs, e mostrou-se que a EC é suprimida em metais e semicondutores para tipo de 
regime de interação. Bulgakova e colaboradores mostraram que a ablação por EC foi simulada em ouro, silício e safira [37]. Estas simulações utilizaram intensidades pouco menores que o limiar de ablação térmica do material. Nessas intensidades, tanto no ouro quanto no silício, o campo elétrico gerado pela emissão de elétrons é suprimido pelo transporte de carga antes que se atinja o limiar do campo elétrico para EC. Nesse mesmo trabalho foi constatado EC para pulsos de ns em silício, mas com o uso de comprimentos de onda no UV.

A geração de campos elétricos intensos da ordem de $10^{10} \mathrm{~V} / \mathrm{m}$ (limiar de campo elétrico) foi detectada mesmo em metais, mas, nestes casos, lasers extremamente potentes foram utilizados com intensidades da ordem de $10^{18} \mathrm{~W} / \mathrm{cm}^{2}$ [60]. Portanto, o fato do limiar de intensidade para EC em metais e semicondutores ser muito maior que os seus respectivos limiares de ablação térmica faz com que a aplicação do regime de EC em que não existe efeito térmico seja restrito apenas aos materiais dielétricos. No caso dos metais existe a região de baixa e alta fluência, na qual existe pouca ou grande zona afetada pelo calor. Mas essas duas regiões são caracterizadas pelo tamanho da zona afetada pelo calor sendo menor ou maior que comprimento óptico de interação dentro do metal (lei de Beer) [61], além da influência térmica do plasma para energias de pulso mais altas.

\subsubsection{Explosão de Fase - Ablação Térmica}

A explosão térmica normalmente ocorre quando o material é aquecido acima de uma temperatura crítica. Esse processo pode ocorrer quando pulsos ultracurtos são usados ( <1ps), e o aquecimento é isocórico e o material pode expandir-se para liberação da energia térmica armazenada. Esse processo é conhecido como explosão de fase ou ebulição explosiva, e tem sido relacionado ao processo de ablação em pulsos de até $\sim 10 \mathrm{~ns}$ [62].

No caso de pulsos ultracurtos, o aquecimento do material, decorrente da transferência da energia dos elétrons para a rede, ocorre numa taxa que depende do tempo de relaxação elétron-fônon como visto na secção 3.1.2. No caso da safira, esse tempo pode ser de $\sim 1$ ps e na sílica esse tempo é ainda menor, da ordem de 100fs. Este rápido aquecimento permite que ocorra a transformação de fase do material de uma 
forma não convencional. Diferentes mecanismos são associados à remoção de material pelo aquecimento de pulsos ultracurtos, como explosão de fase [63- 68], espalação (“spalation") [66] e fragmentação [67; 68].

Perez e colaboradores [67], usando uma combinação de dinâmica molecular e método de Monte Carlo, simularam em um material hipotético, quais seriam os caminhos termodinâmicos possíveis no diagrama de fase em diferentes energias e larguras temporais de pulso. A Figura 3.3 mostra esses possíveis caminhos no diagrama de densidade-temperatura $(\rho-T)$. Nesse gráfico, as letras $\mathbf{L}$ e $\mathbf{G}$ representam a região líquida e gasosa, respectivamente, e $\mathbf{L}+\mathbf{G}$ representa a existência simultânea das duas fases.

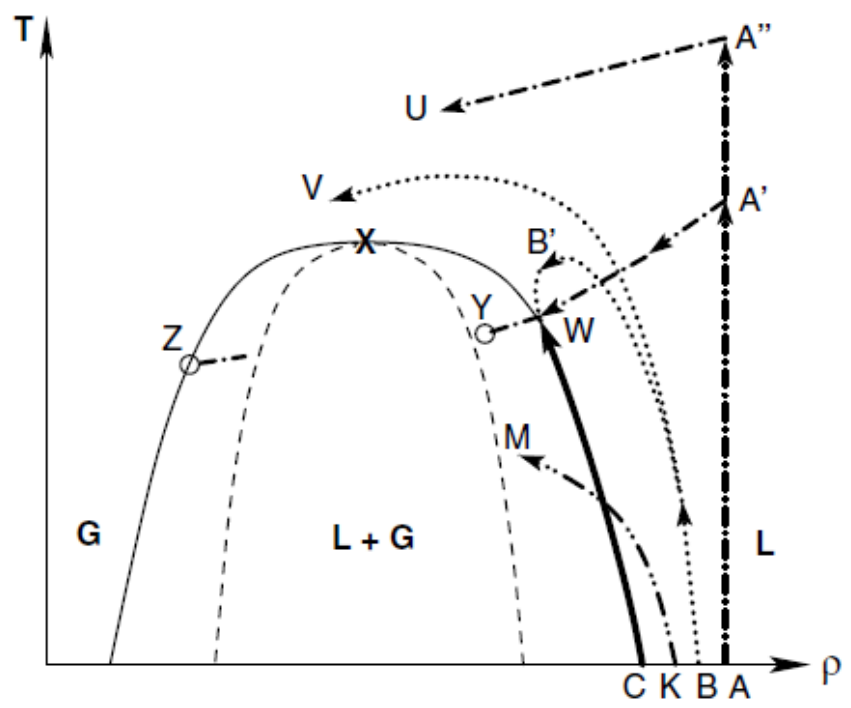

Figura 3.3 - Trajetórias termodinâmicas de um material hipotético sob irradiação de pulsos de fs (linha ponto-traço), ps (linha pontilhada), e ns (linha sólida). Linha sólida fina (binodal); linha tracejada: espinodal; cruz: ponto crítico. L: líquido; G: gás. As outras letras representam caminhos no diagrama de fase (veja texto), adaptado de [67].

A existência de vários mecanismos de ablação pode ser entendida pela taxa de expansão do material aquecido e o subsequente resfriamento. $\mathrm{O}$ caminho percorrido no gráfico $\rho$-T é determinante para separar os diferentes tipos de ablações térmicas. Isso pode ser exemplificado considerando como o material atinge um ponto arbitrário (W) ao longo da binodal (existência de duas fases simultaneamente) no gráfico de $\rho$-T da Figura 3.3. Nessas altas taxas de transferência de calor para a rede, um aquecimento isocórico gera uma grande pressão no material, e posterior rarefação durante expansão 
mecânica. Em altas energias, o resultado da rápida expansão causa o rompimento do fluído supercrítico através da fragmentação $(\mathrm{A} \rightarrow \mathrm{A} " \rightarrow \mathrm{U})$ [68]. Este regime é caracterizado por uma região ablacionada irregular constituída por trincas e ondas de choque mecânicas devido à violência do processo ablativo. Entretanto, perto do limiar de ablação, a expansão é muito lenta para induzir fragmentação, mas é capaz de levar o sistema até o regime metaestável (perto do limite espinodal) antes que ocorra a difusão térmica $\left(\mathrm{A} \rightarrow \mathrm{A}^{\prime} \rightarrow \mathrm{W} \rightarrow \mathrm{Y}\right)$, isto é, através de um resfriamento adiabático. Nesse caso ocorre nucleação homogênea convertendo o material superaquecido numa mistura de líquido e gás $(\mathrm{Y} \rightarrow \mathrm{Z})$, que é uma transição de primeira ordem. Similarmente, durante a irradiação com pulsos longos, o material responde a um aquecimento lento com uma expansão lenta ao longo da binodal $(\mathrm{C} \rightarrow \mathrm{W})$, provavelmente até o ponto crítico $\mathbf{x}$ onde a separação de fase ocorre via transição de segunda ordem. Contudo, para pulsos >100ns a vaporização ainda é importante [62].

Consequentemente, deve existir uma duração de pulso "crítica" na qual a explosão de fase é suprimida. Essa situação é ilustrada pela trajetória $\mathrm{B} \rightarrow \mathrm{B}^{\prime} \rightarrow \mathrm{W}$ para um pulso com duração intermediária (ps). Seguindo a curva de aquecimento não isocórico o sistema esfria através do regime líquido-gás. Nesse caso, entretanto, a expansão ocorre num período da ordem ou maior que o tempo característico para condução de calor $\left(\tau_{\text {th }} \sim 10^{-11} \mathrm{~s}\right.$ [69]). Como resultado o sistema resfriam ao longo da curva binodal por difusão térmica, ou seja, não entra na região metaestável e a explosão de fase não ocorre. Nesse caso, apenas as regiões associadas à expansão acima do ponto crítico contribuem para ablação de massa $(\mathrm{B} \rightarrow \mathrm{V})$ através de fragmentação[67], mas são necessárias energias de pulsos maiores.

Apesar da grande complexidade envolvida nos diferentes processos de ablação, no caso do regime de explosão de fase (fs) é possível aplicar uma simplificação para prever a temperatura de explosão de fase. Considerando-se o caminho termodinâmico esquematizado na Figura 3.4, o material encontra-se no estado sólido e a temperatura ambiente $\left(\rho_{0}, T_{0}\right)$; o rápido aquecimento isocórico leva o material para o estado $\left(\rho_{0}, T_{\text {sep }}\right)$ onde atinge a temperatura de separação; o material então esfria adiabaticamente (devido à rápida expansão) seguindo aproximadamente a relação $T \propto \rho^{2 / 3}$; quando o material entra na região binodal perto do ponto crítico, isso resulta em instabilidades termodinâmicas e na nucleação homogênea. Temperaturas acima da 
$T_{\text {sep }}$ irão ablacionar o material, e temperaturas menores condensarão o material de volta ao substrato[31] .

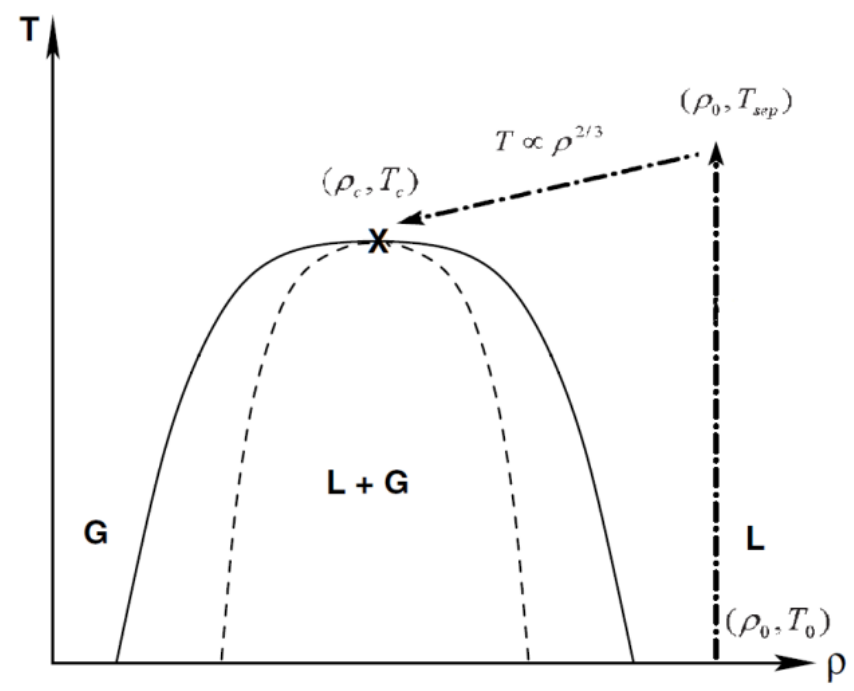

Figura 3.4 - esquema da trajetória aproximada do material entrando na zona de instabilidade perto do ponto crítico

A temperatura de separação pode ser relacionada à temperatura crítica pela relação:

$$
\frac{T_{s e p}}{T_{c}}=\left(\frac{\rho_{0}}{\rho_{c}}\right)^{2 / 3}
$$

Miotello e Kelly [62] argumentam que para pulsos curtos o suficiente $(<1 \mu \mathrm{s}$, dependendo da energia), o rápido aquecimento leva o sistema a uma região metaestável onde a nucleação homogênea de bolhas de gás ocorre. No plano densidade-temperatura $(\rho-T)$, esse processo pode ser representado pela curva $K \rightarrow M$ da Figura 3.3.

\subsection{Incubação}

O processo de incubação está relacionado à diminuição do limiar de ablação pela interação de pulsos sobrepostos. Isto vem do fato de que ao incidir em uma região previamente irradiada, o pulso laser encontra uma região de alguma maneira modificada, e geralmente com limiar de ablação menor do que aquele em regiões sem irradiação alguma. Este fato ocorre mesmo para fluências abaixo do limiar de ablação e apresenta um efeito cumulativo até a ocorrência de uma saturação. A dinâmica dos fenômenos que ocorrem na irradiação múltipla de pulsos é explicada a seguir. 
A excitação eletrônica da banda de valência para a banda de condução pela absorção do laser cria um plasma eletrônico formado por pares elétron-buraco no material dielétrico. Esse plasma é eventualmente eliminado pela recombinação desses pares, entretanto, alguns pares podem escapar da aniquilação. Poucos elétrons podem ser capturados por defeitos e impurezas na estrutura cristalina. Existe também a probabilidade que o par elétron-buraco se separe para criar um defeito estável com estados de energia dentro no gap da banda do material, nesse caso, centros de cor.

A absorção por esses níveis interbanda provenientes desses novos defeitos, seja por absorção linear ou multifotônica, contribuirá para a geração de elétrons na banda de condução pelo próximo pulso. Isso facilita a geração de elétrons e o processo de absorção da radiação pelo material diminuindo a energia de limiar necessária para atingir a densidade eletrônica crítica para ablação. Isso ocorre porque pequenas alterações na estrutura dos níveis de energia em um material com grande gap interbanda podem ter grandes influências na seção de choque de absorção para altas nãolinearidades.

No caso de fortes acoplamentos entre elétrons e buraco na rede cristalina, o portador de carga pode ser "autocapturado" (self-trapped) como um pólaron no seu próprio campo de distorção da rede. Um par ligado de elétron-buraco é geralmente descrito como um éxciton auto aprisionado [70] (self-trapped exciton - STE) e são considerados como precursores de defeitos estáveis na rede cristalina na forma de centros de cor [71]. Alguns autores tratam os próprios STE como defeitos transientes no material [72] sendo que o tempo de vida médio dos STE é da ordem de poucos ns.

Uma rápida descrição da dinâmica de incubação consiste na absorção de um pulso pelo material dielétrico, e com subsequente criação de elétrons livres, porém em quantidade insuficiente para promover uma mudança de fase, mas criando defeitos estáveis. O próximo pulso, com mesma intensidade, encontrará o material com uma densidade de defeitos $D$, que inclui linhas de absorção interbanda no gap do material. Agora o material não possui as mesmas características do encontrado pelo primeiro pulso. As linhas interbanda aumentam a seção de choque multifotônica e consequentemente a geração de elétrons "semente" pelo segundo pulso. Isso permite que esse segundo pulso excite mais elétrons livres que o primeiro pulso. Esse processo ocorre até que no n-ésimo pulso, a excitação eletrônica, eventualmente, atinja o valor 
crítico $n_{c r}$ e o material seja ablacionado. Portanto, o limiar de ablação de pulsos sobrepostos é menor que o limiar para pulsos únicos. Outra implicação dessa dinâmica é que o número de defeitos aumenta exponencialmente até atingir uma saturação de defeitos na rede em dielétricos.

Define-se a partir dessa dinâmica o limiar de ablação para $N$ pulsos sobrepostos, $\mathrm{F}_{\mathrm{th}, \mathrm{N}}$, introduzido por Ashkenasi e colaboradores [23]:

$$
F_{t h, N}=F_{t h, \infty}+\left[F_{t h, 1}-F_{t h, \infty}\right] e^{-k(N-1)}
$$

onde $F_{t h, 1}$ e $F_{t h, \infty}$ são os limiares de dano para pulso único e para spulsos infinitamente sobrepostos respectivamente. $k$ é um parâmetro de ordem empírica (independente de $N$ em primeira aproximação) que caracteriza a sensibilidade do material para o acúmulo de defeitos e aumento da absorção de fótons. Quanto maior $k$, menor será o número de pulsos para alcançar a saturação de defeitos e do limiar de dano, isto é, $F_{t h, N} \approx F_{t h, \infty}$.

\subsubsection{Safira - Monocristalina}

A safira $\left(\mathrm{Al}_{2} \mathrm{O}_{3}\right)$ possui um grande gap de banda $(8.8 \mathrm{eV})$, é um poderoso isolante e seu espectro de transmissão estende-se de $145 \mathrm{~nm}$ a $5.2 \mu \mathrm{m}$ sendo interessante no uso de janelas ópticas. Devido à estrutura cristalina e outras propriedades físicas, a safira é comumente usada como substrato para crescimento epitaxial de vários materiais de grande gap como os semicondutores III-V e II-VI compondo LEDs, detectores infravermelhos, etc $[73 ; 74]$. Propriedades como alta dureza, baixa dependência do índice de refração com a temperatura, alta condutividade térmica, e alta transparência tornam a safira um material ideal para uso como matriz hospedeira de meios de ganho laser. Safira pura é incolor e não mostra nenhuma luminescência, mas impurezas mesmo a baixíssimas concentrações (ppm), ou defeitos como centros de cor geram grande luminescência [75]. Diferentes tipos de centro de cor podem ser induzidos na safira como centro de vacâncias simples como $F$ e $F^{+}$ou centros $\mathrm{F}_{2}, \mathrm{~F}^{2+}$ e centros $\mathrm{F}_{2}{ }^{2+}$ [76].

Após a termalização do plasma elétron-buraco na safira, alguns dos elétrons podem ser capturados por defeitos ou impurezas, e, assim, excluídos do processo de 
recombinação com seus buracos. Como consequência, a concentração de buracos termalizados $h$ na zona afetada vai ser maior que a concentração de elétrons termalizados, o que leva à predominante criação de centros $F^{+}$, que são formados por um único elétron preso em vacância de átomos de oxigênio.

Evidências desses centros de cor (vacâncias de oxigênio com dois elétrons presos) foram obtidas em safira irradiada com elétrons, observando-se a luminescência em 300nm [77] ou em 315 e $413 \mathrm{~nm}$ [78] mesmo o centro $F^{+}$emitindo em 325nm.

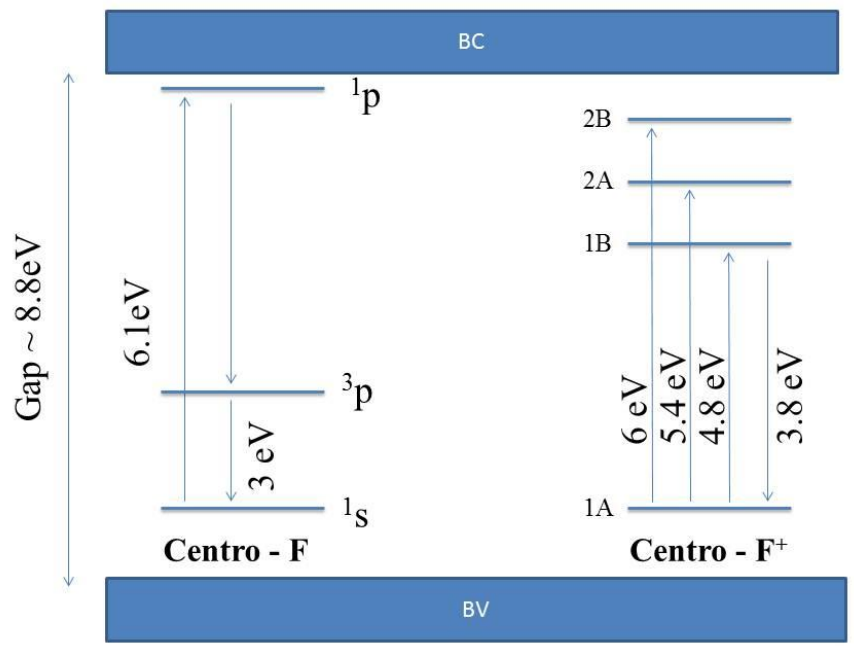

Figura 3.5 - níveis de energia de defeitos em safira (adaptado de [77; 79]).

$\mathrm{Na}$ safira existem dois tipos de sítios de aprisionamento: armadilhas de elétrons rasas (baixas energias) e armadilhas de buracos (altas energias), com um único buraco que funciona como um centro de recombinação. A Figura 3.5 mostra o diagrama de níveis de energia com as energias de absorção e emissão dos centros de cor.

\subsubsection{Sílica -Suprasil ${ }^{\circledR}$}

O Suprasil ${ }^{\circledR}$ Standard é uma sílica fundida $\left(\alpha-\mathrm{SiO}_{2}\right)$ de alta pureza. Este vidro óptico possui baixa concentração de vacâncias de oxigênio, o que confere uma alta transparência no UV comparativamente a outros vidros ópticos. É também um poderoso isolante com um gap de banda de $\sim 9 \mathrm{eV}$.

Estudos de luminescência em sílica feitos por Saeta e colaboradores [80] identificaram dois principais tipos de defeitos em sílica amorfa: os centros $E_{1}^{\prime}$, que são 
vacâncias de oxigênio na rede, e um segundo tipo que são átomos de silício com uma das ligações pendentes.

Experimentos de absorção no UV em Suprasil irradiados com pulsos ultracurtos feitos por Zoubir e colaboradores [81] mostraram bandas de absorção induzidas pelos defeitos na rede do material. Um pico centrado em $214 \mathrm{~nm}(5.8 \mathrm{eV})$ é atribuído a centros Si E', que corresponde a um elétron desemparelhado do átomo de silício ligado somente a três átomos de oxigênio $\left(\equiv \mathrm{Si}^{\bullet}\right)$. Outro pico é encontrado em $248 \mathrm{~nm}(5.0 \mathrm{eV})$ e corresponde à banda $B_{2} \alpha$ e é atribuído à deficiência de um oxigênio e duas ligações desemparelhadas no átomo de silício $\left(=\mathrm{Si}^{\bullet \bullet}\right)$ [82]. O espectro de absorção induzido também mostra a presença de picos em 190nm, que são atribuídos a buracos eletrônicos $(\mathrm{STE})$ de um átomo de oxigênio $\left(\equiv \mathrm{Si}-\mathrm{O}^{\bullet}\right)$ gerando um pico em $6.1 \mathrm{eV} . \mathrm{O}$ aprisionamento desses elétrons na banda de condução em estados STE's tem sido observado numa escala de 150 fs [83].

A Figura 3.6 mostra os níveis de absorção devido aos centros de cor gerados por irradiações precedentes.

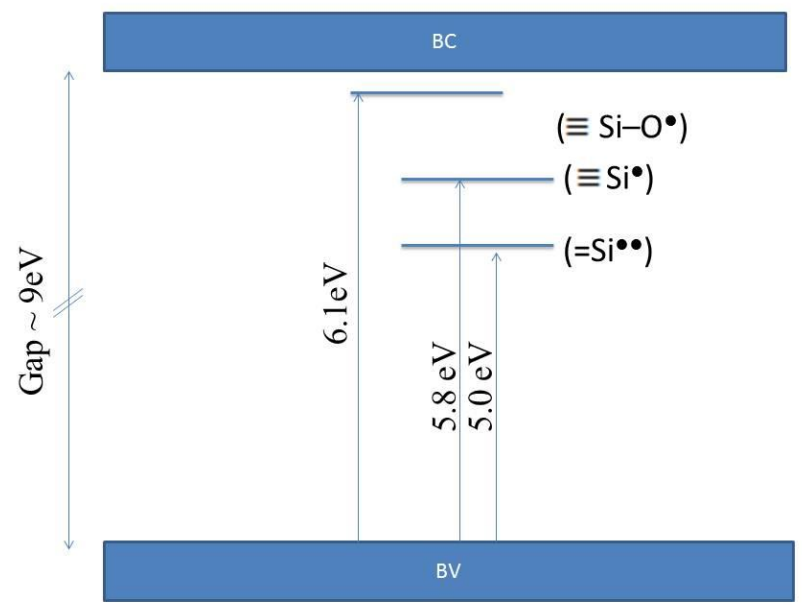

Figura 3.6 - Diagrama de energia mostrando as principais frequências de absorção do $\mathrm{SiO}_{2}$ pelos centros de cor.

\subsubsection{Borosilicato - BK7}

O BK7 é um vidro óptico muito usado em componentes ópticos de alta qualidade. É um vidro de Borosilicato do tipo "Crown" composto pelos seguintes 
óxidos: $\mathrm{SiO}_{2}$ (69.13\%); $\mathrm{B}_{2} \mathrm{O}_{3}(10.75 \%) ; \mathrm{Na}_{2} \mathrm{O}$ (10.40\%); $\mathrm{K}_{2} \mathrm{O}$ (6.29\%); $\mathrm{BaO}(3.07 \%)$; $\mathrm{As}_{2} \mathrm{O}_{3}(0.36 \%)$. Possui alta homogeneidade, alta resistência a riscos e baixo coeficiente de dilatação térmico. Outra razão para o uso desse material como componente óptico é sua excelente transmitância do infravermelho próximo $(2500 \mathrm{~nm})$ ao ultravioleta $(350$ $\mathrm{nm})$.

A energia de gap do BK7 é $4 \mathrm{eV}$, isso significando que são necessários três fótons em 800nm para gerar a absorção multifotônica, para que assim, elétrons atinjam a banda de condução e sejam multiplicados pelo efeito avalanche. Por outro lado, na irradiação com pulsos ultracurtos, devido ao alargamento espectral pela interação com o vidro óptico, efeitos não-lineares como a geração de supercontínuo ou mesmo a chamada geração de escurecimento ("darkening generation" ) no BK7 são responsáveis pela absorção dos pulsos ultracurtos por dois ou apenas um fóton [84- 86].

Diferentemente dos materiais citados anteriormente, o BK7 e alguns outros vidros $[87 ; 88]$ após serem irradiado com pulsos de fs apresentam um largo espectro de absorção no visível devido a defeitos criados na matriz vítrea (veja Figura 3.7), e não apenas bandas estreitas de absorção como na safira e no Suprasil na região do UV. No experimento feito por Stolze e colaboradores [89] o escurecimento de janelas de BK7 é feito usando-se raios-x e o efeito de escurecimento é claramente visível na fotografia da Figura 3.7. Esse escurecimento é devido à formação de centros de cor no BK7 [87].
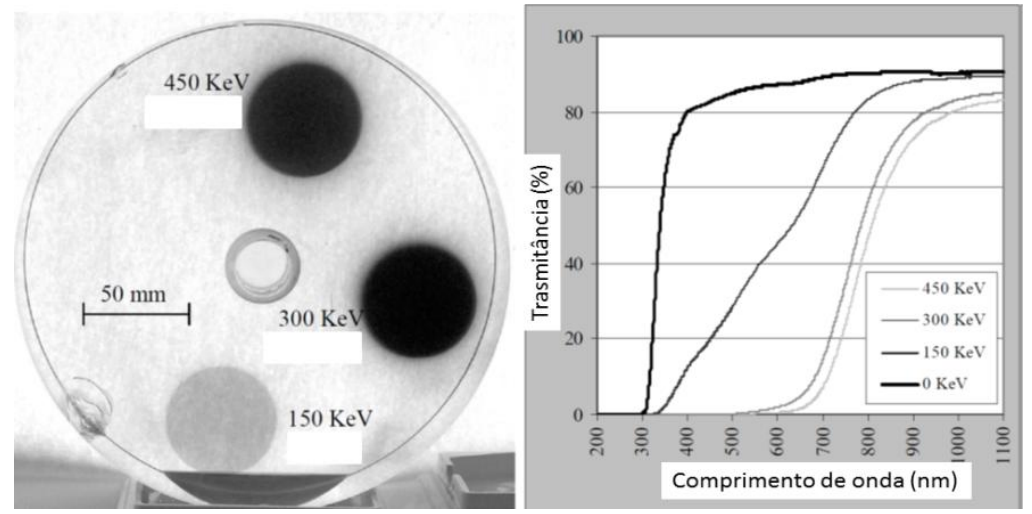

Figura 3.7 -Imagem de uma janela de BK7 de $8 \mathrm{~mm}$ de espessura e $50 \mathrm{~mm}$ de diâmetro exposta à raios-x em diferentes energias 150, 300 e $450 \mathrm{KeV}$ (esquerda). Espectro de transmitância das regiões irradiadas [87] (direita).

O escurecimento do BK7 ocorre também devido à irradiação com pulsos ultracurtos de $800 \mathrm{~nm}$. Os centros de cor foram claramente observados com intensidades 
de $I=10^{-3} I_{0}$ [88], onde $I_{0}$ é a intensidade de limiar para dano óptico [88]. Porém, múltiplas irradiações de feixe focalizado na superfície são usadas para criar centros de cor e escurecer o BK7 [88], mas não é observado o escurecimento perto da superfície da amostra onde a intensidade é maior. Isso sugere que para intensidades baixas de indução de defeitos, o processo de formação está relacionado à absorção de comprimentos de onda menores, gerados pelo supercontínuo. Isso ocorre porque o grau de alargamento espectral gerado pelo supercontínuo é proporcional ao comprimento de interação da amostra com o meio (centenas de mícrons nesse caso). É provável que a geração de defeitos nessas intensidades só seja possível com comprimentos de onda menores gerados pelo supercontínuo muito abaixo da superfície, não contribuindo para o efeito de incubação [88] na superfície. Assim, os defeitos, que poderiam ser responsáveis por um processo de incubação, têm um processo de formação mais eficiente poucos mícrons abaixo da superfície. Outra informação importante é a facilidade com que os centros de cor são destruídos no BK7. Em poucos minutos, à temperatura de 150 graus Celsius, é possível obter a recombinação desses defeitos [88]. 


\section{Simulação da excitação eletrônica por pulsos ultracurtos}

Os fenômenos físicos apresentados anteriormente são essenciais para se abordar o problema do dano óptico e ablação em materiais dielétricos irradiados com pulsos ultracurtos. Todo esse conteúdo serve como base, direta ou indiretamente, para os modelos encontrados atualmente na literatura para a descrição da ablação. Antes de citar, e descrever alguns desses modelos, é mostrado abaixo um resumo dos conceitos físicos que são considerados nos principais modelos de ablação por pulsos ultracurtos:

- O mecanismo de absorção e o balanço entre ionização multifotônica e por tunelamento (fotoionização, geração de elétrons semente);

- Ionização por impacto (efeito avalanche);

- Variações da Refletividade na superfície devido aos elétrons livres (metalização da superfície);

- Termalização elétron-elétron e a redistribuição da energia dentro da banda de condução (distribuição da energia eletrônica na banda de condução);

- Emissão fotoelétrica e acumulo de carga na superfície (efeito Coulomb);

- Armadilhamento de elétrons, tempos característicos nas armadilhas como precursores de defeitos estáveis (éxcitons e "self-trapped" éxcitons);

- Formação de defeitos estáveis e incubação (centros de cor em dielétricos);

- Espalhamento inelástico elétron-fônon e aquecimento da rede (relaxação elétron-fônon);

- Termalização da rede e transformação de fase (transformação de fase espinodal por ponto crítico).

Todos os modelos teóricos que descrevem a absorção de pulsos ultracurtos por materiais dielétricos compartilham o mesmo princípio: a quantificação da densidade eletrônica $n_{\mathrm{e}}$ em função do tempo e da intensidade do pulso laser. 
Alguns modelos teóricos tentam descrever a evolução dos elétrons livres em materiais dielétricos resolvendo equações cinéticas como a equação de Fokker-Planck ou a equação de Boltzmann[17; 39; 90; 91]. No modelo de Stuart e colaboradores [39], a equação de Fokker-Planck é usada para descrever o comportamento da função densidade de probabilidade da energia do elétron $f(\varepsilon, t)$ na banda de condução. Ou seja, o número de elétrons $f(\varepsilon, t) d \varepsilon$ com energia cinética entre $\varepsilon$ e $\varepsilon+d \varepsilon$ no tempo $t$ em função da forma temporal do pulso e sua energia. Historicamente, essa função densidade dos elétrons e a equação Fokker-Plank, foi derivada expandindo-se a equação de transporte de Boltzmann em polinômios de Legendre [46], e assumindo que a função $f(\varepsilon)$ é independente do tempo [39]. A derivação da equação cinética que descreve $f(\varepsilon)$ é uma equação de Fokker-Planck [92; 93], e pode ser derivada de argumentos físicos evitando envolver em manipulações matemáticas necessárias quando se introduz a integral de colisão de Boltzmann no espaço de fase tridimensional. Algumas das vantagens da derivação com a equação de Fokker-Planck, exceto por alguns cortes de formalismo de manipulação, é que sua condição de aplicação é bem conhecida. Outra vantagem é a quantificação da distribuição de energia eletrônica na banda de condução, dada por $f(\varepsilon, t)$, que permite estimar com maior precisão o acoplamento de energia entre elétrons e rede e a dinâmica do efeito avalanche.

O problema da difusão eletrônica e da ionização por impacto (efeito avalanche) no caso de dielétricos submetidos a altas intensidades tem sido vastamente estudado na literatura [29; 94], e cálculos elaborados e simulações computacionais têm sido desenvolvidos.

Alguns aspectos do problema, como o balanço relativo entre diferentes janelas para produção de elétrons livres e aquecimento da rede (ionização multifotônica, ionização por impacto, aquecimento dos elétrons livres, espalhamento elétron-fônon) assim como a exata dependência dos parâmetros envolvidos, ainda estão em discussão [95-97].

Para expressar a distribuição energética dos elétrons na banda de condução, resultados próximos aos encontrado nas equações de Fokker-Planck resolvidas por Stuart foram demonstrados. Em um modelo mais simples baseado em equações de taxa chamado "Multiple rate equation" (MRE) foi possível obter uma quantificação da densidade eletrônica em função da energia do elétron, bem próximas às encontradas por 
Stuart. Esse modelo foi proposto por Rethfeld em 2004 [98] e consiste num sistema de equações de taxa acopladas onde cada equação do sistema descreve a densidade de elétrons em diferentes níveis de energia na banda de condução, excitados em diferentes etapas do processo avalanche. Apenas os elétrons que atingem uma energia crítica na banda de condução contribuem com a ionização por impacto e são multiplicados por efeito avalanche. A abordagem dada por Rethfeld além de mais simples didaticamente, pode ser simulada numericamente com mais facilidade que o modelo com a equação de Fokker-Planck.

Uma simplificação importante veio da solução do modelo de Stuart (equação de Fokke-Planck) e colaboradores [42], que mostra que o coeficiente de ionização por impacto depende linearmente da intensidade do laser, isto é, $\beta=\eta I$, onde $\eta$ é o coeficiente de ionização por avalanche. Stuart mostra que essa simplificação é válida quando larguras temporais de pulso acima de 20 fs são utilizadas.

O uso de modelos dinâmicos (Fokker-Planck) e modelos de equação de taxa mais complexos como o MRE apresentados acima são necessários quando regimes de altas intensidades ou durações muito curtas, inferiores a 20 fs, são utilizadas. Nesses casos, a aplicabilidade de uma taxa de avalanche linearmente proporcional à intensidade é duvidosa já que a consideração de uma distribuição energética de elétrons na banda de condução não é mais constante no tempo [94; 98]. Ou seja, para pulsos muito curtos (<20 fs) não existe tempo suficiente para que os elétrons que são acelerados na banda de condução atinjam a energia suficiente para que ocorra a ionização por impacto. Isso torna o uso dos modelos de Stuart (modelo completo, Fokker-Planck) e Rethfeld necessários para descrever a dinâmica da densidade eletrônica $n_{e}$ apenas em condições nas quais o tempo de interação é muito curto, ou a energia do pulso é muito grande $\left(>10 F_{t h}\right)$.

Atualmente, o modelo mais simples utilizado pela maioria dos autores [99] para estudar a taxa de remoção de material e o limiar de ablação, é a equação de taxa para a densidade de elétrons na banda de condução que utiliza a aproximação do coeficiente de avalanche dependente linearmente da intensidade (aproximação de Stuart). 
Um modelo de equação de taxa simples para a quantificação da densidade eletrônica foi simulado nesse trabalho e é representado pela Eq. 20. Os resultados puderam ser confrontados com dados experimentais e serão mostrados no capítulo de análise dos resultados.

A equação da densidade eletrônica tem duas componentes, uma de bombeio e uma de relaxação eletrônica (Eq. 20). A taxa de crescimento eletrônico é proporcional à absorção multifotônica mais a taxa de ionização por impacto, menos a componente de decréscimo eletrônico. Essa última é relativa ao tempo de relaxação elétron-fônon e é responsável pela perda da energia eletrônica para a rede do material sob a forma de calor ou irradiação. Esse é mostrado no último termo da Eq. 20.

As constantes necessárias para a simulação foram obtidas da literatura e são apresentadas na Tabela 1. A densidade eletrônica na banda de condução é descrita pela seguinte equação:

$$
\frac{\partial n_{e}(r, t)}{\partial t}=\left[\eta \cdot I(r, t) \cdot n_{e}+\sigma_{m} I(r, t)^{m}\right] \frac{n_{a}}{n_{a}+n_{e}}-\frac{n_{e}(r, t)}{\tau_{e}}
$$

onde $n_{e}$ é a densidade de elétrons livres, $\eta$ é o coeficiente de ionização por impacto, $I(r, t)$ é a intensidade em função da distância ao centro do feixe $r, \sigma_{m}$ é o coeficiente de absorção multifotônica. $n_{a}$ é a densidade de centros ionizáveis e $\tau_{e}$ é o tempo de relaxação elétron-fônon. $m$ é a ordem do processo.

A densidade de elétrons na banda de condução provoca uma variação na refletividade da superfície do material. Essa refletividade pode ser descrita pelo modelo de Drude para o índice de refração complexo e deve ser considerada na simulação da interação do feixe com o dielétrico.

A refletividade do material, $R$, é calculada como o máximo da refletividade inerente do dielétrico (ou de "estado estacionário" $R_{e e}$ ) e a refletividade do vidro mais a refletividade do plasma $R_{p}: R(r, t)=\max \left(R_{e e}, R_{p}\right)$. Os dois valores de refletividade são obtidos a partir do índice de refração complexo do material de acordo com a equação de Fresnel: 


$$
R_{p}(r, t)=\frac{(n-1)^{2}+k^{2}}{(n+1)^{2}+k^{2}}
$$

onde $n$ e $k$ são as componentes reais e imaginárias do índice de refração. Na ausência de plasma, a parte real do índice de refração é $n=1.47$, e a refletividade é, por exemplo, $R_{e e}=0,0362$ para a sílica fundida e para um determinado comprimento de onda. Como a densidade de elétrons na banda de condução influencia diretamente a parte real e imaginária do índice de refração, esses são calculados por:

$$
\begin{aligned}
& n=\sqrt{\frac{\varepsilon_{r}+\sqrt{\varepsilon_{r}^{2}+\varepsilon_{i}^{2}}}{2}} \\
& k=\sqrt{\frac{-\varepsilon_{r}+\sqrt{\varepsilon_{r}^{2}+\varepsilon_{i}^{2}}}{2}}
\end{aligned}
$$

A função dielétrica do plasma é calculada de acordo com o modelo de Drude [100]:

$$
\begin{aligned}
& \varepsilon_{r}=\left(1-\frac{\omega_{p}^{2}\left(n_{e}\right) \tau_{d}^{2}}{1+\omega^{2} \tau_{d}^{2}}\right) \\
& \varepsilon_{i}=\left(\frac{\omega_{p}^{2}\left(n_{e}\right) \tau_{d}}{\omega\left(1+\omega^{2} \tau_{d}^{2}\right)}\right)
\end{aligned}
$$

onde $\tau_{d}$ é o tempo de relaxação do elétron, a frequência do laser é $\omega=2 \pi c / \lambda \operatorname{com} c$ sendo a velocidade da luz no vácuo e $\lambda$ o comprimento de onda do laser. $\omega_{p}$ é a frequência de plasma dada por:

$$
\omega_{p}\left(n_{e}\right)=\sqrt{\frac{n_{e}(r, t) e^{2}}{m_{e} \varepsilon_{0}}}
$$

A constante $e$ é a carga do elétron, $m_{e}$ é a sua massa, e $\varepsilon_{0}$ é a permissividade no vácuo. 
Define-se que, na densidade crítica, a frequência de plasma é igual à frequência do laser [101]. Se em algum ponto no material a densidade crítica $n_{c r}$ for atingida, uma porção do material será ablacionada.

A partir das Eq. 21 e Eq. 26, é evidente que a refletividade do material depende de duas variáveis, o tempo de relaxação do elétron na banda de condução $\tau_{d}$ (do modelo de Drude) e a densidade de elétrons. Jiang e Tsai propuseram um modelo para calcular o tempo de relaxação eletrônico baseado no tratamento quântico do calor específico e temperatura dos elétrons $[102 ; 103]$. A partir da investigação da dependência do tempo de relaxação eletrônico e da densidade de elétrons na banda de condução $n_{e}$, pode ser mostrado que a refletividade depende fortemente da densidade de elétrons livres, uma consequência da geração do plasma. Em contraste, a refletividade varia pouco em função do tempo de relaxação $\tau_{d}$ para pulsos maiores que $10 \mathrm{fs}$. Experimentos realizados por Linde e colaboradores [104] mostraram experimentalmente que a refletividade induzida pelo plasma de elétrons em materiais como a safira e a sílica tem um máximo de aproximadamente $70 \%$. Para que o modelo apresentado reproduza os valores de refletividade medidos em [104], o termo $\omega \tau_{d}$ das Eq. 24 e Eq. 25 pode ser escolhido para ser igual a três. Essa aproximação já foi usada anteriormente por Burakov e colaboradores [105].

A densidade de elétrons livres $n_{e}$ foi calculada usando as constantes obtidas da literatura mostradas na Tabela 1. 
Tabela 1 - Valores das constantes encontradas na literatura para a simulação do modelo

\begin{tabular}{ccccccccc}
\hline $\boldsymbol{\eta}\left(\mathbf{c m}^{2} / J\right)$ & $\boldsymbol{m}$ & $\boldsymbol{\tau}_{\boldsymbol{e}}(\mathbf{f s})$ & $\boldsymbol{n}_{\boldsymbol{a}}\left(\mathbf{c m}^{-\mathbf{3}}\right)$ & $\boldsymbol{\sigma}_{\boldsymbol{m}}\left({ }^{\mathbf{1}}\right)$ & $\boldsymbol{n}_{\boldsymbol{c}}\left(\mathrm{cm}^{-3}\right)$ & $\boldsymbol{F}_{\boldsymbol{t h}}$ & Ref. \\
\hline $\mathrm{SiO2}$ & 4.5 & 6 & 60 & $2.10^{22}$ & $6.10^{8}$ & $4,1.10^{19}$ & 3,34 & {$[106]$} \\
$\mathbf{B K 7}$ & 1.2 & 3 & 60 & $2.10^{22}$ & $7.10^{17}$ & $10^{21}$ & 2,26 & {$[106]$} \\
& & & & & & & & \\
Safira & 6 & 6 & 1000 & $2,36.10^{22}$ & $8.10^{9}$ & $1,74.10^{21}$ & 2,97 & {$[99]$} \\
\hline
\end{tabular}

Na simulação, a intensidade do laser na superfície do material é descrita por uma distribuição gaussiana no tempo e no espaço do pulso laser:

$$
I(r, t)=\frac{2 \cdot F_{\text {pico }}}{\sqrt{\pi / \ln 2} \cdot t_{p}}[1-R(r, t)] \cdot \exp \left[-\frac{2 r^{2}}{r_{0}^{2}}-(4 \ln 2) \frac{t^{2}}{\tau_{p}^{2}}\right]
$$

onde $\tau_{p}$ é a duração do pulso laser (FWHM), $w_{0}$ é o raio do feixe na superfície da amostra, $R$ é a refletividade da superfície. A fluência pico do pulso que corresponde à densidade de energia depositada na superfície por área, $F_{\text {pico }}$ é dada por:

$$
F_{\text {pico }}=\frac{2 \cdot E_{\text {pulso }}}{\pi \cdot w_{0}^{2}}
$$

onde, $E_{\text {pulso }}$ é a energia total de um pulso e $w_{0}$ é o raio na cintura do feixe.

A Figura 4.1 mostra a variação temporal da intensidade de um pulso com forma temporal Gaussiana, com fluência pico de $6 \mathrm{~J} / \mathrm{cm}^{2}$ e com 100 fs de largura temporal (curva vermelha). Na mesma figura, a linha verde mostra a intensidade do pulso simulada considerando a refletividade calculada pela Eq. 21, que leva em consideração a densidade eletrônica gerada na superfície do material. A curva (verde) de intensidade incidente menos refletida é responsável pela excitação eletrônica. Ela representa o termo $I(r, t)$ da Eq. 20 no eixo óptico $(r=0)$. A linha azul mostra a ordem do processo.

${ }^{1}$ unidade do coeficiente de absorção multifotônica: $\mathrm{cm}^{-3} \mathrm{ps}^{-1}\left(\mathrm{~cm}^{2} / T W\right)^{m}$, onde $m$ é a 
densidade eletrônica gerada pela absorção do laser. É importante notar que apenas no final do pulso existe absorção significativa de energia (curva azul). No entanto, no final do pulso a densidade eletrônica aumenta muito a refletividade inibindo a absorção do feixe até que o pulso se acabe, os elétrons, então, são absorvidos pela banda de valência e aquecem a rede (relaxação eletrônica).

A simulação foi feita usando o método Runge-Kutta no programa Mathematica.

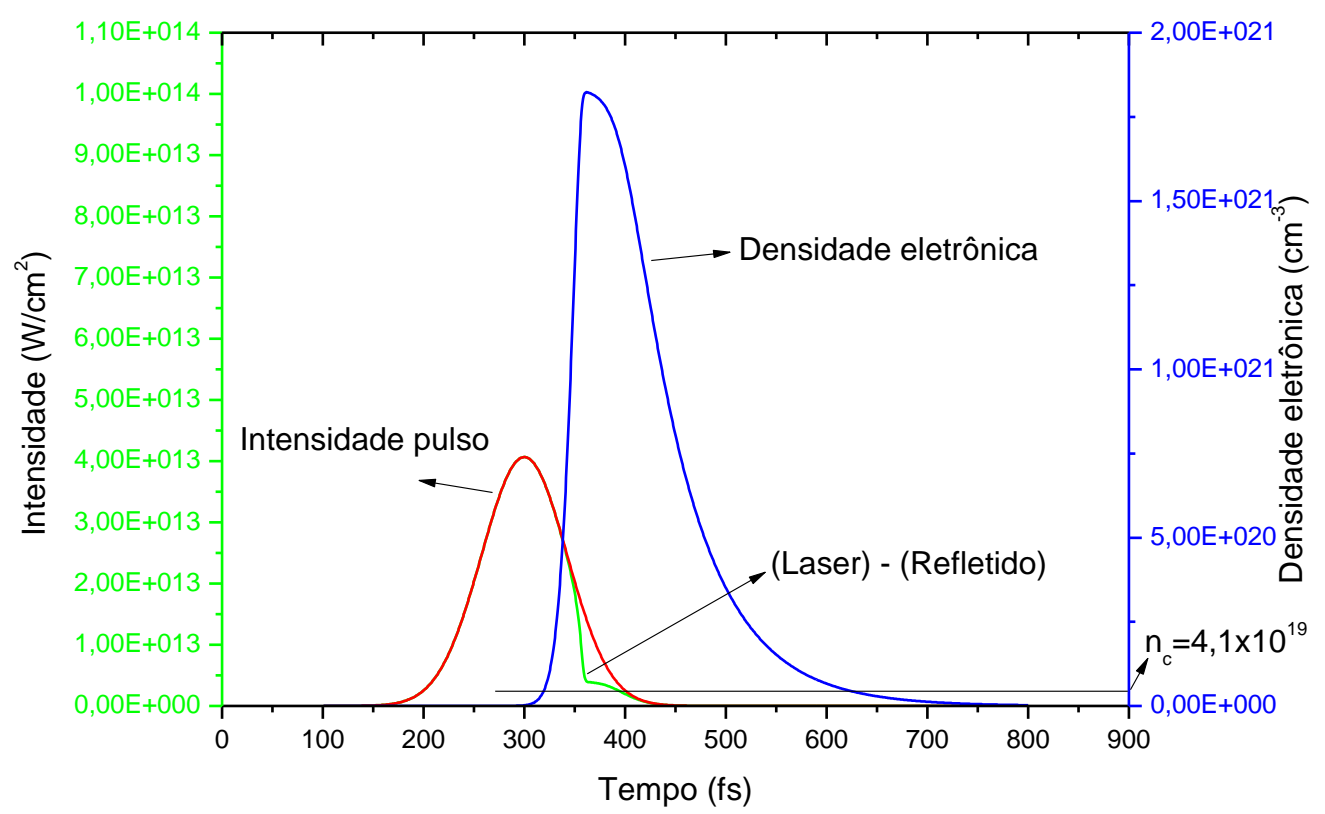

Figura 4.1 - Simulação da intensidade do laser (linha vermelha) e intensidade do laser no centro do feixe menos a intensidade refletida (linha verde) pelo plasma eletrônico do material no Suprasil irradiado com um pulso de $100 \mathrm{fs}$ e $6 \mathrm{~J} / \mathrm{cm}^{2}$ de fluência. A linha azul representa a densidade eletrônica na banda de condução em função do tempo.

Para o cálculo do limiar de ablação teórico definiu-se que quando a densidade eletrônica atinge a densidade crítica $n_{c}$ (veja Tabela 1) o material é ablacionado. A Figura 4.2 apresenta a densidade eletrônica máxima atingida na Sílica fundida (Suprasil) em função da fluência pico (no centro do feixe $r=0$ ) de pulsos de 100 fs. 


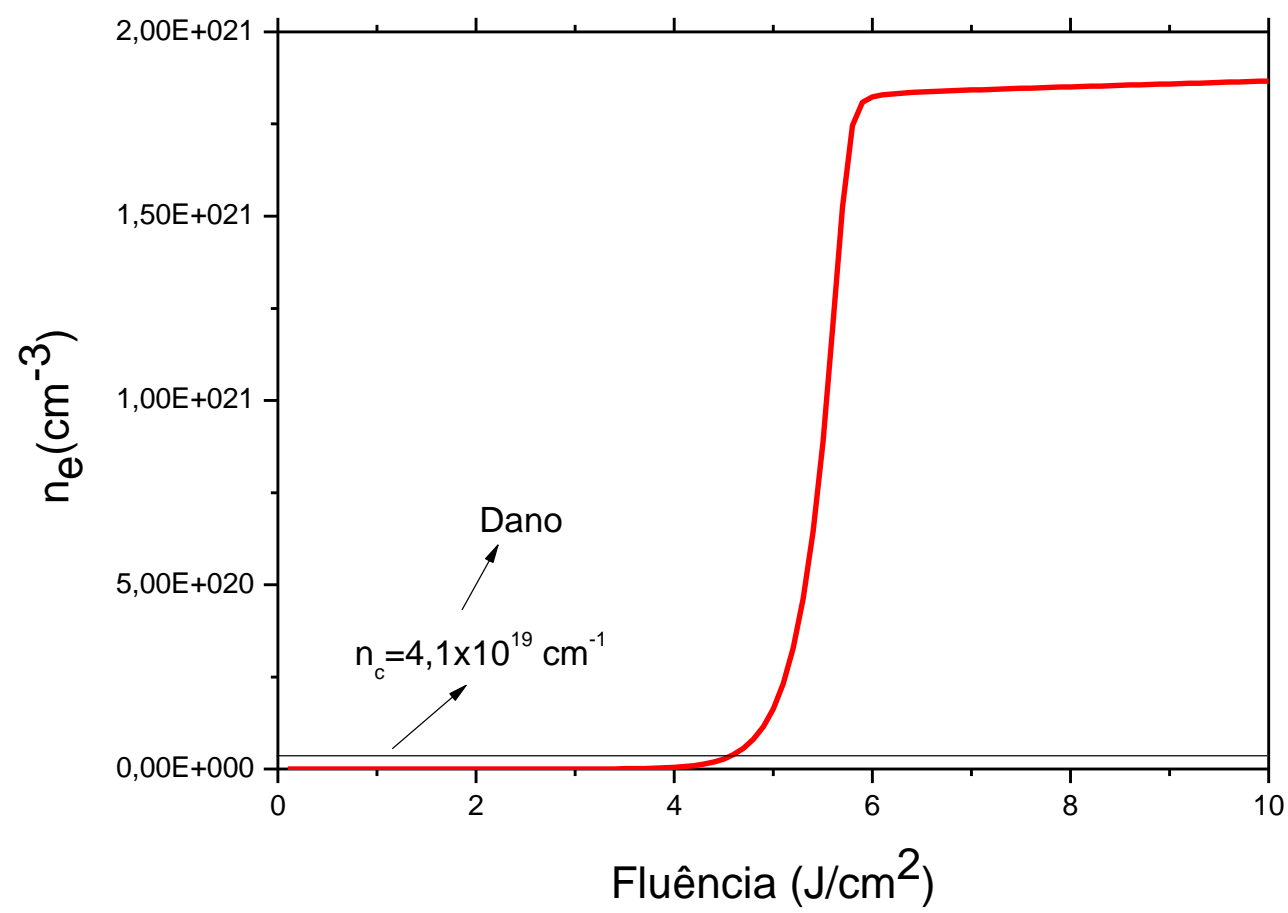

Figura 4.2 - densidade eletrônica máxima na banda de condução do Suprasil gerados pela irradiação de um pulso com diferentes fluências e 100 fs de largura temporal.

Na Figura 4.2 é possível observar uma diminuição na eficiência de geração de elétrons livres na banda de condução da Sílica quando a densidade eletrônica gera uma alta refletividade do material. Como mostrado anteriormente, a diminuição na eficiência de absorção é explicada pelo aumento da refletividade devido ao aumento da densidade do plasma eletrônico. Isso mostra que irradiações com fluência muito acima do limiar de ablação (dobro) perdem em eficiência de absorção devido à reflexão do feixe. Como o limiar de ablação é definido quando a densidade atinge um valor da ordem de $4,1 \times 10^{19}$ elétrons $/ \mathrm{cm}^{3}$ na banda de condução no caso da Sílica. Ou seja, a densidade crítica para ablação do material não é igual a densidade da freqüência de plasma que define a refletividade do material, mas tem um valor específico para cada material. Como mostrado nos valores de $n_{c}$ da Tabela 1.

Fizeram-se os cálculos do limiar de ablação para os diferentes materiais em função da largura temporal de pulso como se pode ser visto na Figura 4.3. 


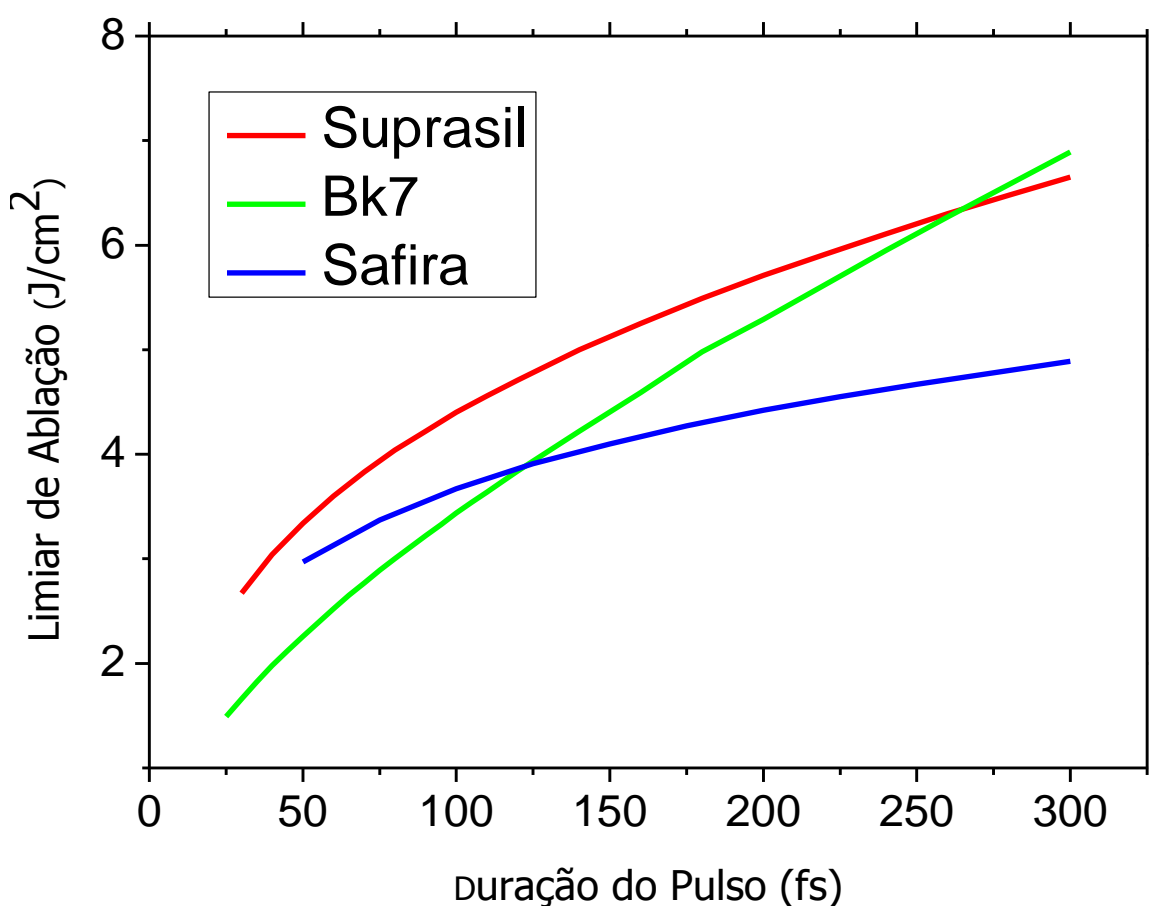

Figura 4.3- a) Simulação do Limiar de ablação em função da largura temporal.

Pode-se observar no gráfico da Figura 4.3 que o limiar de ablação para o BK7 é mais dependente da largura temporal dos pulsos laser que o Suprasil e a safira. Isso é explicado pela maior influência da absorção multifotônica comparado ao efeito avalanche em larguras temporais mais curtas. Haja vista que no BK7, a secção de choque de absorção multifotônica é maior (três fótons) que a secção de choque para o Suprasil e a Safira (seis fótons, Tabela 1).

A maior taxa de crescimento do limiar de ablação do BK7 em função da largura temporal dos pulsos quando comparado com os outros materiais também é explicada pelo menor valor do coeficiente de absorção por impacto no BK7 (avalanche). Isso ocorre, porque, conforme o tempo de interação da radiação com a matéria aumenta, maior é o efeito de crescimento exponencial dos elétrons devido ao efeito avalanche. Assim a eficiência na excitação eletrônica por esse efeito é maior para a safira e o Suprasil.

Como o Suprasil e a safira possuem coeficientes de absorção multifotônico próximos $\left(6 \times 10^{8}\right.$ e $8 \times 10^{9}$ respectivamente), e a principal diferença entre a taxa de crescimento do limiar de ablação em função do tempo é devido à taxa de decaimento eletrônico ser mais lenta na safira ( 1 ps) que no Suprasil (100 fs). Como os elétrons 
ficam mais tempo na banda de condução eles podem ser multiplicados com maior eficiência pelo efeito avalanche. Isso explica a menor taxa de crescimento do limiar de ablação na safira em função da largura temporal.

A simulação com a simples equação de taxa mostrou-se importante para um melhor entendimento da dinâmica de interação com pulsos ultracurtos por materiais dielétricos. Foi possível observar como o limiar de ablação depende da largura temporal e como os diferentes canais de absorção influenciam nessa dinâmica. Essa simulação está comparada no capítulo 8.3 com os resultados experimentais do limiar de ablação em função da largura temporal no BK7. 


\section{Técnicas para a medida do limiar de ablação}

Como visto nas seções anteriores, o limiar de ablação é definido como a menor fluência (energia/área) necessária para que ocorra a ejeção de material de um substrato, e se mostra de suma importância no estudo da absorção de pulsos ultracurtos por materiais transparentes.

Mesmo se utilizando experimentos similares, os valores de limiar de ablação da sílica medido por diferentes autores [40; 41;107-110] variam de 2 a $12 \mathrm{~J} / \mathrm{cm}^{2}$ quando irradiados por pulsos únicos, com $\sim 100 \mathrm{fs}$ e $800 \mathrm{~nm}$ de comprimento de onda. Infelizmente a dispersão dessas medidas é maior que o valor absoluto do limiar de ablação, e dificulta uma determinação precisa desse valor. Sanner e colaboradores [6] atribuíram essa baixa reprodutividade à alta sensibilidade do limiar de dano às características da superfície do material irradiado. Em outro trabalho, Uteza e colaboradores [111] mostraram que o valor varia de 5 a $11 \mathrm{~J} / \mathrm{cm}^{2}$ para uma mesma amostra, mas com diferenças apenas no tipo de polimento das superfícies irradiadas. Bloembergen [48] afirma que diferenças do limiar de dano ("Electric Breakdown") entre a superfície e o bulk (volume do material) em dielétricos se devem à qualidade da superfície. O autor cita que, não só impurezas são responsáveis por essa diferença, visto que mesmo amostras limpas com técnicas como bombardeamento com íons de argônio ou limpeza química da superfície são responsáveis por valores entre 2 e 5 vezes menores na superfície. Essa diferença é explicada pela topografia da superfície, que cria campos eletrostáticos mais intensos em poros, ondulações, riscos, pelo efeito de acúmulo de carga (efeito de ponta). Esse argumento foi provado com experimentos com amostras de quartzo super polidas e mostrou limiares de dano iguais para a superfície e o bulk [112]. Neste último caso os experimentos foram realizados com pulsos de nanossegundos, e pode-se dizer que o efeito de acúmulo de cargas é mais aparente já que o efeito avalanche é o principal efeito de geração eletrônica no material.

Esses argumentos mostram que efeitos extrínsecos ao material dificultam a reprodutividade das medidas de limiar e um consenso sobre um valor confiável do limiar de dano em dielétricos. 
Além de efeitos da superfície, a escolha do tipo de lente para as medições se mostra essencial para uma padronização das medidas do limiar de dano, visto que o raio do feixe na superfície da amostra menores que $\mathrm{w}<10 \mu \mathrm{m}$ resultam em um valor superestimado do limiar de dano em até uma ordem de grandeza [111] dependendo da lente. Esse efeito ocorre devido a área irradiada que quando é menor diminui a probabilidade de elétrons excitados termicamente, ou por defeitos.

Em medidas do limiar de dano estatístico apresentados por Sanner [6], foram medidas as probabilidades de dano em função da fluência do pulso. Neste procedimento, amostras são irradiadas com pulsos únicos com diferentes fluências próximas ao limiar de dano. Mede-se então a probabilidade de dano em função dessas fluências. Sanner e colaboradores mostraram que mesmo para pulsos de 100 fs ocorre o efeito estocástico do limiar de dano e são encontradas variações desse valor, inclusive num mesmo tipo de material e polimento, de até $\Delta \mathrm{F}_{\mathrm{th}}=1,6 \mathrm{~J} / \mathrm{cm}^{2}$ [6]. Nesse caso, a repetibilidade do experimento não dependeria de condições externas, mas da dinâmica de interação que interfere no processo de ablação.

Independentemente dos fatores intrínsecos (efeitos estocásticos da excitação termoeletrônica), as variáveis controláveis dos experimentos são primordiais para a padronização dessas medidas e a melhor confiabilidade dos resultados. Nesse sentido, diferenças na amostra como estado da superfície, posicionamento e características do feixe, bem como a metrologia e o critério de definição de dano e ablação devem ser bem controlados.

Com o objetivo de determinar o limiar de ablação dos diversos dielétricos nesse trabalho, duas técnicas foram usadas. A primeira técnica, denominada de Técnica da Regressão do Diâmetro (TRD), foi introduzida por Liu [20], é bem conhecida e comumente usada na literatura para encontrar o limiar de dano usando feixes gaussianos de pulsos ultracurtos. A segunda técnica, o método D-scan introduzido por Samad e colaboradores [27], permite a obtenção do limiar de dano através de uma varredura de pulsos, diferenciando-se do método tradicional em vários aspectos. Uma extensão da teoria da técnica $D$-scan foi realizada nesse trabalho [113], o que permitiu o uso do $D$ scan para medida do limiar de dano de pulsos sobrepostos longitudinalmente. Esta extensão da técnica foi essencial para a aplicação da técnica D-scan em materiais dielétricos, haja vista que esses materiais são sensíveis a irradiações precedentes de 
pulso. Além disso, a sobreposição de pulsos é intrínseca ao $D$-scan. Os dois métodos juntamente com a extensão da técnica $D$-scan são apresentados a seguir.

\subsection{Técnica de regressão do diâmetro}

Nesse método é suposto que o limiar de dano depende apenas do material e da sobreposição de pulsos. Assim, o diâmetro das marcações para pulsos únicos, ou sobrepostos, focalizados na superfície do material segue a distribuição de fluência do pulso gaussiano utilizada em cada marcação.

Para perfil Gaussiano com raio definido em $1 / e^{2}$ da fluência pico $F_{0}^{\text {pico }}$, a fluência em função da distância $r$ ao centro do feixe é (Figura 5.1):

$$
F(r)=F_{0}^{p i c o} \exp \left(-\frac{2 r^{2}}{\omega_{0}^{2}}\right)
$$

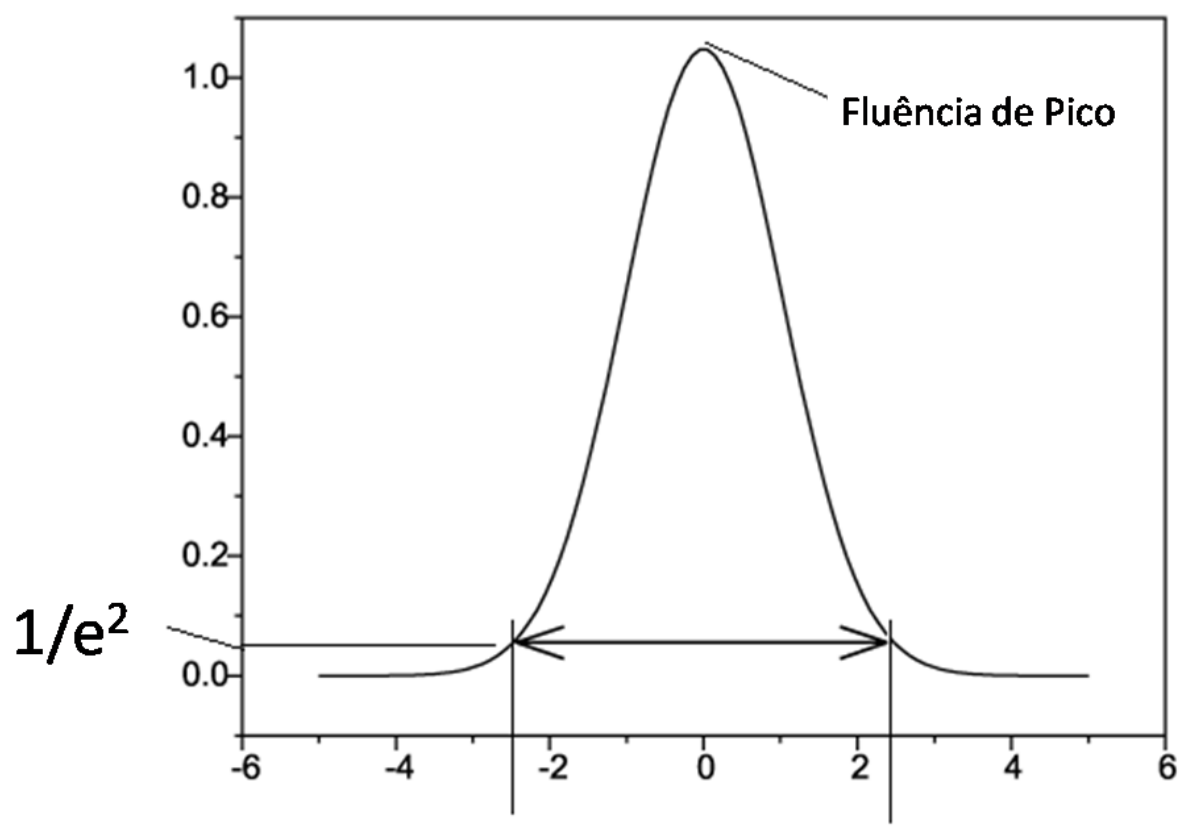

raio do feixe

Figura 5.1 - perfil gaussiano com raio definido a $1 / \mathrm{e}^{2}$ da fluência máxima

Seja $D$ o diâmetro da região danificada, então essa região terá sido ablacionada por uma fluência $F(D / 2)$ de acordo com a Eq. 29. Considerando que o material só pode ser danificado com fluências maiores ou iguais à fluência de limiar, $F_{t h}$, então: 


$$
\begin{gathered}
F_{t h}=F_{0}^{p i c o} \exp \left(-\frac{2(D / 2)^{2}}{w_{0}^{2}}\right)=F_{0}^{p i c o} \exp \left(-\frac{D^{2}}{2 w_{0}^{2}}\right) \Rightarrow \\
\ln F_{t h}=\ln F_{0}^{p i c o}-\frac{D^{2}}{2 w_{0}^{2}} \Rightarrow \frac{D^{2}}{2 w_{0}^{2}}=\ln \left(\frac{F_{0}^{\text {pico }}}{F_{t h}}\right) \Rightarrow \\
D^{2}=2 w_{0}^{2} \ln \left(\frac{F_{0}^{\text {pico }}}{F_{t h}}\right)
\end{gathered}
$$

A fluência pico é relacionada com a energia do pulso por:

$$
2 \pi \int_{0}^{\infty} r F(r) d r=E_{\text {pulso }}=\frac{\pi w_{0}^{2} F_{0}^{p i c o}}{2} \Rightarrow F_{0}^{p i c o}=\frac{2 E_{p u l s o}}{\pi w_{0}^{2}}
$$

A determinação do limiar de ablação é obtida com as medidas experimentais dos diâmetros das regiões danificadas, relacionando-se o "diâmetro ao quadrado" $D^{2}$ da zona danificada como função da fluência $F$ do laser no ponto de interesse. Os dados para os quais o dano é evidente $\left(\mathrm{D}^{2}>0\right)$ são colocados de acordo com a função de correspondência. A extrapolação da curva da Eq. 32 para $D=0$ no gráfico do Diâmetro ao quadrado por Fluência representa o valor da fluência local absoluta e é igual à fluência de limiar de ablação para um pulso. Para a medida do limiar de dano para pulsos sobrepostos $F_{t h, N}$, o mesmo procedimento é realizado para a sobreposição de $\mathrm{N}$ pulsos em cada sitio de interação.

\subsection{Técnica Diagonal-Scan (D-Scan)}

Aqui será descrito um método de medida do limiar de ablação chamado Diagonal-scan (varredura diagonal) ou D-scan [27]. Esse trabalho descreve um método simples e prático para a medida do limiar de ablação por pulsos laser ultracurtos. A descrição teórica da técnica introduzida em [27], contudo, não levava em consideração o efeito de incubação quando se tem pulsos sobrepostos. A principal contribuição do presente trabalho foi a extensão da teoria do $D$-scan para a quantificação do limiar de ablação em diferentes sobreposições de pulso e a comparação com a técnica da regressão do diâmetro que é estabelecida. 
Devemos supor nos cálculos a seguir que na interface entre a região ablacionada e não ablacionada a intensidade do feixe é igual ao limiar para ablação do material (ablação de baixa fluência, sem zona afetada pelo calor), e depende apenas da intensidade do pulso, sem efeitos térmicos colaterais.

O procedimento experimental consiste em irradiar a superfície de uma amostra plana, variando-se simultaneamentes sua posições longitudinal e transversal, ou seja, variando-se a distância ao foco (eixo z) e a sua posição lateral (eixo y) ao mesmo tempo (Figura 5.2.)

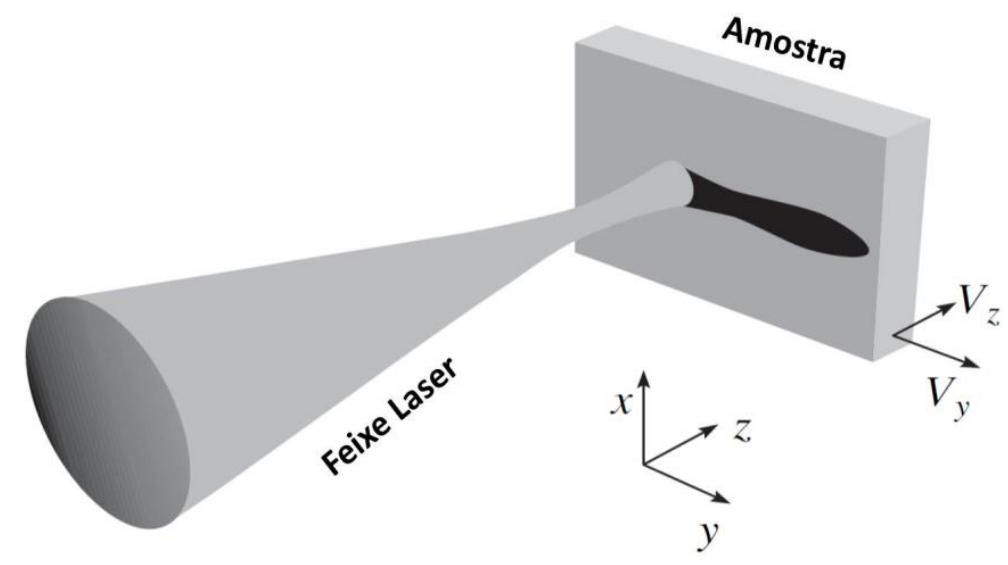

Figura 5.2- Irradiação da amostra com o laser de femtossegundos deslocando a amostra nos eixos $z$ e $y$ simultaneamente (Adaptado de [27]).

Para calcular o limiar devemos primeiramente calcular a geometria da intensidade do feixe, que nesse caso é um feixe gaussiano ortogonal à superfície de interação. Em coordenadas cilíndricas, a distribuição radial de intensidade (densidade de potência) do feixe gaussiano é dada por [27]:

$$
I(r, z)=\frac{2 P_{0}}{\pi w(z)^{2}} e^{-\frac{2 r^{2}}{w(z)^{2}}} \quad P_{0}=\int_{0}^{2 \pi} \int_{0}^{\infty} r I(r, z) d \theta d r
$$

onde $P_{0}$ é a potência do pulso, $r$ e $z$ são as coordenadas radial e longitudinal do feixe, $w(z)$ é o raio do feixe onde a intensidade cai com $1 / e^{2}$ do valor de pico, e é dado por: 


$$
w(z)=w_{0}\left[1+\left(\frac{\lambda M^{2} z}{\pi w_{0}^{2}}\right)^{2}\right]^{1 / 2}=w_{0}\left[1+\left(\frac{z}{z_{R}}\right)^{2}\right]^{1 / 2}
$$

onde $\lambda$ é o comprimento de onda do laser, $w_{0}$ é o raio mínimo, $M^{2}$ é o fator de qualidade, e $z_{R}=\pi w_{0}^{2} /\left(\lambda M^{2}\right)$ é o parâmetro confocal do feixe.

Com a definição dada na expressão da Eq. 34, a densidade de energia pico do laser é $I(r=0)=2\langle I\rangle$, onde $\langle I\rangle$ é a intensidade média do feixe definida por:

$$
\langle I\rangle=\frac{P_{0}}{\pi w^{2}}
$$

que é a média espacial de intensidade.

Numa certa posição $z,(z=0$ é a posição da cintura do feixe) dada a distribuição $I(r)$ e a intensidade de limiar de ablação $I_{t h}$, a intensidade do feixe nessa região será igual à região de limiar de ablação em $\rho(z)$, que é a zona afetada pelo pulso, então:

$$
I_{t h}=\frac{2 P_{0}}{\pi w(z)^{2}} e^{-\frac{2 \rho(z)^{2}}{\omega(z)^{2}}}
$$

Para áreas $\pi r^{2}$ com $0 \leq r \leq \rho$, a intensidade local do feixe será maior que $I_{t h}$, e o material será ablacionado pelo feixe; para raios maiores que o raio de dano, isto é, $r$ $>\rho$, não haverá ablação. O raio da área ablacionada é uma função da posição do feixe, e para determinar essa dependência à coordenada longitudinal $z$ apenas se isola $\rho(z)$ da Eq. 37:

$$
\rho(z)=\sqrt{\frac{w(z)^{2}}{2} \ln \left[\frac{2}{\pi w(z)^{2}} \frac{P_{0}}{I_{t h}}\right]} .
$$

Na Figura 5.3, é desenhada a expressão da Eq. 38 e o perfil do feixe $w(z)$ ao longo da direção longitudinal. Onde foi considerado $P_{0}=6 P_{c r i t}$, e define-se a potência crítica como: 


$$
P_{c r i t}=\frac{1}{2} e \pi w_{0}^{2} I_{t h}
$$

É possível demonstrar que o raio de ablação é igual ao raio óptico na posição simétrica em torno de $z=0$, onde a média da intensidade do feixe é:

$$
\langle I\rangle=\frac{1}{2} e^{2} I_{t h} \approx 3.7 I_{t h}
$$

A curva definida pela expressão da Eq. 38 é simétrica em torno de zero, e para potencias $P_{0}>P_{\text {crit }}$, esse gráfico tem dois pontos de máximo. Quando pulsos ultracurtos são usados em baixa fluência, o raio de ablação varia em função de $z$ de acordo com a expressão da Eq. 38. Se o calor é transferido de regiões mais centrais para o material, o raio de dano $\rho(z)$ não terá mais o contorno de $I_{t h}$.

O dano no material começa a aparecer onde a intensidade local do feixe é igual ou maior que $I_{t h}$, para uma posição longitudinal $z= \pm \zeta$, onde $\rho( \pm \zeta)=0$. Resolvendo a equação, tem-se:

$$
\zeta=z_{0} \sqrt{\frac{2}{\pi w_{0}^{2}} \frac{P_{0}}{I_{\text {th }}}-1}
$$

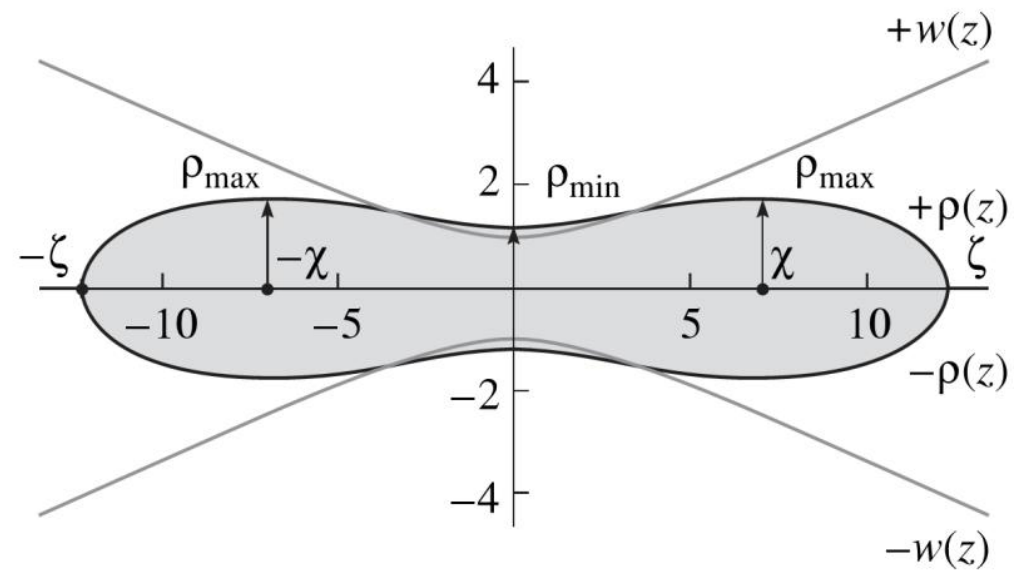

Figura 5.3- Gráfico para $P_{0}=3 e \pi w_{0}^{2} I_{t h}=6 P_{\text {crit }}$. O plano representa a superfície da amostra irradiada. As linhas $+w(z)$ e $-w(z)$ representam o raio do feixe onde a intensidade tem $1 / e^{2}$ do pico; as linhas $+\rho(z)$ e $-\rho(z)$, representam o raio de zona de interação com o feixe. Adaptado de [27]. 
Se a amostra é deslocada longitudinalmente entre $-\zeta<z<+\zeta$, a ablação ocorre.

Derivando a expressão da Eq. 38 e igualando a zero, o mínimo e o máximo da função são encontrados. Devido à simetria de $w(z)$, o ponto de mínimo ocorre em $z=$ 0, e o de máximo ocorre em $\pm \chi$ com

$$
\chi=z_{0} \sqrt{\frac{2}{e \pi w_{0}^{2}} \frac{P_{0}}{I_{t h}}-1}
$$

Pode-se facilmente mostrar que o raio de dano mínimo, $\rho_{\min }$ e o máximo, $\rho_{\max }$, são:

$$
\rho_{\text {min }}=\rho(z=0)=w_{0} \sqrt{\frac{1}{2} \ln \left(\frac{2}{\pi w_{0}^{2}} \frac{P_{0}}{I_{t h}}\right)}
$$

$\mathrm{e}$

$$
\rho_{\max }=\rho(z= \pm \chi)=\sqrt{\frac{1}{e \pi} \frac{P_{0}}{I_{t h}}} \approx 0.342 \sqrt{\frac{P_{0}}{I_{t h}}}
$$

Isolando o limiar de ablação da Eq. 44:

$$
I_{t h}=\frac{P_{0}}{e \pi \rho_{\max }^{2}} \approx 0.117 \frac{P_{0}}{\rho_{\max }^{2}}
$$

A última expressão para o limiar de dano $I_{t h}$, é simples, dependendo apenas de dois parâmetros: o máximo raio, $\rho_{\max }$, e a potencia do laser $P_{0}$. Movendo a amostra longitudinalmente através do feixe, começando de uma posição $-z$ onde não há ablação, para uma posição $+z$ depois que a ablação para, o raio máximo da área afetada será $\rho_{\max }$, que pode facilmente ser medido. Nenhum outro parâmetro geométrico do feixe laser será necessário.

Para calcular a fluência de limiar simplesmente multiplica-se a equação anterior pela largura temporal do pulso, assim, obtendo-se: 


$$
F_{t h}=\frac{E_{0}}{e \pi \rho_{\max }^{2}} \approx 0.117 \frac{E_{0}}{\rho_{\max }^{2}}
$$

O método $D$-Scan supõe que a área ablacionada corresponde à região que foi irradiada com intensidade igual ou maior que a intensidade de limiar. Porém, como já foi estudado, o limiar de dano depende das irradiações precedentes dos pulsos (efeito de incubação), e a ablação do material com sobreposição de pulsos poderá ablacionar material mesmo abaixo da intensidade de limiar. Sendo assim é preciso determinar também a sobreposição utilizada nessas irradiações.

A seguir será mostrada a contribuição teórica desse trabalho à técnica $D$ scan.

Nesse caso será considerada a sobreposição de pulsos longitudinal, já que a área ablacionada corresponderá a uma varredura de pulsos na direção y como mostrado na Figura 5.2.

Para determinar a fluência do limiar de ablação para pulsos sobrepostos, $\mathrm{F}_{\text {th,N }}$, a sobreposição de pulsos que ablacionada $\rho_{\max }$ na posição $\chi$ precisa ser conhecida. Supõe-se que a sobreposição $N$ na posição $\chi$ é dada pela soma das intensidades geradas nesse ponto por todos os pulsos que atingem a amostra durante uma varredura de $D$ scan, normalizado pela intensidade do pulso centrado em $\chi$ [113]. Então, para determinar $N$, inicialmente calcula-se a intensidade gerada numa posição $(\chi, q)$ por um único pulso na posição $(y, 0)$, como indicado na Figura 5.4. Nessa figura, o eixo y é paralelo à superfície da amostra, e o eixo z, é o eixo do feixe que é transversal à superfície. A distância $q$ do eixo y é usada por generalidade.

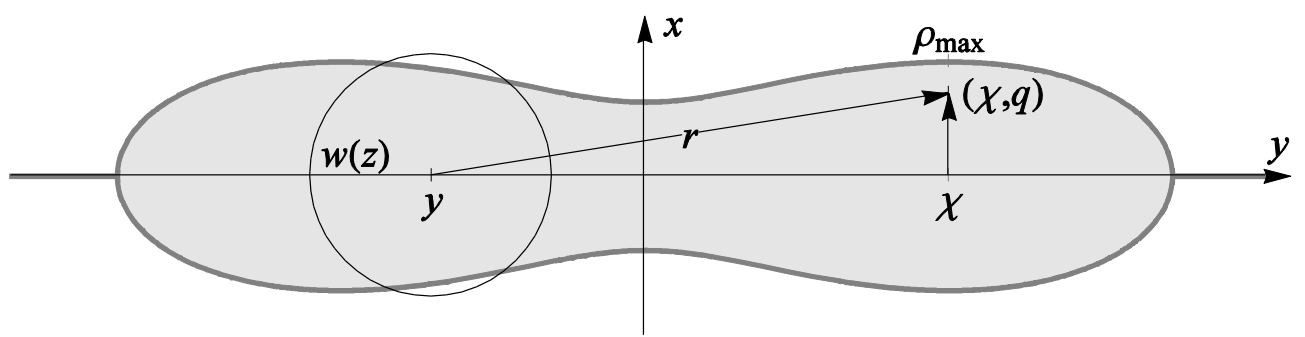

Figura 5.4 - Coordenadas para derivação da sobreposição.

Quando um pulso atinge a amostra na posição $y$, esse tem uma cintura de 
feixe $w(z)$ dada pela Eq. 35 e uma distribuição de intensidade dada por pela Eq. 34

A intensidade gerada pelo pulso na posição $y$ em $(\chi, q)$ é então:

$$
I(q, y, z)=\frac{2 P_{0}}{\pi w(z)^{2}} e^{-2 \frac{q^{2}+(\chi-y)^{2}}{w(z)^{2}}}
$$

Considerando-se agora que no tempo $t_{0}=0$ um pulso atinge a amostra em $y=\chi$, gerando a intensidade $I(q, \chi, z)$. Nesta posição, o feixe causa uma ablação com um perfil máximo, $\rho_{\max }$, e por definição, a amostra está localizada na posição $z=\chi$ no eixo longitudinal, e consequentemente sua intensidade em $q$ é $I(q, \chi, \chi)$. O próximo pulso atingirá a amostra após um intervalo $1 / f$, onde $f$ é a taxa de repetição, quando a amostra se desloca de $v_{y} / f$ e $v_{z} / f$ nas direções $y$ e $z$, respectivamente, com $v_{y} e \mathrm{v}_{\mathrm{z}}$ sendo o a velocidade de deslocamento nessas direções. Entretanto, a intensidade gerada em $q$ pelo $n$-ésimo pulso ao atingir a amostra é $I_{t_{0}+\frac{n}{f}}=I\left(q, \chi+n \frac{v_{y}}{f}, \chi+n \frac{v_{z}}{f}\right)$, dada por:

$$
I_{t_{0}+\frac{n}{f}}=\frac{2 P_{0}}{\pi w\left(\chi+\frac{n v_{z}}{f}\right)^{2}} e^{-2 \frac{q^{2}+\left(\frac{n v_{y}}{f}\right)^{2}}{w\left(\chi+\frac{n v_{z}}{f}\right)^{2}}}
$$

e a intensidade total em $q, I_{T o t}$, será então:

$$
I_{T o t}=\sum_{n=-\infty}^{\infty} I_{t_{0}+\frac{n}{f}}=\frac{2 P_{0}}{\pi} \sum_{n=-\infty}^{\infty} \frac{1}{w\left(\chi+\frac{n v_{z}}{f}\right)^{2}} e^{-2 \frac{q^{2}+\left(\frac{n v_{y}}{f}\right)^{2}}{w\left(\chi+\frac{n v_{z}}{f}\right)^{2}}} .
$$

Para resolver a soma mostrada na Eq. 49, vamos considerar que o diâmetro do feixe não muda consideravelmente em torno de $\chi$, e pode ser considerado constante $\mathrm{e}$ igual a $w(\chi)$. Essa aproximação considera que as velocidades de deslocamento transversal $v_{y}$, longitudinal $v_{z}$ e o tamanho do foco devem ser escolhidos de tal maneira que se produza um perfil de ablação alongado. Para isso as velocidades na direção $y$ e $z$ devem ser ajustadas para que $\zeta>>\rho_{\max }$, ou seja, $v_{z}<<v_{y}$ durante a varredura e variação do tamanho das marcações adjacentes feitas por cada pulso seja minimizada $\left(\mathrm{ou} \frac{\partial \rho}{\partial y} \approx 0\right)$. 
Ainda, a aproximação leva em consideração que os pulsos, os quais tem uma distribuição de intensidade espacial gaussiana contribuem pouco na posição $(\chi, q)$ quando esses se afastam de uma distância de poucos diâmetros de feixe $w$ da posição $\chi$.

Substituindo a Eq. 45 em Eq. 42 temos:

$$
\chi=\rho_{\max } z_{0} \sqrt{\frac{2}{w_{0}^{2}}-1}
$$

e substituindo essa última na Eq. 35 temos:

$$
\omega(\chi)=w_{0}\left[1+\left(\sqrt{\frac{2 \rho_{\max }^{2}}{w_{0}^{2}}-1}\right)^{2}\right]^{1 / 2}=\sqrt{2} \rho_{\text {max }}
$$

Como:

$$
\omega(\chi)=\sqrt{2} \rho_{\max }
$$

a equação Eq. 49 pode ser reescrita como:

$$
I_{T o t}=\frac{P_{0}}{\pi \rho_{\max }^{2}} e^{-\frac{q^{2}}{\rho_{\max }^{2}}} \sum_{n=-\infty}^{\infty} e^{-\left(\frac{v_{y}}{f \rho_{\max }}\right)^{2} n^{2}} .
$$

Para obter a sobreposição $N$, a Eq. 53 tem que ser normalizada pela intensidade $I_{0}$ de um único pulso centrado em $\chi$. Substituindo $n=0$ na Eq. 48 nos dá o valor de $I_{0}$, o qual é o termo da esquerda na somatória na Eq. 53, e consequentemente, a razão $N=I_{T o t} / I_{0}$ é simplesmente:

$$
N=\frac{I_{T o t}}{I_{0}}=\sum_{n=-\infty}^{\infty} e^{-\left(\frac{v_{y}}{f \rho_{\max }}\right)^{2} n^{2}}
$$

O somatório na equação Eq. 54 é uma das definições da função Teta de Jacobi $\vartheta_{3}(\alpha, \beta)$, permitindo que a equação seja reescrita como [113]: 


$$
N=\vartheta_{3}\left(0, e^{-\left(\frac{v_{y}}{f f_{\max }}\right)^{2}}\right)
$$

Como $v_{y} /\left(f \rho_{\max }\right)$ é sempre positivo, o segundo argumento da função theta de Jacobi na Eq. 55 pode ser assumido como estando entre 0 e 1, e $N$ é limitado de 1 a infinito, como esperado. Para altas taxas de repetição ou pequenas velocidades de deslocamento, $v_{y} /\left(f \rho_{\max }\right) \approx 0$ e o segundo argumento de $\vartheta_{3}$ se aproxima da unidade; nesse limite a função theta de Jacobi para argumentos reais pode ser aproximada por:

$$
\vartheta_{3}(0, x) \cong \sqrt{\frac{\pi}{1-x}}, \quad \text { para } x<1 \text {. }
$$

Substituindo a identidade mostrada na Eq. 56 e na Eq. 55 simplifica-se para:

$$
N=\sqrt{\pi} \frac{f \rho_{\max }}{v_{y}} \approx 1.8 \frac{f \rho_{\max }}{v_{y}}, \quad \text { para } \frac{v_{y}}{f \rho_{\max }} \approx 0
$$

resultando em uma simples fórmula para a determinação da sobreposição de pulsos na posição $\chi$ a partir dos dados experimentais. Para altas velocidades de translação ou pequenas taxas de repetição, $v_{y} /\left(f \rho_{\max }\right)$ tende ao infinito e a Eq. 57 não é mais válida; nesse caso a Eq. 55 deve ser usada resultando em um valor de $N$ próximo de 1, como esperado em sobreposições de poucos pulsos. Na Figura 5.5, é mostrada a comparação entre os valores calculados pela Eq. 55 e Eq. 57. Nessa figura, a linha vermelha é o cálculo usando a função Teta de Jacobi, Eq. 55, e a linha tracejada apresenta os resultados para Eq. 57. Pode ser visto que eles divergem quando $v_{y} /\left(f \rho_{\max }\right)>1$, diferindo por menos de 2,5\% para valores desse argumento abaixo de 1,5. Isso mostra que a Eq. 57 pode ser usada para sobreposições acima de 2 pulsos.

Para garantir a validade da aproximação que considera o diâmetro do feixe constante na vizinhança de $\chi$, a Eq. 54 foi calculada numericamente para o caso no qual o índice do somatório $n$ é limitado no intervalo de $-m$ a $m$. Isso representa a sobreposição de $2 m+1$ pulsos, e o resultado para $m=1,10,100$ e 1000 são mostrados na Figura 5.5 pelas linhas azuis. Pode ser visto que a soma finita somente diverge da função $\vartheta_{3}$ (soma de $-\infty$ a $+\infty$, linha vermelha no gráfico) quando a sobreposição $N$ é maior que $m$. Isso significa que somente $2 m+1 \approx 2 N$ pulsos devem ser considerados para 
obter a sobreposição de $N$ pulsos na posição $\chi$, uma vez que as condições experimentais (velocidade de deslocamento, diâmetro do feixe) para a geração de um feixe alongado seja satisfeita, esses $2 N$ pulsos estão imediatamente na vizinhança de $\chi$, e pulsos mais distantes não contribuem significativamente para o efeito de incubação nessa posição.

A sobreposição $N$ definida aqui pela Eq. 55 não é a mesma usada pelo método tradicional, no qual os $N$ pulsos estão completamente sobrepostos. Entretanto admite-se que essas condições são equivalentes uma vez que o resultado numérico de considerar um número finito de termos na Eq. 54 demonstra que somente pulsos imediatamente na vizinhança de $\chi$ têm que ser considerados para se obter a sobreposição com o método $D$-scan, numa condição similar ao método tradicional. Adicionalmente, apresentou-se uma definição numérica que permite uma sobreposição fracionada, significando que pulsos deslocados da posição $\chi$ tem uma contribuição que adiciona linearmente ao efeito de incubação nesse ponto.

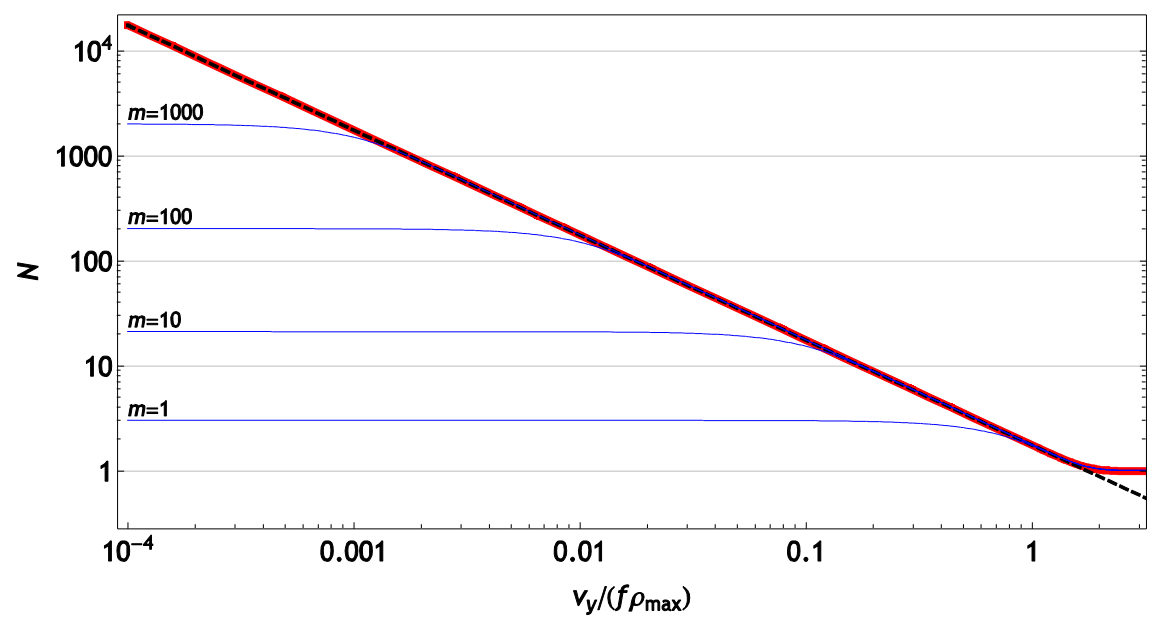

Figura 5.5 - a linha vermelha é o cálculo usando a função theta de Jacobi, Eq. 55. A linha tracejada apresenta os resultados para Eq. 57. As linhas azuis mostram o calculo de $N$ usando a Eq. 54 no intervalo de $-m$ a $m$. Onde $m=1,10,100$ e 1000.

Usando a hipótese anterior, a determinação da fluência de limiar necessita apenas da execução de uma varredura de $D$-scan na amostra e a medida da região de máxima ablação transversal; o uso das expressões Eq. 46 e Eq. 55 dão o valor de limiar $F_{\text {th }}$ para $N$ pulsos sobrepostos, quantificando o efeito de incubação nessa condição.

A principal hipótese desse trabalho afirma que a o limiar de ablação encontrado com a técnica $D$-scan e Tradicional são equivalentes, e que a quantificação 
da sobreposição de pulsos na técnica $D$-scan permite a equivalência entre as técnicas. Essa hipótese foi testada e é mostrada nesse trabalho para diferentes materiais. 


\section{Arranjo Experimental}

Os experimentos utilizaram dois sistemas lasers diferentes em diferentes períodos da realização desse trabalho. O primeiro sistema foi um laser de Ti:safira de femtossegundos amplificado pelo método de amplificação por varredura de frequência (Odin - Quantronix) que gera continuamente na saída do amplificador pulsos de $35 \mathrm{fs}$ (FWHM) com 30 a $40 \mathrm{~nm}$ de largura de banda (FWHM) centrados em $800 \mathrm{~nm}$ com taxa de repetição de $1000 \mathrm{~Hz}$ e energia menor <1 mJ. Esse primeiro sistema apresentou flutuações da energia dos pulsos em mais de $40 \%$ rms durante seu funcionamento. Esse problema foi resolvido indiretamente e não atrapalhou nas medidas dos limiares de dano e será detalhado adiante. Logo após alguns ensaios, esse laser foi substituído por um novo sistema mais estável e garantiu uma maior repetibilidade da energia dos pulsos. $\mathrm{O}$ novo sistema é também um laser de Ti:safira de femtossegundo amplificado pelo método de amplificação por varredura de frequência (Femtopower Compact Pro CEPhase HP/HR da marca Femtolasers) que gera continuamente pulsos de 25 fs (FWHM) centrados em $775 \mathrm{~nm}$ com $40 \mathrm{~nm}$ de largura de banda (FWHM), taxa de repetição máxima de $4 \mathrm{kHz}$ e energias máxima por pulso de $750 \mu \mathrm{J}$.

O feixe foi gerado no laboratório $\mathrm{T}^{3}$ (Table-Top-Terawatt) no Centro de Lasers (CLA) e Aplicações do IPEN e percorreu aproximadamente 30 m (Figura 6.1) até o sistema de guiamento de feixe existente no laboratório de aplicações industriais do CLA. Nesse sistema, o feixe, polarizado linearmente, foi centrado em uma íris de 12 mm de diâmetro. Após passar por um obturador pneumático controlável, o feixe teve seu diâmetro reduzido em duas vezes por um expansor invertido para que pudesse ser compatível com uma óptica de $6 \mathrm{~mm}$ de diâmetro livre. Para o controle da intensidade na amostra, foi usada uma placa de meia onda para girar a polarização seguida de um polarizador Glan-Thompson para atenuar componentes perpendiculares ao polarizador. A parte do feixe que é atenuada pelo polarizador é desprezada. Os pulsos então sofrem quatro reflexões consecutivas em dois espelhos (Chirped Mirror) que compensam parte da dispersão positiva adquirida durante a propagação pelo ar e pelos componentes ópticos. Mais compensação de dispersão foi introduzida pelas grades de difração na saída do amplificador, pois os espelhos de correção não foram suficientes para compensar toda a dispersão positiva. Para evitar anisotropia da região ablacionada 
durante a usinagem, uma placa de $1 / 4$ de onda foi usada para tornar o feixe circularmente polarizado. Após algumas reflexões em espelhos de guiamento, o feixe foi focalizado na amostra de dielétrico. Nos métodos com a TRD e D-Scan foram utilizadas duas lentes com comprimento focal de 50 e $38 \mathrm{~mm}$, e uma objetiva da marca Mitutoyo do tipo "long working distance" com abertura numérica de 0,42 e distância de trabalho de $20 \mathrm{~mm}$ e comprimento focal $4 \mathrm{~mm}$. Para as medidas e usinagem, o posicionamento da amostra foi feito por um sistema $C N C X-Y$ e mais um eixo de ajuste em $Z$ manual, ambos com precisão micrométrica [114].

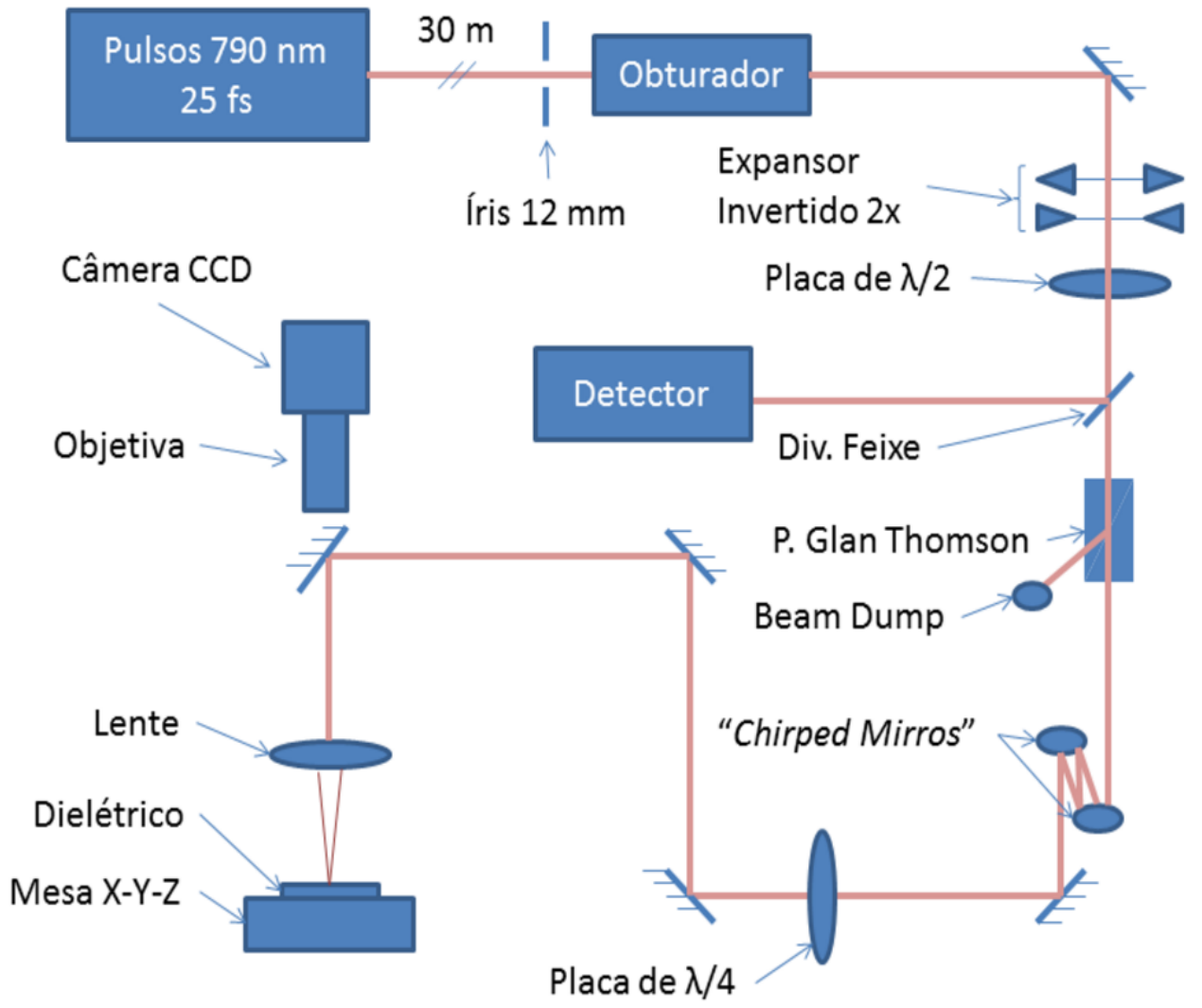

Figura 6.1 - Arranjo ótico do sistema de entrega do feixe e visualização.

Caracterizações espaciais do feixe laser: A determinação do limiar de dano usando a técnica de regressão do diâmetro, assim como o processo de usinagem necessitaram do conhecimento das dimensões do feixe e da distribuição da energia sobre a superfície da amostra. Para isto, a propagação do feixe foi caracterizada pela utilização de um analisador de feixe da marca Coherent. Isto foi feito no foco, em campo próximo e em campo distante usando uma lente de comprimento focal longo 
(500 mm). A Figura 6.2 mostra o perfil espacial do feixe na região do foco quando focalizado com a lente de $500 \mathrm{~mm}$.

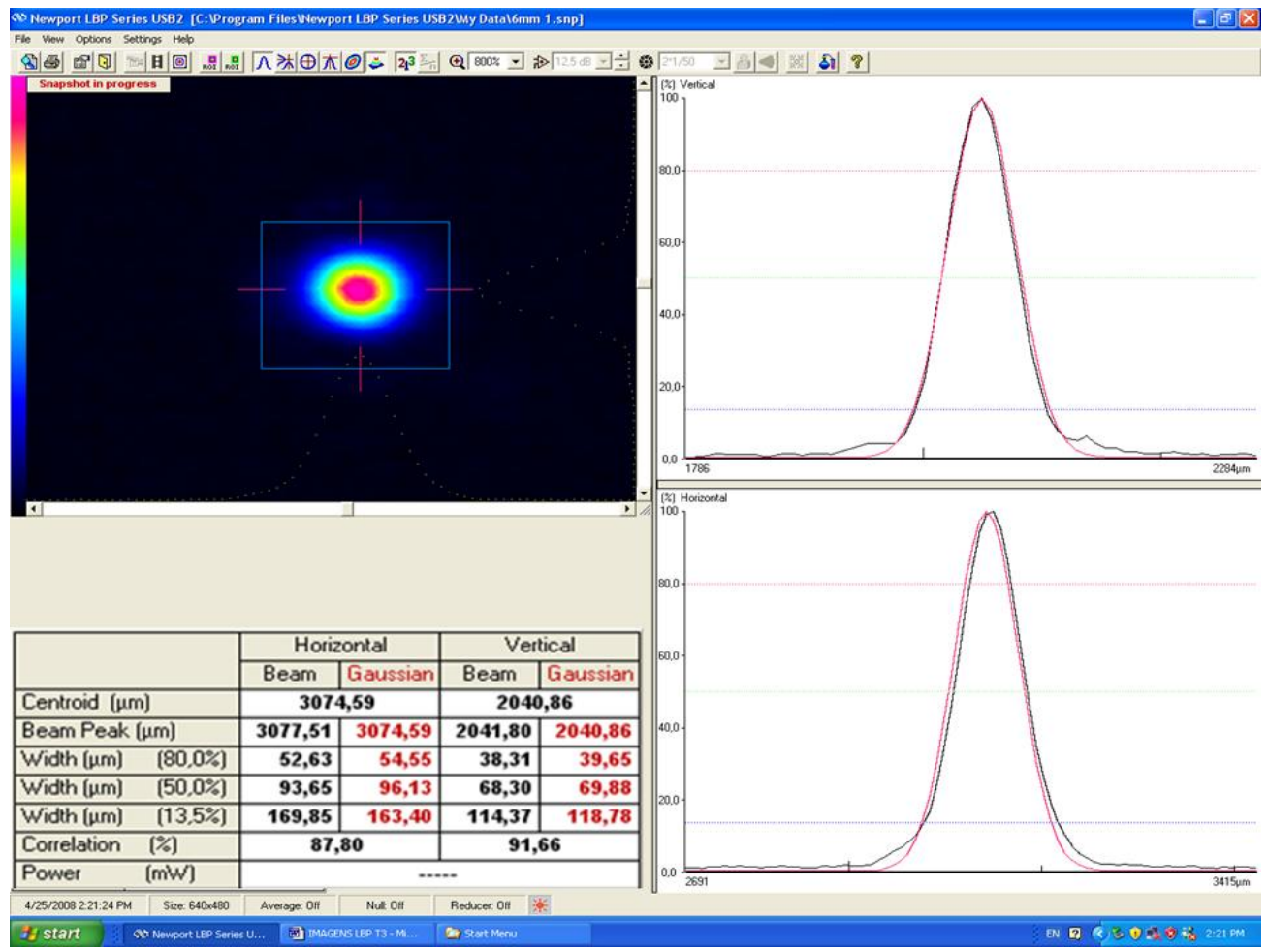

Figura 6.2 - Perfil espacial do foco do feixe laser focalizado por uma lente de $f=500$ $\mathrm{mm}$. O perfil se aproxima muito de um perfil Gaussiano.

A introdução de uma íris de diâmetro de $12 \mathrm{~mm}$ no caminho do feixe laser transformou o perfil gaussiano e perturbou o perfil do feixe no foco. Este perfil se transformou em uma distribuição quase Gaussiana com uma leve "ondulação" ao redor do centro [115] (veja Figura 6.2). Por terem pouca intensidade, estas ondulações podem ser desprezadas para os casos de ablação de materiais dielétricos. Assim, foi preciso um cuidado especial para se manter a superfície irradiada o mais próximo possível do foco para que a mesma distribuição espacial fosse mantida para a medida do limiar de dano e para as usinagens.

Estimativa da fluência: Considerando-se o modelo de propagação de um feixe gaussiano, o valor teórico do raio do feixe na superfície é [116]

$$
\left.w_{0}=2 M^{2} \lambda L /\left(\pi \cdot \phi_{0}\right)\right)
$$

onde $M^{2}$ é o fator de qualidade do feixe, $\lambda$ é o comprimento de onda do laser, $L$ é o comprimento focal da lente e $\phi_{0}$ é o diâmetro do feixe na entrada da lente. 
A quantificação da fluência na amostra usando a Eq. 58, quando essa é posicionada na cintura do feixe, pode não ser precisa. Isso ocorreu por motivos experimentais de dificuldade prática em encontrar a posição da cintura do feixe, visto que as lentes utilizadas ( $38 \mathrm{~mm}$ na maioria dos experimentos) possuem um parâmetro confocal de aproximadamente $170 \mu \mathrm{m}$. No caso deste trabalho, esse posicionamento é primordial para a correta quantificação da fluência na superfície da amostra e deve ser feita de forma precisa, ou seja, com precisão de pelo menos $10 \%$ do intervalo de Rayleigh.

Nesse sentido, o posicionamento da amostra perto da região focal foi feita da seguinte maneira: a energia dos pulsos e a taxa de repetição foram ajustados para 100 $\mu \mathrm{J}$ e $4 \mathrm{kHz}$ respectivamente, nessas condições é possível visualizar a formação de plasma no ar, então, a superfície da amostra é posicionada manualmente próxima ao ponto luminoso, visível através dos óculos de proteção. A energia dos pulsos é então diminuída para $20 \mu \mathrm{J}$ e a taxa de repetição baixada para $5 \mathrm{~Hz}$. Seguidamente são feitas irradiações sobrepostas de 5 pulsos em diferentes posições no eixo x e no eixo z com deslocamentos de $50 \mu \mathrm{m}$ e $20 \mu \mathrm{m}$ respectivamente, veja Figura 6.3.

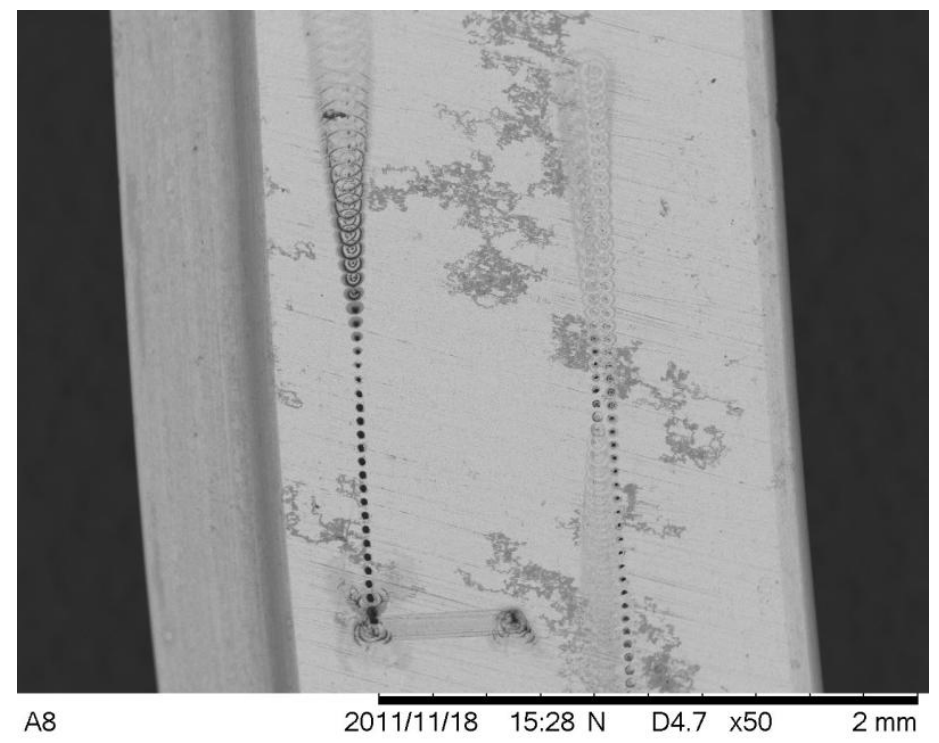

Figura 6.3 - Exemplo do procedimento usado para posicionar o foco na superfície da amostra (para uma melhor visualização, é mostrado uma amostra de aço). As posições focal e lateral são deslocadas, então a posição focal de menor marcação é usada para realização dos experimentos. 
Como cada marcação corresponde a uma posição focal diferente em torno da posição ajustada manualmente, foi possível encontrar, através de um microscópio, a menor marcação que corresponde à irradiação com o $w$ o mais próximo possível de $w_{0}$ (cintura do feixe). Este plano focal é então usado no procedimento para irradiações no foco com o método tradicional e para a usinagem dos microcanais. Esse procedimento funcionou para encontrar as marcações pela cintura do feixe com amostras dielétricas e foi utilizado na maioria dos experimentos desse trabalho. A energia e o número de pulsos usados neste procedimento podem variar dependendo do tipo de material usado. É possível observar a formação de anéis nas regiões fora do foco, mostrando que, quando o feixe passa pela íris existe efeito de difração do feixe, justificando o uso do feixe apenas na região perto do foco na qual o perfil é mais próximo do perfil Gaussiano.

Caracterização Temporal: Os pulsos curtos utilizados no experimento possuem uma banda de espectro de $40 \mathrm{~nm}$. E a forma temporal é de uma secantehiperbólica. A transmissão desses pulsos através de alguns metros de ar e elementos ópticos dispersivos causa a dispersão positiva e alarga-os temporalmente. As larguras temporais tanto na saída do laser quanto no laboratório a $30 \mathrm{~m}$ de distância foram medidas com um autocorrelador de pulso único modelo SSA-F da Coherent inc. Mesmo com os "Chirped Mirros" (Figura 6.2) ocorreu dispersão positiva e mostrou-se um alargamento temporal do feixe, de 25 fs na saída do laser para 56 fs na superfície da amostra devido ao caminho óptico percorrido pelos pulsos. A largura foi de $100 \mathrm{fs}$ sem os dois "chirped mirrors". Para corrigir esse problema, em alguns casos, a largura temporal foi controlada mudando a distância entre as grades de difração do amplificador e mudando os atrasos de fases dos pulsos permitindo que o feixe chegasse com aproximadamente 35 fs na superfície da amostra no laboratório de aplicações industriais. Quando os experimentos foram realizados no laboratório $\mathrm{T}^{3}$ com apenas poucos metros de distância do laser a largura temporal usada foi de 25 fs.

Além da dispersão por atraso de fases, efeitos não lineares gerados pelas altas potências pico são responsáveis pela autofocalização do feixe. Esses também são responsáveis pela absorção não linear e a geração de harmônicos, os quais provocam distorções espaciais e temporais dos pulsos. Aberrações, causadas por esses fenômenos quando o feixe ainda se propaga pelo ar, podem influenciar no processo de ablação 
quando esses pulsos atingem as superfícies das amostras. Para evitar esses tipos de problemas, em todos os experimentos de irradiação com o foco do feixe perto da amostra, a densidade de potência $I$ do feixe no ar foi mantida abaixo da densidade crítica $\left(I<I_{\text {critica,ar }} \approx \mathrm{GW} / \mathrm{cm}^{2}\right)$.

Como mencionado na introdução desse capítulo, foram utilizados dois lasers de diferentes marcas. O desvio padrão da energia dos pulsos laser no primeiro sistema laser, a partir de certo momento, foi maior que $40 \%$ rms. Essa instabilidade não acarretou maiores problemas, pois foram feitas medidas individuais da energia de cada pulso que irradiou a amostra e isso garantiu um menor nos resultados. Neste caso, a incerteza foi relacionada apenas com o fotodetector do tipo piroelétrico que mede a energia individual dos pulsos. No segundo laser, a energia dos pulsos teve alta repetibilidade. A flutuação foi menor que $5 \% \mathrm{rms}$, permitindo o uso de um detector de potência, sendo que o valor da energia medido correspondeu à potência média dividida pela taxa de repetição dos pulsos. A potência média do feixe foi constantemente controlada durante os experimentos por um medidor de potência para evitar possíveis erros sistemáticos gerados por um algum desalinhamento do sistema óptico de geração e entrega dos pulsos.

Técnica da Regressão do Diâmetro (TRD): Para a medida de limiar de ablação, a superfície da amostra foi irradiada com energia do pulso laser que foi aumentada pouco a pouco. Esta variação de energia foi realizada em um largo intervalo com incrementos pequenos, o que permitiu uma precisa determinação do limiar de ablação para pulsos únicos. Para cada energia foram realizadas seis irradiações em diferentes regiões da amostra, mantendo sempre o cuidado de posicionar a irradiação distante da zona afetada pelo feixe anterior. $\mathrm{O}$ deslocamento da amostra foi feito de maneira precisa através da mesa $\mathrm{CNC}$ de precisão micrométrica. $\mathrm{O}$ posicionamento foi monitorado por um sistema de visualização em tempo real do local constituído por uma objetiva acoplada a uma câmera CCD (veja Figura 6.1). O número de pulsos sobre o alvo foi controlado por um obturador mecânico e por um seletor de número de pulsos.

Para examinar as amostras após a irradiação e verificar a existência de possíveis danos, foi utilizado um microscópio óptico da marca Leica com um aumento de 500x para a análise desses danos. O dano foi definido como qualquer modificação 
visível permanente sobre a superfície. O menor dano observado foi de aproximadamente $5 \mu \mathrm{m}$ de diâmetro.

Usando as imagens digitais obtidas dos danos causados por diferentes energias de pulsos foi possível medir os diâmetros das marcações para diferentes energias. O programa Image ${ }^{\circledR}$ permitiu a medida dos diâmetro dos danos através da medida do números de pixels correspondentes aos diâmetros na imagem, e o número de pixel $/ \mu \mathrm{m}$ foi medido através de uma imagem de calibração que correspondeu a uma imagem com a mesma ampliação de um filme gravado numa escala micrométrica fornecida pelo fabricante do microscópio.

O valor utilizado para os cálculos foi a média das seis irradiações para cada energia e os respectivos desvios padrões. Os dados foram ajustados num gráfico mono$\log \left(D^{2}\right.$ x Fluência $)$. A partir do ajuste da Eq. 37 foi possível calcular o raio do feixe $w$ que é proporcional ao coeficiente angular da reta no ajuste. A partir desse valor medido de $w$, as fluências foram recalculadas e corrigidas; um novo gráfico de $D^{2}$ x Fluência foi então gerado e o limiar de ablação corrigido pode ser calculado.

As medidas de profundidade e de volume dos canais usinados foram feitas através das imagens obtidas por OCT (Tomografia por Coerência Óptica) da marca Thorlabs e modelo 930 sr localizado no laboratório de OCT do Centro de Lasers e Aplicações do IPEN.

Limpeza: Um dos parâmetros críticos que influenciam a medida do limiar de ablação é a limpeza da amostra. Impurezas na superfície da amostra aumentam o número médio de elétrons livres na região de irradiação, ou causam um acumulo de carga, isso pode aumentar a probabilidade de fotoionização mudando o valor do limiar de ablação de forma aleatória e atrapalhar a confiabilidade das medidas. A fim de padronizar a qualidade da superfície, todas as amostras foram limpas com acetona em um aparelho de ultrassom por cerca de três minutos e em seguida secas com papel para limpeza de superfícies ópticas para eliminar qualquer resíduo na superfície do vidro. Os parâmetros de limpeza adotados foram mantidos fixos para todas as amostras.

Durante a realização do trabalho desse período, a mesa de deslocamento CNC micrométrica, que era usada para a usinagem dos microcanais e experimentos com limiar de ablação foi danificada e parou de funcionar. O laboratório dispunha de três 
eixos de deslocamento motorizados com precisão nanométrica da marca Thor® modelo Z812B comprecisão submicrométric. Este sistema possui interface com o programa LabView, mas diferentemente do sistema que quebrou, não existia um programa para a execução de comandos CAD/CAM em linguagem ISO gerados pelo Mastercam. Consequentemente, tornou-se difícil a execução do método suave de usinagem de microcanais. Isso porque são necessárias as varreduras de muitas camadas com o laser, um controle dinâmico das velocidades e distâncias laterais de varredura. O uso do pósprocessamento do caminho da ferramenta pelo programa Mastecam tornou-se essencial para a continuação desse trabalho.

Durante o período em que a placa de controle do sistema inativo estava sendo importada para correção do imprevisto, foi criado um programa para a execução de comandos ISO pelo sistema de posicionamento nanométrico.

Usando programação em LabView, foi criado um programa que reconheceu os comandos escritos pelo Mastercam e o controle numérico de dois eixos do sistema nanométrico foi possível.

A elaboração do programa consistiu em três sub-rotinas. A primeira parte do programa lê o arquivo ".txt" contendo o código ISO gerado pelo Mastercam. As informações de posição, velocidades, números de pulsos e acionamento do obturador são extraídas do arquivo e armazenadas em uma matriz. A segunda parte do programa é responsável pela interpolação dos semiarcos em seguimentos de retas quando se tem um comando para execução de um arco pelo arquivo ISO. A terceira parte do programa utiliza a matriz com as coordenadas de posição e velocidades para ativar as "VI's" (ou "virtual instruments") fornecidas pela Thor ${ }^{\circledR}$ para movimentação dos motores.

Esse trabalho levou a uma melhora do equipamento de deslocamento nanométrico permitindo que desenhos feitos em CAD/CAM fossem usados para a usinagem micrométrica com precisão submicrométrica. E permitiu a continuidade dos experimentos durante o trabalho. 


\section{Técnica da regressão do diâmetro com pulsos únicos}

\subsection{BK7 e Suprasil ${ }^{\circledR}$}

Aqui são mostrados os resultados dos limiares de ablação medidos em BK7 e Suprasil para pulsos únicos usando a técnica da regressão do diâmetro (TRD). Seus resultados serão apresentados na ordem cronológica de realização durante esse trabalho. Isso facilitará a descrição do procedimento de realização das medidas e soluções dos problemas encontrados durante sua execução.

Numa primeira abordagem para testar a TRD, o tipo de lente, o intervalo de fluências e o procedimento de medida dos danos foram testados em dois ensaios numa amostra de BK7. Duas lentes foram utilizadas, uma de $10 \mathrm{~mm}$ e outra de $38 \mathrm{~mm}$ de distância focal. Fez-se o gráfico do diâmetro ao quadrado em função da fluência de cada pulso corrigida pela regressão do diâmetro, que são mostrados na Figura 7.1. Os resultados obtidos usando os dois comprimentos focais mostraram-se compatíveis. $\mathrm{O}$ limiar de dano encontrado para pulsos de 100 fs foi de $4,51 \pm 0,81 \mathrm{~J} / \mathrm{cm}^{2}$ para lente de 38 $\mathrm{mm}$ e $3,84 \pm 0,14 \mathrm{~J} / \mathrm{cm}^{2}$ usando a lente de $10 \mathrm{~mm}$. A partir do resultado encontrado foi possível estabelecer um intervalo de energia adequado para o ajuste dos gráficos seguintes. Essas duas medidas serviram também para se escolher um padrão de lente a ser usado na medição do limiar de dano que fosse mais conveniente em termos experimentais. A lente de $38 \mathrm{~mm}$ foi escolhida devido as seguintes características: tem um parâmetro confocal maior que a lente de $10 \mathrm{~mm}$, implicando em um posicionamento da amostra perto da cintura do feixe facilitado (que se mostrou muito complicado em termos práticos no começo desse trabalho); a área afetada é maior, o que implica no uso de maiores energias (entre $10-50 \mu \mathrm{J}$ ) para uma mesma fluência comparada com a lente de $10 \mathrm{~mm}$, o que garantiu uma medida da energia dos pulsos dentro de um intervalo de medida mais confiável do detector. E por fim, os diâmetros medidos foram maiores, o que facilitou a medição das imagens dos danos proporcionando maior precisão na medida.

A medida dos diâmetros ablacionados foi feita como descrito no capítulo “Descrição experimental”. A incerteza na medida com o microscópio foi estimada em 1 $\mu \mathrm{m}$. Dentre os dois tipos de detectores, o de potência e o de energia, foi escolhido o 
detector de potência. A energia dos pulsos foi obtida pela divisão da potência média medida pela taxa de repetição do laser. Os desvios padrões dos diâmetros foram usados como barras de erro no ajuste.

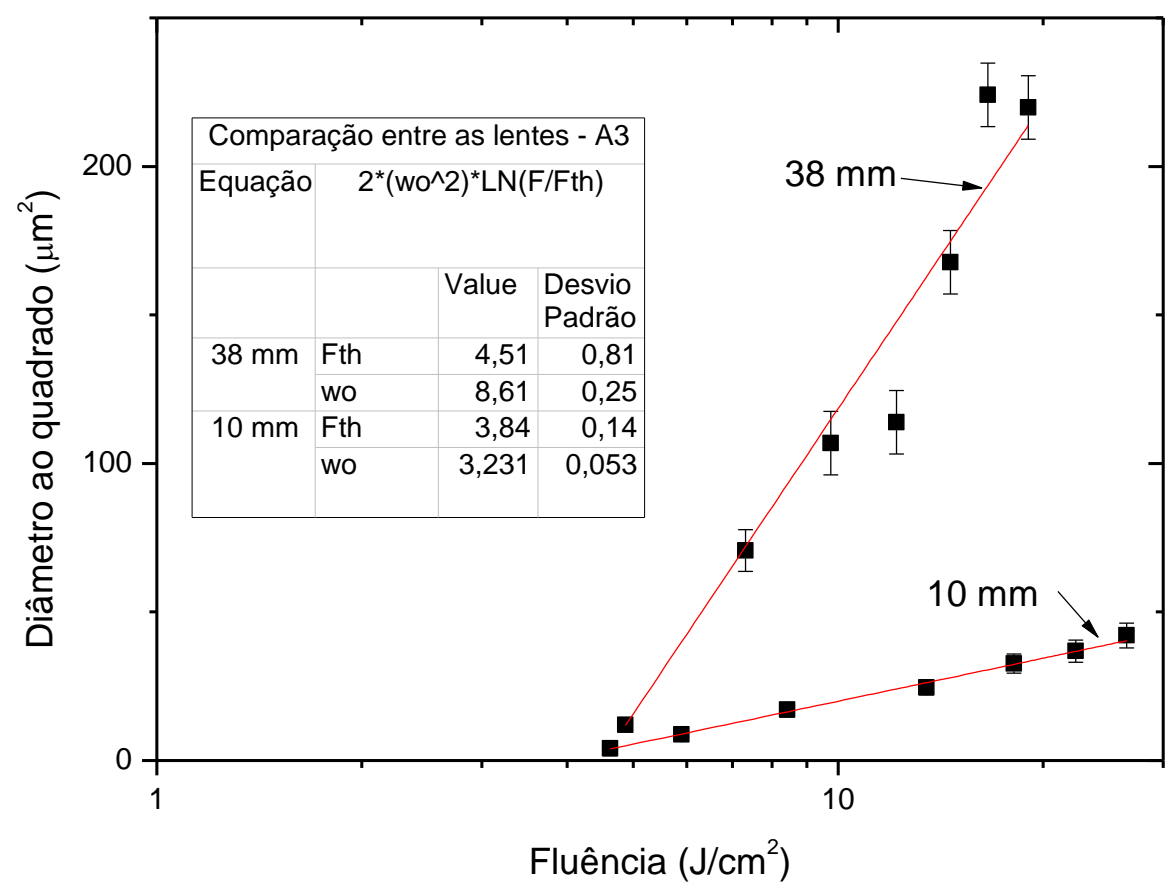

Figura 7.1 Fluência média $x D^{2}$ com a lente de 10 e $38 \mathrm{~mm}$, primeiros testes na amostra A3.

Depois desse primeiro teste, foi possível realizar as medidas de limiar de dano para o BK7 e o Suprasil utilizando os parâmetros adequados para sua realização. Cada medida foi feita em uma amostra diferente, portanto, para as amostras de BK7, os ensaios serão referidos por (An) onde $n$ representa o número da amostra. No caso do Suprasil será (Suprasiln). Como foi esclarecido no capítulo 6, foram usados dois lasers diferentes. Os diferentes tipos de laser serão referidos por laser1 e laser2 de acordo com a ordem em que foram usados.

Amostra A4 - Usando a lente de $38 \mathrm{~mm}$ fez-se uma medida do limiar usando mais pontos experimentais. Como nos primeiros ensaios, foram consideradas as incertezas dos valores dos diâmetros $D$ como sendo o desvio padrão da média dos diâmetros $\left(\sigma_{D}\right)$. A incerteza do valor do diâmetro ao quadrado foi de $2 \sigma_{D} D$; Foi considerada a energia média, e a incerteza na energia dos pulsos levou em conta a flutuação do laser que foi medida pelo detector sendo $<5 \%$ rms. Entretanto, não foi 
considerada na propagação de erros para a medida do limiar de ablação pelo fato de contribuírem muito menos na incerteza final em relação ao desvio padrão do diâmetro dos danos.

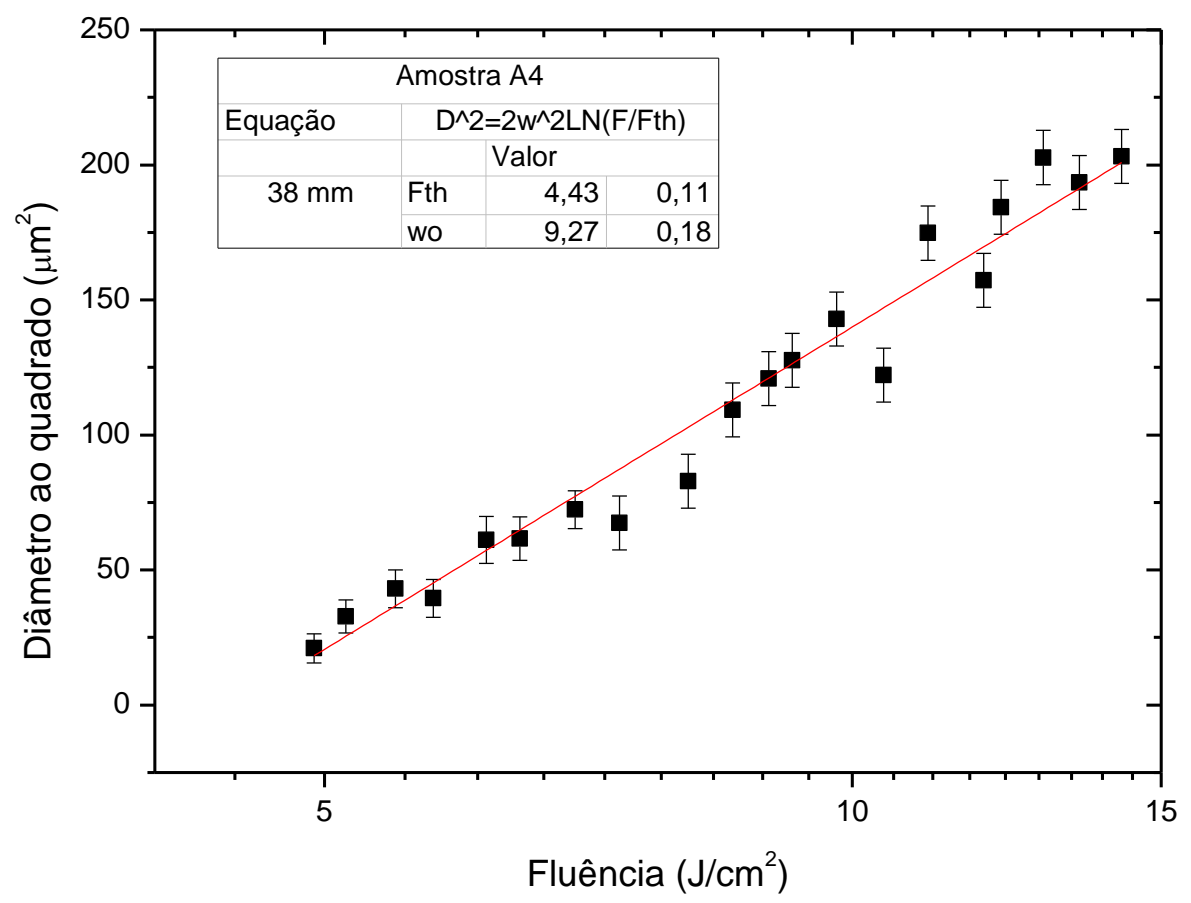

Figura 7.2 - Gráfico do $D^{2}$ X Fluência média - usando mais pontos experimentais com intervalos menores de energias. Limiar de ablação: $4,43 \mathrm{~J} / \mathrm{cm}^{2}$

O valor do limiar de ablação obtido para o BK7-A4 foi de $(4,43 \pm 0,11)$ $J / \mathrm{cm}^{2}$. O valor do raio do feixe na amostra encontrado foi de $w=(9,27 \pm 0,18) \mu \mathrm{m}$.

Suprasil 1 - Mais medidas foram feitas do limiar de ablação para pulsos únicos no Suprasil.

Durante o período de realização desse experimento com a irradiação de pulsos únicos, o laser1 apresentou problemas de instabilidade na energia dos pulsos. A energia média dos pulsos flutuou em mais que $10 \%$ em períodos de tempo de alguns minutos, enquanto que o desvio rms chegou a $40 \%$.

Em termos de confiabilidade, o procedimento usado até tinha sido comprometido. Isso ocorreu porque a fluência de cada ponto no ajuste correspondeu a uma média de 6 irradiações, e devido à grande instabilidade do laser, o desvio padrão da média de seis irradiações foi cerca de 30 a $40 \%$ do valor da média dos diâmetros. Consequentemente, a confiabilidade do resultado final do limiar de ablação foi 
prejudicada. O gráfico da Figura 7.3 mostra os pontos correspondentes às médias dos diâmetros ao quadrado com um alto desvio padrão.

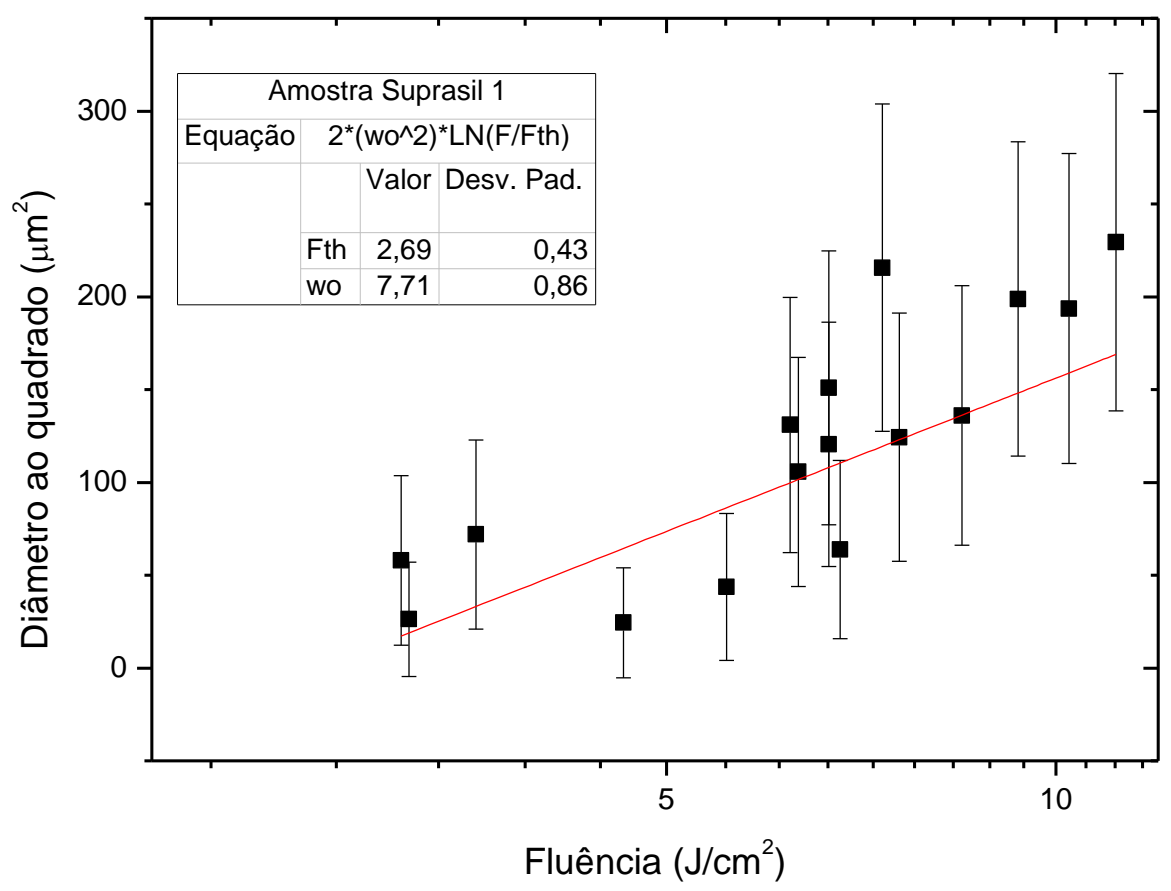

Figura 7.3 - Limiar de dano calculado para o Suprasil com o laser1 apresentando instabilidades na energia. É possível observar um maior desvio dos dados devido à flutuação na energia dos pulsos.

Para resolver esse problema foi realizado um procedimento experimental diferente com o objetivo de diminuir os erros de medidas. Portanto foram realizadas medidas diretas da energia de cada pulso que irradiou a amostra, e não apenas a medida da energia média dos pulsos que são gerados pelo laser. Assim eliminou-se a flutuação da energia do laser que foi intrínseca ao sistema laser.

A medida direta da energia foi possível devido à mudança do sistema de entrega do feixe que permitiu total automatização das irradiações e da medida das energias dos pulsos. Com esse novo sistema de entrega, cada pulso que irradia a amostra teve sua energia medida e armazenada num computador e comparada com as imagens da zona ablacionada.

Mesmo com o laser apresentando instabilidades, o novo aparato experimental permitiu uma nova serie de medidas do limiar de dano para pulsos únicos e foi testada no BK7 antes de ser realizada novamente no Suprasil. 
A Figura 7.4 mostra um maior número de pontos experimentais (15 pulsos) para cada energia média, num total de 12 energias (12 linhas). Cada linha representa um conjunto de mesma energia média, contudo, cada pulso irradiado foi medido individualmente, eliminando a incerteza na flutuação da energia. A incerteza dos diâmetros considerados nesse arranjo experimental foi de $10 \%$. A propagação de erros foi feita como nos procedimentos anteriores.

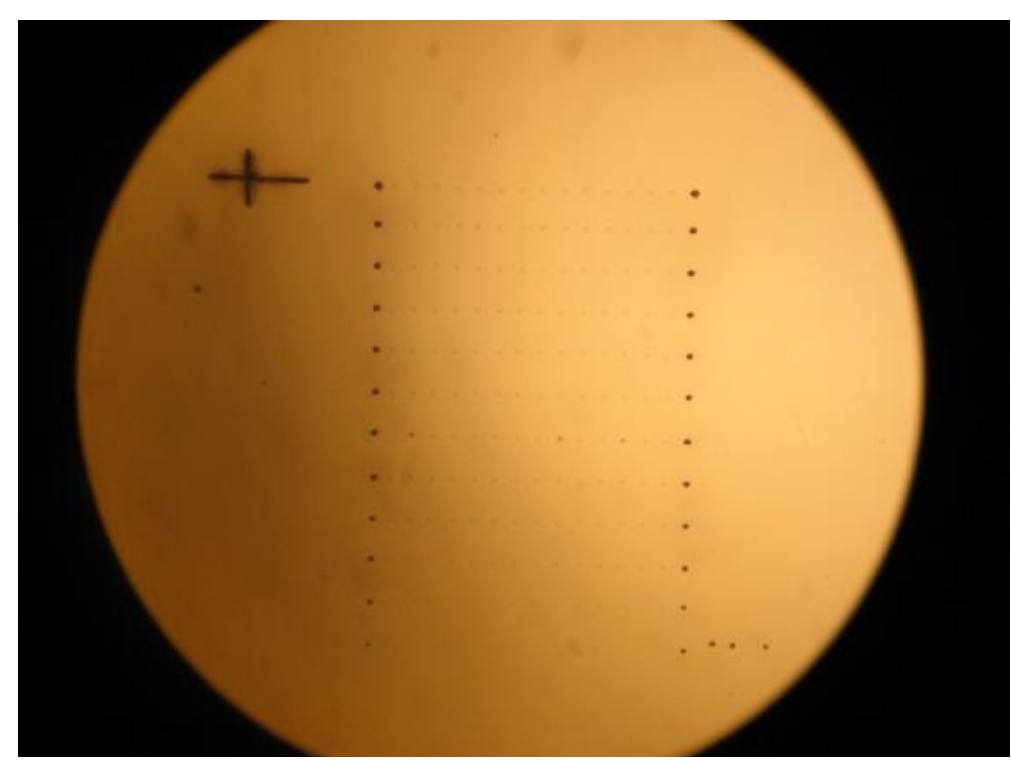

Figura 7.4 - Irradiações com pulsos únicos. Cada linha representa energias médias diferentes, mas cada irradiação foi medida individualmente.

O limiar de dano da amostra Suprasil 2 foi encontrado usando o gráfico da Figura 7.5 e o valor foi de $(6,894 \pm 0,013) \mathrm{J} / \mathrm{cm}^{2}$ para pulsos de $100 \mathrm{fs}$, e o valor do raio de $(7,14 \pm 0,05) \mu \mathrm{m}$. 


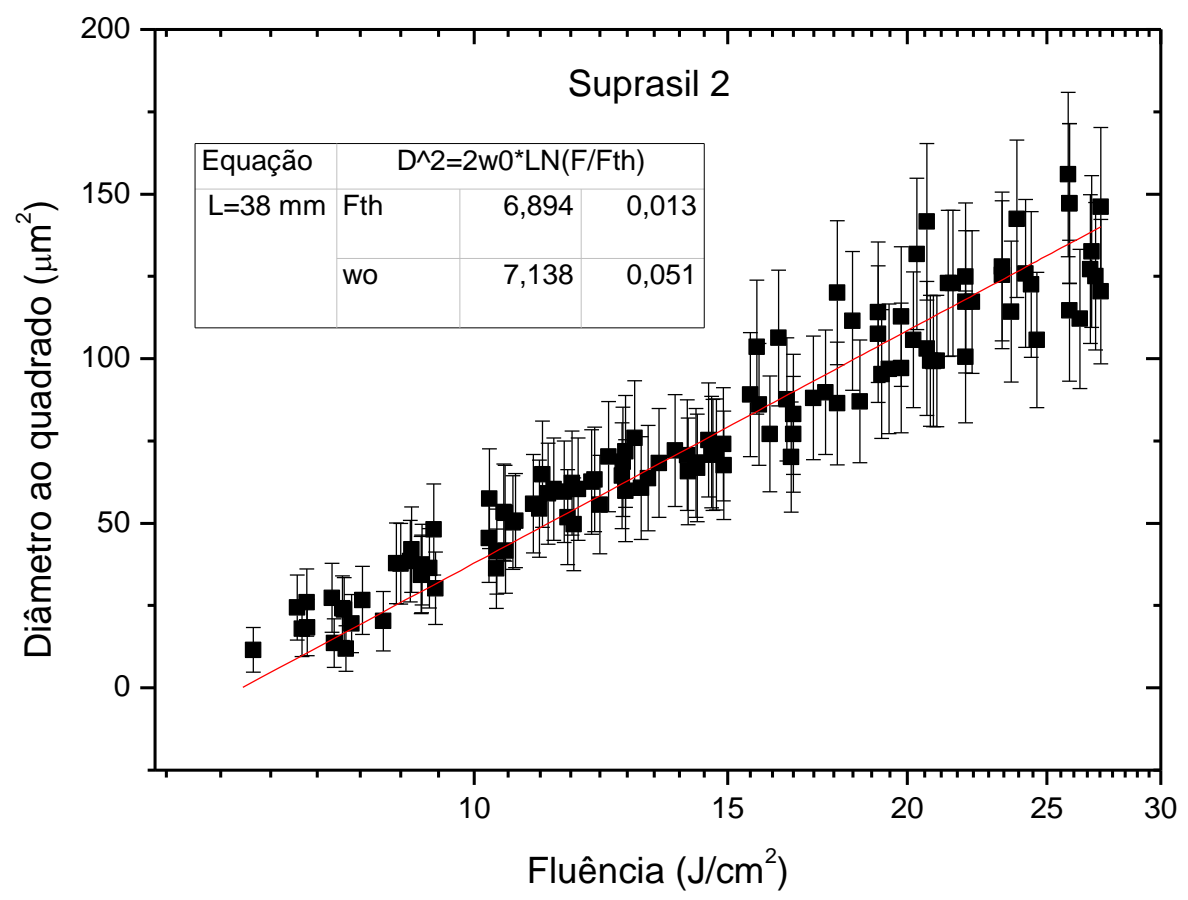

Figura 7.5 - Fluência em função do diâmetro ao quadrado de pulsos únicos irradiados no BK7. Medidas individuais da energia de cada irradiação foram feitas.

Amostras -BK7-A6 e Suprasil 3 - Nessas amostras o laser2 foi utilizado. Esse laser apresentou melhor estabilidade (5\% rms) e maior energia por pulso que o laser1, energia máxima chegando a $150 \mu \mathrm{J}$.

As medidas das energias dos pontos experimentais foram feitas usando o detector de potência como nos primeiros ensaios antes que laser1 apresentasse instabilidades. Cada ponto experimental também utiliza o valor da fluência média corrigida pelo coeficiente angular $\left(2 \mathrm{w}_{0}^{2}\right)$, e o quadrado da média dos diâmetros de seis irradiações com suas respectivas incertezas propagadas do desvio padrão dos diâmetros.

O limiar de dano encontrado na amostra A6 de BK7 foi de $(4,71 \pm 0,21)$ $\mathrm{J} / \mathrm{cm}^{2}$ para $100 \mathrm{fs}$ (Figura 7.6). 


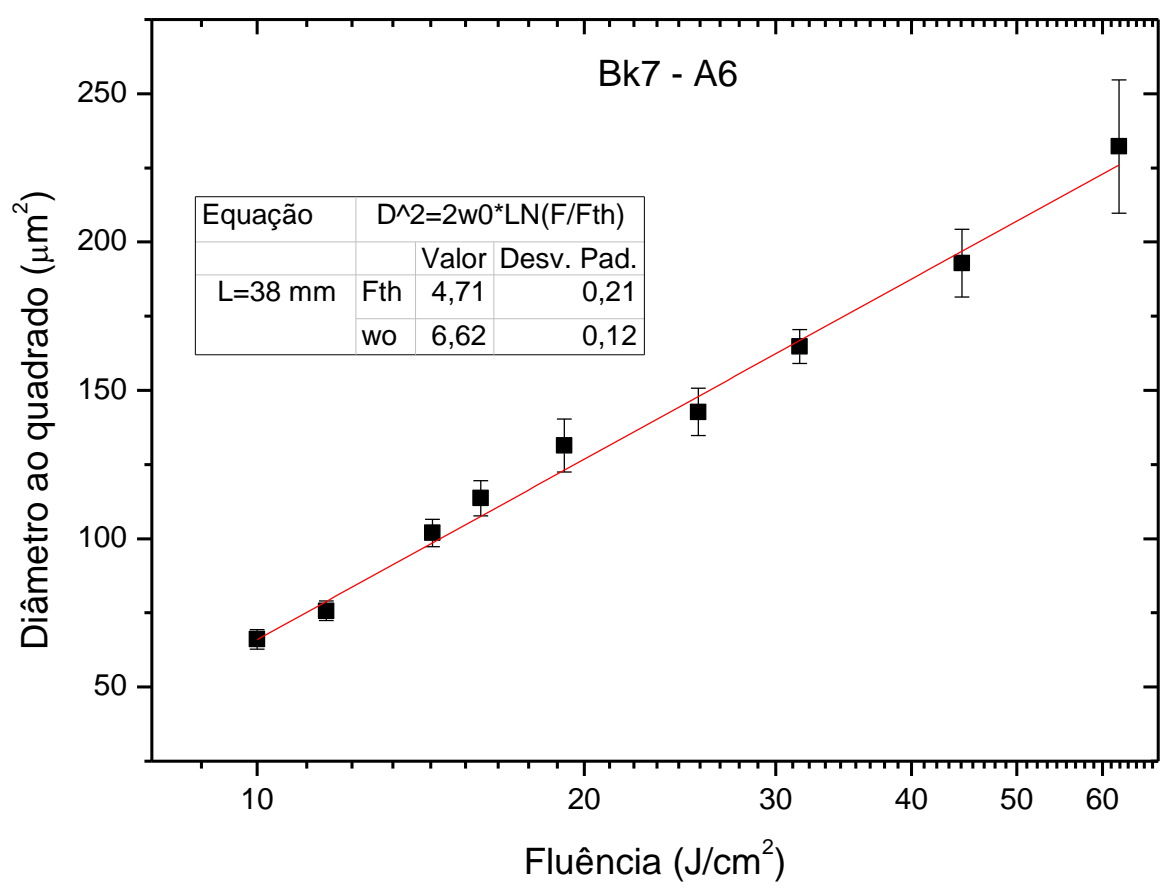

Figura 7.6 - Ajuste para o cálculo do limiar de ablação da amostra BK7 - A6.

No Suprasil 3 foi possível irradiar a amostra com energias de pulso de até $150 \mu \mathrm{J}$, o que possibilitaria testar um possível regime de ablação de alta fluência. Esse regime, como explicado no capitulo 3.3.2, caracteriza-se por uma interação térmica, ou seja, o dano provocado é relacionado à explosão de fase e a taxa de remoção de material é aumentada. Além disto existe influência térmica significativa do plasma formado na superfície durante a interação. A partir de uma fluência específica, a zona afetada pelo laser não é mais definida pelo limiar de ablação de baixa fluência como calculado até aqui, mas segue o limiar de alta fluência. Nesse regime, o calor gerado pelo pulso e pelo plasma em regiões centrais do feixe gaussiano difunde-se e ablaciona uma região que não teria fluência suficiente para ser ablacionada. A consequência disso é um dano com um diâmetro maior que o previsto pelo modelo da Eq. 32. Portanto, o diâmetro do feixe não segue mais a distribuição gaussiana de intensidade, mas tem-se um "raio" do feixe efetivo, que está relacionado à difusão térmica da energia do pulso, e um novo "limiar de dano" para altas fluências maior que para baixas fluências.

No gráfico da Figura 7.7 são mostrados todos os pontos medidos até com fluências maiores que $70 \mathrm{~J} / \mathrm{cm}^{2}$. Para fluências maiores que $50 \mathrm{~J} / \mathrm{cm}^{2}$ os diâmetros ao quadrado crescem acima do ajuste do modelo teórico e mostram uma tendência de 
crescimento da taxa de remoção de material comparado com os "danos" para fluências menores. Mesmo com essa tendência, a incerteza dos pontos e o pequeno intervalo de energias (apenas 4 pontos) em que essa tendência ocorre, não se permite concluir que exista um regime de alta fluência nesse intervalo de fluências. O limiar de ablação

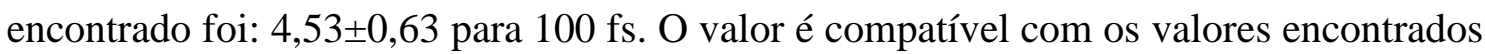
na literatura para a sílica: $4 \mathrm{~J} / \mathrm{cm}^{2}$ a 100 fs [110].

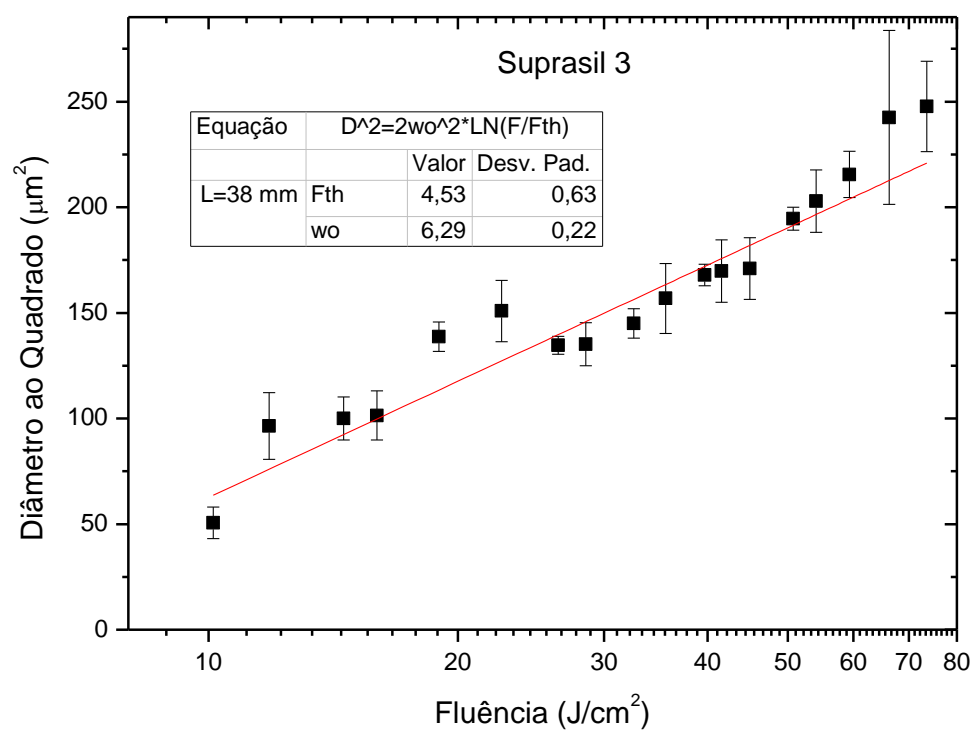

Figura 7.7 - Gráfico da fluência x diâmetro ao quadrado - limiar de dano do Suprasil para pulsos únicos (regime de baixa e alta fluência).

\subsection{Safira e Ti:Safira}

Safira pulsos únicos TRD: A Figura 7.8 mostra o gráfico do diâmetro ao quadrado em função das fluências das irradiações de pulsos únicos em Safira monocristalina. Utilizou-se o laser 2 e o detector de potência para medida da energia média e cada ponto no gráfico corresponde à média do diâmetro de seis irradiações e seus respectivos desvios padrões assim como nos primeiros experimentos com o BK7. Os dados do gráfico da Figura 7.8 apresentaram um comportamento diferente dos resultados obtidos anteriormente de limiar em BK7 e Suprasil para pulsos únicos. Estes dados apresentaram uma descontinuidade a partir de $40 \mathrm{~J} / \mathrm{cm}^{2}$ na taxa de remoção de material. Esse comportamento já foi observado antes em outro trabalho com a safira [117] e correspondem aos dois regimes de ablação: o "gentle ablation" (ou baixa fluência) responsável por ablacionar pequenas volumes de material, no caso da safira, 
$\sim 55 \mathrm{~nm}$ por pulso, e o "strong ablation" (alta fluência) com taxas maiores de ablação da ordem de $500 \mathrm{~nm}$ por pulso[117].

O limiar de ablação no regime de baixa fluência encontrado foi de $F_{t h, b}=$ $(5,59 \pm 0,52) \mathrm{J} / \mathrm{cm}^{2}$, o coeficiente angular do gráfico retorna o valor do raio do feixe na amostra $w_{0}=(6,58 \pm 0,93) \mu m$ que é compatível com o valor esperado do raio (como medido nos experimentos anteriores).

Através da extrapolação da reta ajustada no regime de alta fluência, que pode ser visto na Figura 7.8-a, o valor de "limiar de ablação" de alta fluência encontrado pela TRD foi de $F_{t h, a}=(21,6 \pm 1,1) \mathrm{J} / \mathrm{cm}^{2}$.

O regime de alta fluência é definido no intervalo onde a taxa de remoção de material é maior que o no de baixa fluência. Em alta fluência, o calor gerado pelo decaimento eletrônico é grande o suficiente para que seja possível uma transformação de fase no material, juntamente com difusão térmica e efeito de "espalação" para além da região da fluência de limiar para baixa fluência, superestimando o diâmetro das zonas ablacionadas. Assim, o coeficiente $2 w^{2}$ da Eq. 32 não se relaciona mais com a distribuição espacial de intensidade do feixe gaussiano, mas sim como uma convolução entre essa distribuição do feixe e uma difusão térmica. Além disso, o plasma gerado no processo de ablação em alta fluência normalmente tem duração de alguns nanossegundos e pode transferir uma quantidade de calor para o material suficiente para ajudar no processo térmico e gerar uma zona termicamente afetada. Portanto o raio do feixe medido pela TRD deve ser maior (superestimado) no regime de alta fluência. $\mathrm{O}$ coeficiente angular do gráfico retorna o valor do raio do feixe na amostra superestimado: $w=(12,08 \pm 0,33) \mu m$. 


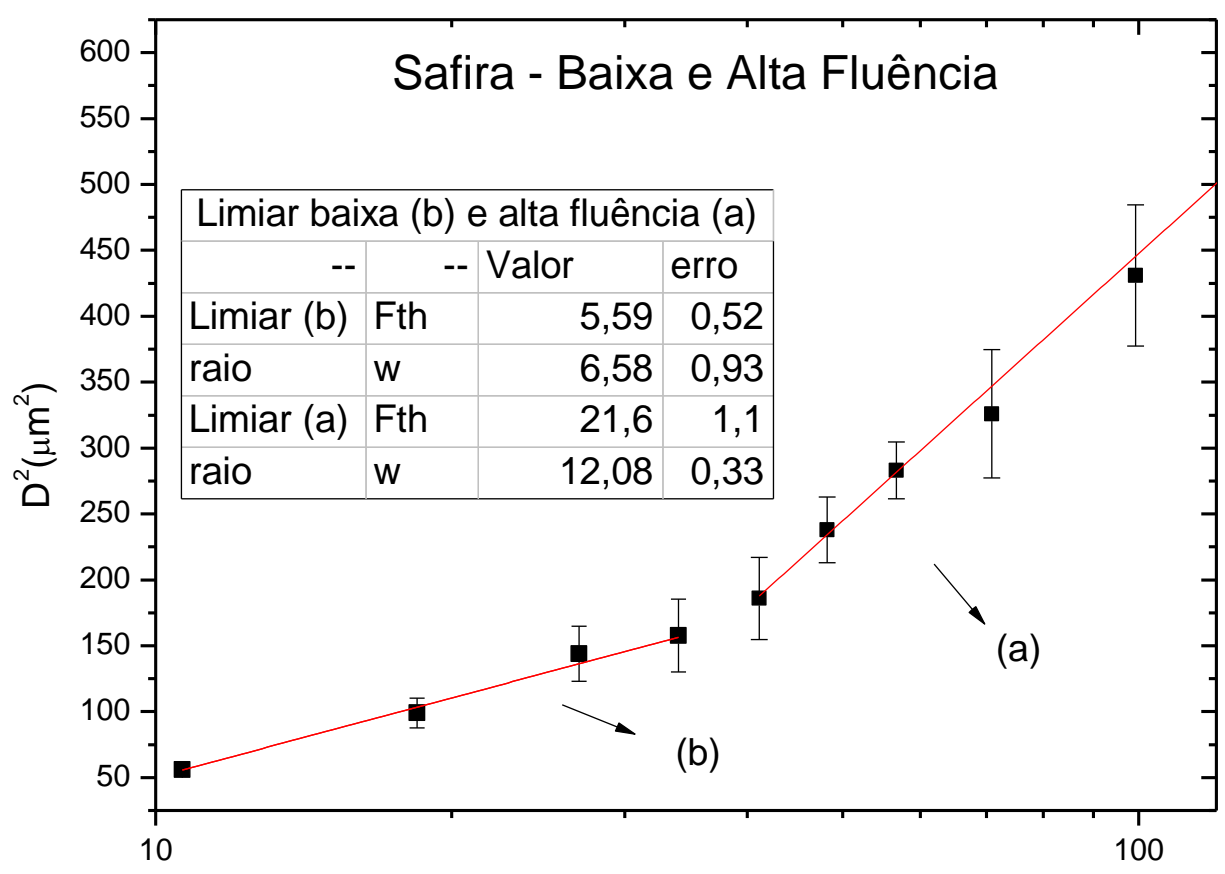

Fluence $\left(\mathrm{J} / \mathrm{cm}^{2}\right)$

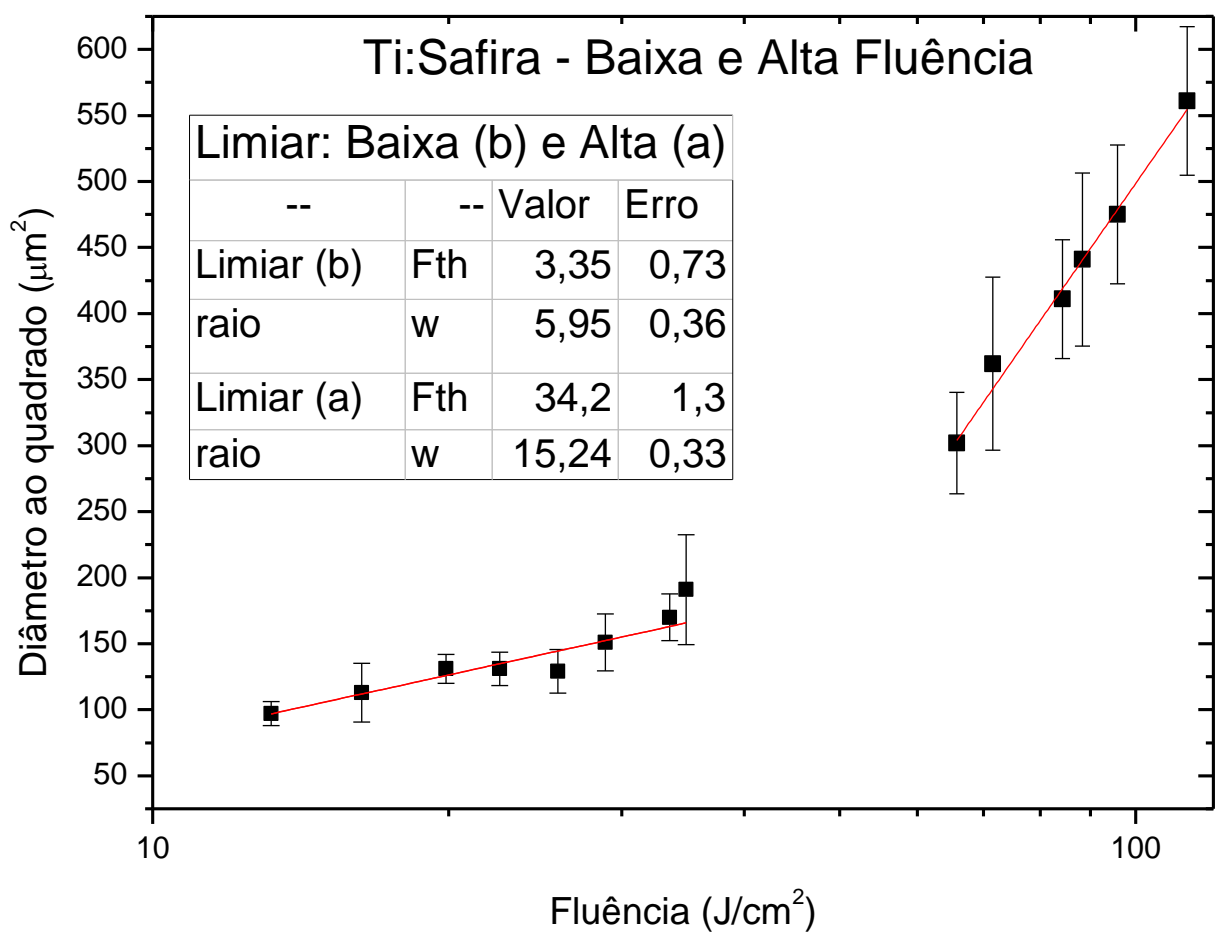

Figura 7.8- a) Diâmetro ao quadrado x Fluência para pulsos únicos em safira, mostrando os regimes de baixa e de alta fluência, bem como o limiar de ablação. b) Ti: Safira. 
A Figura 7.9 mostra os dois regimes de ablação.
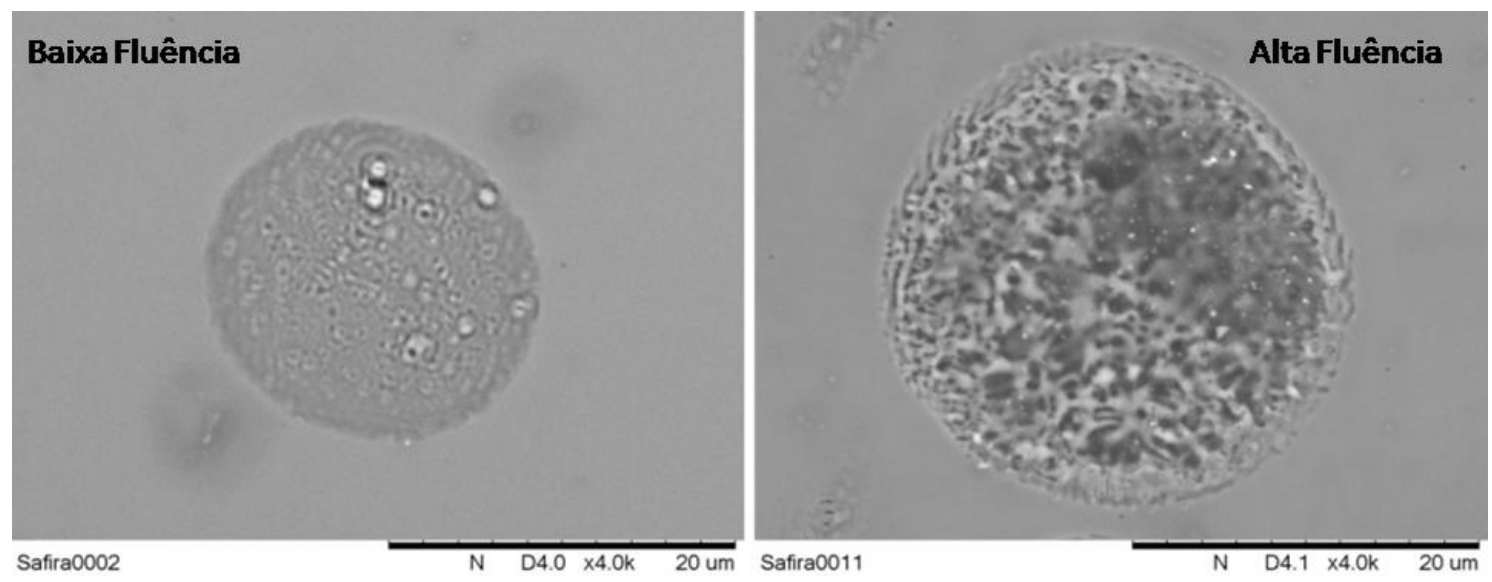

Figura 7.9 - Efeito da baixa e alta fluência na safira.

O aparecimento dos dois regimes de interação é claramente observado na safira. Como este material possui um tempo longo de relaxação elétron-fônon ( 1 ps), o tempo de aquecimento da rede estende-se por tempos maiores que a duração do pulso de 55 fs. Estes elétrons permanecem excitados na banda de condução até sua relaxação para a banda de valência, gerando fônons numa taxa relacionada ao tempo de decaimento de 1 ps da safira, e que independe da duração do pulso pois é muito maior que esta. Durante a relaxação, o calor tem tempo para se difundir no material, afetandoo colateralmente antes de causar uma explosão de fase.

A ausência do regime de alta fluência no BK7 e no Suprasil nas fluências estudadas aqui pode ser explicada pela dinâmica de relaxação dos elétrons livres. Ou seja, devido ao forte acoplamento elétron-fônon nesses materiais ( 100 fs) $\mathrm{o}$ aquecimento da rede ocorre quase que simultaneamente à duração do pulso ( 100 fs). Além disso, a menor difusividade térmica comparada com a safira não permite que ocorra difusão térmica significativa (veja Tabela 2). Dessa forma, o diâmetro da região ablacionada relaciona-se com a distribuição gaussiana do feixe e não é possível observar uma descontinuidade na relação da Eq. 32 no dado intervalo de energias utilizadas, mesmo em altas fluências $\left(<80 \mathrm{~J} / \mathrm{cm}^{2}\right)$. Portanto no caso do Suprasil e do BK7 o regime térmico se sobrepõe ao regime não térmico deslocando o intervalo de fluências do regime de altas fluências para valores mais elevados do que na Safira. 
Tabela 2 - Difusividade e ponto de vaporização dos dielétricos.

\begin{tabular}{ccc} 
Material & Difusividade $\left(\mathbf{m m}^{2} / \mathbf{s}\right)$ & $\begin{array}{c}\text { Ponto de vaporização } \\
\left({ }^{\circ} \mathbf{C}\right)\end{array}$ \\
\hline Si0 & & 2950 \\
Safira & 1.4 & 2980 \\
Ti:safira & 14 & - \\
BK7 & 14,6 & - \\
\hline
\end{tabular}

Ti:Safira - Para a análise das medidas feitas com o Ti:safira, deve-se entender como ocorre o processo de absorção nesse material, visto que ele não se comporta como a safira monocristalina.

$\mathrm{O}$ Ti:safira é produzido pela mistura de $\mathrm{Ti}_{2} \mathrm{O}_{3}$ em $\mathrm{Al}_{2} \mathrm{O}_{3}$ fundido, onde uma pequena parte do $\mathrm{Al}^{3+}$ na safira é substituído por $\mathrm{Ti}^{3+}$. $\mathrm{O} \mathrm{Ti}^{3+}$ possui apenas um elétron, e consequentemente, apenas dois níveis de energia possíveis. Esses dois níveis geram um par de bandas pela interação vibrônica entre a banda de condução e a banda de valência. A absorção ocorre em comprimentos de onda de $400 \mathrm{~nm}$ e $600 \mathrm{~nm}$ pela banda mais energética, conforme mostrado na Figura 7.10. Os elétrons excitados nos níveis da segunda banda podem criar fônons na própria banda e depois decair para a primeira banda vibracional do $\mathrm{Ti}^{3+}$ menos energética. Isso permite uma emissão com banda no infravermelho entre $650 \mathrm{~nm}$ a $1050 \mathrm{~nm}$. Portanto, os pulsos ultracurtos gerados pelo Ti:safira não são absorvidos linearmente pelo próprio Ti:safira, haja vista que o laser de Ti:safira é um laser de quatro níveis.

O limiar de dano do Ti:Safira (Figura 7.8-b) também foi medido para pulsos únicos pela TRD. O valor do limiar de dano foi $(3,35 \pm 0,73) \mathrm{J} / \mathrm{cm}^{2}$ em baixa fluência e $(34,2 \pm 1,3) \mathrm{J} / \mathrm{cm}^{2}$ em alta fluência. O raio do feixe encontrado no regime de baixa fluência foi de $(5,95 \pm 0,33) \mu \mathrm{m}$ e é compatível com o valor esperado do raio na superfície, mostrando o regime de baixa fluência. 
O limiar de dano para baixas fluências neste caso, foi menor que o limiar da safira monocristalina. A dinâmica de geração de elétrons livres no Ti:safira é diferente e poderia ser explicada pelas bandas vibrônicas geradas pelo $\mathrm{Ti}^{3+}$ na rede da safira e será detalhada a seguir.

Todos os processos de ionização estudados nesse trabalho (ablação da safira, sílica e do BK7) não ocorrem por absorções lineares (absorção de fótons únicos). No caso da safira, por exemplo, a absorção multifotônica é responsável pela excitação do material. O Ti:safira também é transparente $(780 \mathrm{~nm})$, e absorção também só é permitida no caso de absorções não lineares, com mais de um fóton. Porém, as bandas vibracionais criadas funcionam como "pontes" de ionização para um efeito multifotônico de menor ordem. Consequentemente, menos fótons são necessários para os elétrons serem excitados a níveis intermediários, o que torna o efeito mais provável. Estes níveis servem como pontes para absorções multifotônicas e geração de elétrons "sementes" na banda de condução mais eficientemente. Quanto mais rápida a criação de elétrons na banda de condução, maior será o efeito avalanche (ionização por impacto) e maior o efeito fotoelétrico durante a irradiação do laser. Então, o aumento do efeito fotoelétrico implica na ampliação da carga positiva superficial no material, e isso é responsável pela diminuição do limiar de dano no regime de baixa fluência.

Já o regime de alta fluência, como discutido anteriormente, está relacionado à explosão térmica juntamente com difusão térmica, efeito de e "spalação" e influência do plasma. A potência de calor absorvida pela rede é proporcional à taxa de decaimento destes elétrons excitados em fônons na rede. Um dos caminhos prováveis de decaimento dos elétrons no Ti:Safira, gerados por absorção multifotônica e efeito avalanche na banda de condução, ocorre diretamente da banda de condução para a base da banda de valência criando fônons ou fótons. Outra possibilidade é o decaimento por níveis vibracionais interbandas que emitem na banda de emissão (fluorescência) do Ti:safira (650 a $1050 \mathrm{~nm}$ ). Esse caminho alternativo que os elétrons percorrem na relaxação pode ser responsável por um desvio da energia, que na safira monocristalina é usada para a geração de fônons e o aquecimento do material, e sendo assim o limar de alta fluência no Ti:safira é menor. 

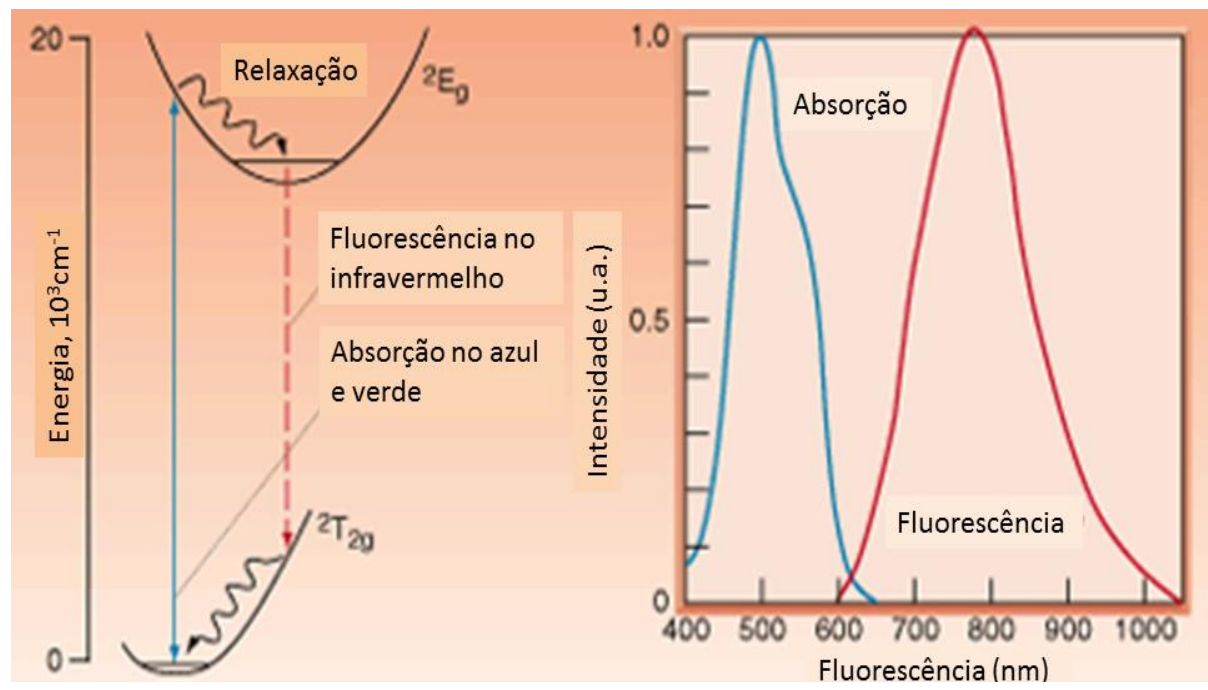

Figura 7.10 - diagrama das bandas vibrônicas geradas no Ti:safira pelos íons $\mathrm{Ti}^{3+}$. O Ti:safira absorve linearmente fótons aproximadamente entre 400 e $600 \mathrm{~nm}$, e irradia numa banda larga que vai de 650 a $1050 \mathrm{~nm}$.

A Tabela 3 mostra um resumo de todos os experimentos realizados para encontrar o limiar de dano de baixa e alta fluência para pulsos únicos. Todos os valores foram representam a fluência de pico (que equivale ao dobro da fluência média):

Tabela 3- Limiares de dano (pico) encontrado para BK7 e Suprasil com diferentes lasers e sistema de aquisição de medidas.

\begin{tabular}{|c|c|c|c|c|c|c|}
\hline Amostra & $F_{t h}(b)\left(J / c^{2}\right)$ & $F_{\mathrm{th}}(\mathrm{a})\left(\mathrm{J} / \mathrm{cm}^{2}\right)$ & $\tau_{\mathrm{L}}(\mathrm{fs})$ & Laser & Comentário & $w_{0}(\mu \mathrm{m})$ \\
\hline Bk7-A3 & $4,51 \pm 0,81$ & - & 100 & 1 & & 8,6 \\
\hline Bk7-A4 & $4,602 \pm 0,014$ & - & 100 & 1 & & 9,3 \\
\hline Bk7-A5 & - & - & 100 & 1 & apenas $N>1$ & \\
\hline Bk7-A6 & $4,71 \pm 0,21$ & - & 100 & 2 & m. est. & 6,6 \\
\hline $\begin{array}{c}\text { Suprasil } \\
1\end{array}$ & $2,69 \pm 0,43$ & - & 100 & 1 & & 7,7 \\
\hline $\begin{array}{c}\text { Suprasil } \\
2\end{array}$ & $6,894 \pm 0,013$ & - & 100 & 1 & m. est. & 7,1 \\
\hline $\begin{array}{c}\text { Suprasil } \\
3\end{array}$ & $4,53 \pm 0,63$ & - & 100 & 2 & & 6,3 \\
\hline Safira & $5,59 \pm 0,52$ & $21,6 \pm 1,2$ & 55 & 2 & & 6,6 \\
\hline Ti:safira & $3,35 \pm 0,73$ & $34,2 \pm 1,3$ & 55 & 2 & & 6,0 \\
\hline Bk7 & $5,10 \pm 0,08$ & - & 200 & & [118] & \\
\hline Sílica & 4 & & 100 & & [109] & \\
\hline
\end{tabular}

- Laser1: Experimentos usando o primeiro laser - Esse laser ao longo do tempo de apresentou instabilidades na forma espacial do feixe e na precisão da geração de pulsos com mesma energia. 
- Melhor estatística (m. est.): Para lidar com a alta instabilidade inerente ao laser foi utilizado outro procedimento experimental que mede a energia individual de cada irradiação. Esse método automatizado de aquisição de medidas possibilitou melhor confiabilidade estatística mesmo com grandes flutuações na energia do laser,

- Laser 2: Experimentos usando o laser novo (laser 2 - com melhor confiabilidade dos parâmetros).

As medidas feitas com a técnica da regressão do diâmetro puderam ser comparadas e validadas com valores da literatura para sílica, BK7 e Safira. No caso da amostra "Suprasil 3" o valor encontrado foi de $(4,53 \pm 0,63) \mathrm{J} / \mathrm{cm}^{2}$ para $100 \mathrm{fs}$ e é compatível com os resultados encontrados nas referência [110] de $4 \mathrm{~J} / \mathrm{cm}^{2}$ e na

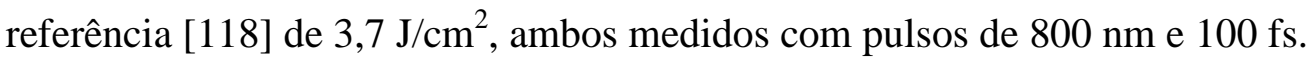

Os valores encontrados nas amostras de BK7-A3 $(4,51 \pm 0,81) \mathrm{J} / \mathrm{cm}^{2}$, A4 $(4,602 \pm 0,014) \mathrm{J} / \mathrm{cm}^{2}$ e A6 $(4,71 \pm 0,21) \mathrm{J} / \mathrm{cm}^{2}$ tiveram repetibilidade. Porém, o único experimento encontrado na literatura para o limiar de ablação no BK7 foi para pulsos de

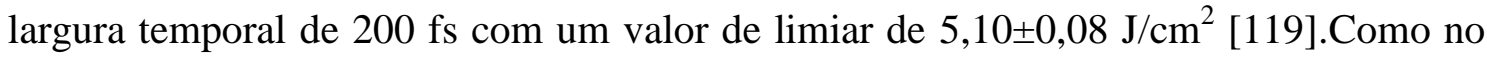
presente trabalho o a largura temporal foi de 100 fs, espera-se que o limiar de ablação seja também menor (veja simulação no capítulo 4).

O limiar de ablação da safira medido para pulsos de 55 fs foi de $(5,59 \pm 0,52)$ $\mathrm{J} / \mathrm{cm}^{2}$. Este valor é compatível com o resultado encontrado na literatura em safira monocristalina irradiada com pulsos de $45 \mathrm{fs}$ e $800 \mathrm{~nm}$ que é de $4,5 \mathrm{~J} / \mathrm{cm}^{2}$ [120].

No caso do "Suprasil 1" o valor encontrado para limiar de ablação foi excepcionalmente menor $\left(2,69 \mathrm{~J} / \mathrm{cm}^{2}\right)$ e poderia ser explicado pela flutuação do laser1 e o grande desvio padrão das medidas dos diâmetros para o ajuste do gráfico da Figura 7.3. No "Suprasil 2" um valor superestimado foi encontrado de $6,894 \pm 0,013 \mathrm{~J} / \mathrm{cm}^{2}$. Nesse caso, outros parâmetros além da energia podem ter flutuado como, por exemplo, a largura temporal do laser e a forma espacial do feixe, que seriam responsáveis pelo aumento do limiar de dano.

As medidas dos limiares de ablação para pulsos únicos na safira e no Ti:Safira mostraram uma diferença significativa em seus valores. Esta diferença foi discutida e atribuída à banda de absorção do Ti:Safira que diminui a ordem do processo 
de absorção para geração de elétrons livres na banda de condução, diminuindo o limiar de ablação.

Na safira e no Ti:safira, foram observados dois regimes de ablação, um de baixa e outro de alta fluência. Diferentemente, na sílica e no BK7 os dois regimes não puderam ser observados. A explicação dada para essa diferença se deve ao tempo de relaxação elétron-fônon e a difusividade térmica serem muito menores no BK7 e no Suprasil, o que não permite a diferenciação entre os dois regimes neste intervalo de fluências.

A definição do limiar de ablação de alta fluência não é a mesma que o de baixa fluência, visto que ele não depende somente da fluência do feixe da superfície e das características do material, mas depende da difusão térmica no material e da influência térmica do plasma. O regime de alta fluência serve então para mostrar que a partir de certa fluência, o efeito térmico não é bem localizado, e a ablação pode ter influências espaciais para além da distribuição espacial do laser, diferentemente do modelo simplista de quantificação da densidade eletrônica permitido pelo uso de pulsos ultracurtos. Mostrando que mesmo para pulsos ultracurtos existe a possibilidade de zona afetada pelo calor.

Partes dos objetivos propostos foram cumpridas nesse capitulo. A técnica de regressão do diâmetro pôde ser testada e validada em diferentes materiais. Seus valores foram comparados com os encontrados na literatura e foi confirmada a reprodutibilidade e repetibilidade do procedimento realizado nesse trabalho com a técnica da regressão do diâmetro. Isso permitiu utilizar essa técnica para as medidas do limiar de ablação de pulsos sobrepostos para a comparação do método D-scan. 


\section{Medida do limiar de dano para pulsos sobrepostos.}

A quantificação da sobreposição $N$ na varredura de $D$-scan feita nesse trabalho possibilitou a comparação dos dados de limiar de ablação obtidos com o $D$ scan e com o modelo tradicional (TRD). Nesse sentido, a hipótese central desse trabalho que propõe equivalência dos dois métodos pôde ser testada.

A fim de verificar a equivalência das técnicas, medidas do limiar de ablação com pulsos sobrepostos usando a técnica tradicional (TRD) e medidas de $D$-scan para diferentes sobreposições foram realizadas em BK7, Suprasil e Safira.

\subsection{BK7}

As medidas dos limiares de ablação para diferentes sobreposições, feitas com a técnica TRD, utilizaram o mesmo procedimento usado para pulsos únicos. Neste caso, contudo, $N$ pulsos foram sobrepostos. Outro detalhe, é que a correção da fluência pelo coeficiente angular do gráfico $\left(2 \mathrm{w}_{0}{ }^{2}\right)$ só foi feita para sobreposições de até 2 pulsos; esse mesmo valor de correção foi utilizado nos outros ajustes com maior sobreposição. Esse procedimento é justificado, pois, a correção do raio do feixe na superfície da amostra só pode ser realizada quando não existe zona afetada pelo calor (1 ou 2 pulsos no máximo). Isto não ocorre quando se tem pulsos sobrepostos, visto que o regime de alta fluência é predominante nesses casos [117], e o raio acabaria sendo superestimado. Esse efeito pode ser visto na safira, Figura 8.1, que mostra regiões ablacionadas com pulsos de mesma energia, mas diferentes sobreposições: $\mathrm{N}=1,4$ e 16 pulsos. Na sobreposição com 4 pulsos é possível observar o aparecimento da região de explosão térmica no centro do dano; na sobreposição de 16 pulsos a ablação térmica é dominante e aparece em todo o sítio irradiado. 


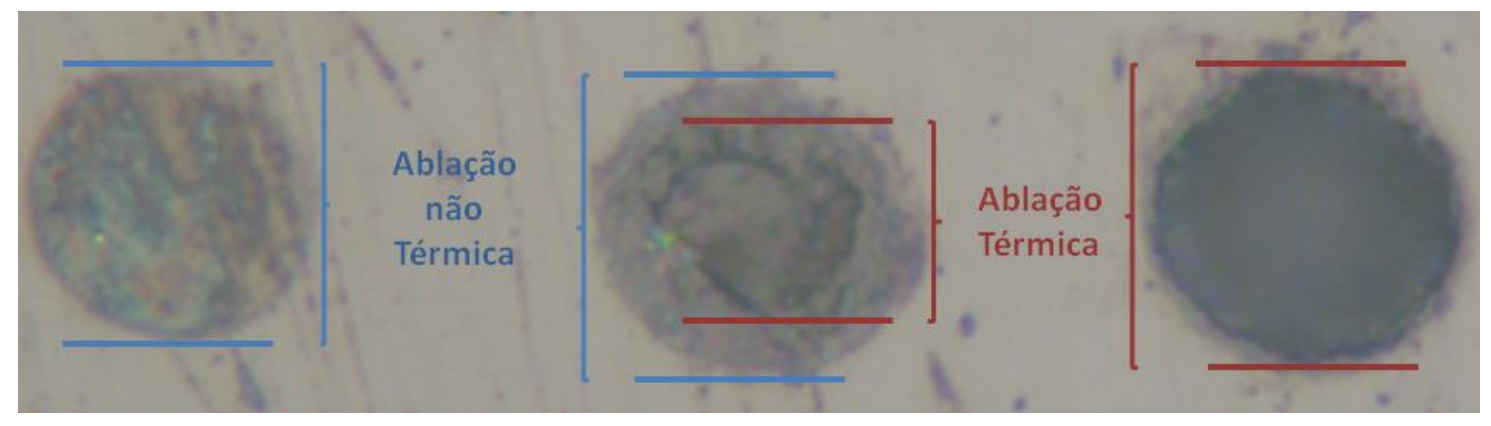

Figura 8.1 - Imagem de regiões ablacionadas com pulsos de mesma energia em safira. Sobreposição de 1, 4 e 16 pulsos, da esquerda para a direita. É possível observar a transição da ablação não térmica para uma ablação térmica

O aparecimento do regime de ablação térmica para pulsos sobrepostos é explicado pelo efeito de incubação que diminui o limiar de ablação por gerar mais elétrons livres, aumentando a absorção do laser Além disso causa um aumento da secção de choque elétron-fônon criada pelos centros de cor, o que aumenta taxa com que os elétrons relaxam e geram calor na rede [23].

Descrição do método Tradicional: As irradiações múltiplas foram realizadas usando um sistema automático de contagem de pulsos. O sistema de movimentação XY, comandado por CNC, o obturador e o detector foram acoplados a um mesmo computador. A taxa de repetição do laser foi reduzida para poucos Hertz $(1 \mathrm{~Hz}$ para sobreposições de 1 a 16 pulsos; $10 \mathrm{~Hz}$ para 32 e 128 pulsos; e $50 \mathrm{~Hz}$ entre 510 e 1020 pulsos) a fim de evitar erro na obturação de pulsos devido a uma possível falta de sincronia do obturador. Finalmente, um programa foi feito para gerar o conjunto de irradiações nas amostras como no exemplo da Figura 8.2.

Para uma mesma energia média, foi feito um conjunto de 6 pontos de dano para cada sobreposição. As sobreposições foram de 1, 2, 4, 16, 32, 120, 510, 1020 pulsos (linhas na Figura 8.2); matrizes com pontos como os da Figura 8.2 foram repetidas para diferentes energias. Para cada sobreposição foi ajustado um gráfico para o cálculo do limiar de dano como feito para pulsos únicos.

A Figura 8.3 mostra uma imagem de microscopia óptica da zona afetada no BK7 com sobreposição de 510 pulsos (linha 1) e 1020 pulsos (linha 2). 


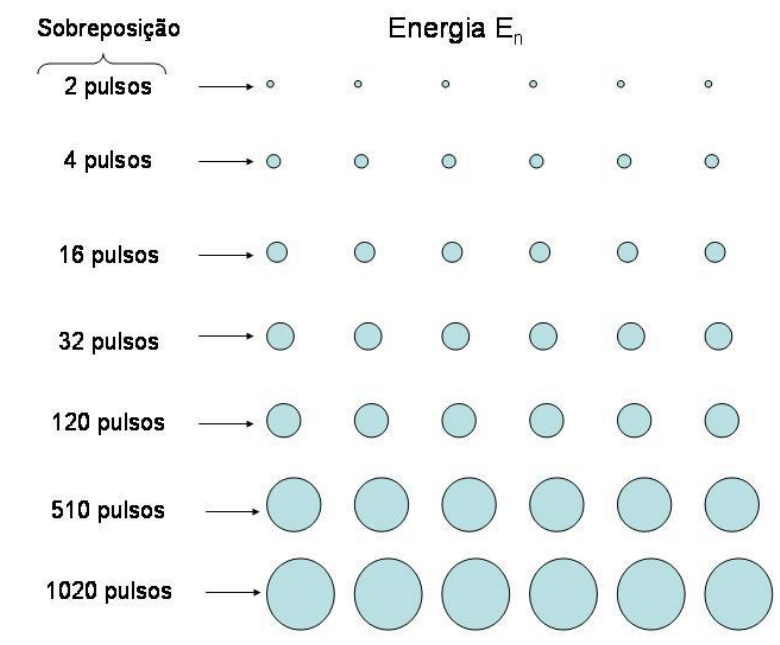

Figura 8.2 - Matriz de pontos com mesma energia variando a sobreposição (linhas) cada linha contem 6 elementos repedidos com mesma sobreposição.

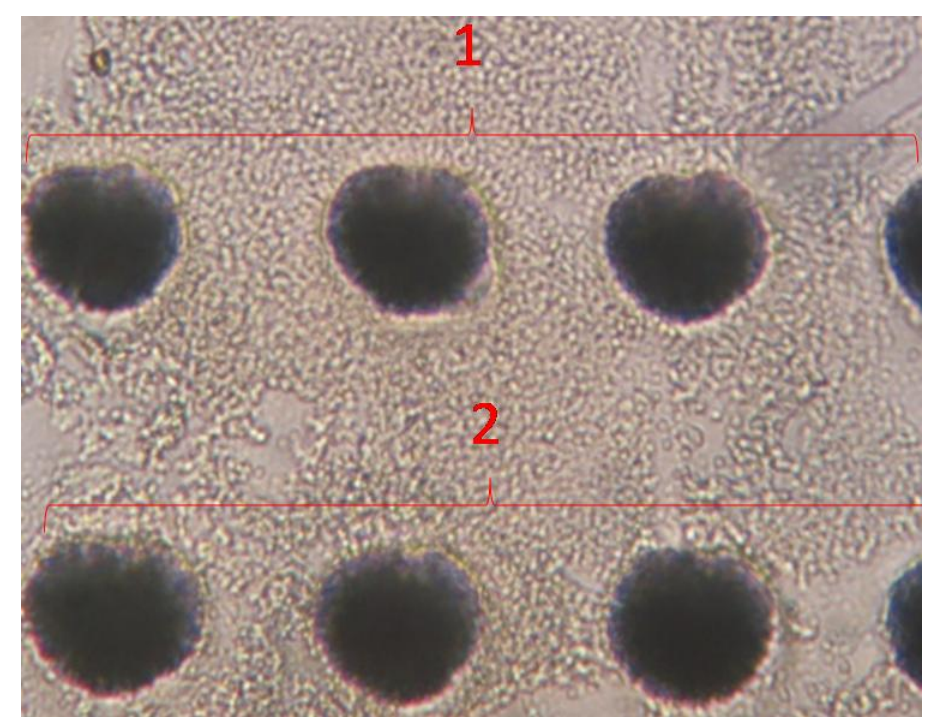

Figura 8.3 - Imagem de microscopia óptica da zona afetada no BK7 com sobreposição de 510 pulsos (linha 1) e 1020 pulsos (linha 2).

A Figura 8.4 mostra um ajuste para o cálculo do limiar de ablação para 510 pulsos no BK7. Foram feitos também ajustes gráficos com a TRD para todas as outras sobreposições no BK7, no Suprasil e na safira. Os resultados de limiar de ablação para pulsos sobrepostos serão apresentados juntamente com os resultados medidos com a técnica de $D$-scan. 


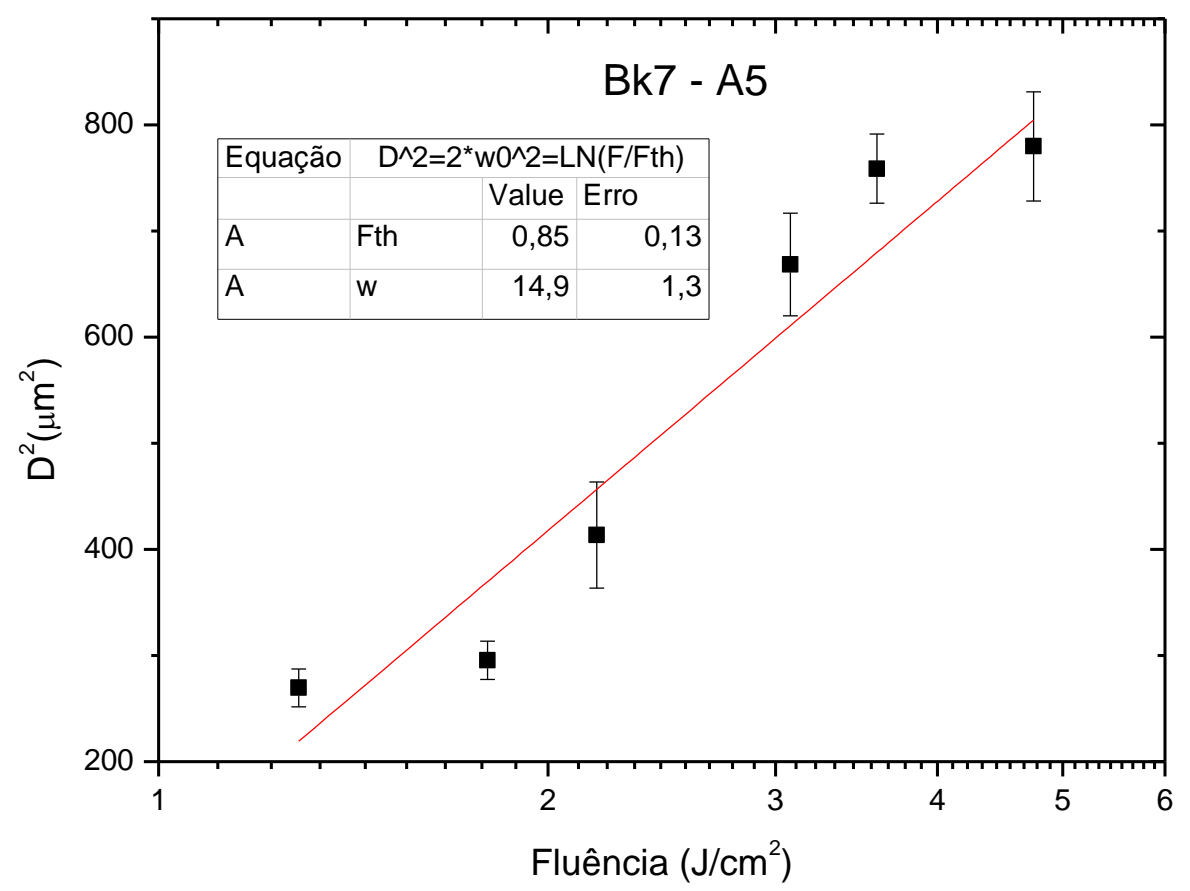

Figura 8.4 - Limiar de ablação para sobreposição de 520 pulsos em BK7.

D-scan: Para realização do experimento com a técnica de D-Scan no BK7, amostras semelhantes às utilizadas nos outros experimentos foram usadas. O laser foi focalizado com a mesma lente de $38 \mathrm{~mm}$. Três energias de pulso foram escolhidas para a ablação das amostras: 134, 71 e $31 \mu \mathrm{J}$. Para cada energia 9 diferentes velocidades de deslocamento no eixo $y(6,12,25,50$ e $100 \mathrm{~mm} / \mathrm{min}$ ) foram utilizadas (secção 5.2), assim como várias taxas de repetição do laser $f(50,100,500,1000,2000 \mathrm{~Hz})$. A razão $v_{y} / v_{z}$ foi mantida constante para produzir perfis de ablação com o mesmo comprimento. Algumas combinações de $f$ e $v_{y}$ resultaram em sobreposições fracionadas. O valor de $\rho_{\max }$ usado foi a média da medida de duas varreduras de $D$-scan irradiadas com os mesmos parâmetros. A incerteza na medida de $\rho_{\max }$ foi estimada a partir da região irregular na borda das varreduras. Além disso, a teoria prevê que o perfil ablacionado deve ser simétrico [27], mas assimetrias são claramente vistas na Figura 8.5. Isso ocorreu porque a parte esquerda do perfil foi ablacionada quando a amostra estava localizada antes da cintura do feixe, onde o plasma é formado no ar. Esse plasma distorce a frente de onda do feixe, modificando-o, o que resulta em um perfil assimétrico. Por essa razão, $\rho_{\max }$ foi medido à esquerda do traço, e o valor do limiar de 
ablação, $F_{t h}$, foi calculado usando a Eq. 46. A Figura 8.5 mostra duas micrografias dos perfis ablacionados por diferentes sobreposições nas quais as medidas foram feitas. $\mathrm{O}$ software Mathematica foi usado para calcular os valores das sobreposições $N$ usando a função Teta de Jacobi, Eq. 55.

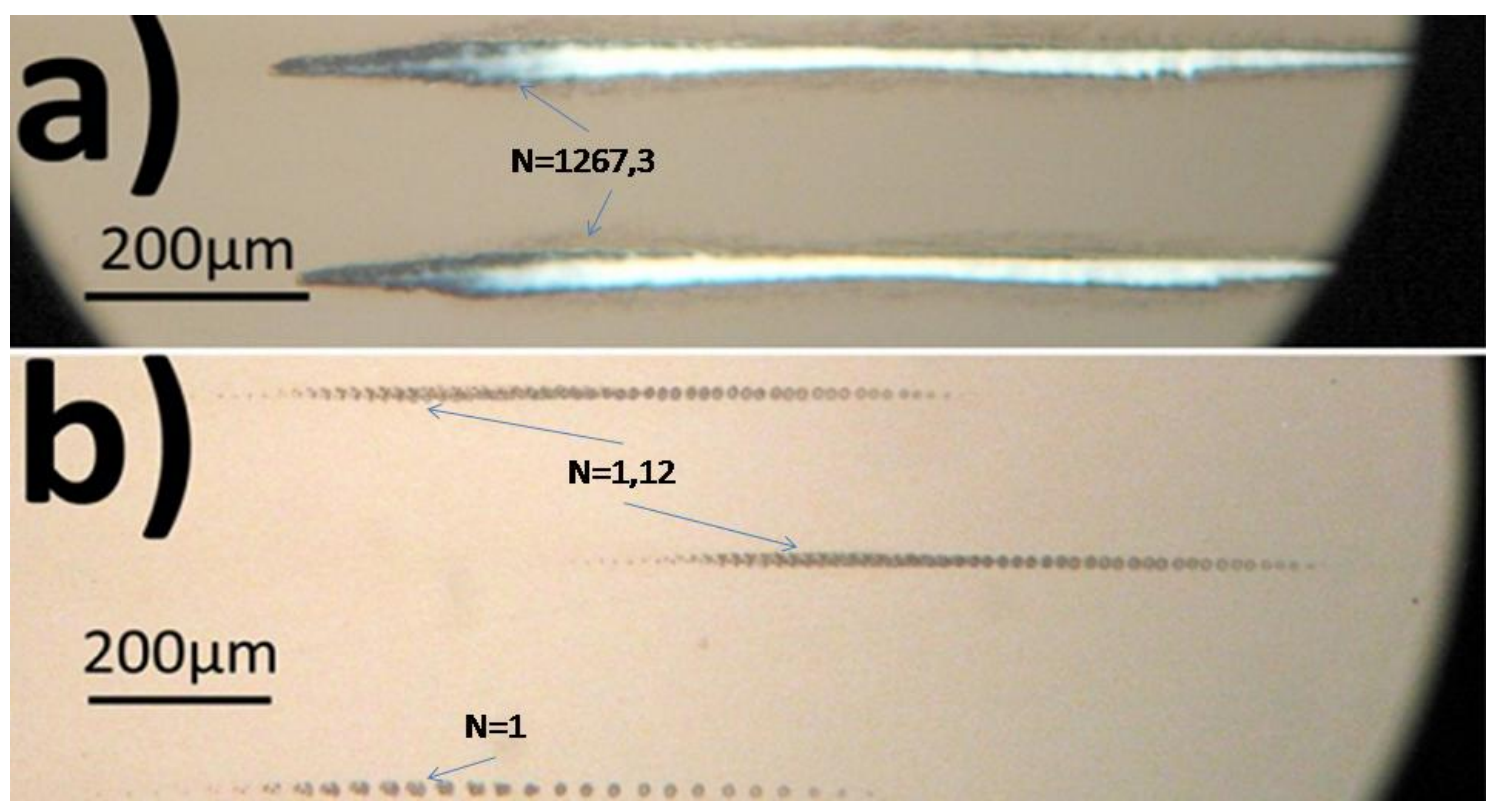

Figura 8.5 - Micrografias de amostras ablacionadas pelo método D-scan. a) 1267.3 pulsos sobrepostos para $E_{0}=71 \mu \mathrm{J}$. b) para $E_{0}=31 \mu \mathrm{J}$, os perfis superiores representam a sobreposição de 1.12 pulsos, e o perfil mais baixo é um perfil para pulsos únicos.

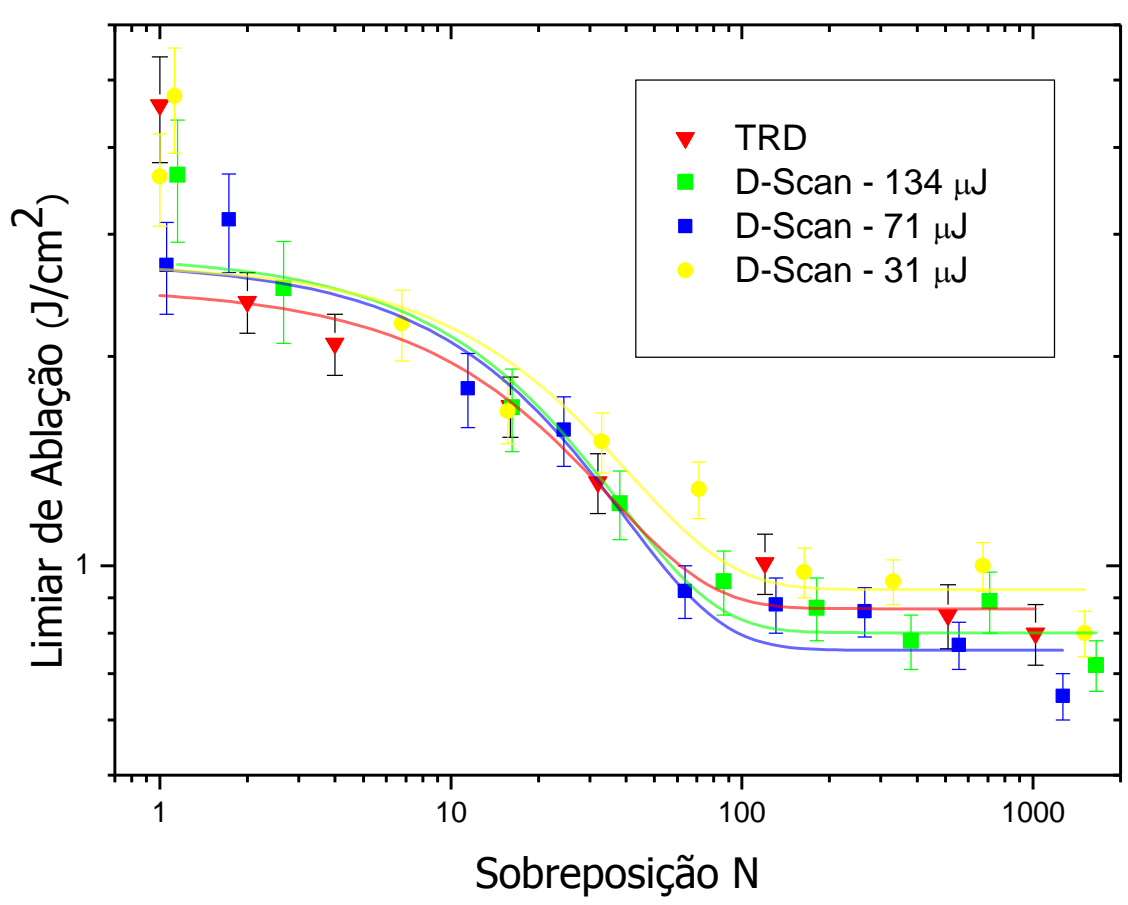


Figura 8.6 - Medidas do limiar da ablação do BK7 em função da sobreposição de pulsos usando a TRD e o $D$-scan com diferentes energias de pulso.

A Figura 8.6 mostra a comparação entre os dois métodos, com a mesma largura temporal de 100 fs sendo usada pelas duas técnicas. É possível observar uma grande concordância entre os métodos $D$-scan e TRD. Da mesma maneira, os ajustes do modelo de incubação da EEq. 19 (linhas coloridas no gráfico da Figura 8.6) em todos os dados experimentais apresentam uma ótima compatibilidade com os dados experimentais (Tabela 4). O perfil de diminuição do limiar de ablação em função da sobreposição de pulsos e uma saturação de defeitos mostra uma estabilização na diminuição do limiar. Além disso, os valores para pulsos com sobreposição maior que 1500 pulsos chegam a ser 7 vezes menores que o valor para pulso único. Esse comportamento é compatível com o modelo teórico do parâmetro de incubação [23] apresentado no capítulo 3.4 .

Estes resultados demonstram que a sobreposição definida nesse trabalho é equivalente à tradicional na qual os pulsos se sobrepõem totalmente. Esses resultados comfirmam a hipótese principal desse trabalho no caso do BK7.

Tabela 4 - Limiar de ablação para um pulso único, parâmetro de incubação e limiar de saturação calculado pelo modelo de incubação exponencial (100 fs).

\begin{tabular}{cccc}
\hline Método & $\mathbf{F}_{\text {th }, \mathbf{1}}\left(\mathbf{J} / \mathbf{c m}^{2}\right)$ & $\mathbf{k}$ & $\mathbf{F}_{\text {th, }}\left(\mathbf{J} / \mathbf{c m}^{2}\right)$ \\
\hline TRD & $2,44 \pm 0,25$ & $0,040 \pm 0,014$ & $0,867 \pm 0,075$ \\
\hline D-scan - 134 $\boldsymbol{\mu J}$ & $2,72 \pm 0,36$ & $0,040 \pm 0,010$ & $0,80 \pm 0,037$ \\
\hline D-scan-71 $\boldsymbol{\mu J}$ & $2,66 \pm 0,35$ & $0,039 \pm 0,010$ & $0,755 \pm 0,042$ \\
D-scan-31 $\boldsymbol{\mu J}$ & $2,66 \pm 0,45$ & $0,034 \pm 0,015$ & $0,923 \pm 0,015$ \\
\hline
\end{tabular}

As imagens da Figura 8.7 mostram a microscopia óptica dos perfis de $D$ scan irradiados com alta sobreposição e diferentes energias. Cada traço foi fotografado 
lateralmente e paralelamente à superfície da amostra. Assim foi possível observar a profundidade de ablação em cada região do traço. Foi possível notar que a região ablacionada mais profunda se localiza onde o foco do laser está abaixo da superfície do vidro. Isso mostra a importância da posição do foco na taxa de remoção de material e deve ser levado em conta nos experimentos de micro usinagem dos microcanais.

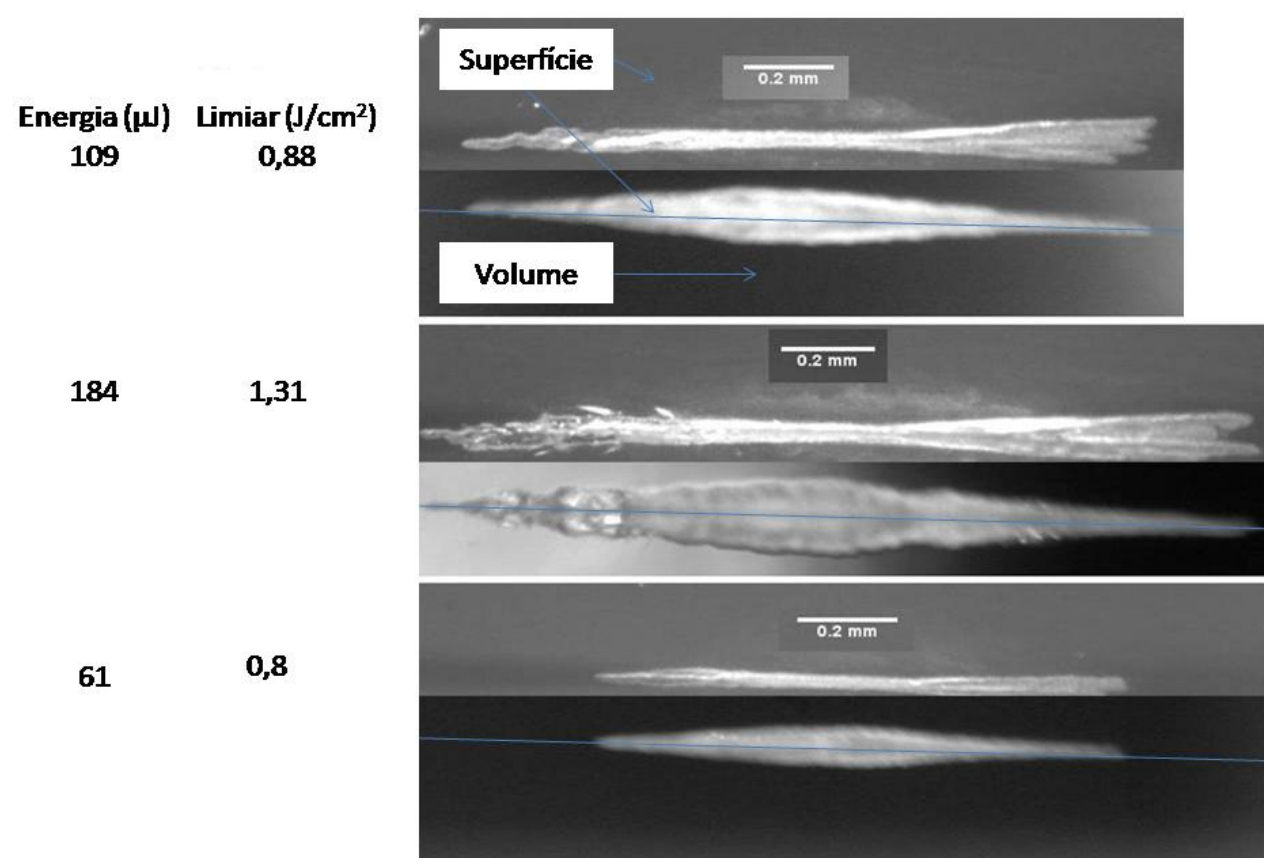

Figura 8.7 - Micrografia dos traços irradiados com o método D-scan. Vista da superfície (figuras de cima) e visão lateral (figuras de baixo).

\subsection{Suprasil e Safira}

No uso da técnica do D-scan tanto no Suprasil como na safira, diferentes velocidades de varredura foram utilizadas para diferentes sobreposições, e foi definida a velocidade transversal como sendo o dobro da velocidade longitudinal $\left(v_{x}=2 v_{z}\right)$. Essa última condição foi necessária para permitir o uso da aproximação feita pelo modelo descrito na secção 5.2 para garantir uma marcação de $D$-scan alongada. O procedimento para calcular o valor de limiar $F_{t h}$, e a sobreposição $N$ com o método $D$-scan tanto na safira quanto no Suprasil foi o mesmo que o usado no BK7 explicado no capítulo 5.2.

Suprasil: No Suprasil com na técnica TRD foi utilizada lente de $38 \mathrm{~mm}$ e largura temporal de $55 \mathrm{fs}$, e no procedimento com o $D$-scan foram usadas energias por pulso de aproximadamente $94 \mu \mathrm{J}$, lente de focalização de $50 \mathrm{~mm}$ e largura temporal de 25 fs. 
Safira: No uso da técnica TRD na safira foi utilizada a lente de $38 \mathrm{~mm}$ e largura temporal de 35 fs. No procedimento com o $D$-scan, a lente de focalização e a largura temporal dos pulsos foram as mesmas utilizadas no Suprasil, $50 \mathrm{~mm}$ e $25 \mathrm{fs}$ respectivamente. Porém a energia por pulso foi de $126 \mu \mathrm{J}$.

A diferença entre os principais parâmetros nas duas técnicas são resumidas na Tabela 5 .

Tabela 5 - Principais parâmetros entre os dois métodos

\begin{tabular}{lcccc}
\hline & \multicolumn{2}{c}{ D-scan } & \multicolumn{2}{c}{ TRD } \\
\hline Material & Lente (mm) & L. Temporal (fs) & Lente (mm) & L. Temporal (fs) \\
Suprasil & 50 & 25 & 38 & 55 \\
Safira & 50 & 25 & 38 & 35 \\
\hline
\end{tabular}

Na Figura 8.8 e Figura 8.9 são mostradas as medidas do limiar de dano do Suprasil e da safira monocristalina, respectivamente, em função da sobreposição usando as duas técnicas.

No Suprasil, os parâmetros obtidos pelos ajustes da EEq. 19 não apresentaram diferenças estatísticas no valor do parâmetro de incubação e no limiar de ablação para pulsos únicos (veja Figura 8.8). Porém existe uma diferença significativa entre os valores de saturação do limiar de ablação obtidas pelas duas técnicas. 


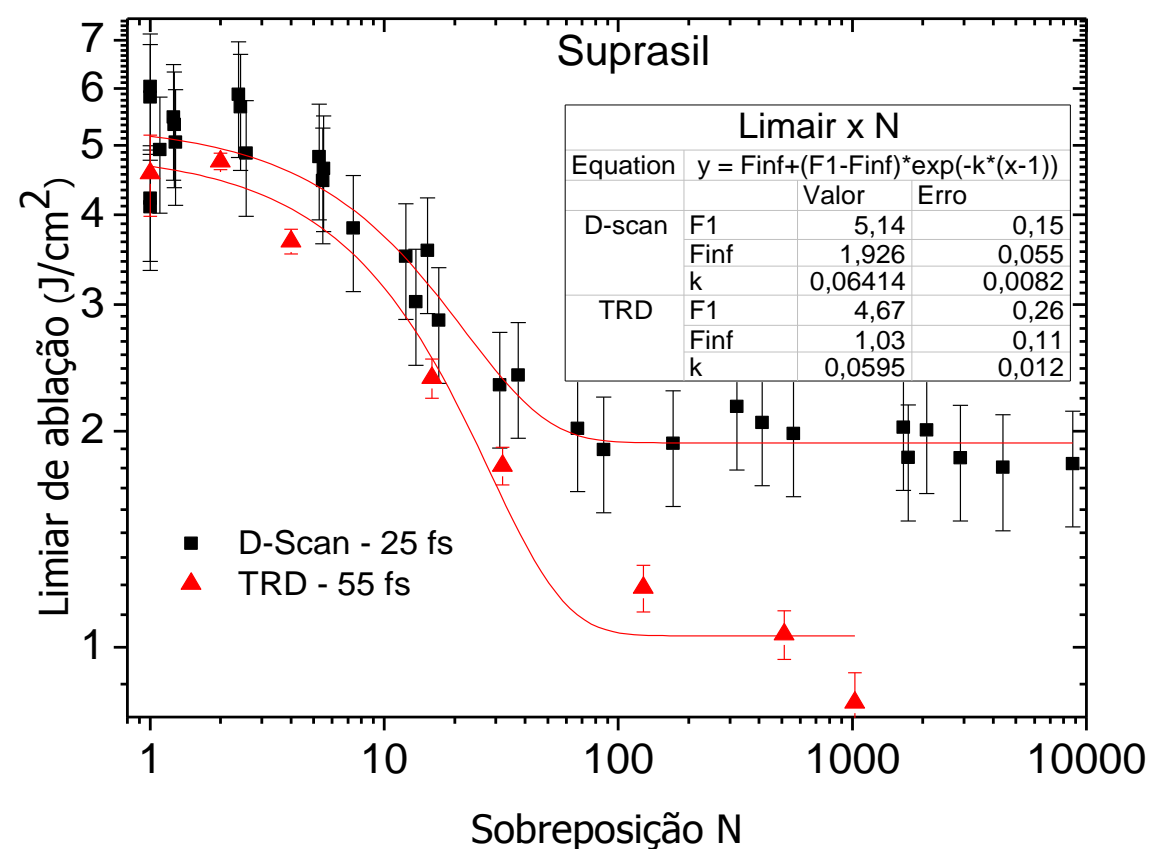

Figura 8.8 - Limiar de ablação do Suprasil em função da sobreposição para Suprasil comparação entre os dois métodos.

Na safira, Figura 8.9, é encontrada uma diferença menos significativa nos valores de limiar de ablação saturados, e pode-se dizer que os resultados foram compatíveis dentro do erro experimental.

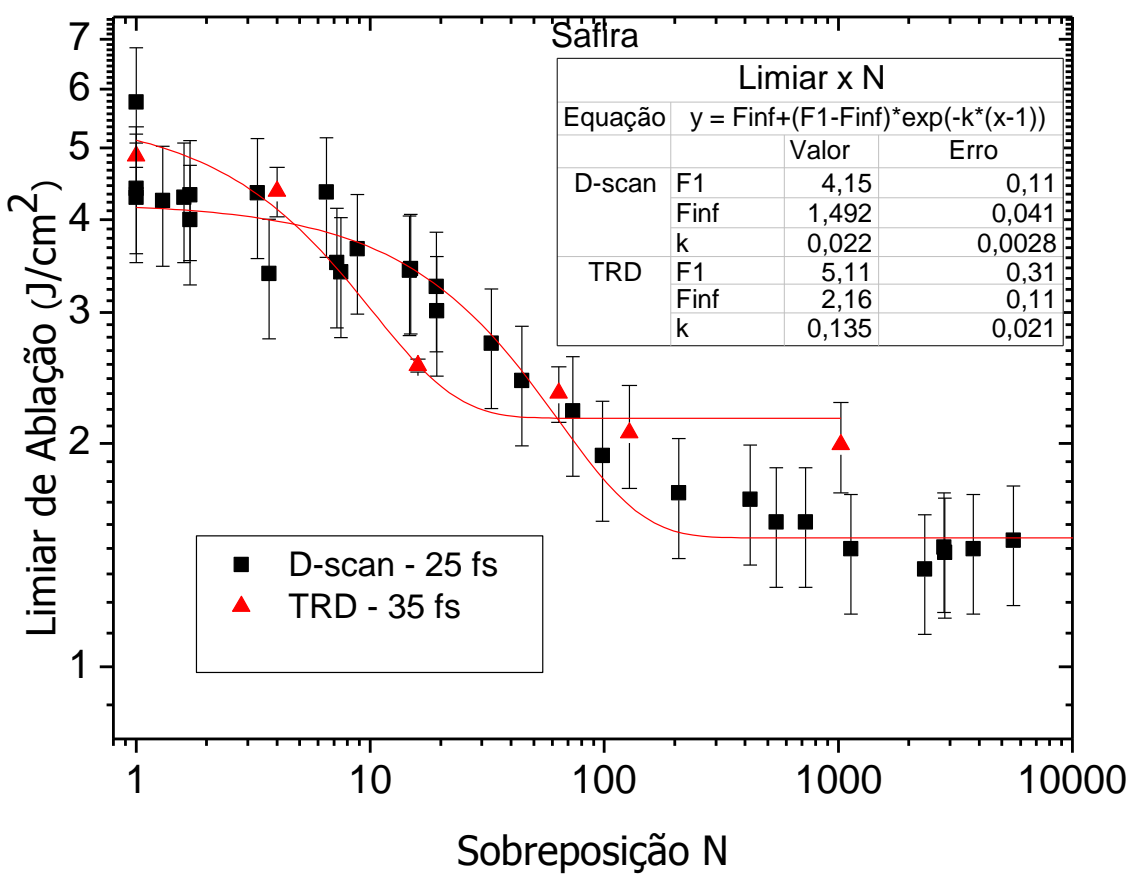

Figura 8.9-Limiar de ablação da Safira em função da sobreposição - comparação entre os dois métodos. 
Com base nos resultados e na confiabilidade dos mesmos, duas hipóteses são levantadas para explicar a diferença entre as duas técnicas encontrada no caso do Suprasil.

A primeira hipótese afirma que os dois métodos são equivalentes, e apenas a diferença na largura temporal utilizada nos dois métodos, 25 e 55 fs, é o motivo da diferença. O fato da largura dos pulsos na técnica TRD ser duas vezes maior que no método com o D-scan, pode resultar em um efeito mais eficiente na produção de elétrons pelo processo de avalanche. Este efeito seria significante apenas quando se tem linhas de absorção interbandas devido aos defeitos, o que teria um efeito de mudança no limiar de dano apenas para pulsos com maior sobreposição. Mas não explicaria por que os valores são próximos em baixas sobreposições.

A segunda hipótese considera que a diferença dos limiares entre os dois métodos para pulsos com alta sobreposição se deve ao efeito colateral térmico, devido à diferente distribuição espacial da energia entre os métodos. Ou seja, com a técnica TRD, o feixe tem sempre uma distribuição espacial fixa devido ao procedimento que fixa a posição da cintura do feixe na superfície da amostra. Isso faz com que o gradiente de fluência entre o centro do feixe e a região medida seja maior que no $D$-scan. Isso provoca no caso da TRD um regime de alta fluência com zona afetada pelo calor, subestimando o limiar de ablação para pulsos sobrepostos.

Para embasar essa hipótese deve-se calcular e comparar a distribuição de intensidades típicas usadas pelos dois métodos. Além disso, o gradiente de fluências ao longo da superfície na direção radial deve ser quantificado.

Define-se nesse trabalho, o gradiente de fluência na direção radial entre a borda do dano e o centro do feixe como sendo:

$$
\nabla \overrightarrow{\mathrm{F}}_{r}(\rho) \equiv \frac{F_{\text {pico }}-F_{t h}}{\rho} \mathbf{r}
$$

onde $F_{\text {pico }}$ é a fluência pico do centro do feixe e $F_{t h}$ é a fluência de limiar responsável pela ablação da borda do dano.

No caso da TRD a fluência no centro do feixe é igual à fluência pico dada pela Eq. 33, e a fluência medida na borda do dano é simplesmente $F_{t h}$ dada pela própria 
definição do método que diz que na região de medida do diâmetro do dano a fluência é igual à $F_{t h}$. A partir da Eq. 29:

$$
F_{t h}=F_{\text {pico }}(\rho) e^{\left(\frac{-2 \rho^{2}}{w^{2}}\right)}
$$

Logo,

$$
F_{\text {pico }}(\rho)=F_{t h} e^{\left(\frac{2 \rho^{2}}{w^{2}}\right)}
$$

Onde $\rho$ é a distância do centro à borda da região ablacionada e $w$ é o raio do feixe que é fixo na superfície da amostra na TRD.

Para calcular o gradiente de fluência no método $D$-scan, deve-se também calcular a fluência pico em função da distância da borda da região ablacionada. A partir da Eq. 46 tem-se que o limiar de ablação depende apenas da energia do pulso e da largura máxima de um traço de $D$-scan:

$$
F_{t h}=\frac{E_{0}}{e \pi \rho_{\max }^{2}}
$$

Usando o valor da fluência de pico,

$$
F_{\text {pico }}=\frac{2 E_{0}}{\pi w^{2}}
$$

A razão entre a fluência pico e a fluência de limiar vale:

$$
\frac{F_{\text {pico }}}{F_{t h}}=\frac{2 E_{0}}{\pi w^{2}} \frac{e \pi \rho_{\max }^{2}}{E_{0}}=\frac{2 e \rho_{\max }^{2}}{w^{2}}
$$

a partir da Eq. 52 sabe-se que na região da medida de $\rho_{\max }$ :

$$
w=\sqrt{2} \rho_{\max }
$$

Então, a razão entre a fluência de pico e a fluência de limiar entre qualquer varredura $D$-scan vale: 


$$
\frac{F_{p i c o}}{F_{t h}}=e
$$

A Figura 8.10 mostra uma comparação qualitativa das distribuições de fluência envolvidas entre os métodos TRD e D-Scan. É possível observar que para a realização das irradiações no método TRD, são necessárias várias irradiações com diferentes fluências de pico várias vezes maiores que o limiar de ablação do material para ser possível ajustar um gráfico de $D^{2}$ em função da fluência. Por outro lado, numa varredura $D$-scan, a fluência pico máxima atingida é sempre $\left(e \cdot F_{t h}\right)$ como visto na Eq. 66.

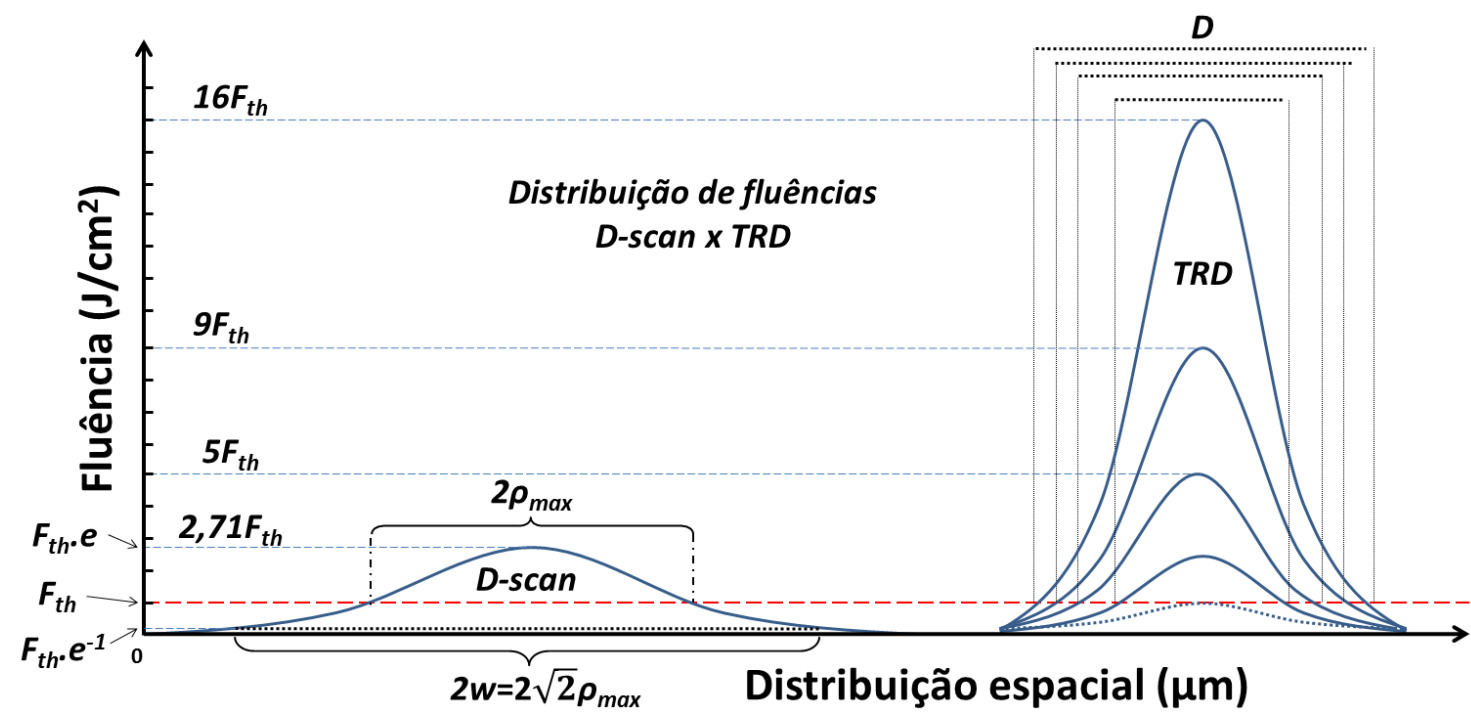

Figura 8.10 - Comparação entre o $D$-scan e o TRD da distribuição de fluências típicas para a medida do limiar de ablação. Cada traço no eixo $y$ equivale a $F_{t h}$.

A partir das Eq. 61, Eq. 59 e Eq. 66 é possível calcular o gradiente de fluências entre os dois métodos e as fluências pico em função da distância $\rho$ da borda da região ablacionada até o centro. $\mathrm{O}$ módulo do gradiente das fluências normalizado por $F_{\text {th }} \mathrm{em}$ função de $\rho$ nas técnicas TRD e $D$-scan, respectivamente, são:

$$
\frac{\left|\nabla \overrightarrow{\mathrm{F}}_{r}(\rho)_{T R D}\right|}{F_{t h}}=\frac{e^{\left(\frac{2 \rho^{2}}{w^{2}}\right)}-1}{\rho}
$$




$$
\frac{\left|\nabla \overrightarrow{\mathrm{F}}_{r}(\rho)_{D-s c a n}\right|}{F_{t h}}=\frac{e-1}{\rho}
$$

O gráfico da Figura 8.11 mostra uma comparação da fluência de pico e o gradiente de fluência em função da distância $\rho$ do centro à borda utilizada nos dois métodos. O raio utilizado para a simulação é $w=6 \mu m$, para ser compatível com os resultados obtidos por esse trabalho com a lente de $38 \mathrm{~mm}$. É possível observar que um aumento exponencial da fluência pico e do gradiente na TRD são necessários para aumentar a distância do diâmetro D (ou $2 \rho$ ) da região ablacionada. Por outro lado, as curvas do comportamento da fluência no $D$-scan mostram que a fluência pico é sempre constante, e com o aumento do tamanho de $\rho_{\max }$ (que depende de $E_{\text {pulso }}$ e $F_{t h}$ ) o gradiente de fluência é inversamente proporcional à distância $\rho_{\max }$.

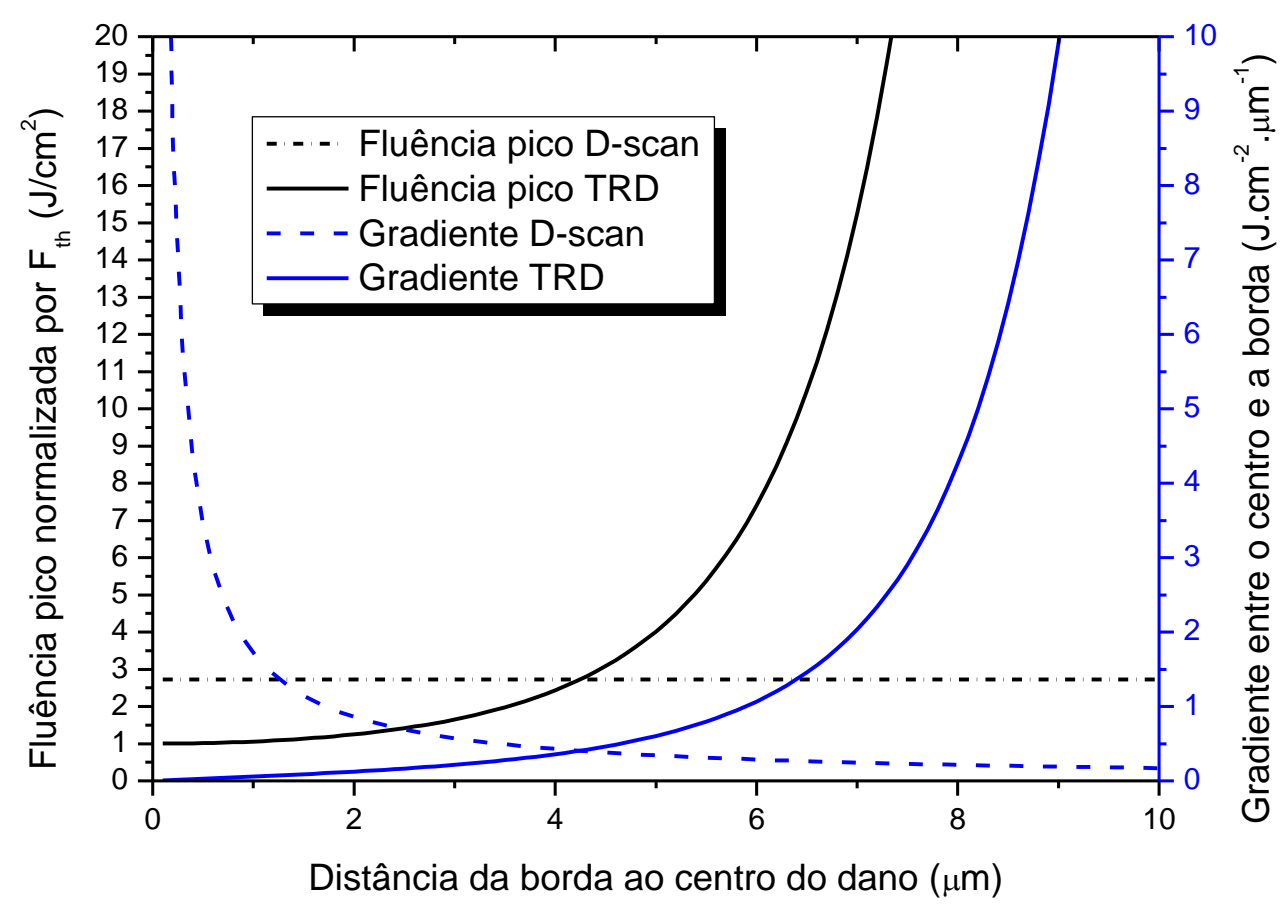

Figura 8.11 - Cálculo da fluência pico e do gradiente de fluência utilizada pelos métodos TRD e $D$-scan. Devido à característica intrínseca de cada método, o gradiente de fluência e a fluência pico são distintos em comportamento e valores em função do tamanho da distância $\rho$ entre a borda do dano e o centro do feixe.

Estas considerações podem ser usadas para embasar a hipótese de que no caso do Suprasil possa estar ocorrendo influência térmica da parte mais central do feixe na região onde se tem a ablação ou do plasma formado em regiões onde existe maior fluência. Ou seja, no caso com a TRD, o maior gradiente de fluência entre o centro e a 
borda pode estar ablacionando material mesmo com fluências abaixo do limiar de dano (regime de alta fluência). Nesse caso com o Suprasil, somente com grande sobreposição esse efeito térmico tem influência. No método $D$-scan o gradiente térmico é menor para marcações maiores que $4 \mu \mathrm{m}$ no caso da lente de $38 \mathrm{~mm}$ (o que foi atingido por todas as varreduras $D$-scan nesse trabalho).

A Figura 8.12 mostra imagens de MEV que evidenciam o efeito colateral devido ao alto gradiente de fluência. No caso do Suprasil é possível observar a formação de uma região quebradiça na borda dos danos. Essa região de borda onde o material foi arrancado provavelmente está abaixo do limiar de ablação do material para esses parâmetros. $\mathrm{O}$ efeito da ejeção de material de regiões centrais poderia contribuir para arrancar material na periferia e esse seria um efeito de "espalação" [66]. Portanto, esse efeito ocorre preferencialmente para pulsos com maior sobreposição apenas no Suprasil, a medida da marcação com um diâmetro superestimado poderia subestimar os valores do limiar de ablação para pulsos com maior sobreposição com a TRD somente no Suprasil.

Diferentemente, as Figura 8.13 e Figura 8.14 mostram o detalhe da borda de um traço de $D$-scan na safira. É possível observar a formação de "ripples"; isso mostra que o regime de ablação é não térmico e é caracterizado pelo efeito Coulomb na borda do traço $[43 ; 57]$. 


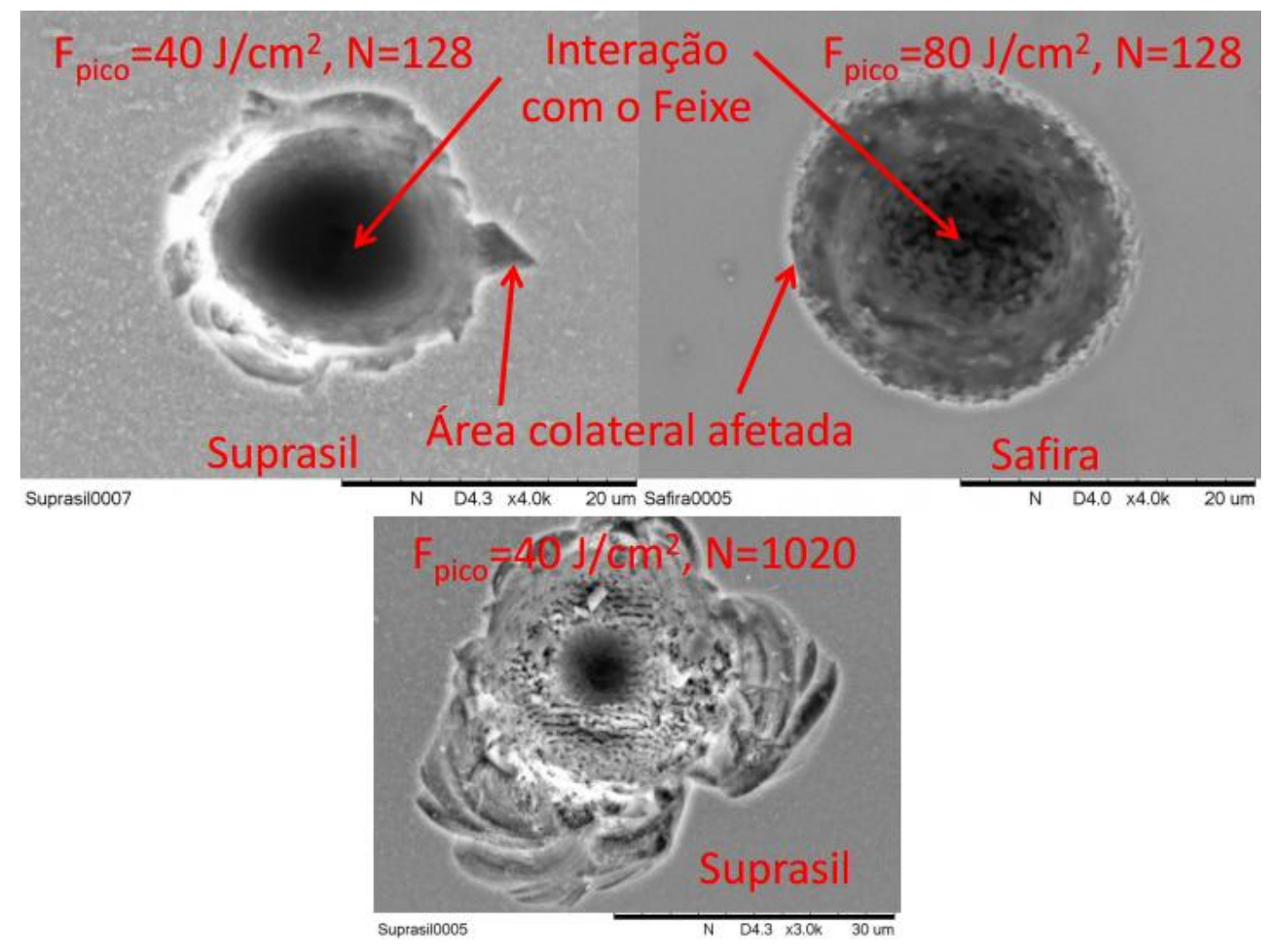

Figura 8.12 - Evidência de zona colateral afetada devido ao alto gradiente de fluências durante a irradiação para a TRD no Suprasil. Na safira não foi possível observar efeito colateral.

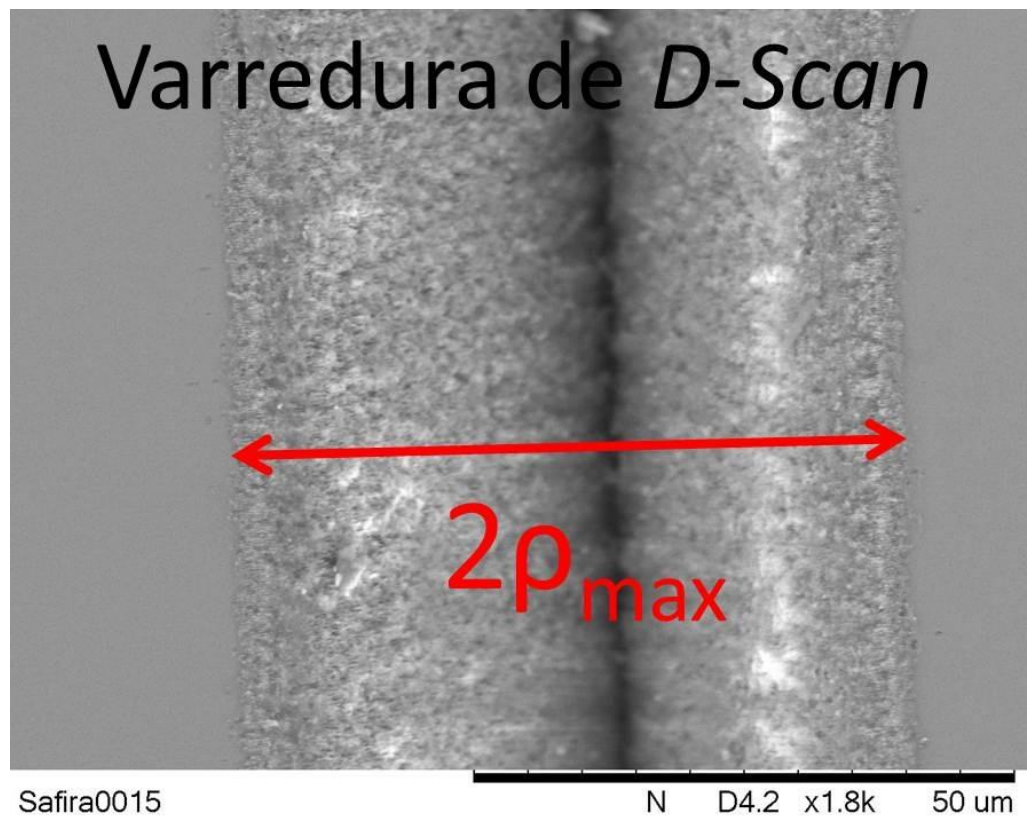

Figura 8.13 - Imagem de microscopia eletrônica de varredura da região onde é feita a medida de $\rho_{\max }$. 


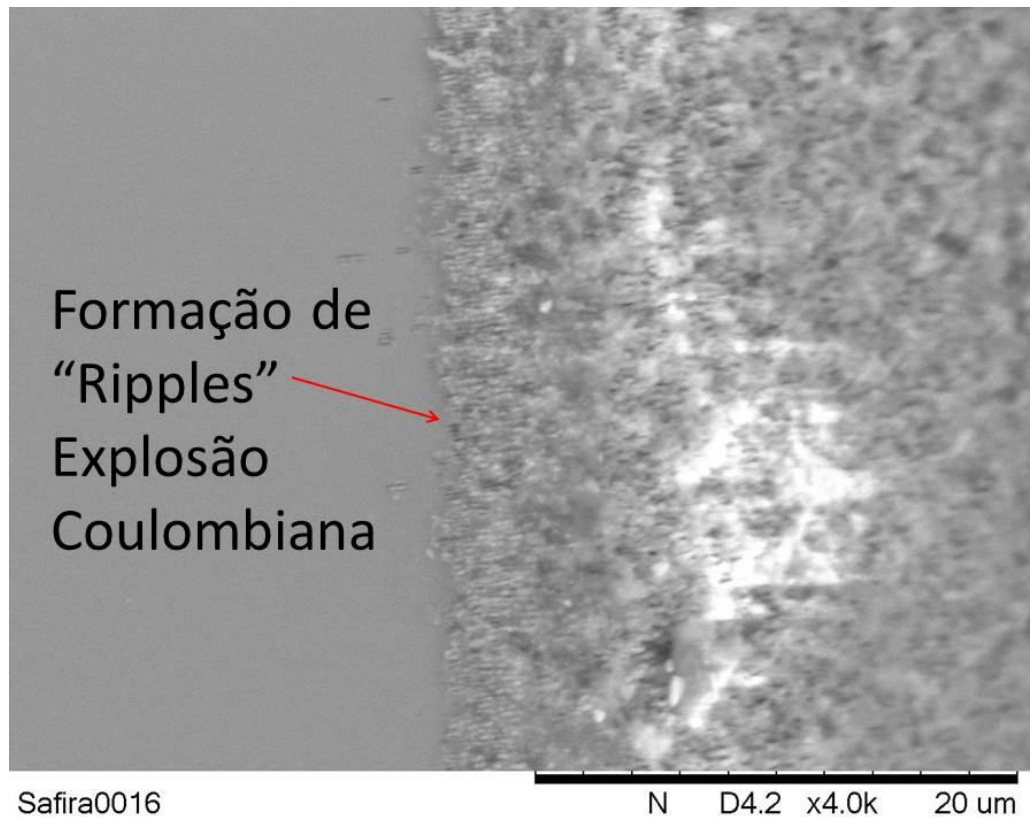

Figura 8.14 - Imagem de MEV mostrando o detalhe da borda de um traço de D-scan. É possível observar a presença de "ripples" na borda do traço sem trincas. Ou seja, explosão Coulombiana.

A partir da definição do gradiente de fluência radial mostra-se que a influência de um regime de alta fluência é pouco provável com o método $D$-scan. Por outro lado, o alto gradiente de fluências usado pela técnica TRD pode atrapalhar na medida do limiar de ablação por uma influência colateral à região central ablacionando material mesmo para fluências abaixo do limiar de ablação, subestimando-o para altas sobreposições. Nesse caso o método $D$-scan é mais adequado para calcular o limiar de ablação sem influências colaterais do feixe no Suprasil, independentemente da energia dos pulsos e da sobreposição.

O método $D$-scan mostra três características vantajosas em relação à TRD. Primeiramente, a varredura dos pulsos na medida do limiar de ablação é intrínseca ao $D$-scan, o que faz o processo de medida se aproximar de um processo de usinagem real no qual os pulsos não se sobrepõem totalmente e a varredura de pulsos é necessária. A segunda característica é o menor gradiente de fluências em relação a TRD, o que evita um dano ou térmico, ou devido ao plasma colateral, mascarando a região ablacionada de limiar. E por fim, é uma técnica mais rápida, simples que a TRD e não necessita de um arranjo experimental mais sofisticado para sua execução. Ou seja, apenas uma lente de focalização e um sistema de varredura com velocidade controlável. 


\subsection{Limiar de Ablação com a técnica $D$-scan em função da largura temporal dos pulsos}

A varredura $D$-scan foi utilizada para a medida do limiar de ablação do BK7 com diferentes larguras temporais de pulso.

$\mathrm{O}$ arranjo experimental é o mesmo utilizado nos experimentos anteriores com o Suprasil e a safira. Na Figura 8.15 são mostrados os traços de D-scan no BK7 para pulsos de 152 fs. É possível observar que a posição de $\rho_{\max }$ na Figura 8.15 varia de acordo com a sobreposição, mostrando o comportamento de incubação e a necessidade de quantificar a sobreposição de acordo com a Eq. 55 (Teta de Jacobi).

\section{D-Scan - Energia: $207 \mu \mathrm{J}-\mathrm{Bk} 7$}

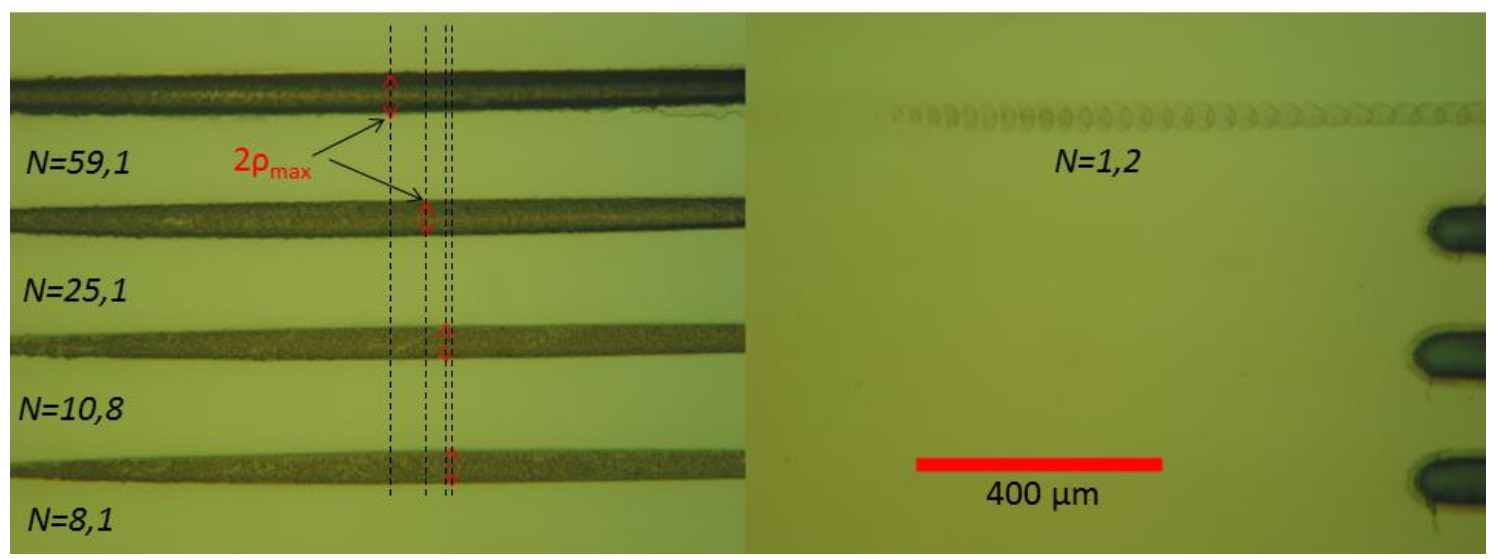

Figura 8.15 - Microscopia óptica dos traços de D-scan realizados com pulsos de 152 fs e energia de $207 \mu \mathrm{J}$. É possível observar as diferentes posições das medições de $\rho_{\max }$ para diferentes sobreposições.

Neste experimento a incerteza na medida da largura da marcação feita pelo $D$-scan foi de $6 \mu \mathrm{m}$. A lente de focalização utilizada foi de $50 \mathrm{~mm}$ de comprimento focal. Além disso, a largura temporal dos pulsos pôde ser controlada através da inserção dos prismas do compressor do feixe na saída do amplificador do laser. Através do ajuste do posicionamento das grades foi possível mudar a dispersão das fases das diferentes componentes espectrais do pulso. Isso permitiu que a largura temporal dos pulsos fosse ajustada de 25 a 150 fs. As larguras temporais foram medidas com a técnica FROG [121].

Para cada diferente largura temporal, foi feito um gráfico do limiar de ablação em função da sobreposição no BK7. Foram utilizadas 23 diferentes velocidades 
de varredura para cada largura temporal. Então, com ajuste da EEq. 19 foi possível obter os limiares de ablação de pulsos únicos, saturados e o parâmetro de incubação em função da largura temporal. As Figura 8.16 e Figura 8.17 mostram os limiares de ablação para pulsos de 22,8 fs e 144 fs. É possível observar a diferença nos valores ajustados pela função de incubação. $\mathrm{O}$ mesmo gráfico foi feito para 8 larguras temporais diferentes e a mesma função foi ajustada.

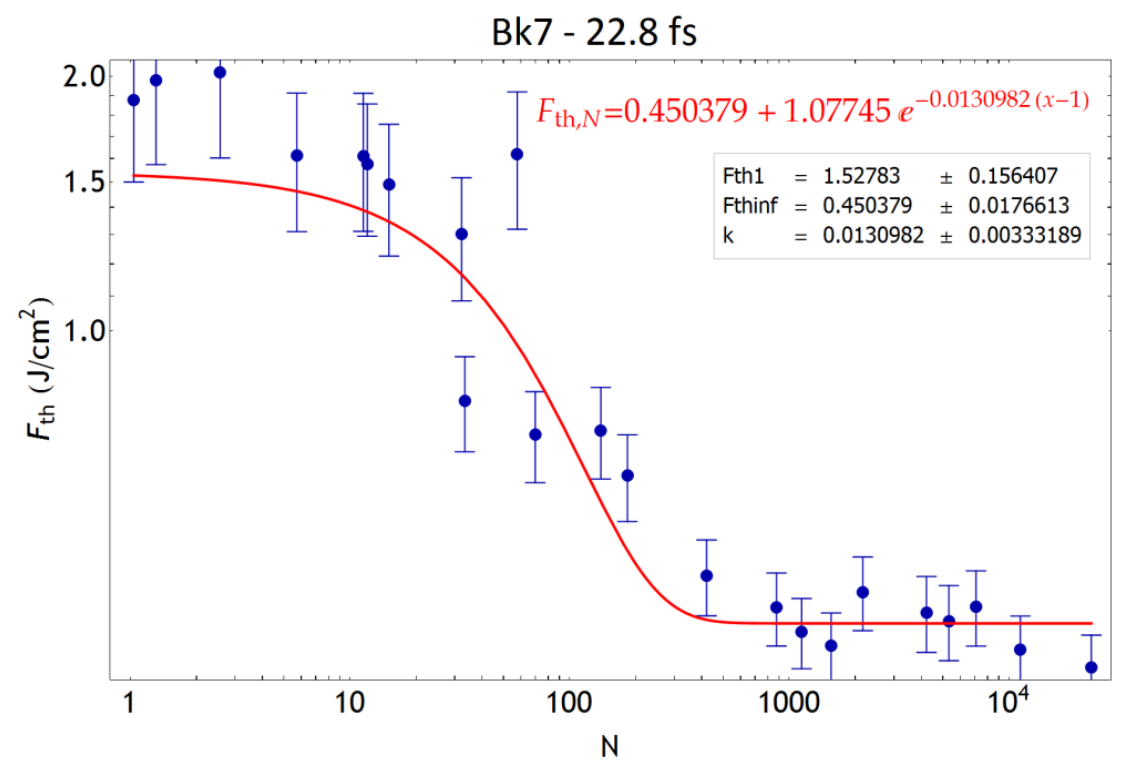

Figura 8.16 - Limiares de ablação em função da sobreposição obtida pelo método $D$ scan. BK7 - 22,8 fs.

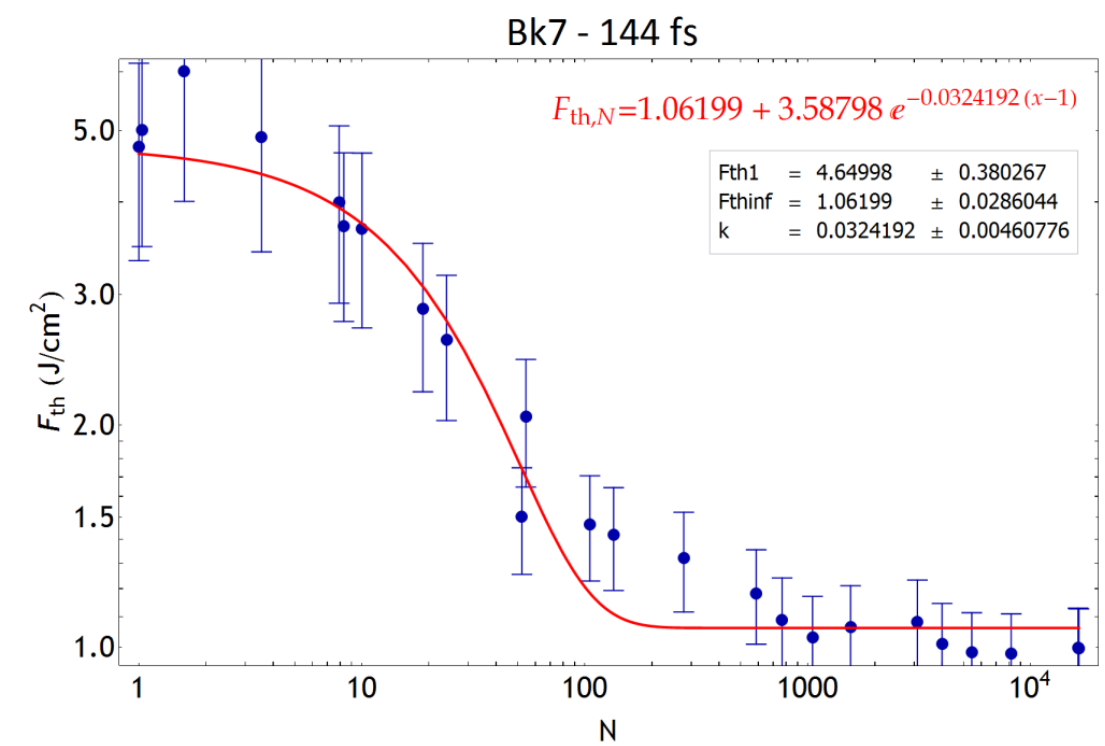

Figura 8.17 - Limiar de ablação em função da sobreposição obtida pelo método $D$-scan. BK7 - 144 fs. 
A seguir são apresentados os resultados dos ajustes das três grandezas em função da largura temporal em todas as larguras temporais medidas. No gráfico da Figura 8.18 além dos resultados experimentais é mostrada a simulação do limiar de ablação para pulsos únicos em função da largura temporal (detalhada no capítulo 4).

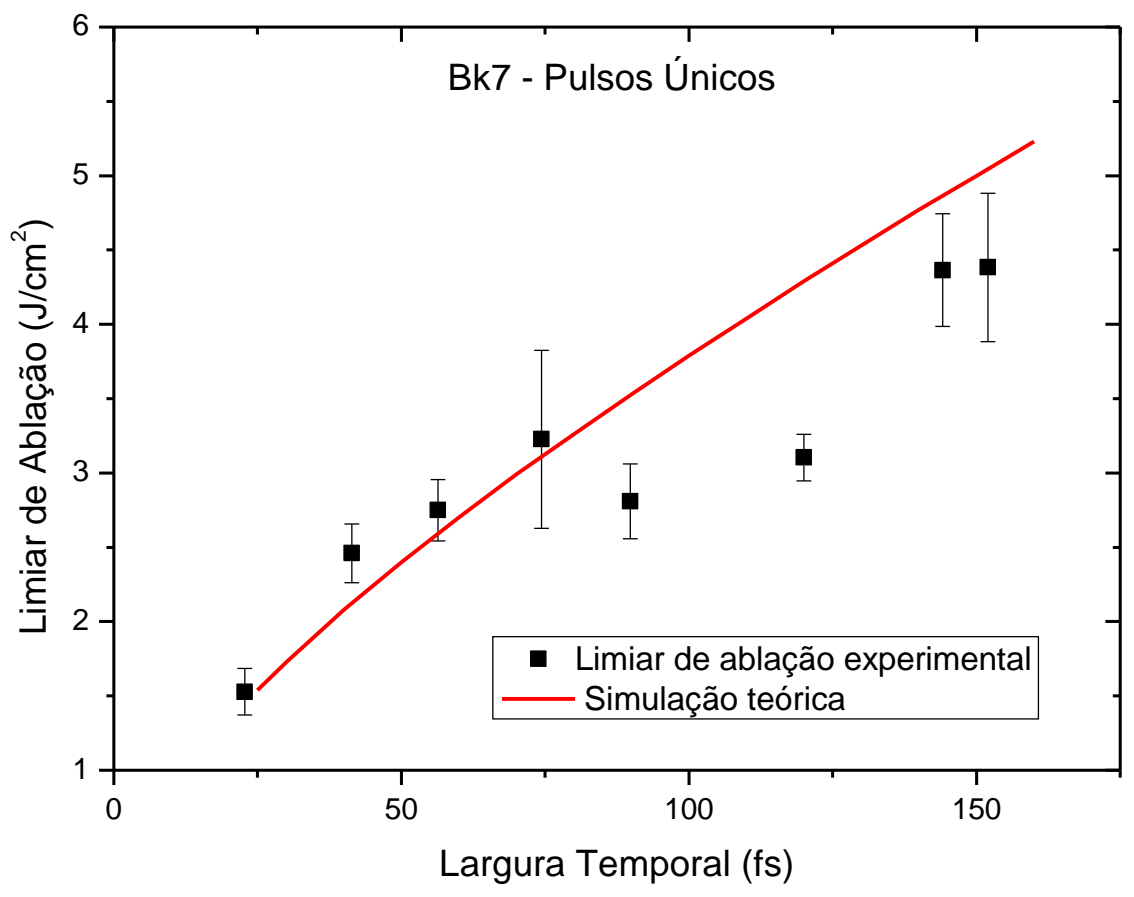

Figura 8.18 - Limiar de ablação para pulsos únicos obtidos através do ajuste da EEq. 19 dos valores de limiar de diversas medidas de D-scan e simulação do limiar de ablação no BK7. 


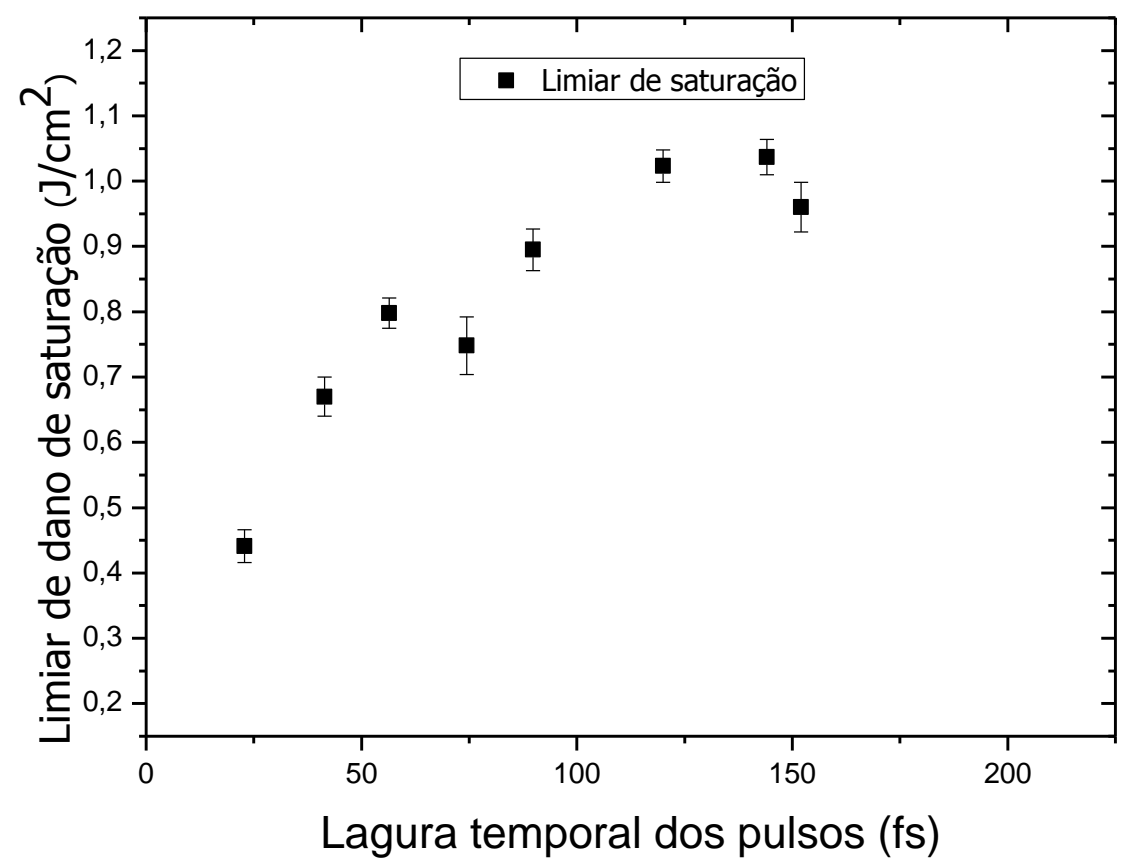

Figura 8.19 - Limiar de ablação de saturação obtidos através do ajuste da EEq. 19 dos valores de limiar de diversas medidas de D-scan.

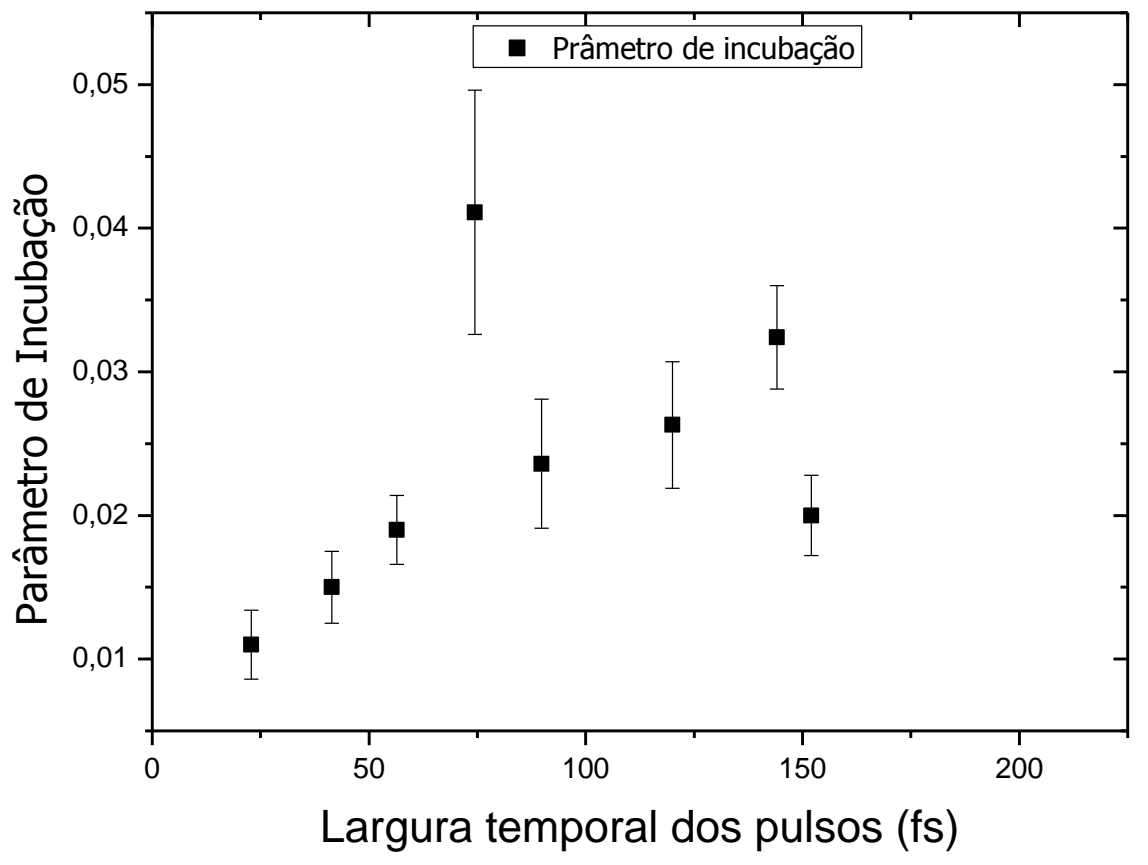

Figura 8.20 -Parâmetros de incubação obtidos através do ajuste da EEq. 19 dos valores de limiar de diversas medidas de D-scan.

Os resultados mostram claramente uma tendência de aumento do limiar de ablação para os pulsos únicos, infinitos pulsos e o parâmetro de incubação. Além disso, 
esses dados mostram que a variação de poucos fs na largura temporal mudar em até duas vezes o limiar de ablação de pulso único, e até quatro vezes o limiar de ablação de saturação. Também é possível observar uma ótima concordância entre o modelo teórico (simulação) de quantificação da densidade eletrônica e os resultados experimentais.

Na simulação mostrada na Figura 8.18, o aumento do limiar de ablação em função da largura temporal está relacionado a uma diminuição na produção total de elétrons livres na banda de condução. O que é compatível com a definição do modelo da simulação que define o limiar de dano quando a densidade eletrônica atinge um valor crítico $n_{c r}$.

Os resultados apresentados aqui mostram que o comportamento esperado do aumento do limiar de ablação em função da largura temporal foi verificado no BK7. Os resultados do limiar de ablação para pulsos únicos puderam ser comparados com uma simulação teórica e os resultados foram compatíveis.

Diferentemente da maioria dos trabalhos publicados na literatura para medidas de limiar de ablação com a TRD, nesse trabalho foi mostrado um grande conjunto de pontos experimentais (duas dezenas por largura temporal). Isso foi possível devido à simplicidade e rapidez da técnica D-Scan comparada ao modelo tradicional, tanto devido à irradiação quanto nas medidas das áreas ablacionadas. 


\section{Microcanais}

A manipulação precisa e controlada de pequenas quantidades de fluídos torna necessária a produção de montagens químicas e biológicas com dimensões cada vez menores. Conjuntos chamados de microfluídicos, com dimensões micrométricas têm sido produzidos já em escala comercial para atender a esta necessidade. Normalmente são bidimensionais e produzidos na superfície de materiais transparentes, mas podem ser tridimensionais e produzidos em qualquer tipo de material [122]. A estrutura básica mais utilizada é um canal com dimensões micrométricas chamados de microcanais. Geralmente sua seção transversal é arredondada, com dezenas a poucas centenas de micra, e comprimentos que podem chegar a alguns centímetros. As aplicações vão desde analisadores de DNA [123] até reatores químicos microscópicos [124]. O método mais utilizado para confecção destes microcanais é o de fotolitografia, onde uma sensibilização óptica combinada com um ataque químico é capaz de produzir uma estrutura micrométricas com grande precisão e ótimo acabamento superficial. Este método, contudo é muito trabalhoso, tornando caro e demorado o processo de fabricação. A diminuição do custo e aumento da produtividade só é obtida quando da produção em massa de uma peça vinda da mesma máscara matriz.

Uma alternativa muito interessante à produção destes microcanais é a usinagem com pulsos laser ultracurtos $[125 ; 126]$. Com este método, o desenho da estrutura pode ser facilmente modificado para cada peça individual. Praticamente não há restrição para o tipo de material, as dimensões podem ser controladas com precisão, e a razão de aspecto (largura / profundidade) pode ser de até algumas dezenas.

Por ser um método relativamente recente e extremamente complexo, a física da interação de pulsos laser ultracurtos com a matéria ainda é objeto de intensos estudos. Embora ainda não sendo um processo totalmente dominado, a usinagem com este tipo de pulsos tem sido utilizada para a produção de estruturas micrométricas em diversos tipos de materiais. Não existe uma metodologia e uma carta de processos estabelecida para a remoção de material, mas apenas modelos de interação para pulsos únicos, o que obviamente precisa ser corrigido quando da usinagem de cavidades que necessitam de uma sobreposição grande de pulsos laser. Neste contexto, este trabalho buscou obter uma relação entre a remoção de material e o número de pulsos laser 
sobrepostos em um mesmo ponto, levando em conta o parâmetro de incubação. Isto possibilitou a usinagem de microcanais em BK7 com dimensões controladas e grandes profundidades mesmo sem a ocorrência de uma zona afetada termicamente.

\subsection{Estratégias de usinagem - Controle da forma}

O conhecimento do parâmetro de incubação mostra a necessidade da criação de uma estratégia de usinagem de microcanais que leve em consideração o processo de sensibilização e acúmulo de danos no material por irradiações precedentes. Nesse sentido foram testadas duas diferentes estratégias de usinagem: A usinagem direta (intensa) e a usinagem suave ou "Smooth Ablation" [127].

Em ambas as estratégias as varreduras foram feitas longitudinalmente aos canais (Figura 9.1). Os parâmetros variados foram:

- $\quad$ sobreposição lateral das varreduras $(d)$;

- $\quad$ sobreposição longitudinal (variando-se a velocidade de varredura $v$ ): $N$

- $\quad$ energia dos pulsos: $E_{\text {pulso }}$

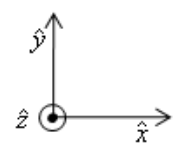

\section{Camada de usinagem}

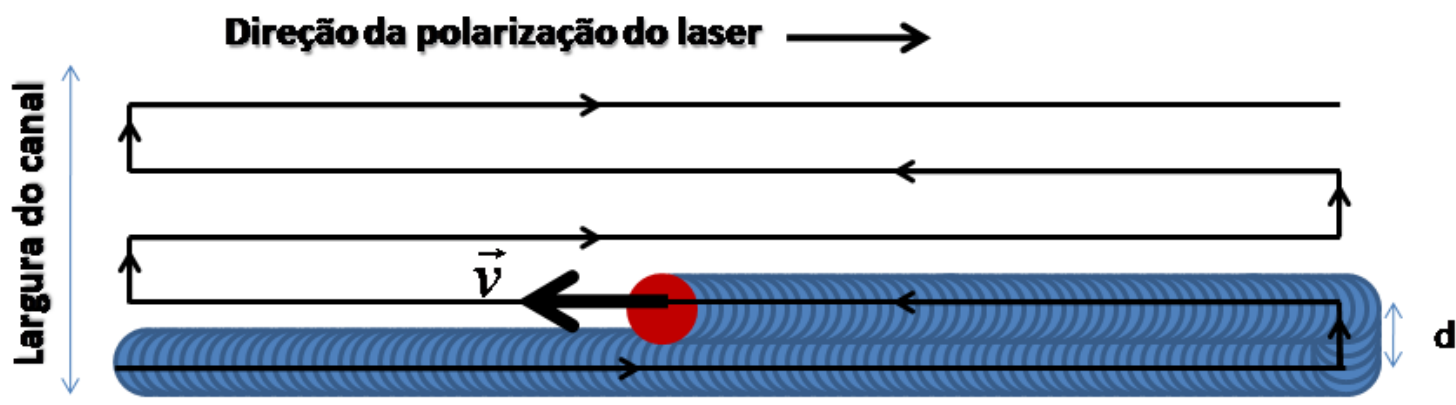

\section{1-Sobreposição longitudinal $N \longrightarrow$ velocidade de varredura: 2-Sobreposiçäo Lateral d}

Figura 9.1 - Esquema do trajeto feito pelo laser para formar uma "camada" de usinagem. A polarização possui a mesma direção da varredura do laser. As varreduras foram feitas longitudinalmente aos canais com velocidade $\vec{v}$.

Parte das análises foi feita com o uso do OCT (Tomografia de Coerência Óptica). Essa técnica permite o mapeamento tomográfico de alterações feitas no 
material transparente. É possível medir alterações do índice de refração no material induzida pelo laser.

\subsubsection{Primeira estratégia: Usinagem Direta}

Nesta estratégia utilizou-se uma grande sobreposição longitudinal com o objetivo de ablacionar uma grande quantidade de material em cada varredura. Sendo assim, o objetivo dessa análise preliminar foi comparar canais de mesma largura final com suas formas finais em função apenas da variação da distância lateral de cada varredura do laser. Para tanto, quatro diferentes canais foram usinados.

A largura total escolhida, de $100 \mu \mathrm{m}$, foi obtida por varreduras longitudinais ao canal como mostrado no esquema da Figura 9.1, e o único parâmetro variado em cada canal foi a sobreposição lateral (ou distância entre as varreduras). Os deslocamentos laterais foram variados de $\mathrm{d}=10,20,30$ e $40 \mu \mathrm{m}$ permitindo uma diferente sobreposição lateral em cada canal. Todos os canais tiveram a mesma sobreposição longitudinal de 500 pulsos e a mesma energia de $33 \mu \mathrm{J}$ por pulso, correspondendo a $22 \mathrm{~J} / \mathrm{cm}^{2}$ (considerando $\omega_{0}=6,7 \mu \mathrm{m}$ com lente de $38 \mathrm{~mm}$ ). O número $N$ de pulsos sobrepostos longitudinalmente (ao longo do canal) foi determinado pela relação entre a velocidade de varredura $v$, o raio do feixe na superfície da amostra $w_{0}$ e a taxa de repetição $f$ dos pulsos:

$$
N \cong 1.25 \frac{w_{0} f}{v}
$$

Assim, com uma taxa de repetição de $1000 \mathrm{~Hz}$ a velocidade de varredura utilizada nessa estratégia foi de $1,6 \mathrm{~mm} / \mathrm{min}$.

Apesar da irradiação controlada e uniforme, assimetria e conicidade foram verificadas nos perfis dos canais usinados. Pode se notar na imagem de OCT da Figura 9.2 uma região esbranquiçada cônica, muito profunda e afetada logo abaixo do canal usinado. Esta região corresponde a uma mudança do índice de refração do material causado pela absorção não linear do feixe. Do ponto de vista da utilização prática destes canais, tal defeito não implicaria em um problema. No entanto, o resultado correspondente nos mostra que a energia do pulso não está sendo eficientemente 
utilizada para a remoção de material, e parte dela penetra para além do fundo do canal. Assim, conforme as camadas de usinagem se sobrepõem umas às outras, uma camada abaixo da superfície usinada não é ablacionada, contudo sua estrutura cristalina é modificada (modificando o índice de refração). A assimetria transversal e a mudança do índice de refração abaixo dos canais usinados podem ser explicadas pela alta sobreposição longitudinal utilizada em cada varredura. Nesta condição, a usinagem das varreduras paralelas posteriores foi influenciada pelas anteriores, ou seja, ao se deslocar a amostra para as próximas varreduras o feixe focalizado não encontrou uma superfície plana e uniforme (Figura 9.2). Como na primeira varredura, apenas encontrou uma parede inclinada originada da usinagem precedente. Logo, essa parede contribuiu para refletir e espalhar o feixe laser o que diminuiu a eficiência de ablação e não permitiu uma ablação simétrica do canal.

A geometria de usinagem, somada ao perfil espacial gaussiano dos pulsos laser levam então à estrutura verificada na Figura 9.2-b:
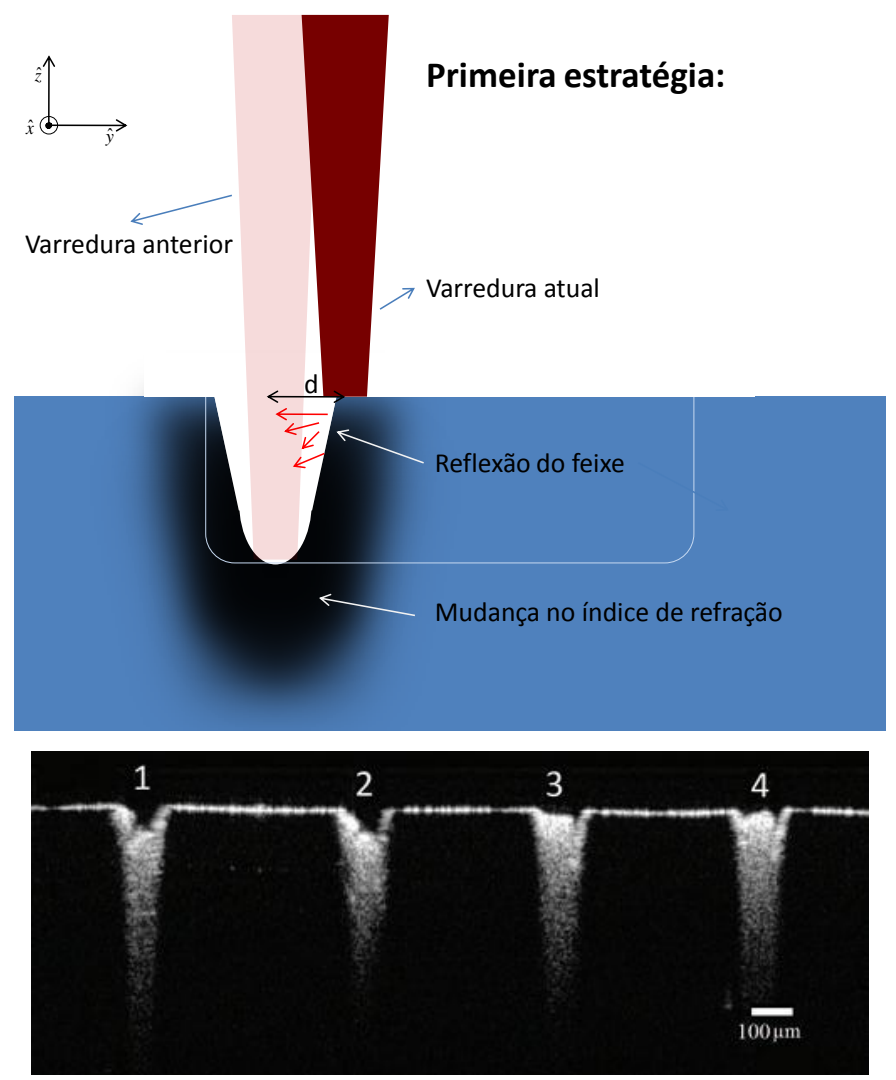

Figura 9.2 - a) Esquema de usinagem resultante da aplicação da usinagem direta. Apenas uma camada é usada e a sobreposição longitudinal é suficientemente alta para alcançar a profundidade desejada. b)Imagens de OCT. 


\subsubsection{Usinagem suave}

Esta estratégia usa o mesmo princípio de irradiação apresentado na Figura 9.1 na qual são feitas varreduras paralelas ao canal, porém, buscou-se neste caso, diminuir a sobreposição longitudinal de cada varredura. Assim foi preciso mais que um conjunto de varreduras para garantir a mesma fluência total (soma de toda energia depositada por área na amostra) em cada canal. Por conseguinte, várias camadas de usinagem como mostrado no esquema da Figura 9.1 são necessárias para se atingir a profundidade escolhida para cada canal. Diferente do ocorrido no primeiro caso, as distâncias entre as varreduras foram escolhidas de acordo com as larguras de cada traço usinado previstas pelo parâmetro de incubação. A largura dos traços $D$ é calculada a partir da Eq. 70 e é uma função da sobreposição $N$ e da fluência pico de cada pulso. Nesse experimento $N$ foi calculado de acordo com a equação Eq. 69, mas poderia ser calculado de acordo com a equação Eq. 57 substituindo $\rho_{\max }$ por $w_{0} \sqrt{2}$. A largura do traço usinado é:

$$
D\left(N, F_{0}^{\text {pico }}\right) \equiv w_{0} \sqrt{2 \ln \left(\frac{F_{0}^{\text {pico }}}{F_{t h, N}(N)}\right)}
$$

A Eq. 70 fornece o valor da largura dos traços $D\left(N, F_{0}^{p i c o}\right)$ para a $\mathrm{N}$-ésima sobreposição longitudinal em função da fluência média $F_{0}^{\text {pico }}$ dos pulsos. Definimos a sobreposição lateral entre cada traço como d. Para distâncias de varredura iguais a $D$, $l=1$ e para sobreposição total de dois traços $l=0$. Para isso a distância usada entre cada varredura é l.D. A profundidade total foi obtida dividindo-se o processo em camadas formadas por traços paralelos usinados como descrito na Figura 9.1. Nesta segunda estratégia em particular, canais de $100 \mu \mathrm{m}$ de largura também foram usinados, com uma sobreposição lateral de $20 \%(l=0,8)$ em todas as camadas de material arrancado. Para a primeira camada foi escolhida uma sobreposição longitudinal de 4 pulsos, e a distância lateral entre as varreduras foi de $l . D\left(4, F_{0}^{\text {pico }}\right)$, que corresponde à largura relativa a quatro pulsos sobrepostos vezes a sobreposição lateral $l$. Para a próxima camada de varredura a sobreposição longitudinal (velocidade) e a sobreposição lateral (deslocamento lateral) foram recalculados com base na Eq. 70. Neste caso, por exemplo, uma sobreposição longitudinal de 16 pulsos foi escolhida e sendo assim, essa 
segunda camada teve traços com sobreposição de 12 pulsos para atingir o total predeterminado de 16 pulsos. O mesmo foi feito com as camadas seguintes até 128 pulsos sobrepostos longitudinalmente. Isso significa que a largura do dano aumenta com o número de sobreposições de pulsos, isto é, para cada camada esse efeito deve ser levado em consideração para manter fixas as distâncias entre as bordas de cada traço usinado. No presente caso, dividiu-se a usinagem num conjunto de quatro camadas, onde, para cada uma delas, a velocidade e a sobreposição lateral foram modificadas levando-se em conta o parâmetro de incubação para garantir uma sobreposição lateral de cada traço de 20\%. Na Figura 9.3-b a imagem de OCT mostra canais usinados com esse procedimento. É mostrado nessa última imagem dois conjuntos de canais usinados com energias constantes de 10 e $33 \mu \mathrm{J}$. Em ambos os conjuntos foram feitas irradiações com apenas uma camada de $\mathrm{N}_{T}=4$, canais com duas camadas $\mathrm{N}_{\mathrm{T}}=16$ e até canais com quatro camadas completando uma sobreposição total $\mathrm{N}_{\mathrm{T}}=128$ pulsos sobrepostos.

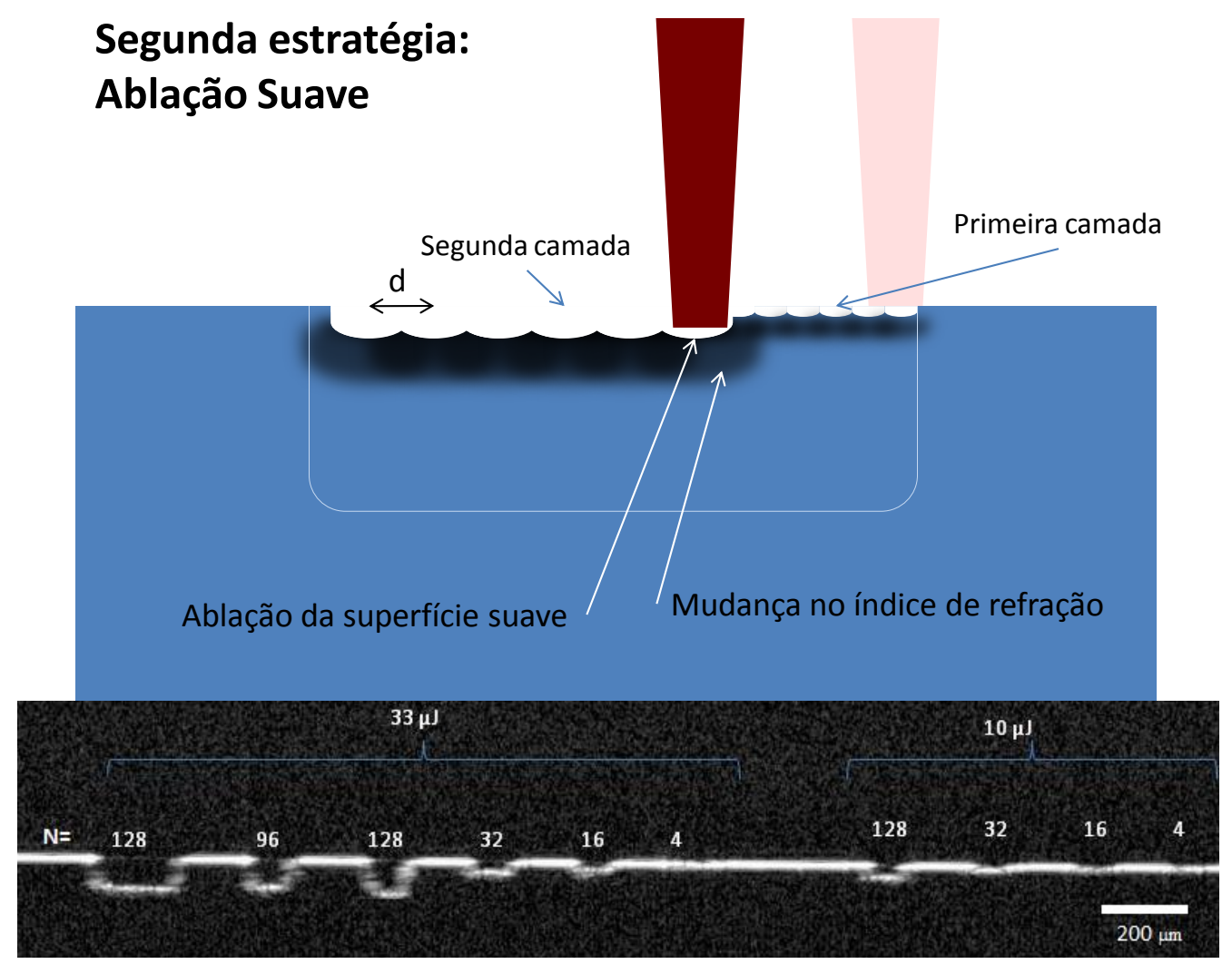

Figura 9.3 - a) método da ablação suave - O canal usinado é formado por várias camadas onde a sobreposição lateral e longitudinal são variadas em cada camada para levar em consideração o diâmetro de cada traço. b) Imagem de OCT dos canais usinados. Cada canal tem uma sobreposição total de $N$ pulsos (soma das camadas igual a N). Duas energias são mostradas 33 e $10 \mu \mathrm{J}$. 
O procedimento de ablação suave foi responsável pela incubação homogênea da região ablacionada, permitindo que o canal usinado por varreduras paralelas tenha uma superfície homogênea e livre de assimetrias como mostrado na Figura 9.3-b. Fica nítido não só a melhora no perfil dos traços bem como a ausência de uma região afetada abaixo do fundo dos canais. A usinagem suave proporcionou uma superfície mais plana ao longo de toda usinagem e um perpendicularismo maior do feixe no fundo do canal ao longo de toda usinagem. Isto permitiu melhor controle da simetria final dos canais já que os traços anteriores não foram profundos o suficiente para espalhar o feixe como observado na primeira estratégia. As altas velocidades aplicadas em cada varredura e a necessidade de várias camadas de usinagem permitiram um melhor aproveitamento da energia já que reflexões nas paredes dos traços puderam ser evitadas. Em todos os canais usinados foi possível observar uma grande simetria e perpendicularismo das bordas .
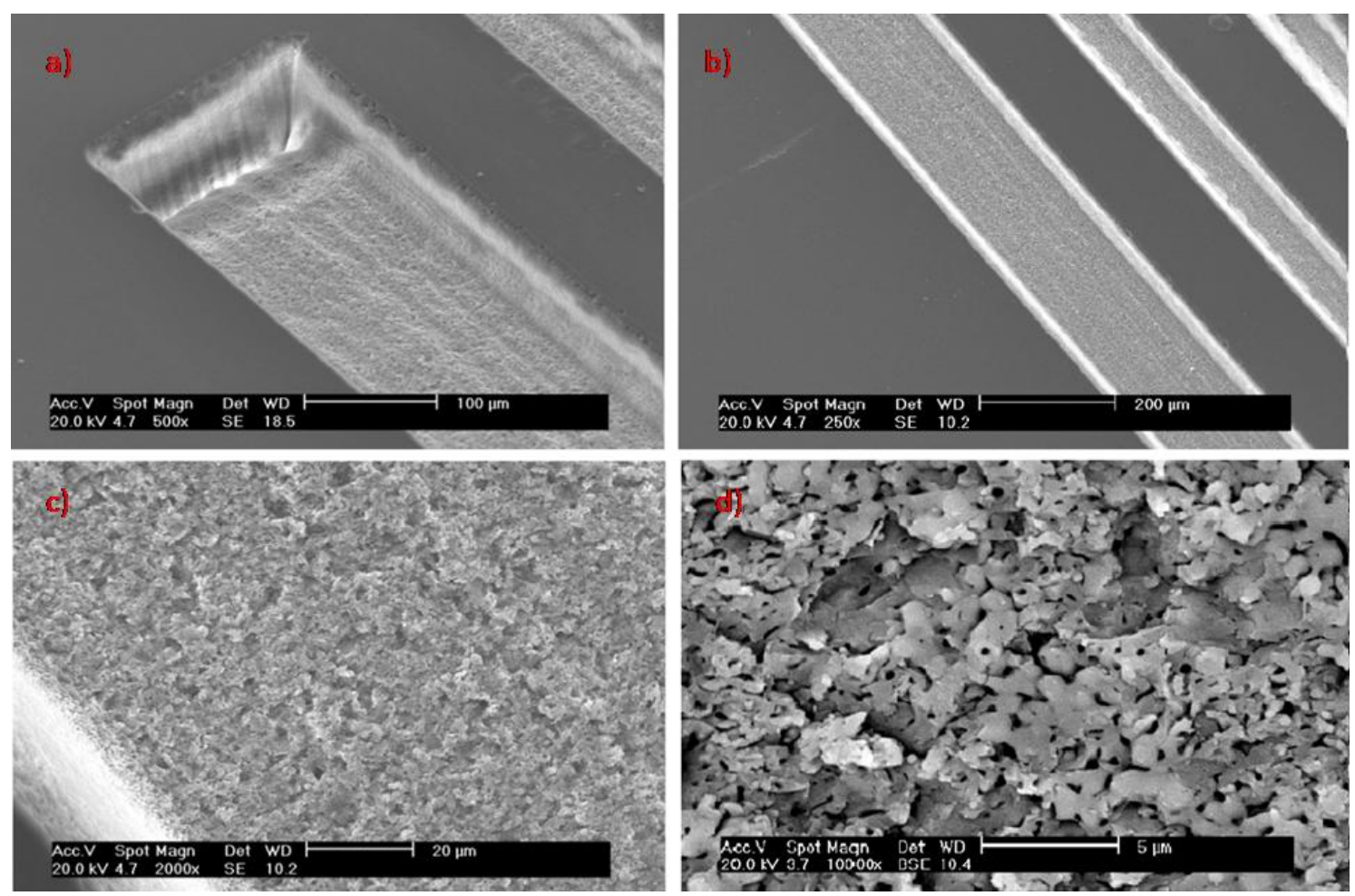

Figura 9.4 - Microscopia eletrônica de varredura dos canais usinados com o método "Smooth ablation". Cada figura (a,b,c,d) mostram um mesmo canal de N=128 e $200 \mu \mathrm{m}$ de largura com diferentes ampliações. 


\subsection{Controle da profundidade}

Para projetar um microcanal, contudo, é preciso conhecer a taxa de remoção de material em função da sobreposição e energia a fim de controlar a profundidade e sua forma. Para esse fim, nessa seção, são mostradas perfilometrias tomográficas através de imagens de OCT de canais usinados em BK7 pelo método suave em função da energia e sobreposição longitudinal como definido na Eq. 55. As profundidades máximas dos microcanais foram medidas e são apresentadas na Figura 9.5 juntamente com os perfis medidos com OCT Figura 9.7.

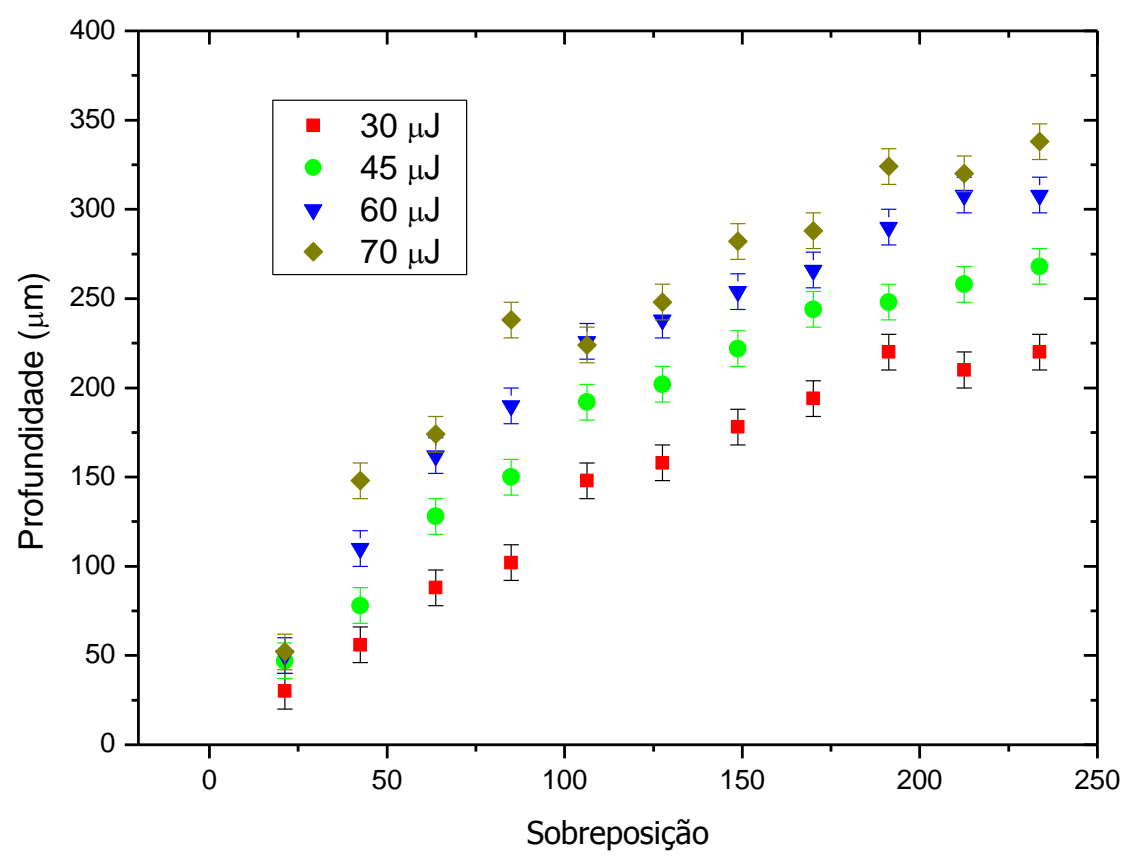

Figura 9.5 - Profundidade em função da sobreposição longitudinal de canais de $100 \mu \mathrm{m}$ usinados em BK7 usando o método suave para diferentes energias. 


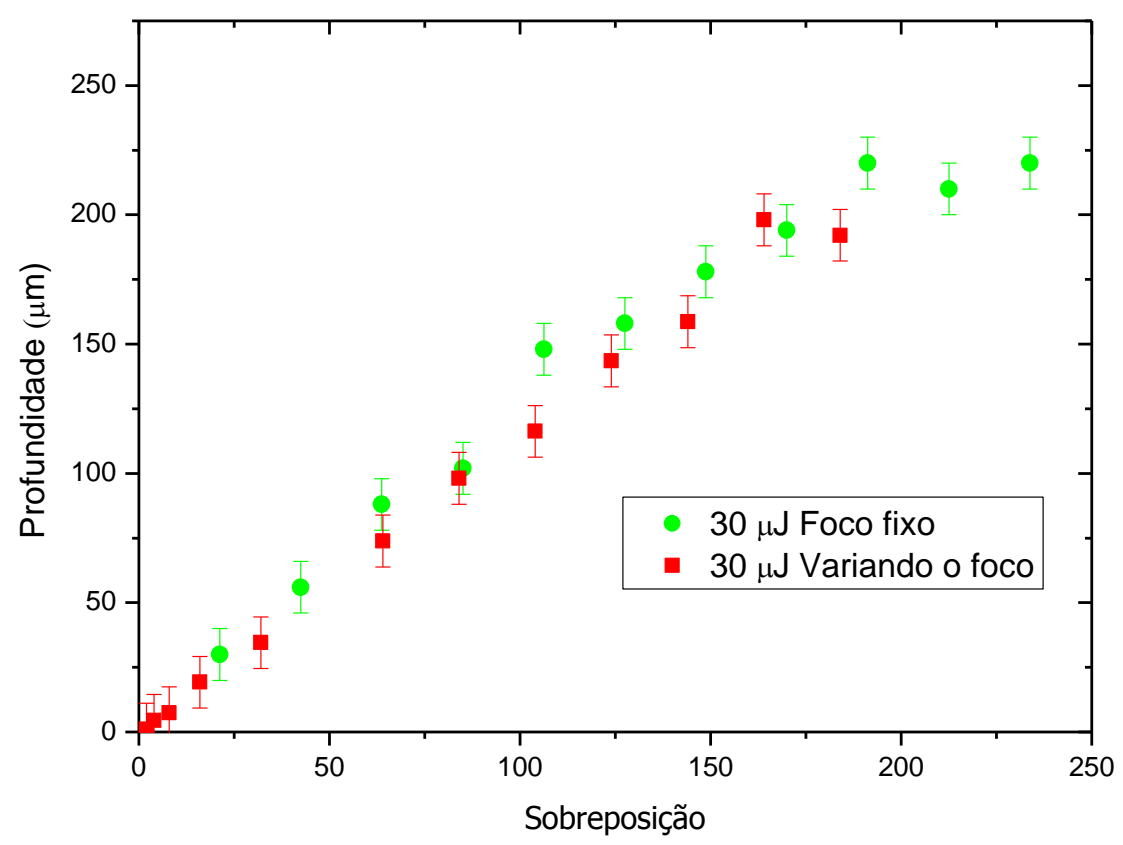

Figura 9.6 - Profundidade em função da sobreposição longitudinal N com pulsos de 30 $\mu \mathrm{J}$. Pontos vermelhos: ajustou-se a posição focal para ficar na superfície da região usinada. Pontos verdes: a posição focal permaneceu na superfície da amostra durante a usinagem.

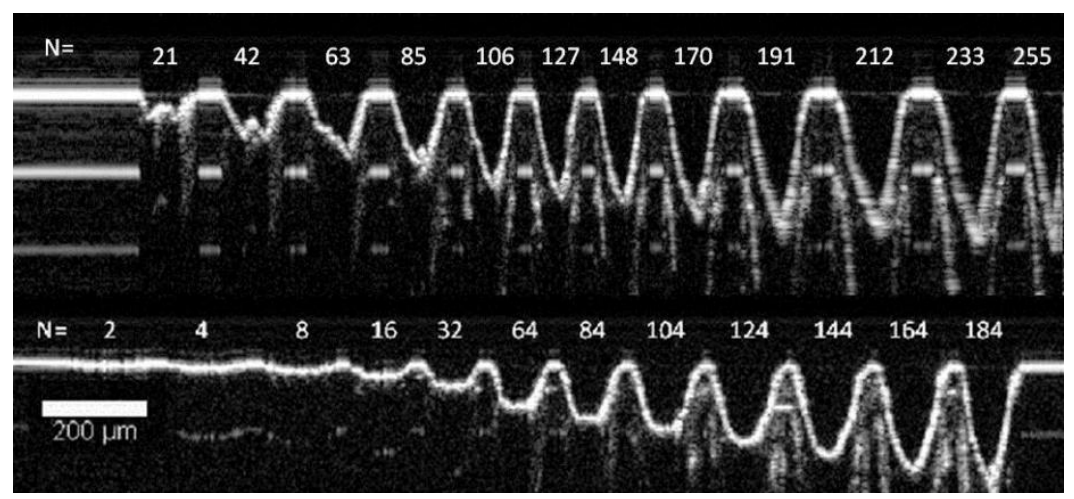

Figura 9.7 - Imagem de OCT de microcanais de $100 \mu \mathrm{m}$ de largura usinados com o método suave e $30 \mu \mathrm{J}$ por pulso. $\mathrm{O}$ conjunto de canais de cima corresponde à irradiação sem variar o foco, abaixo os canais foram usinados com o foco ajustado para ficar na superfície em cada camada. 


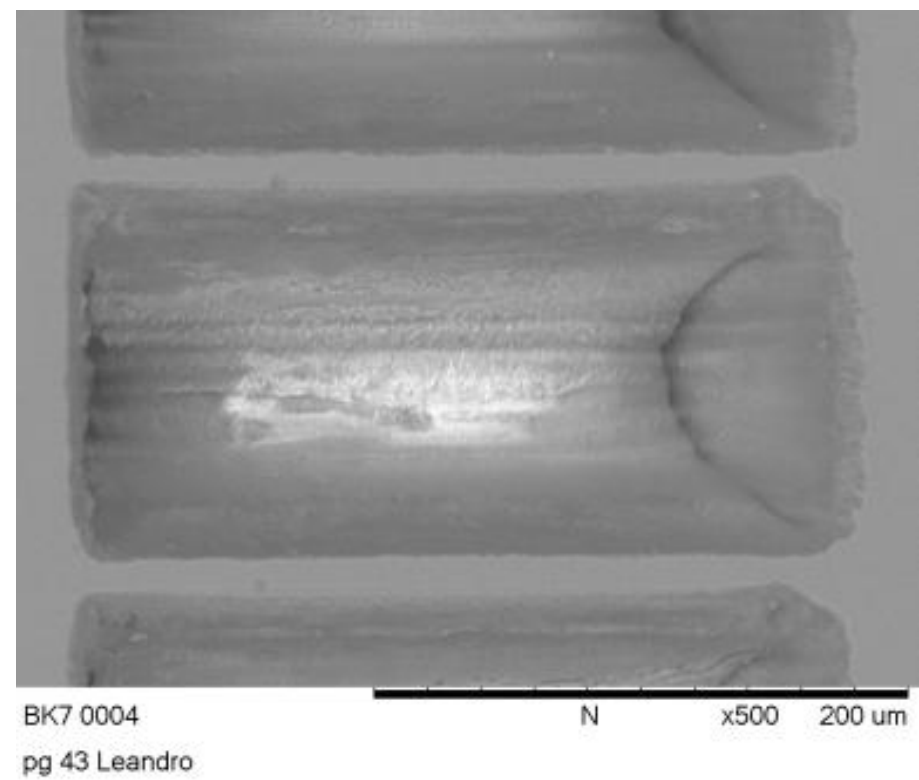

Figura 9.8 - Imagem de MEV do canal com variação do foco e sobreposição total de 104 pulsos.

No procedimento de usinagem desses canais, o foco foi mantido fixo na superfície da amostra durante toda a usinagem. Isso significa que na superfície do fundo do canal o feixe possui características diferentes do feixe no começo da usinagem (parâmetro confocal $\sim 170 \mu \mathrm{m}$ ), e, devido ao caminho óptico do feixe até o fundo do canal a distribuição de intensidade é alterada. Para estudar uma possível diferença na qualidade de usinagem e na taxa de remoção de material durante a usinagem dos canais, o mesmo método suave com energia de $30 \mu \mathrm{J}$ foi usado, porém, usando os valores previamente medidos de profundidade apresentados na Figura 9.6 e a posição focal foi ajustada durante a usinagem para que em cada camada usinada, a cintura do feixe se encontrasse o mais próximo possível fundo do canal. A comparação da profundidade entre os dois procedimentos é mostrado na Figura 9.7 e não é possível observar diferença significativa na profundidade máxima para sobreposições próximas nos diferentes processos. Porém, analisando as imagens de OCT da Figura 9.7 pode-se observar uma diferença sutil no perfil dos microcanais. Nos canais usinados com o foco posicionado no fundo do canal em cada varredura, os perfis finais possuem uma forma mais arredondada (Figura 9.7 o canal produzido pela sobreposição de 104 pulsos) enquanto que nos usinados como foco fixo os perfis apresentam uma forma em "V".

Na Figura 9.9 são apresentados os mesmos valores da Figura 9.6 (pontos vermelhos) que correspondem aos valores da profundidade final de canais usinados com 
$30 \mu \mathrm{J}$ de energia de pulso, com o método suave. Juntamente nesse mesmo gráfico, são apresentadas as profundidades máximas de traços únicos, ambos usinados com diferentes sobreposições longitudinais.

No gráfico da Figura 9.9, os pontos verdes representam traços únicos usinados com apenas uma varredura do feixe, e as diferentes sobreposições são obtidas por diferentes velocidades de varredura. Os traços representados pelos pontos pretos foram usinados com várias sobreposições de varreduras únicas com uma mesma velocidade num mesmo caminho, e as diferentes sobreposições se devem à soma da sobreposição de cada camada de varredura. A partir da comparação da profundidade alcançada por sobreposições finais iguais, não foi possível observar diferença entre os dois procedimentos. Uma hipótese de que efeitos de incubação dinâmicos (recombinação de defeitos) pudessem diferenciar os resultados das duas abordagens descritas acima pode ser descartada dentro do erro experimental.

A diferença entre a profundidade final dos microcanais e dos traços únicos foi significativamente grande. Essa diferença é esperada, visto que na usinagem dos traços únicos, após um valor de sobreposição $N$, o feixe não irradia uma superfície plana, isso provoca reflexões nas paredes do traço usinado, além do mais, a distribuição gaussiana do feixe não permite uma distribuição uniforme da energia e um perfil em "V" é inevitável (Figura 9.10) e isso limita a profundidade desses traços.

Contrariamente, no método de usinagem suave (canais $100 \mu \mathrm{m}$ ), a usinagem em múltiplas camadas permite que o feixe encontre uma superfície plana mesmo a grandes profundidades, até que o efeito de borda (reflexões do feixe) se torne significante e prejudique a eficiência de ablação em profundidades maiores. Esse efeito é claro mesmo para os canais de $100 \mu \mathrm{m}$ quando a profundidade é grande. 


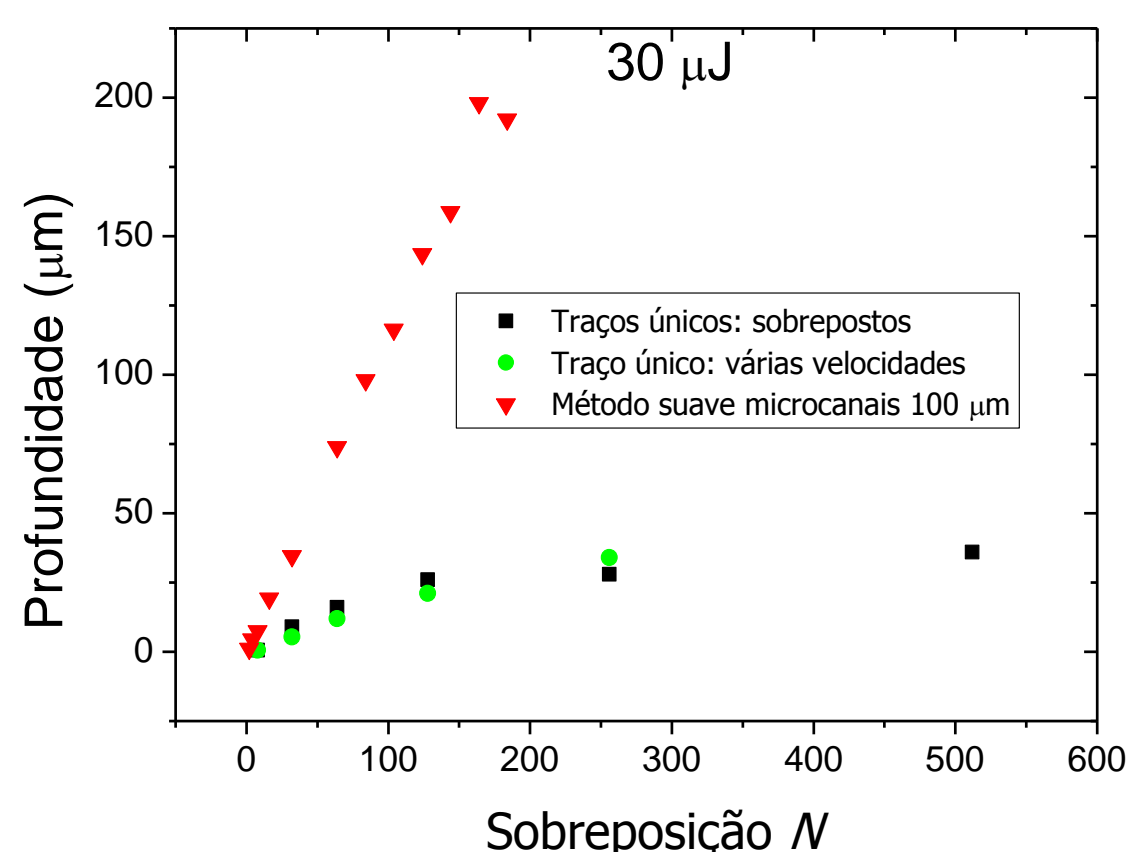

Figura 9.9 - Profundidade em função da sobreposição. Pontos verdes: Microcanais de $100 \mu \mathrm{m}$ usinados com o método suave com pulsos de $30 \mu \mathrm{J}$. Pontos pretos: traços únicos sobrepostos com mesma velocidade de varredura. Pontos vermelhos: traços únicos sobrepostos com apenas uma varredura, as diferentes sobreposições são alcançadas com diferentes velocidades de varredura.

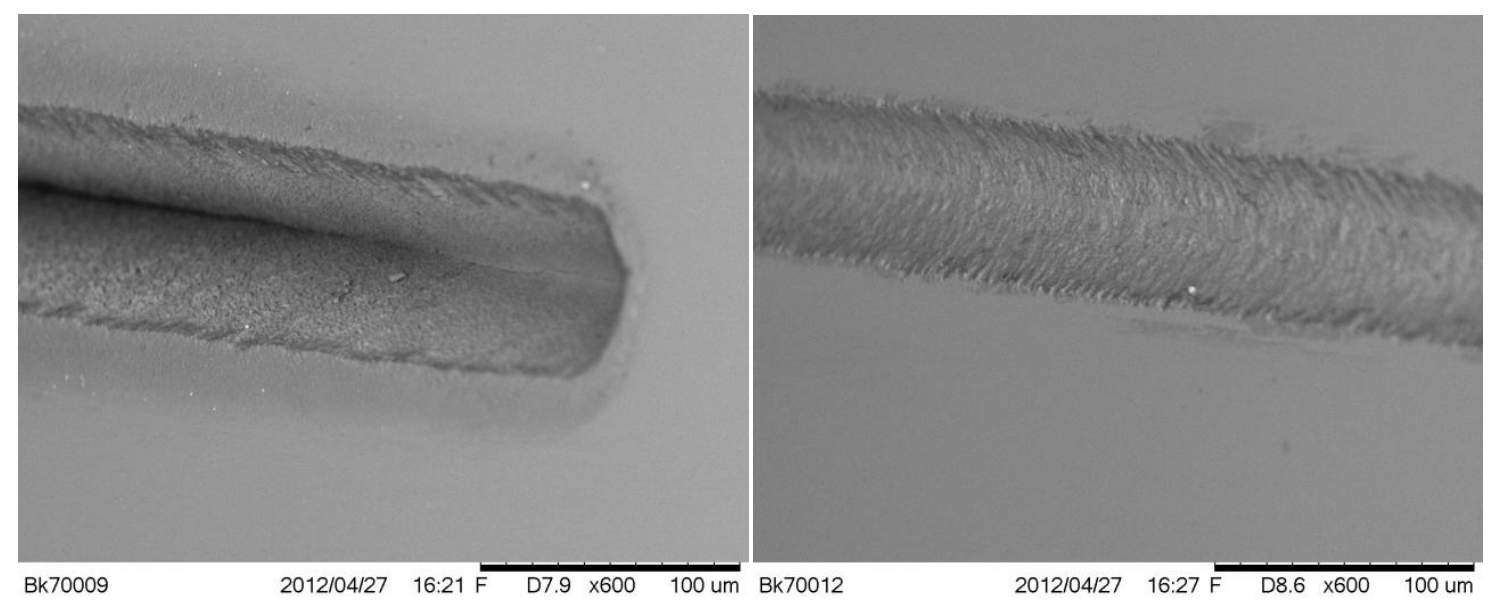

Figura 9.10 - Exemplo de alta e baixa sobreposição em traços usinados no BK7 fora do foco (diâmetro do feixe $\sim 100 \mu \mathrm{J}$ ). a) Alta sobreposição forma em "V" reflexões laterais. b) Baixa sobreposição forma mais arredondada. 


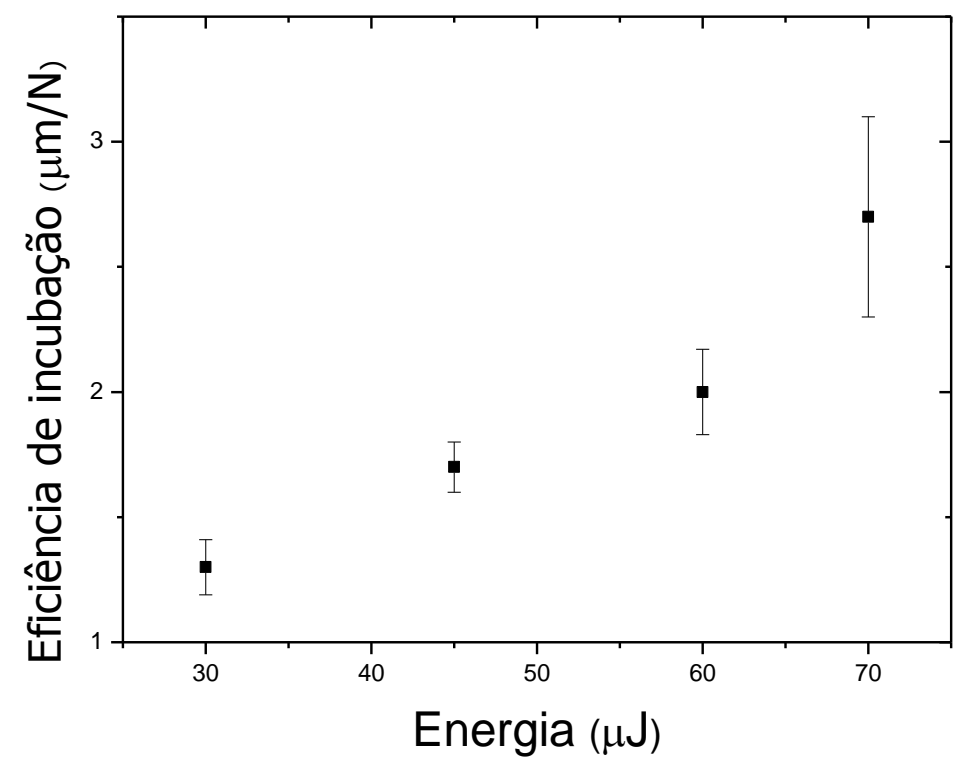

Figura 9.11 - b) eficiência de incubação na usinagem com o método suave.

A eficiência de incubação com o método suave foi obtida através do coeficiente angular do gráfico da profundidade em função da sobreposição. Os valores de eficiência para as diferentes energias são mostrados na Figura 9.11 e mostram, como esperado, um aumento na eficiência de incubação com o aumento da energia dos pulsos.

Na usinagem dos microcanais a sobreposição lateral tem um importante papel no processo de incubação, pois o caminho de varredura do feixe está sendo incubado por varreduras paralelas laterais. Esse efeito permite que a profundidade (no caso dos parâmetros usados nesse experimento) cresça linearmente com a sobreposição como pode ser visto na Figura 9.9 (pontos vermelhos). Diferentemente, em varredura de traços únicos, apresentam um caminho de saturação mais rápido e uma eficiência baixa (mesmo para pequenas profundidades, Figura 9.9 pontos verdes e pretos). Mostrando que a usinagem suave permitida pelas várias camadas de usinagem garante a maior eficiência na taxa de remoção de material e permite que a razão de aspecto dos canais usinados seja maior sem que efeitos de borda atrapalhem o processo de ablação.

Esses resultados permitiram que a profundidade dos microcanais usinados com o método suave fossem controlados eficientemente. Isso proporcionou a usinagem de alguns circuitos microfluídicos para aplicações.

É claro que este procedimento ainda é uma aproximação. Ele não leva em conta a retirada de material quando do cálculo do acúmulo de pulsos $(N)$, e também não 
corrige a posição focal. Ainda apresenta limitação de forma quando da usinagem de traços estreitos e profundos. Mesmo assim, este método representa um avanço e se mostrou bastante útil e para uma microusinagem de precisão.

O procedimento de ablação suave de microcanais, ou "Smooth Ablation", foi apresentado na forma oral no congresso internacional: " Laser in Manufacturing" em Munique no começo de 2011. Um trabalho completo também foi publicado no periódico desse mesmo congresso [127]. 


\section{Microfluídica}

Para as aplicações em microfluídica foram desenvolvidos conectores para o acoplamento dos microcanais com bombas de injeção de líquidos controladas por computador. O sistema de injeção de líquidos dos microcanais consistiu em motores de passo conectados a micrômetros de acoplamento. Os torques dos motores foram transferidos através de polias e correias para os micrômetros, através dos quais foi possível movimentar os êmbolos de seringas médicas de $1 \mathrm{ml}$. Os motores de passo foram comandados por placas controladoras de motor de passo da marca Akiyama. Cada controlador possui duas entradas de sinal digital (0 - $5 \mathrm{~V})$, uma entrada de sentido de movimento e outra de "clock", ou frequência de execução dos passos. Os sinais digitais de 0 e $5 \mathrm{~V}$ foram gerados por um microcontrolador da marca Microchip ${ }^{\circledR}$ modelo PIC $18 \mathrm{f} 4550$ que foi interfaceado usando uma conexão USB e programado. Através de um programa desenvolvido em LabView foi possível a geração de pulsos pelo microcontrolador para execução dos comandos de direção e frequência da placa controladora dos motores. Essa interface permitiu um controle preciso da injeção de líquidos em microcanais com resolução de dezenas de nanolitros.

As conexões das mangueiras nos microcanais foram feitas lateralmente. Isso foi possível através de canais de $600 \mu \mathrm{m}$ de largura e profundidade usinados nas laterais dos substratos, permitindo a conexão entre os microcanais e tubos metálicos (Figura 10.1). Os tubos metálicos foram fixados com cola resina nas laterais do BK7. O confinamento do líquido nos microcanais foi feito pelo uso de uma película de um Silicone elastômero chamado PDMS (polydimethylsiloxane), evitando qualquer vazamento, (Figura 10.1 e Figura 10.2). O PDMS fica entre o substrato com os microcanais na superfície e uma lâmina de BK7 que o pressiona contra o substrato.

A Figura 10.3, à esquerda, mostra o acoplamento das mangueiras nos microcanais usinados, à direita é mostrado o sistema microfluídico com o programa em LabView, sistema de bombeamento, e visualização dos microcanais. 


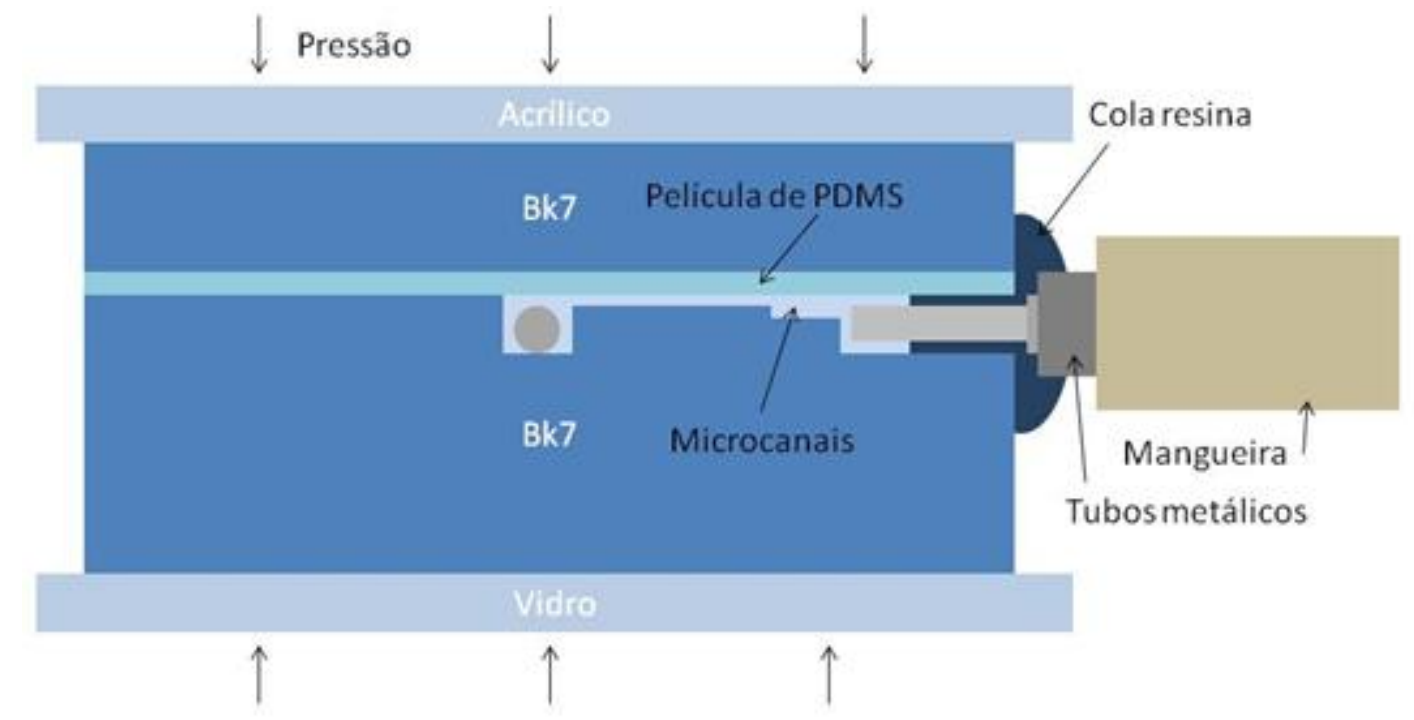

Figura 10.1 - Esquema do sistema de acoplamento das mangueiras fluídicas com o circuito microfluídico.

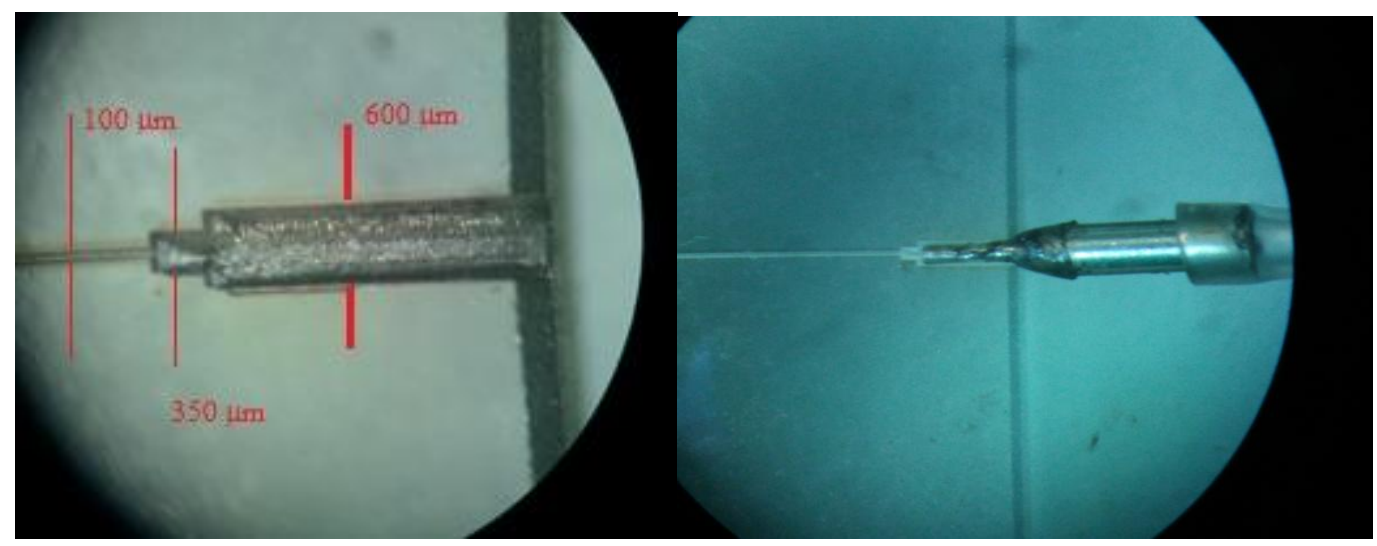

Figura 10.2 - Imagem da conexão feita usando a técnica desenvolvida nesse trabalho.

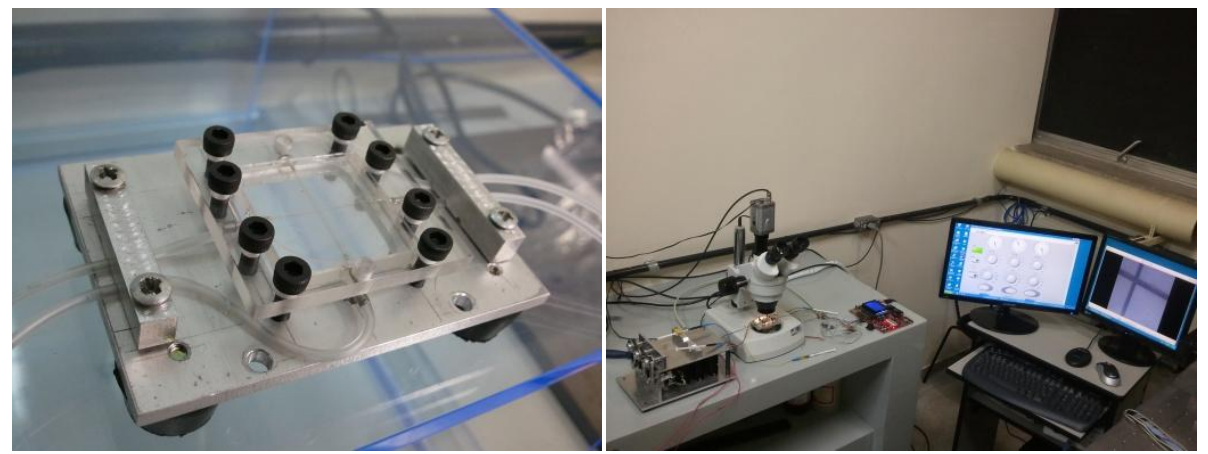

Figura 10.3 - Sistema de acoplamento microfluídico com sistema de visualização e controle de fluxo. 
Para demonstração do sistema, foi bombeada água colorida por um circuito microfluídico em forma de cruz com três entradas de líquido e uma saída. Foi possível observar o fluxo laminar devido à dimensão microscópica do fluxo e o controle adequado de bombeamento (Figura 10.4). A Figura 10.5 mostra os canais sendo usinados.

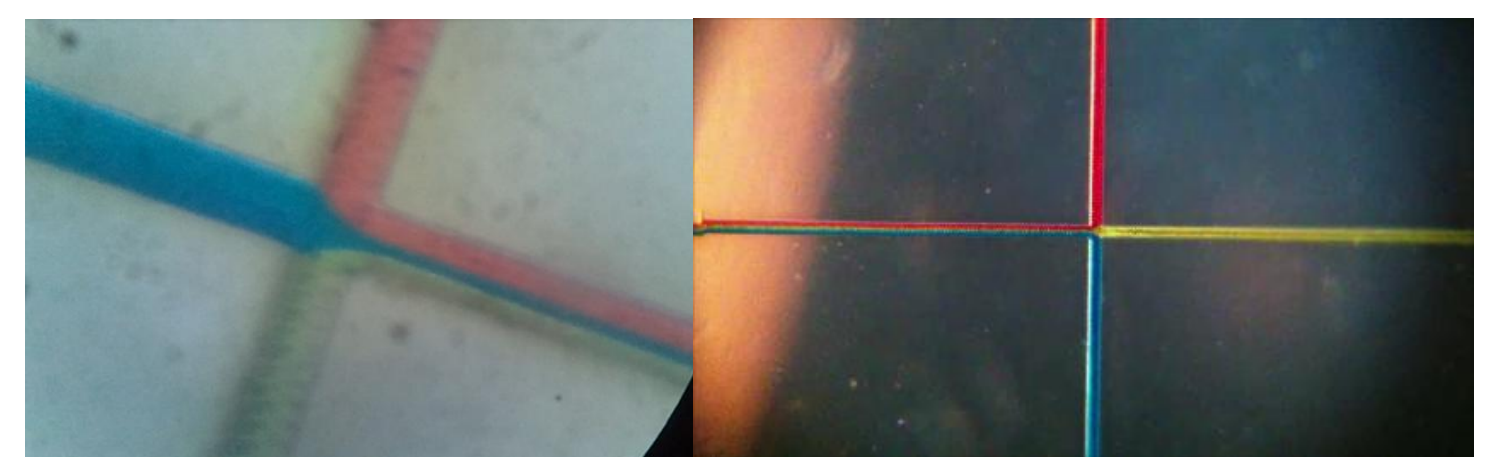

Figura 10.4 - Fluxo laminar de água colorida injetada nos microcanais usinados por laser.

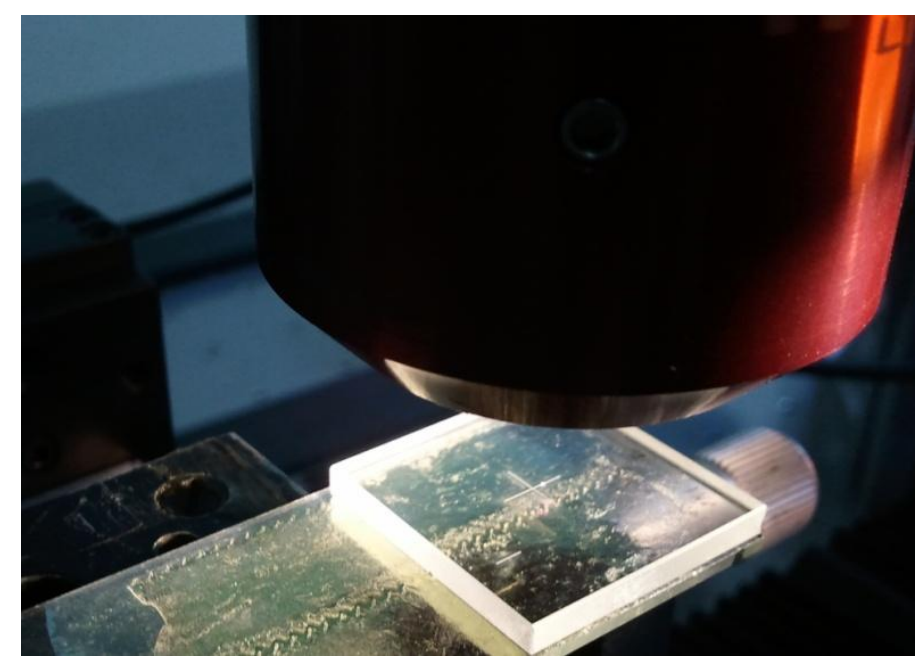

Figura 10.5 - Microusinagem de canais de $100 \mu \mathrm{m}$ em BK7 em forma de cruz.

O desenvolvimento do equipamento para controle microfluídico foi importante para testar os microcanais usinados. Esses serão usados futuramente por esse Grupo de pesquisa para a realização de diversos experimentos de microfluídica. Para isso será necessário um controle automatizado do fluxo de líquidos que deve ser precisamente controlado e interfaceado com outros programas em LabView para uma correta sincronia. 


\section{Conclusões}

Através do estudo dos principais fenômenos físicos envolvidos no processo de ablação por pulsos ultracurtos, uma simulação para a quantificação da densidade do plasma eletrônico foi feita na safira, Suprasil e BK7 e seu resultado pôde ser comparado com os resultados experimentais apresentando ótima concordância.

A técnica de regressão do diâmetro (TRD) foi usada em todos os materiais propostos e foi encontrada compatibilidade com os valores reportados na literatura. A medidas com a TRD do limiar de ablação para pulsos únicos na Safira e no Ti:safira mostraram um regime de alta fluência com zona afetada pelo calor. Esse regime pode ser verificado pela divergência do tamanho das regiões ablacionadas em relação ao esperado pelo modelo a partir de certa fluência. Aqui foi sugerido que esse efeito é decorrente do calor residual ocasionado pelo alto gradiente de fluências intrínseco à TRD. Além disso, o limiar de ablação encontrado para o Ti:safira foi menor que o encontrado para safira. Esse resultado pôde ser explicado pela dinâmica da absorção multifotônica que é facilitada pela absorção de linhas interbanda presentes no Ti:safira.

O método para a medida do limiar de dano, o $D$-scan, teve seu formalismo expandido para a quantificação da sobreposição de pulsos. Seus resultados de varreduras de $D$-scan foram comparados com os valores de pulsos sobrepostos medidos com a TRD. Os resultados dessas medidas mostraram uma ótima compatibilidade entre os dois métodos nas medidas feitas no BK7 e Safira. Entretanto, no Suprasil houve uma diferença significativa entre os valores de limiar de dano para pulsos com grande sobreposição $(N>10)$ entre as duas técnicas. Foram levantadas duas hipóteses para explicar essa incompatibilidade. A diferença nas larguras temporais utilizadas ou algum efeito colateral devido às altas fluências utilizadas na TRD (10x maiores que a $\left.F_{t h}\right)$. Além disso, com a TRD, o Suprasil apresentou efeito colateral como trincas e ejeção de material por "espalação" para altas sobreposições. O que indica que o processo de ablação com a TRD é prejudicado por esses efeitos colaterais. Para comprovar essas hipóteses, esses resultados serão comparados com trabalhos futuros de medidas do limiar de ablação em função da largura temporal para diversas sobreposições na safira e Suprasil, isso poderá comprovar se alguma das hipóteses levantadas explica a divergência nos resultados com o Suprasil. 
Ainda utilizando a técnica de $D$-scan, foram realizadas as medidas do limiar de ablação para pulsos com diferentes larguras temporais e diferentes sobreposições no BK7. A grande quantidade de pontos experimentais de sobreposição (23) e larguras temporais (8) é inédita na literatura e foi possível devido à rapidez e simplicidade da técnica $D$-scan. Foi possível observar uma clara influência da largura temporal no limiar de ablação para pulsos, sobreposição saturada e parâmetro de incubação.

No contexto da microusinagem de microcanais, a utilização do conhecimento do parâmetro de incubação se mostrou muito importante na dinâmica de ablação com pulsos sobrepostos. Assim, uma técnica que utiliza uma ablação suave composta de várias camadas de varredura do laser e incubação de defeitos como parâmetro de usinagem foi desenvolvido e possibilitou a criação de canais sem zona afetada pelo calor, trincas ou respingos de material. Medidas da profundidade dos traços quando se utiliza essa técnica foram experimentadas,e possibilitando o controle adequado de profundidade e forma para a criação de microcanais para aplicação em microfluídica.

Além da carta de processo para o desenvolvimento de microcanais, o protótipo de um sistema microfluídico foi desenvolvido para que os primeiros experimentos em microfluídica tivessem início.

Finalmente, foram realizadas medidas do índice de refração não linear do BK7 com a técnica Z-scan de amostras irradiadas e não irradiadas com pulsos ultracurtos. A presença de centros de cor gerados pelos pulsos ultracurtos proporcionaram uma mudança no índice de refração não-linear, aumentando seu valor em duas vezes. 


\section{Trabalhos publicados}

Esse trabalho possibilitou a publicação de dois trabalhos completos em periódicos internacionais e dois trabalhos completos em congresso nacional.

Machado, L. M. ; Samad, Ricardo Elgul ; de Rossi, Wagner ; Junior, Nilson Dias Vieira . D-Scan measurement of ablation threshold incubation effects for ultrashort laser pulses. Optics Express, v. 20, p. 4114, 2012. [113]

Machado, L.M. ; Samad, R.E. ; Freitas, A.Z. ; Vieira, N.D. ; de Rossi, W. . Microchannels Direct Machining using the Femtosecond Smooth Ablation Method. Physics Procedia, v. 12, p. 67-75, 2011. [127]

Machado, L. M.; SAMAD, R. E. ; Vieira Jr., N. D; BERRETTA, J. R. ; ROSSI, W. ; FREITAS, A.Z ; Neves . Corte de metais por ablação com pulsos laser ultracurtos. In: 4 Congresso Brasileiro de Engenharia de Fabricação, 2007, Estância de São Pedro. 4 Congresso Brasileiro de Engenharia de Fabricação, 2007. v. 4. p. 83-83.

Machado, L. M. ; SAMAD, R. E. ; FREITAS, A.Z ; VIDAL, J. T. ; Vieira Jr., N. D ; NOGUEIRA, G. E. C. ; ROSSI, W. . Usinagem de microcanais com laser de femtossegundos para uso em microfluídica. In: $6^{\circ}$ CONGRESSO BRASILEIRO DE ENGENHARIA DE FABRICAÇÃO, 2011, Caxias do Sul - RS. $6^{\circ}$ CONGRESSO BRASILEIRO DE ENGENHARIA DE FABRICAÇÃO, 2011.

\section{Trabalhos aceitos para publicação:}

Capítulo de livro: "Ultrashort Laser Pulses Machining” que será publicado pela INTECH.

Trabalhos completos: $7^{\circ}$ Congresso Brasileiro de Engenharia de Fabricação: "Usinagem de circuitos microfluídicos com laser de pulsos ultracurtos" 
Physics Procedia "7th International Conference on Photonic Technologies": "D-scan measurement of the ablation threshold and incubation parameter of optical materials in the ultrafast regime" 


\section{Referências}

1 MAIMAN, T. H. Stimulated Optical Radiation in Ruby. Nature, v. 187, n. 4736, p. 493-494, 1960

P. MAKER, R. T., AND C. SAVAGE, P. GRIVET, AND N. BLOEMBERGEN. Proceedings of the Third International Conference on Quantum Electronics, v. Proceedings of the Third International Conference on Quantum Electronics, p. 15559,

HERCHER, M. Laser-induced damage in transparent media. J. Opt. Soc. Am., v. 54, p. $563,1964$.

KASAAI, M. R. et al. The interaction of femtosecond and nanosecond laser pulses with the surface of glass. Journal of Non-Crystalline Solids, v. 319, p. 129-135, 2003.

JANDELEIT, J. et al. Fundamental investigations of micromachining by nano- and picosecond laser radiation. Applied Surface Science, p. 885-891, 1998. thresholds in dielectrics. Applied Physics A: Materials Science \& Processing, v. 94, p. 889-897, March 1, 20092009.

STRIGIN, M. B.; CHUDINOV, A. N. Cutting of glass by picosecond laser radiation. Optics Communications, v. 106, p. 223-226, 1994. >.

GOWER, M. C. Industrial applications of laser micromachining. Opt. Express, v. 7, n. 2, p. 56-67, 2000.

MATSUSAKA, S.; WATANABE, T. Micro-machinability of silverâ $€$ "sodium ionexchanged glass by UV nanosecond laser. Journal of Materials Processing Technology, v. 202, p. 514-520, 2008.

STRICKLAND, D.; MOUROU, G. Compression of amplified chirped optical pulses. Optics Communications, v. 56, n. 3, p. 219-221, Dec 1985.

DIELS, J.-C.; RUDOLPH, W. Ultrashort laser pulse phenomena : fundamentals, techniques, and applications on a femtosecond time scale. 2nd. Burlington, MA: Academic Press, 2006. 
KELLER, U. Ultrafast solid-state laser oscillators: a success story for the last 20 years with no end in sight. Applied Physics B-Lasers and Optics, v. 100, p. 15-28, Jul 2010. of Applied Physics, v. 85, n. 9, p. 6803-6810, 1999.

SUNDARAM, S. K.; MAZUR, E. Inducing and probing non-thermal transitions in semiconductors using femtosecond laser pulses. Nat Mater, v. 1, n. 4, p. 217-224, 2002.

GAMALY, E. G. et al. Ablation of solids by femtosecond lasers: Ablation mechanism and ablation thresholds for metals and dielectrics. Physics of Plasmas, v. 9, n. 3, p. 949-957, 2002.

CHICHKOV, B. N. et al. Femtosecond, picosecond and nanosecond laser ablation of solids. Applied Physics A: Materials Science \& Processing, v. 63, n. 2, p. 109-115, 1996.

KAISER, A. et al. Microscopic processes in dielectrics under irradiation by subpicosecond laser pulses. Physical Review B, v. 61, n. 17, p. 11437-11450, 2000.

HALLO, L. et al. Model and numerical simulations of the propagation and absorption of a short laser pulse in a transparent dielectric material: Blast-wave launch and cavity formation. Physical Review B, v. 76, n. 2, p. 024101, 2007.

BULGAKOVA, N. M. et al. Electronic transport and consequences for material removal in ultrafast pulsed laser ablation of materials. Physical Review B (Condensed Matter and Materials Physics), v. 69, n. 5, p. 054102-12, 2004.

LIU, J. M. Simple technique for measurements of pulsed Gaussian-beam spot sizes. Opt. Lett., v. 7, n. 5, p. 196-198, 1982.

CHIMIER, B. et al. Damage and ablation thresholds of fused-silica in femtosecond regime. Physical Review B, v. 84, n. 9, p. 094104,

ZHOU, Y. et al. Near-field enhanced femtosecond laser nano-drilling of glass substrate. Journal of Alloys and Compounds, v. 449, p. 246-249, 2008.

ASHKENASI, D.; ROSENFELD, A.; STOIAN, R. Laser-induced incubation in transparent materials and possible consequences for surface and bulk microstructuring with ultrashort pulses. Society of Photo-Optical Instrumentation Engineers (SPIE) Conference Series. April 1, 2002, 2002. 90-98 p. 
GROJO, D. et al. Exciton-seeded multiphoton ionization in bulk $\mathrm{SiO}_{2}$. Physical Review B, v. 81, n. 21, p. 212301,

The effect of damage accumulation behaviour on ablation thresholds and damage morphology in ultrashort laser micro-machining of common metals in air. Appl. Surf. Sci., v. 233, n. 1-4, p. 275, 2004.

LIM, Y. C. et al. Direct-write femtosecond laser ablation and DNA combing and imprinting for fabrication of a micro/nanofluidic device on an ethylene glycol dimethacrylate polymer. Journal of Micromechanics and Microengineering, v. 21, n. 1, p. 015012,

SAMAD, R.; VIEIRA, N. Geometrical method for determining the surface damage threshold for femtosecond laser pulses. Laser Physics, v. 16, n. 2, p. 336-339, 2006.

JONES, S. C. et al. Recent progress on laser-induced modifications and intrinsic bulk damage of wide-gap optical materials. Optical Engineering, v. 28, p. 1039-1068, October 1, 19891989.

ARNOLD, D.; CARTIER, E. Theory of laser-induced free-electron heating and impact ionization in wide-band-gap solids. Physical Review B, v. 46, n. 23, p. 15102, 1992.

A. PROKHOROV, V. K., I. URSU, AND I. MIHAILESCU. Laser Heating of Metals. Adam Hilger, Bristol, 1990.

VIDAL, F. et al. Critical-Point Phase Separation in Laser Ablation of Conductors. Physical Review Letters, v. 86, n. 12, p. 2573-2576, 2001.

ANISIMOV S.I., K. B. L., PEREL'MAN T.L. Sov. Phys. JETP, v. 66, p. 776-781, 1974.

M. I. KAGANOV, I. M. L., AND L. V. TANATAROV, "," VOL. , PP. 232-237, ENGLISH TRANSLATION IN, VOL. 4, PP. 173-178, 1957. . Relaxation between electrons and the crystalline lattice. Soviet Physics. JETP, v. 4, p. 173-178, 1957.

ALLEN, P. B. Theory of thermal relaxation of electrons in metals. Physical Review Letters, v. 59, n. 13, p. 1460-1463, 1987.

JIANG, L.; TSAI, H.-L. Improved Two-Temperature Model and Its Application in Ultrashort Laser Heating of Metal Films. Journal of Heat Transfer, v. 127, n. 10, p. 1167-1173, 2005. 
SINGH, N. Relaxation between electrons and surface phonons of a homogeneously photoexcited metal film. Pramana, v. 63, n. 5, p. 1083-1087, 2004.

BULGAKOVA, N. M. et al. A general continuum approach to describe fast electronic transport in pulsed laser irradiated materials: The problem of Coulomb explosion. Applied Physics A: Materials Science \& Processing, v. 81, n. 2, p. 345-356, 2005.

A.A. MANEKOV, A. M. P. Sov.Phys.Usp, v. 29, p. 104, 1986.

STUART, B. C. et al. Nanosecond-to-femtosecond laser-induced breakdown in dielectrics. Physical Review B, v. 53, p. 1749-1761, January 1, 1996.

DU, D. et al. Laser-induced breakdown by impact ionization in $\mathrm{SiO}_{2}$ with pulse widths from 7 ns to 150 fs. Applied Physics Letters, v. 64, n. 23, p. 3071-3073, 1994.

VAREL, $\mathrm{H}$. et al. Laser-induced damage in $\mathrm{SiO}_{2}$ and $\mathrm{CaF}_{2}$ with picosecond and femtosecond laser pulses. Applied Physics A: Materials Science \& Processing, v. 62, p. 293-294, March 1, 19961996.

STUART, B. C. et al. Optical ablation by high-power short-pulse lasers. J. Opt. Soc. Am. B, v. 13, n. 2, p. 459-468, 1996.

REIF, J. et al. Femtosecond Laser Interaction with Solid Surfaces: Explosive Ablation and Self-Assembly of Ordered Nanostructures. In: (Ed.). Advances In Atomic, Molecular, and Optical Physics: Academic Press, v.Volume 53, 2006. p.227-251.

Keldysh et al., Sov. Phys-JETP, v. 20, p. 1307, 1965.

SCHAFFER, C. B.; BRODEUR, A.; MAZUR, E. Laser-induced breakdown and damage in bulk transparent materials induced by tightly focused femtosecond laser pulses. Measurement Science and Technology, v. 12, p. 1784-1794, November 1, 20012001. insulating crystals. Journal of Applied Physics, v. 46, n. 1, p. pp. 279-291, 1975.

SEAH, M. P.; DENCH, W. A. Quantitative electron spectroscopy of surfaces: A standard data base for electron inelastic mean free paths in solids. Surface and Interface Analysis, v. 1, n. 1, p. 2-11, 1979. 
BLOEMBERGEN, N. Laser-induced electric breakdown in solids. Quantum Electronics, IEEE Journal of, v. 10 n. 3, p. 375 - 386, Mar 1974. by impact ionization in $\mathrm{SiO}_{2}$ with pulse widths from 7 ns to 150 fs Appl. Phys. Lett., v. 64, p. 3071, 1994.

JESCHKE, H. O.; GARCIA, M. E.; BENNEMANN, K. H. Microscopic analysis of the laser-induced femtosecond graphitization of diamond. Physical Review B, v. 60, n. 6, p. R3701-R3704, 1999.

JESCHKE, H. O. et al. Laser ablation thresholds of silicon for different pulse durations: theory and experiment. Applied Surface Science, n. 0, p. 839-844, 2002.

COSTACHE, F.; KOUTEVA-ARGUIROVA, S.; REIF, J. Sub-damage-threshold femtosecond laser ablation from crystalline $\mathrm{Si}$ : surface nanostructures and phase transformation. Applied Physics A: Materials Science \& Processing, v. 79, n. 4, p. 1429-1432, 2004.

REIF, J.; VARLAMOVA, O.; COSTACHE, F. Femtosecond laser induced nanostructure formation: self-organization control parameters. Applied Physics A: Materials Science \& Processing, v. 92, n. 4, p. 1019-1024, 2008.

ROUSSE, A. et al. Non-thermal melting in semiconductors measured at femtosecond resolution. Nature, v. 410, n. 6824, p. 65-68, 2001.

STOIAN, R. et al. Coulomb explosion in ultrashort pulsed laser ablation of $\mathrm{Al}_{2} \mathrm{O}_{3}$. Physical Review B, v. 62, n. 19, p. 13167-13173, 2000.

REIF, J. R. et al. Ripples revisited: non-classical morphology at the bottom of femtosecond laser ablation craters in transparent dielectrics. Applied Surface Science, n. 0, p. 891-895, 2002.

STOIAN, R. et al. Laser ablation of dielectrics with temporally shaped femtosecond pulses. Applied Physics Letters, v. 80, n. 3, p. 353-355, 2002.

STOIAN, R. et al. Surface Charging and Impulsive Ion Ejection during Ultrashort Pulsed Laser Ablation. Physical Review Letters, v. 88, n. 9, p. 097603, 2002. 
BORGHESI, M. et al. Measurement of highly transient electrical charging following high-intensity laser--solid interaction. Applied Physics Letters, v. 82, n. 10, p. 15291531, 2003.

NOLTE, S. et al. Ablation of metals by ultrashort laser pulses. J. Opt. Soc. Am. B, v. 14, n. 10, p. 2716-2722, 1997.

KELLY, R.; MIOTELLO, A. Contribution of vaporization and boiling to thermal-spike sputtering by ions or laser pulses. Physical Review E, v. 60, n. 3, p. 2616-2625, 1999.

KELLY, R et al.. Comments on explosive mechanisms of laser sputtering. Applied Surface Science, n. 0, p. 205-215, 1996.

CHENG, C.; XU, X. Molecular dynamic study of volumetric phase change induced by a femtosecond laser pulse. Applied Physics A: Materials Science \& Processing, v. 79, n. 4, p. 761-765, 2004.

YOO, J. H. et al. Evidence for phase-explosion and generation of large particles during high power nanosecond laser ablation of silicon. Applied Physics Letters, v. 76, n. 6, p. 783-785, 2000.

ZHIGILEI, L. V. Dynamics of the plume formation and parameters of the ejected clusters in short-pulse laser ablation. Applied Physics A: Materials Science \& Processing, v. 76, n. 3, p. 339-350, 2003.

LORAZO, P.; LEWIS, L. J.; MEUNIER, M. Short-Pulse Laser Ablation of Solids: From Phase Explosion to Fragmentation. Physical Review Letters, v. 91, n. 22, p. 225502, 2003.

PEREZ, D.; LEWIS, L. J. Molecular-dynamics study of ablation of solids under femtosecond laser pulses. Physical Review B, v. 67, n. 18, p. 184102, 2003.

VON DER LINDE, D.; SOKOLOWSKI-TINTEN, K.; BIALKOWSKI, J. Laser solid interaction in the femtosecond time regime. Applied Surface Science, n. 0, p. 1-10, 1997.

WILLIAMS, R. T.; SONG, K. S. The self-trapped exciton. Journal of Physics and Chemistry of Solids, v. 51, n. 7, p. 679-716, 1990.

SCHMID, A.; KELLY, P.; BRÃUNLICH, P. Optical breakdown in alkali halides. Physical Review B, v. 16, n. 10, p. 4569-4582, 1977. 

irradiation of dielectric surfaces: desorbed ion kinetics and defect dynamics. Applied Physics A: Materials Science \& Processing, v. 92, n. 4, p. 897-902, 2008.

LIU, M.; KIM, H. K. Strain-induced channel waveguiding in bulk sapphire substrates. Applied Physics Letters, v. 79, n. 17, p. 2693-2695, 2001.

AONO, K. et al. Annealing effects on luminescence from Ce-implanted $\mathrm{Al}_{2} \mathrm{O}_{3}$. Nuclear Instruments and Methods in Physics Research, Section B: Beam Interactions with Materials and Atoms, v. 175-177, p. 580-584, 2001.

NAGABHUSHANA, $\mathrm{H}$. et al. Photoluminescence studies of $1 \mathrm{MeV}$ Ni8+ ion irradiated $\mathrm{Al}_{2} \mathrm{O}_{3}$ single crystals. Spectrochimica Acta Part A: Molecular and Biomolecular Spectroscopy, v. 73, n. 4, p. 637-641, 2009.

AL GHAMDI, A.; TOWNSEND, P. D. Ion beam excited luminescence of sapphire. Nuclear Instruments and Methods in Physics Research Section B: Beam Interactions with Materials and Atoms, v. 46, p. 133-136, 1990.

CAULFIELD, K. J.; COOPER, R.; BOAS, J. F. Luminescence from electron-irradiated sapphire. Physical Review B, v. 47, n. 1, p. 55-61, 1993.

AOKI, Y. et al. Luminescence of sapphire and ruby induced by $\mathrm{He}$ and $\mathrm{Ar}$ ion irradiation. Nuclear Instruments and Methods in Physics Research Section B: Beam Interactions with Materials and Atoms, v. 114, p. 276-280, 1996.

LEE, K. H.; CRAWFORD, J. H., JR. Luminescence of the F center in sapphire. Physical Review B, v. 19, n. 6, p. 3217-3221, 1979.

SAETA, P. N.; GREENE, B. I. Primary relaxation processes at the band edge of $\mathrm{SiO}_{2}$. Physical Review Letters, v. 70, n. 23, p. 3588-3591, 1993.

ZOUBIR, A. et al. Laser-induced defects in fused silica by femtosecond IR irradiation. Physical Review B, v. 73, n. 22, p. 224117, 2006.

SKUJA, L. Optically active oxygen-deficiency-related centers in amorphous silicon dioxide. Journal of Non-Crystalline Solids, v. 239, p. 16-48, 1998.

PETITE, G. et al. Conduction electrons in wide-bandgap oxides: a subpicosecond timeresolved optical study. Nuclear Instruments and Methods in Physics Research Section B: Beam Interactions with Materials and Atoms, v. 107, p. 97-101, 1996. 
DICKINSON, J. T. et al. Color center formation in soda lime glass and $\mathrm{NaCl}$ single crystals with femtosecond laser pulses. Applied Physics A: Materials Science \& Processing, v. 79, n. 4, p. 859-864, 2004.

FENG, Q. et al. Theory and simulation on the threshold of water breakdown induced by focused ultrashort laser pulses. Quantum Electronics, IEEE Journal of, v. 33, n. 2, p. 127-137, 1997.

JAMSHIDI-GHALEH, K.; MASALEHDAN, H. Modeling of nonlinear responses in BK7 glass under irradiation of femtosecond laser pulses. Optical and Quantum Electronics, v. 41, n. 1, p. 47-53, 2009.

PAPAZIAN, H. A. Color center defects: An alternative view. Solid State Ionics, v. 38, p. 5-8, 1990.

EFIMOV, O. M. et al. Color-center generation in silicate glasses exposed to infrared femtosecond pulses. J. Opt. Soc. Am. B, v. 15, n. 1, p. 193-199, 1998.

STOLZ, C. J. et al. Influence of BK7 substrate solarization on the performance on hafnia and silica multilayer mirrors. Laser-Induced Damage in Optical Materials: 2002 and 7th International Workshop on Laser Beam and Optics Characterization. Boulder, CO, USA: SPIE, 2003. 38-47 p.

APOSTOLOVA, T.; HAHN, Y. Modeling of laser-induced breakdown in dielectrics with subpicosecond pulses. Journal of Applied Physics, v. 88, n. 2, p. 1024-1034, 2000 .

VATSYA, S. R.; NIKUMB, S. K. Modeling of laser-induced avalanche in dielectrics. Journal of Applied Physics, v. 91, n. 1, p. 344-351, 2002.

HOLWAY, L. H. Temporal Behavior of Electron Distributions in an Electric Field. Physical Review Letters, v. 28, n. 5, p. 280, 1972.

HOLWAY, J. L. H. High-frequency breakdown in ionic crystals. Journal of Applied Physics, v. 45, n. 2, p. 677-683, 1974.

TIEN, A.-C. et al. Short-Pulse Laser Damage in Transparent Materials as a Function of Pulse Duration. Physical Review Letters, v. 82, n. 19, p. 3883, 1999.

RAJEEV, P. P. et al. Field Dependent Avalanche Ionization Rates in Dielectrics. Physical Review Letters, v. 102, n. 8, p. 083001-4, 2009. 
OTOBE, T. et al. First-principles electron dynamics simulation for optical breakdown of dielectrics under an intense laser field. Physical Review B (Condensed Matter and Materials Physics), v. 77, n. 16, p. 165104-5, 2008.

BRENK, O.; RETHFELD, B. Electron dynamics in transparent materials under highintensity laser irradiation. In: EXARHOS, G. J.;GRUZDEV, V. E., et al (Ed.). LaserInduced Damage in Optical Materials: 2011. Bellingham: Spie-Int Soc Optical Engineering, v.8190 (Proceedings of SPIE).

RETHFELD, B. Unified Model for the Free-Electron Avalanche in Laser-Irradiated Dielectrics. Physical Review Letters, v. 92, n. 18, p. 187401, 2004.

WU, B.; SHIN, Y. C. A simplified predictive model for high-fluence ultra-short pulsed laser ablation of semiconductors and dielectrics. Applied Surface Science, v. 255, n. 9, p. 4996-5002, 2009.

CAMPBELL, S. et al. Single-pulse femtosecond laser machining of glass. Journal of Optics A: Pure and Applied Optics, v. 7, n. 4, p. 162, 2005. Subpicosecond Pulses. Physical Review Letters, v. 74, n. 12, p. 2248-2251, 1995.

JIANG, L.; TSAI, H. L. Prediction of crater shape in femtosecond laser ablation of dielectrics. Journal of Physics D: Applied Physics, v. 37, n. 10, p. 1492, 2004.

JIANG, L. et al. Energy transport and material removal in wide bandgap materials by a femtosecond laser pulse. International Journal of Heat and Mass Transfer, v. 48, p. 487-499, 2005.

LINDE, D. V. D.; SCHÜLER, H. Breakdown threshold and plasma formation in femtosecond laser solid interaction. J. Opt. Soc. Am. B, v. 13, n. 1, p. 216-222, 1996.

BURAKOV, I. M. et al. Theoretical investigations of material modification using temporally shaped femtosecond laser pulses. Applied Physics A: Materials Science \& Processing, v. 81, n. 8, p. 1639-1645, 2005.

HELTZEL, A. et al. Nanostructuring Borosilicate Glass With Near-Field Enhanced Energy Using a Femtosecond Laser Pulse. J Heat Transfer, v. 129, n. 1, p. 53-59, 2007. 
ROSENFELD, A. et al. Ultrashort-laser-pulse damage threshold of transparent materials and the role of incubation. Applied Physics A: Materials Science \& Processing, v. 69, n. 7, p. S373-S376, 1999.

TIEN, A.-C. et al. Short-Pulse Laser Damage in Transparent Materials as a Function of Pulse Duration. Physical Review Letters, v. 82, n. 19, p. 3883-3886, 1999.

CHOWDHURY, I. H. et al. Ultra-fast laser absorption and ablation dynamics in wideband-gap dielectrics. Applied Physics A: Materials Science \& Processing, v. 81, n. 8, p. 1627-1632, 2005.

GIGUÈRE, D. et al. Laser ablation threshold dependence on pulse duration for fused silica and corneal tissues: experiments and modeling. J. Opt. Soc. Am. A, v. 24, n. 6, p. 1562-1568, 2007.

UTEZA, O. et al. Laser-induced damage threshold of sapphire in nanosecond, picosecond and femtosecond regimes. Applied Surface Science, v. 254, p. 799-803, December 1, 2007.

FRADIN, D. W.; BASS, M. Comparison of laser-induced surface and bulk damage. Applied Physics Letters, v. 22, n. 4, p. 157-159, 1973.

MACHADO, L. M. et al. D-Scan measurement of ablation threshold incubation effects for ultrashort laser pulses. Opt. Express, v. 20, n. 4, p. 4114-4123,

VIDAL, J. T. Desenvolvimento de um sistema opto-mecânico para usinagem com laser de femtossegundo. (Dissertação de Mestrado) - Instituto de Pesquisas Energéticas e Nucleares, São Paulo, 2010.

BELLAND, P.; CRENN, J. P. Changes in the characteristics of a Gaussian beam weakly diffracted by a circular aperture. Appl. Opt., v. 21, n. 3, p. 522-527, 1982. pulse ablation threshold of $\mathrm{Al} 2 \mathrm{O} 3$ (corundum) at different etch phases. Applied Surface Science, v. 154â€"155, n. 0, p. 40-46, 2000.

ASHKENASI, D. et al. Surface damage threshold and structuring of dielectrics using femtosecond laser pulses: the role of incubation. Applied Surface Science, v. 150, n. 1-4, p. 101-106, 1999. 

glass. Journal of Applied Physics, v. 96, n. 9, p. 5316-5323, 2004. Science, v. 225, n. 1-4, p. 339-346, 2004.

TREBINO, R. Frequency-Resolved Optical Gating: The Measurement of Ultrashort Laser Pulses. Kluwer Academic, 2000.

KRISHNA C., et al. Shape control of microchannels fabricated in fused silica by femtosecond laser irradiation and chemical etching. OPTICS EXPRESS, v. 17, n. 102009

BURNS, M. A. et al. An Integrated Nanoliter DNA Analysis Device. Science, v. 282, n. 5388, p. 484-487, October 16, 1998. Biomedical Engineering, v. 13, n. 1, ultraviolet and femtosecond lasers. Biomaterials, v. 26, n. 36, p. 7642-7649, 2005. microcomponents in a single glass chip by femtosecond laser direct writing for biochemical analysis. Applied Surface Science, v. 253, n. 15, p. 6595-6598, 2007.

MACHADO, L. M. et al. Microchannels Direct Machining using the Femtosecond Smooth Ablation Method. Physics Procedia, v. 12, Part B, n. 0, p. 67-75, 1996. 